\title{
THERMAL ENHANCEMENT OF A BUILDING INTEGRATED PHOTOVOLTAIC/THERMAL SYSTEM COUPLED WITH AN AIR SOURCE HEAT PUMP
}

\author{
By \\ Edward Vuong \\ Bachelor of Engineering (B.Eng) \\ Ryerson University, 2015 \\ A thesis presented to Ryerson University

\begin{abstract}
in partial fulfilment of the
Master of Applied Science

in the program of

Mechanical Engineering
\end{abstract} \\ requirements for the degree of \\ Toronto, Ontario, Canada, 2017 \\ CEdward Vuong 2017
}




\section{Author's Declaration}

I hereby declare that I am the sole author of this dissertation. This is a true copy of the thesis, including any required final revisions, as accepted by my examiners.

I authorize Ryerson University to lend this thesis to other institutions or individuals for the purpose of scholarly research.

I further authorize Ryerson University to reproduce this thesis by photocopying or by other means, at the request of other institutions or individuals for the purpose of scholarly research.

I understand that my dissertation may be made electronically available to the public. 


\author{
Abstract \\ THERMAL ENHANCEMENT OF A BUILDING INTEGRATED \\ PHOTOVOLTAIC/THERMAL SYSTEM COUPLED WITH AN AIR SOURCE \\ HEAT PUMP \\ Master of Applied Science, 2017 \\ Edward Vuong \\ Mechanical Engineering, Ryerson University
}

Enhancements of a building integrated photovoltaic/thermal (BIPV/T) system intended for coupling with an air source multispeed heat pump (MSHP) is presented. The systems were analyzed using a modified version of EnergyPlus, a quasi-steady state building energy simulation program. A sensitivity analysis of the internal channel surface and cover emissivity parameters of the Opaque $\mathrm{BIPV} / \mathrm{T}$, transparent $\mathrm{BIPV} / \mathrm{T}$, and building integrated solar air heater collectors (BISAH) was conducted. In addition, collector arrangement analyses were performed. A BIPV/TBISAH array design was selected based on the results of the analyses and evaluated using a netzero energy house and an energy efficient house. The integrated BIPV/T-BISAH coupled ASHP system reduced space heating electricity consumption of the net-zero house by $6.5 \%$ and the energy efficient house by $3.4 \%$. These low levels of savings were largely due to the passive design of the houses that reduced heating loads during sunny hours; this resulted in a mismatch between the hours when the integrated system could provide energy savings and the need for space heating. 


\section{Acknowledgement}

I would like to thank my supervisor, Dr. Alan S. Fung for giving me an opportunity as an undergraduate student to learn as an RA in his lab and the constant guidance and support throughout all these years. I would like to thank Dr. Wey H. Leong and Dr. David Naylor for their time and willingness to let me consult about this work.

I would like to thank the Toronto and Region Conservation Authority (TRCA) and their staff for their help in my research. I would also like to acknowledge the Ontario Graduate Scholarship, MITACS, Ryerson International, Yeates School of Graduate Studies, CUPE, and Ryerson Student Union for their financial support.

I am grateful to Altamash, Navid, Aidan, Raghad, Annie, Waleed, Brandon, and Kajen for their encouragement and support. 


\section{Table of Contents}

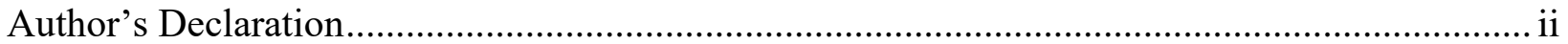

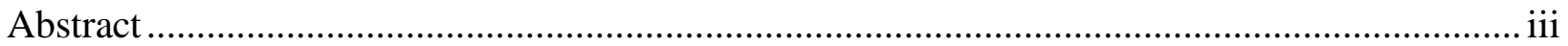

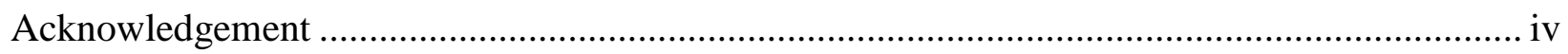

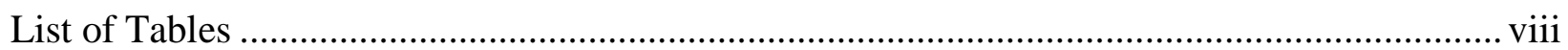

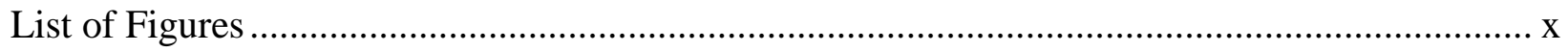

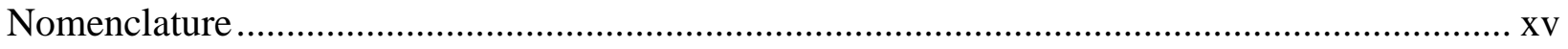

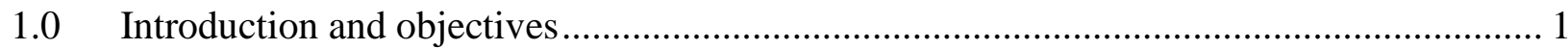

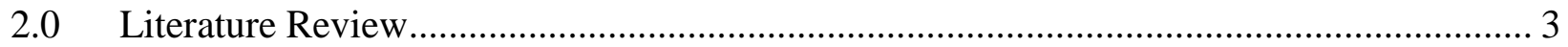

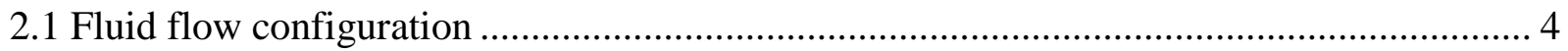

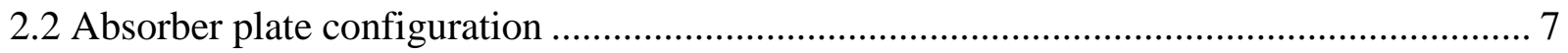

2.3 Solar absorption characteristics of air thermal and photovoltaic collectors ..................... 9

2.4 Internal channel fins ...................................................................................... 11

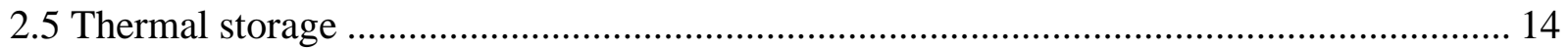

2.6 Non-finned heat transfer surface modification ...................................................... 16

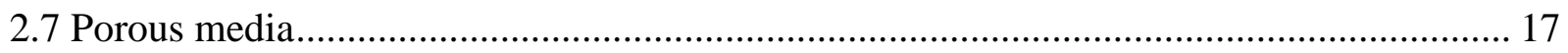

2.8 Coupling PVT systems with air source heat pumps ................................................ 19

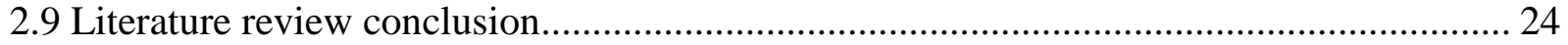

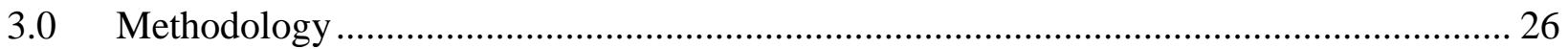

3.1 Transient and quasi-steady state collector models ............................................... 26

3.2 Modelling of an Opaque Building Integrated Photovoltaic/ Thermal (OBIPV/T) system . 28

3.2.1 Energy balance of the OBIPV/T model ....................................................... 28

3.2.2 Modification of the electrical and solar optical model of the OBIPV/T model.......... 30

3.2.3 Estimation of the PV cell efficiency ............................................................. 31

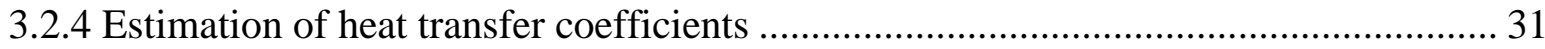


3.3 Modelling of a Transparent Building Integrated Photovoltaic/Thermal (TPBIPV/T) system

3.3.1 Energy balance of the TBIPV/T model .......................................................... 33

3.3.2 Modification of the solar transmittance-absorptance of the PV layer of TBIPV/T model 36

3.3.3 Estimation of heat transfer coefficients ...................................................... 36

3.4 Modelling of a Building Integrated Solar Air Heater (BISAH) ................................... 36

3.4.1 Energy balance of the BISAH model............................................................ 37

3.4.2 Estimation of heat transfer coefficients ....................................................... 39

3.5 Differential control volume energy balance ........................................................... 40

3.6 EnergyPlus V8.0: a quasi-steady state building energy simulation program .................. 40

3.7 Modelling of an Air Source Heat Pump coupled with a photovoltaic/thermal and solar air

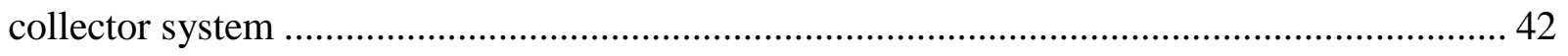

3.8 Modelling a source flowrate modulated ASHP in EnergyPlus .................................... 44

3.8.1 Estimating nominal and defrost adjusted heating capacity and power input ............. 45

3.8.2 Control of the Multispeed Heat Pump in EnergyPlus............................................ 48

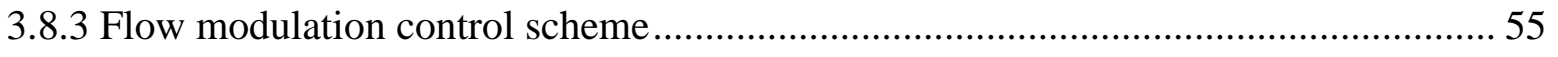

3.9 Modelling OBIPV/T, TBIPV/T, and BISAH in a building using EnergyPlus V8.0 ......... 61

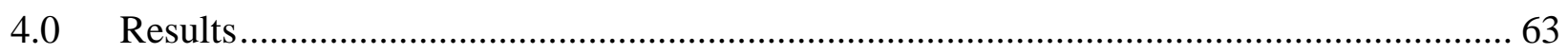

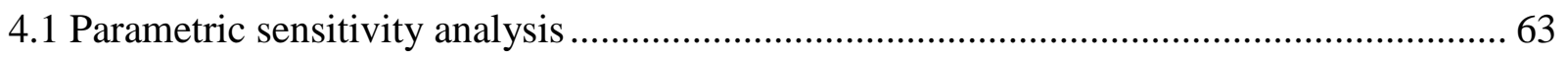

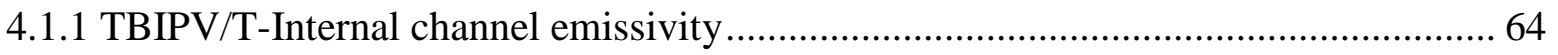

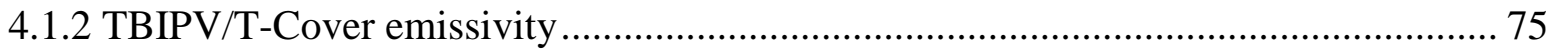

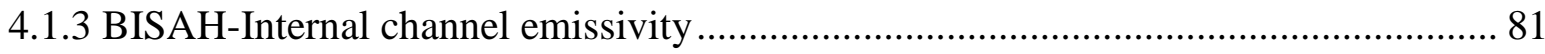

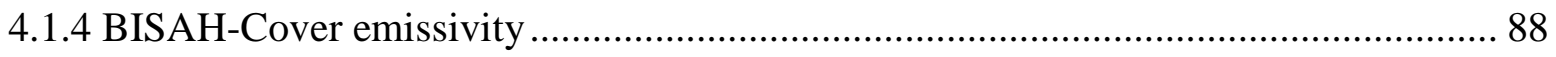

4.1.5 OBIPV/T-Internal channel emissivity ..................................................... 91

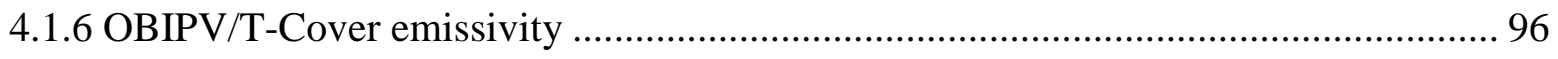


4.2 Collector arrangement analysis .................................................................................. 101

4.2.1 Enhancing OBIPV/T and TBIPV/T systems with BISAH collectors........................ 102

4.2.2 Comparative analysis of replacing OBIPV/T-BISAH systems with TBIPV/T systems 108

4.2.3 Concentrating and dispersing solar radiation collection...................................... 111

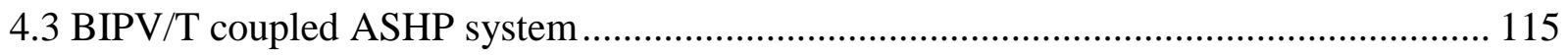

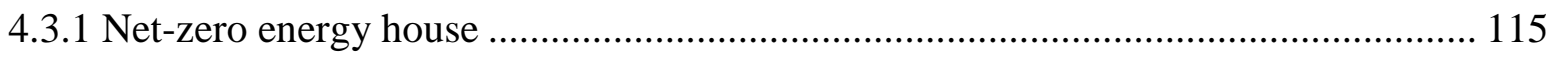

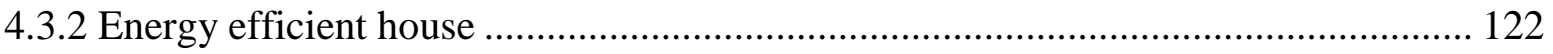

4.3.3 BIPV/T-BISAH coupled MSHP for different houses................................................ 125

4.3.4 Limitations on the energy savings of integrated BIPV/T-BISAH coupled MSHP

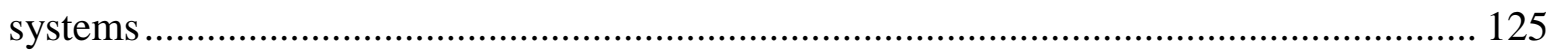

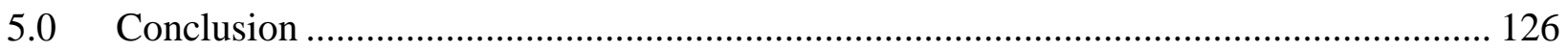

6.0 Future work and recommendation ........................................................................ 128

Appendix A-Algebraic grouped terms of the BISAH model....................................................... 129

Appendix B-Variable speed air source heat pump performance data......................................... 130

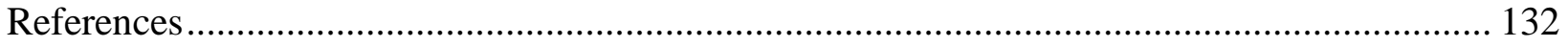




\section{List of Tables}

Table 2-1 Outlet temperature and thermal efficiency results (Fudholi et al. 2013.)................... 13

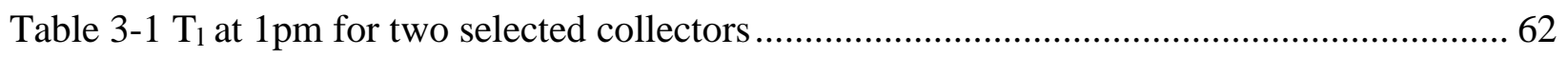

Table 4-1 TBIPV/T collector parameters for internal emissivity analysis .............................. 64

Table 4-2 Annual electrical generation of a single row for different internal channel emissivity 65

Table 4-3 Frequency of when the upper surface was warmer than the lower surface for each

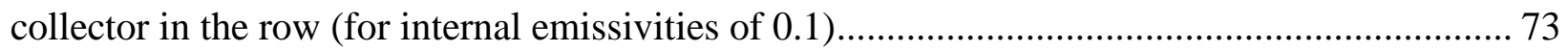

Table 4-4 Row configuration with different collectors with different emissivity values ............ 74

Table 4-5 Heating season thermal energy generated for incremental change in collectors with high

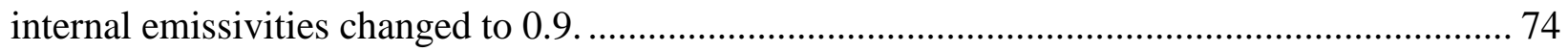

Table 4-6 TBIPV/T collector parameters for cover emissivity analysis................................ 75

Table 4-7 Row configuration with different collectors with different cover emissivity values ... 78

Table 4-8 BISAH collector parameters for internal channel emissivity analysis ...................... 81

Table 4-9 BISAH parameters for cover emissivity analysis ............................................. 88

Table 4-10 OBIPV/T collector parameters for internal channel emissivity analysis ................. 91

Table 4-11 Frequency of when the upper surface was warmer than the lower surface for each

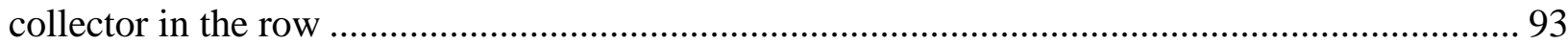

Table 4-12 Row configuration with different collectors with different emissivity values .......... 94

Table 4-13 OBIPV/T collector parameters for cover emissivity analysis ............................... 96

Table 4-14 Row configuration with different collectors with different emissivity values .......... 99

Table 4-15 OBIPV/T collector parameters ..................................................................... 103

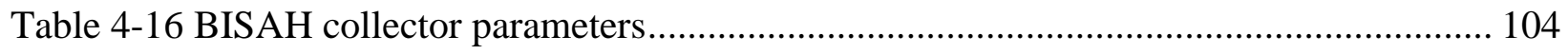

Table 4-17 Summary of the 5 OBIPV/T +1 BISAH and 4 OBIPV/T +2 BISAH thermal and electrical energy generated during the heating season.................................................. 106

Table 4-18 TBIPV/T collector parameters ...................................................................... 106

Table 4-19 Summary of the 5 OBIPV/T +1 BISAH and 5 TBIPV/T +1 BISAH thermal and

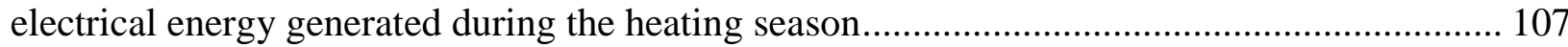

Table 4-20 Summary of the 5 OBIPV/T +1 BISAH and 4 TBIPV/T +2 BISAH thermal and

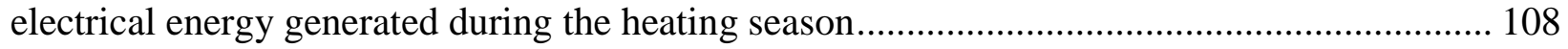
Table 4-21 Summary of the 4 different row configurations thermal and electrical energy generated

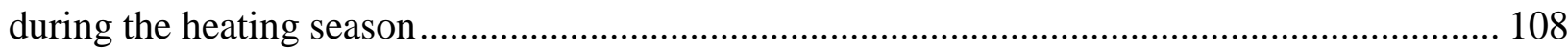


Table 4-22 Summary description of the row configuration for a comparative analysis of TBIPV/T

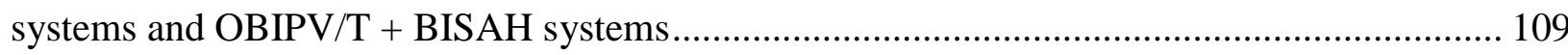

Table 4-23 Summary of the thermal and electrical energy generated for Row A to Row D3.... 110 Table 4-24 Summary description of the enhanced TBIPV/T row configuration for a comparative analysis of TBIPV/T systems and OBIPV/T + BISAH systems ......................................... 110 Table 4-25 Summary of the thermal and electrical energy generated for Row A to Row B and Row

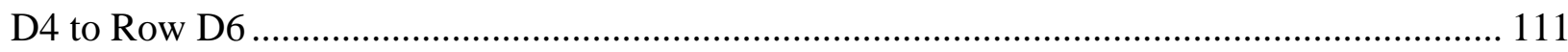

Table 4-26 Description of the row configuration for concentration vs dispersion analysis ....... 112 Table 4-27 TBIPV/T collector parameters for the solar concentration vs dispersion analysis .. 113 Table 4-28 BISAH collector parameters for the solar concentration vs dispersion analysis...... 113 Table 4-29 Heating season generated thermal and electrical energy for Set E, F, and G rows .. 114 Table 4-30 Heating season thermal energy generated by Row E1 and E2 ........................... 115

Table 4-31 Heating season electrical energy generated by Row E1 and E2 ......................... 115

Table 4-32 Net-zero energy house construction ............................................................... 116

Table 4-33 MSHP simulation parameters for the NZE house .......................................... 117

Table 4-34 TBIPV/T collector parameters of the 6x6 BIVP/T-BISAH system ...................... 118

Table 4-35 BISAH collector parameters of the 6x6 BIVP/T-BISAH system ........................ 118

Table 4-36 BIPV/T-BISAH air supply variable speed fan parameters................................. 119

Table 4-37 Outdoor air supply variable speed fan parameters ........................................... 119

Table 4-38 Energy efficient house construction ......................................................... 122

Table 4-39 MSHP simulation parameters for the energy efficient house............................... 124 


\section{List of Figures}

Figure 2-1 Theoretical and experimental temperature rise for different flowrates (Othman et al.,

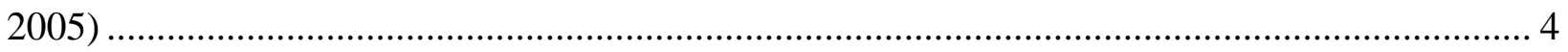

Figure 2-2 Efficiency for various mass flowrates (Othman et al., 2005) ………………............. 5

Figure 2-3 Schematic of perforated collector (Vaziri, Ilkan, \& Egelioglu, 2015) .......................... 5

Figure 2-4 Temperature rise for green, blue and transpired collectors throughout the day (Vaziri,

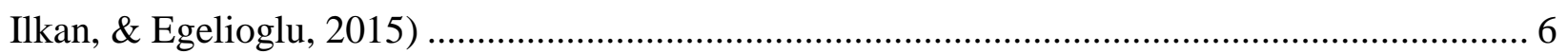

Figure 2-5 Temperature rise for white, yellow, and transpired collectors throughout the day

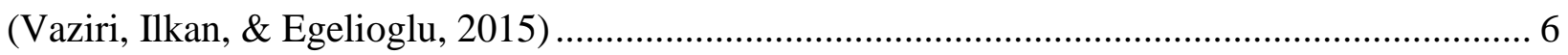

Figure 2-6 Model 1 (dimensions in mm) (Koyuncu, 2006)..................................................... 7

Figure 2-7 Model 2 (dimensions in $\mathrm{mm}$ ) (Koyuncu, 2006)......................................................... 8

Figure 2-8 Model 6 (dimensions in $\mathrm{mm}$ ) (Koyuncu, 2006) ....................................................... 8

Figure 2-9 Model 4 (dimensions in $\mathrm{mm}$ ) (Koyuncu, 2006)....................................................... 8

Figure 2-10 Unglazed IAM (Tesfamichael and Wackelgard, 2000) …………............................ 11

Figure 2-11 4 mm glazed IAM (Tesfamichael and Wackelgard, 2000) ....................................... 11

Figure 2-12 Thermal efficiency of a finned collector for different flowrates for irradiance of 500

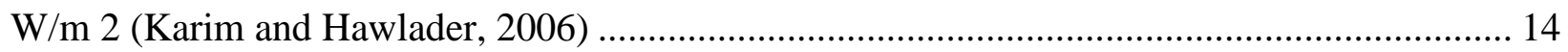

Figure 2-13 Solar collector with thermal storage (Aboul-Enein et al., 2000) ............................. 15

Figure 2-14 Hourly outlet temperature of solar collector with different types of thermal storage

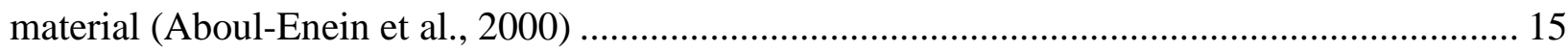

Figure 2-15 ASHP COP for various flow velocities (Li, Cao, Feng, Zhang and Huang, 2015) .. 21

Figure 2-16 R410A split residential heat pump (Payne et al., 2009) ........................................... 22

Figure 2-17 Heat pump setup with improper flow fault (Payne et al., 2009) .............................. 22

Figure 2-18 Heat pump performance at different fault levels at indoor and outdoor temperature of

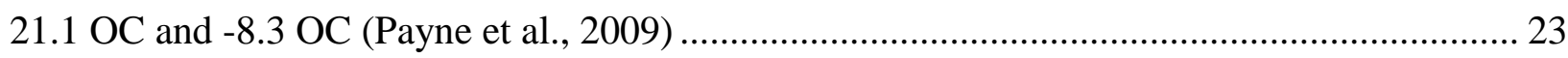

Figure 2-19 Heat pump performance at different fault levels at indoor and outdoor temperature of

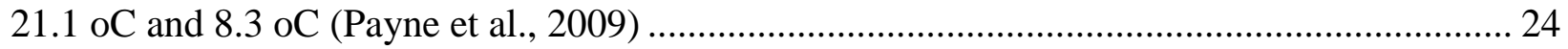

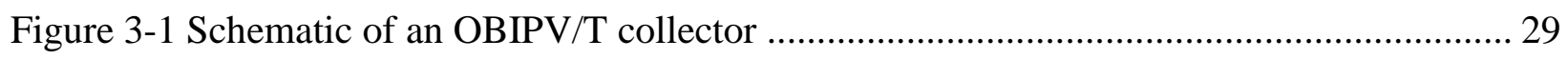

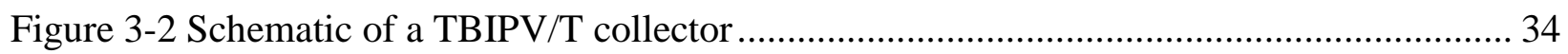

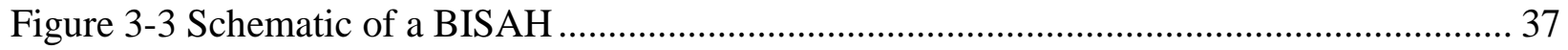

Figure 3-4 Energy balance of the top surface of the glass cover ................................................ 38 
Figure 3-5 Energy balance of the upper surface of the air channel 38

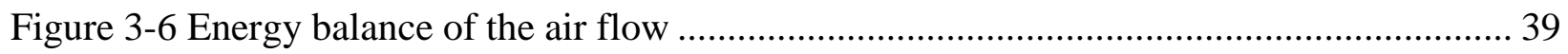

Figure 3-7 Energy balance of the lower surface of the air channel ......................................... 39

Figure 3-8 Schematic of the AirLoopHVAC:UnitaryHeatPump:AirToAir:Multispeed object and the HVAC system (Ernest Orlando Lawrence Berkeley National Laboratory, 2013a).............. 48 Figure 3-9 Flow diagram of the MSHP controller, in relation to the rest of the HVAC simulation

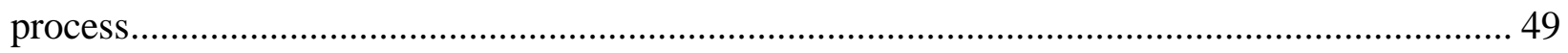

Figure 3-10 Flow diagram of the control process for speed 1 operation ................................ 52

Figure 3-11 Flow diagram of the control process for higher speed operation........................... 54

Figure 3-12 MSHP control process with a flow modulation step for speed 1 operation............. 56

Figure 3-13 MSHP control process with a flow modulation step for higher speed operation...... 57

Figure 4-1 Annual thermal energy generation of a single row for different internal channel

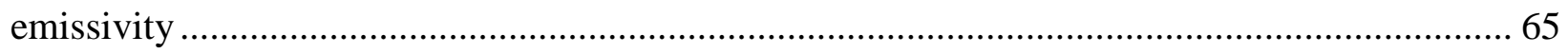

Figure 4-2 Heating season thermal energy generation for each collector of the row ................. 66

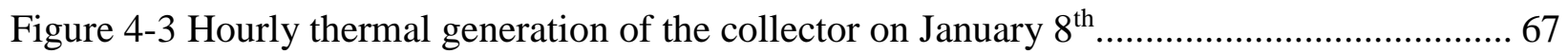

Figure 4-4 Upper and lower surface temperatures for collector with 0.1 internal emissivity on

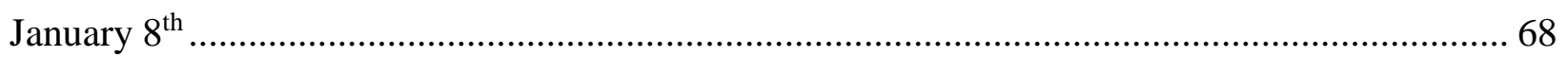

Figure 4-5 Upper surface temperature of the collector for different internal emissivity on January $8^{\text {th }}$

Figure 4-6 Lower surface temperature of the collector for different internal emissivity on January $8^{\text {th }}$

Figure 4-7 Total convective and radiative heat loss for the collector for different internal

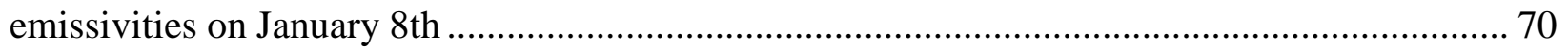

Figure 4-8 Thermal energy generation by a collector with two different internal emissivities on January $1^{\text {st }}$ 71

Figure 4-9 Hourly upper and lower surface temperature for the collector with 0.1 internal emissivities 71

Figure 4-10 Lower surface temperature of the collector for two different emissivities 72

Figure 4-11 Convective and radiative heat loss for the collector for two different emissivities on January 1st . 72 
Figure 4-12 Heating season thermal energy generated by a collector for various cover emissivities

Figure 4-13 Heating season electrical energy generated by a collector for various cover emissivities 76

Figure 4-14 Total, convective, and radiative losses for a collector on January $1^{\text {st }}$ at $1 \mathrm{pm} . . . . . . . .77$ Figure 4-15 Heat flux from the PV layer to the upper surface for the collector on January $1^{\text {st }}$ at 1

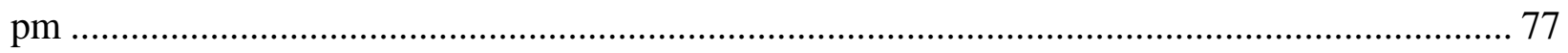

Figure 4-16 Heating season thermal energy generated for different row configuration.............. 79

Figure 4-17 Heating season electrical energy generated for different row configuration ............ 79

Figure 4-18 Heating season thermal energy generated by one row of TBIPV/T collectors where

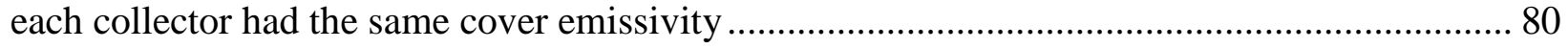

Figure 4-19 Heating season electrical energy generated by one row of TBIPV/T collectors where each collector had the same cover emissivity 80

Figure 4-20 Heating season thermal energy generated by a collector for various internal channel emissivities. 82

Figure 4-21 Upper and lower surface temperatures for a collector with internal emissivities of 0.9 on January $1^{\text {st }}$..... 82 Figure 4-22 Internal longwave radiation heat transfer from the lower surface to the upper surface for the collector on January $1^{\text {st }}$ 83

Figure 4-23 Upper surface temperature for the collector for two different internal emissivities on January $1^{\text {st }}$ 84 Figure 4-24 Lower surface temperature for the collector for two different internal emissivities on January $1^{\text {st }}$ 84

Figure 4-25 Convective and radiative heat loss by the collector for two different internal emissivities on Jan $1^{\text {st }}$. 85

Figure 4-26 Heating flux from the lower surface to the interior zone surface for the collector for two different internal emissivities. 86 Figure 4-27 Heating season thermal energy generated for each collector based on position ....... 87 Figure 4-28 Heating season thermal energy generated by one row for various internal emissivities 87 
Figure 4-29 Heating season thermal energy generated by a collector for various cover emissivities

Figure 4-30 Convective and radiative heat loss for the collector for two different cover emissivities on January $1^{\text {st }}$. 89

Figure 4-31 Heating season thermal energy generated for one row for two different cover emissivities.

Figure 4-32 Heating season thermal energy generated by one row for various cover emissivities 91

Figure 4-33 Heating season thermal energy generated by a collector for various internal channel emissivities. 92

Figure 4-34 Heating season electrical energy generated by a collector for various internal channel emissivities. 92

Figure 4-35 Heating season thermal energy generated for different row configuration 94

Figure 4-36 Heating season electrical energy generated for different row configuration 95 Figure 4-37 Heating season thermal energy generated for one row for various internal emissivities 95

Figure 4-38 Heating season electrical energy generated for one row for various internal emissivities. 96

Figure 4-39 Heating season thermal energy generated by a collector for various cover emissivities 97

Figure 4-40 Heating season electrical energy generated by a collector for various cover emissivities 97

Figure 4-41 Convective and radiative heat loss for the collector on January $1^{\text {st }}$ at $1 \mathrm{pm}$........... 98 Figure 4-42 Heating season thermal energy generated by different row configurations............. 99 Figure 4-43 Heating season electrical energy generated by different row configurations ......... 100 Figure 4-44 Heating season thermal energy generated by rows with different cover emissivity 100 Figure 4-45 Heating season electrical energy generated by rows with different cover emissivity 101

Figure 4-46 One row of 5 OBIPV/T collectors ........................................................... 103

Figure 4-47 5 OBIPV/T collectors with 1 BISAH collector................................................. 104

Figure 4-48 5 OBIPV/T collectors with 2 BISAH collectors ............................................ 105 
Figure 4-49 Sketchup model of the NZE house........................................................ 116

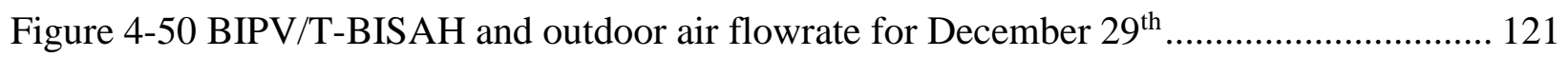
Figure 4-51 BIPV/T-BISAH average outlet temperature, outdoor temperature, and mixed air

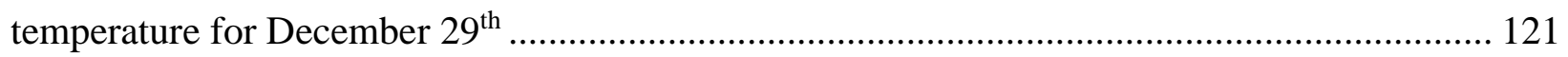

Figure 4-52 BIPV/T-BISAH coupled MSHP and base case MSHP electricity consumption.... 122 Figure 4-53 Sketchup model of the energy efficient house ............................................ 123 


\title{
Nomenclature
}

\author{
a $\quad$ Algebraic grouped term \\ $A_{\text {panel }} \quad$ Collector area $\left(\mathrm{m}^{2}\right)$ \\ $A_{P V}$ cell Total area of the PV cells for one PV panel $\left(\mathrm{m}^{2}\right)$ \\ $b \quad$ Algebraic grouped term \\ $c_{1}, c_{2}, c_{3}, c_{4}, c_{5} \quad$ Fan performance coefficient (-) \\ $c_{\#, E F}, c_{\#, E T} c_{\#, Q F}, c_{\#, Q T}$ \\ $c_{p}$ \\ HP performance curve regression coefficient e.g. $c_{1, E F}, c_{2, E T}(-)$ \\ Specific heat capacity of air $(\mathrm{J} / \mathrm{kg} \cdot \mathrm{K})$ \\ $\mathrm{C}_{\mathrm{X}} \quad$ Entrance effect factor (-) \\ COP cycling Coefficient of performance of a HP when cycling (-)

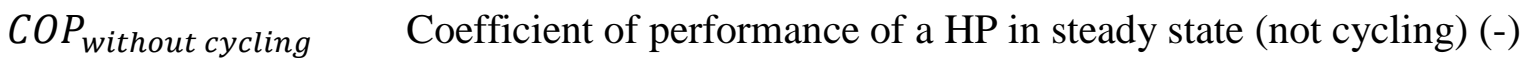 \\ $d \quad$ Duct height (m) \\ $D_{h} \quad$ Hydraulic diameter of BIPV/T-BISAH duct (m) \\ $E_{p v} \quad$ Electricity generation power (W) \\ $E f f_{I} \quad$ PV linear modifying factor- irradiance (-) \\ $E f f_{T} \quad$ PV linear modifying factor- temperature (-) \\ EIR Energy input ratio (inverse of the COP) (-) \\ EIR rated Rated EIR (inverse of the rated COP) (-) \\ $E I R_{T} \quad$ EIR factor- function of temperature (-) \\ $E I R_{f} \quad$ EIR factor- function of flow fraction (-) \\ $f \quad$ Actual indoor coil flowrate to rated flowrate ratio (flow fraction) (-) \\ $f_{p l} \quad$ Fan part load fraction (-) \\ $f_{P V T} \quad$ Mass Flow fraction of a BIPV/T-BISAH array to the fan's design \\ mass flowrate (which is the HP's required source flowrate). Also \\ known as, Ratio of BIPV/T-BISAH array flowrate to HP's required \\ source flowrate (-) \\ $g \quad$ Acceleration constant $\left(9.81 \mathrm{~m} / \mathrm{s}^{2}\right)$ \\ $h_{a} \quad$ Convective heat transfer coefficient of air within he BIPV/T-BISAH \\ channel $\left(\mathrm{W} / \mathrm{m}^{2} \cdot \mathrm{K}\right)$
}




\begin{tabular}{|c|c|}
\hline$h_{c}$ & $\begin{array}{l}\text { Convective heat transfer coefficient for the wind and cover } \\
\left(\mathrm{W} / \mathrm{m}^{2} \cdot \mathrm{K}\right)\end{array}$ \\
\hline$h_{\text {rad }, u-l}$ & $\begin{array}{l}\text { Radiative heat transfer coefficient between the collector air } \\
\text { channel's upper and lower surface }\left(\mathrm{W} / \mathrm{m}^{2} \cdot \mathrm{K}\right)\end{array}$ \\
\hline$h_{r s}$ & Radiative heat transfer coefficient the cover and the sky $\left(\mathrm{W} / \mathrm{m}^{2} \cdot \mathrm{K}\right)$ \\
\hline$I_{B}$ & Incident beam irradiance on a tilted surface $\left(\mathrm{W} / \mathrm{m}^{2}\right)$ \\
\hline$I_{G R}$ & Incident ground diffused irradiance on a tilted surface $\left(\mathrm{W} / \mathrm{m}^{2}\right)$ \\
\hline$I_{\text {ref }}$ & Reference irradiance $\left(3600 \mathrm{~W} / \mathrm{m}^{2}\right)$ \\
\hline$I_{S}$ & Incident sky diffused irradiance on a tilted surface $\left(\mathrm{W} / \mathrm{m}^{2}\right)$ \\
\hline$I_{T}$ & Total irradiance on a tilted surface $\left(\mathrm{W} / \mathrm{m}^{2}\right)$ \\
\hline$K$ & Glazing extinction coefficient $\left(\mathrm{m}^{-1} 1\right)$ \\
\hline$k_{g}$ & Thermal conductivity of the glass cover $(\mathrm{W} / \mathrm{m} \cdot \mathrm{K})$ \\
\hline$l_{g}$ & Glazing thickness (m) \\
\hline$L$ & Collector length (parallel to the direction of flow) (m) \\
\hline$\dot{m}$ & Air mass flowrate $(\mathrm{kg} / \mathrm{s})$ \\
\hline$\dot{m}_{H P}$ & HP required source flowrate $(\mathrm{kg} / \mathrm{s})$ \\
\hline$\dot{m}_{o a, i}$ & $\begin{array}{l}\text { Outdoor air stream flowrate when mixing during MSHP flow } \\
\text { modulation, for a particular iteration }(\mathrm{kg} / \mathrm{s})\end{array}$ \\
\hline$\dot{m}_{p v t, i}$ & $\begin{array}{l}\text { Mass flowrate from BIPV/T-BISAH array flowrate when mixing } \\
\text { during MSHP flow modulation, for a particular iteration }(\mathrm{kg} / \mathrm{s})\end{array}$ \\
\hline$\dot{m}_{P V T, \text { row }}$ & Air mass flowrate through one row of a BIPV/T-BISAH array $(\mathrm{kg} / \mathrm{s})$ \\
\hline MSHP $P_{\text {Residual }}$ & Convergence criterion (-) \\
\hline $\mathrm{n}$ & Glass refractive index (-) \\
\hline $\mathrm{Nu}$ & Nusselt number (-) \\
\hline$P_{\text {defrost }}$ & Input power defrost factor (-) \\
\hline$\dot{P}_{f a n-o a, i}$ & $\begin{array}{l}\text { Fan power for drawing in outdoor air during MSHP flow } \\
\text { modulation, for a particular iteration (W) }\end{array}$ \\
\hline$\dot{P}_{f a n-p v t, i}$ & $\begin{array}{l}\text { Fan power for drawing in BIPV/T-BISAH array air MSHP flow } \\
\text { modulation, for a particular iteration }(\mathrm{W})\end{array}$ \\
\hline
\end{tabular}




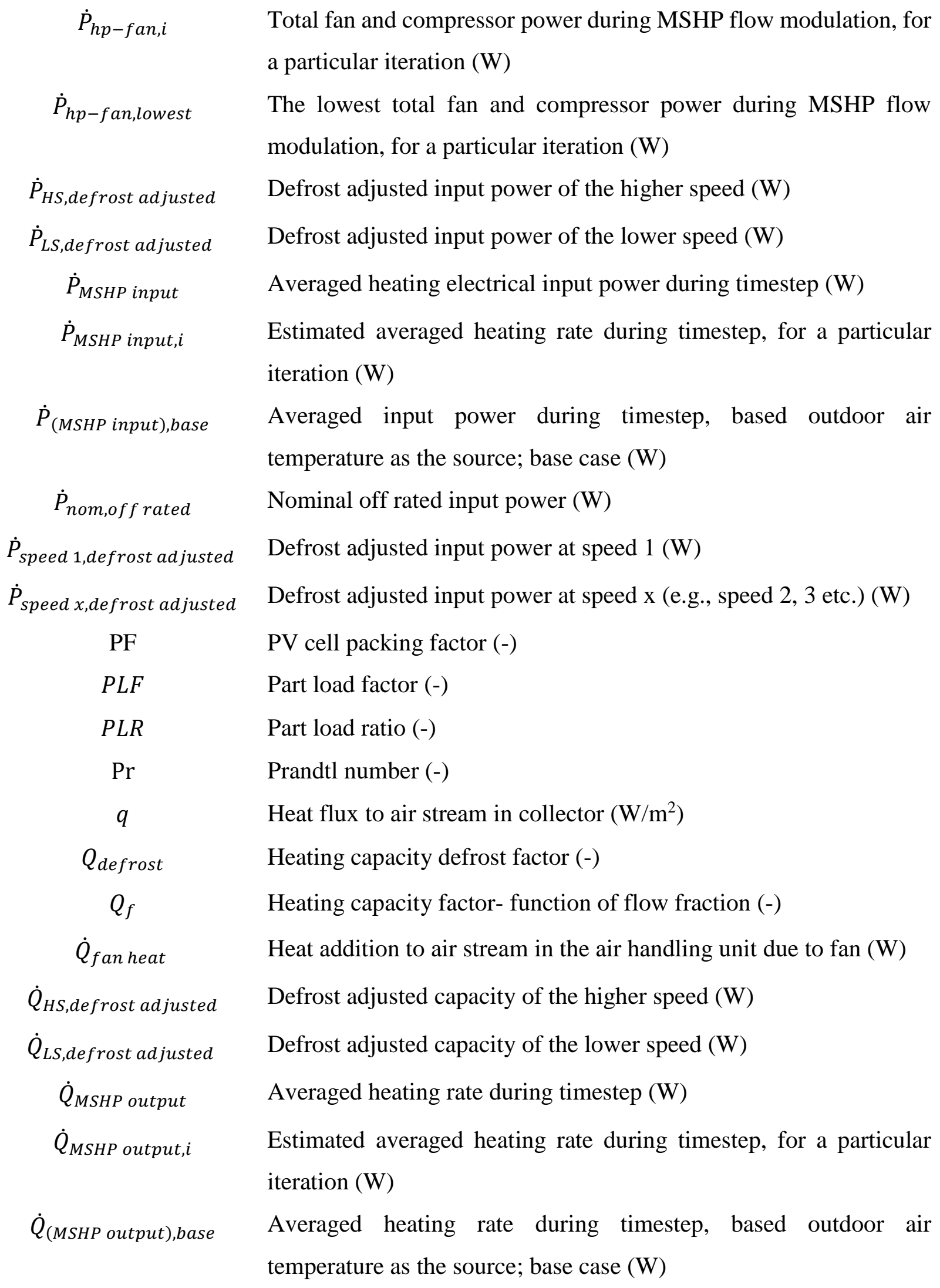




\begin{tabular}{|c|c|}
\hline$\dot{Q}_{\text {nom,off rated }}$ & Nominal heating capacity at off rated conditions (W) \\
\hline$\dot{Q}_{\text {rated }}$ & Heating capacity at rated conditions (W) \\
\hline$\dot{Q}_{\text {speed } 1, \text { defrost adjusted }}$ & Defrost adjusted capacity at speed $1(\mathrm{~W})$ \\
\hline$\dot{Q}_{\text {speed } x, \text { defrost adjusted }}$ & Defrost adjusted capacity at speed x (e.g., speed 2, 3 etc.) (W) \\
\hline$Q_{T}$ & Heating capacity factor- function of temperature (-) \\
\hline$\dot{Q}_{\text {zone laod }}$ & Heating load of a zone $(\mathrm{W})$ \\
\hline$R a$ & Rayleigh number $\left(\mathrm{m}^{2} \cdot \mathrm{K} / \mathrm{W}\right)$ \\
\hline$R e$ & Reynolds number $\left(\mathrm{m}^{2} \cdot \mathrm{K} / \mathrm{W}\right)$ \\
\hline$R_{g}$ & R-value of glazing $\left(\mathrm{m}^{2} \cdot \mathrm{K} / \mathrm{W}\right)$ \\
\hline$R_{\text {ins }}$ & R-value of roof insulation $\left(\mathrm{m}^{2} \cdot \mathrm{K} / \mathrm{W}\right)$ \\
\hline$R_{p v-u}$ & $\begin{array}{l}\text { R-value measured from PV layer to the upper surface of the air } \\
\text { channel of a collector }\left(\mathrm{m}^{2} \cdot \mathrm{K} / \mathrm{W}\right)\end{array}$ \\
\hline$R T F$ & Run time fraction (-) \\
\hline$S$ & $\begin{array}{l}\text { Net absorbed solar thermal flux at the PV layer for an OBIPV/T } \\
\text { collector }\left(\mathrm{W} / \mathrm{m}^{2}\right)\end{array}$ \\
\hline$S_{1}$ & $\begin{array}{l}\text { Net absorbed solar thermal flux at the PV layer for a TBIPV/T } \\
\text { collector }\left(\mathrm{W} / \mathrm{m}^{2}\right)\end{array}$ \\
\hline$S_{2}$ & $\begin{array}{l}\text { Net absorbed solar thermal flux at the lower surface for a TBIPV/T } \\
\text { collector }\left(\mathrm{W} / \mathrm{m}^{2}\right)\end{array}$ \\
\hline slope & Slope of collector, from the horizontal (rad) \\
\hline$S R$ & Speed ratio \\
\hline$T_{a}$ & Average air temperature through the collector $\left({ }^{\circ} \mathrm{C}\right)$ \\
\hline$T_{a m b}$ & temperature of ambient/outdoor air $\left({ }^{\circ} \mathrm{C}\right)$ \\
\hline$T_{c}$ & Temperature of the cover $\left({ }^{\circ} \mathrm{C}\right)$ \\
\hline$T_{c, \text { kelvin }}$ & Temperature of the cover in kelvin $(\mathrm{K})$ \\
\hline$T_{i}$ & Temperature of the indoor air $\left({ }^{\circ} \mathrm{C}\right)$ \\
\hline$T_{\text {in }}$ & Temperature at the inlet $\left({ }^{\circ} \mathrm{C}\right)$ \\
\hline$T_{l}$ & Temperature of the lower channel surface $\left({ }^{\circ} \mathrm{C}\right)$ \\
\hline$T_{l, k e l v i n}$ & Temperature of the lower channel surface in kelvin $(\mathrm{K})$ \\
\hline$T_{m, i}$ & Temperature of the mixed air stream $\left({ }^{\circ} \mathrm{C}\right)$ \\
\hline
\end{tabular}




$\begin{array}{cl}T_{o} & \text { Temperature of the outdoor air/ source air for a } \mathrm{HP}\left({ }^{\circ} \mathrm{C}\right) \\ T_{o a} & \text { Ambient outdoor air temperature }\left({ }^{\circ} \mathrm{C}\right) \\ T_{\text {out }} & \text { Temperature of the collector oulet }\left({ }^{\circ} \mathrm{C}\right) \\ T_{p v} & \text { Temperature of the PV layer }\left({ }^{\circ} \mathrm{C}\right) \\ T_{p v t, i} & \text { Average BIPV/T-BISAH array outlet temperature for a particular } \\ & \text { timestep }\left({ }^{\circ} \mathrm{C}\right) \\ T_{r e f} & \text { Reference temperature for PV model }\left(25^{\circ} \mathrm{C}\right) \\ T_{s k y} & \text { Sky temperature }(\mathrm{K}) \\ T_{u} & \text { Temperature of the upper air channel surface }\left({ }^{\circ} \mathrm{C}\right) \\ T_{u, k e l v i n} & \text { Temperature of the upper air channel surface in kelvin }(\mathrm{K}) \\ T_{z} & \text { Interio zone surface temperature }\left({ }^{\circ} \mathrm{C}\right) \\ V_{W} & \text { Wind speed }(\mathrm{m} / \mathrm{s}) \\ w & \text { Width of collector (dimension perpendicular to air flow) }\end{array}$

\section{GREEK SYMBOLS}

$\begin{array}{cl}\alpha_{\text {air }} & \left(\mathrm{m}^{2} / \mathrm{s}\right) \\ \alpha_{1} & \text { Solar absorptance of the lower surface (-) } \\ \alpha_{\mathrm{pv}} & \text { Solar absorptance of the PV cell (-) } \\ \Delta P_{\text {design,PVT }} & \text { BIPV/T-BISAH array's fan design pressure rise. It is equal to the } \\ & \text { pressure drop though one BIPV/T-BISAH row. (Pa) } \\ \Delta T_{u-l} & \text { Difference in the upper and lower surface temperature }\left({ }^{\circ} \mathrm{C}\right) \\ \epsilon_{c} & \text { Emissivity of the glass cover (-) } \\ \epsilon_{1} & \text { Emissivity of the internal channel's lower surface (-) } \\ \epsilon_{\mathrm{u}} & \text { Emissivity of the internal channel's upper surface (-) } \\ \eta_{f a n} & \text { Efficiency of the fan and motor (-) } \\ \eta_{\text {nominal }} & \text { Nominal cell efficiency (-) } \\ \eta_{p v} & \text { PV cell efficiency (-) } \\ \theta_{r, x} & \text { Refractive angle for particular solar component (beam, sky diffuse, } \\ & \text { ground diffuse) (rad) } \\ \theta_{x} & \text { Incident radiation angle for particular solar component (beam, sky } \\ & \text { diffuse, ground diffuse) (rad) }\end{array}$




\begin{tabular}{|c|c|}
\hline$\mu$ & Dynamic viscosity $(\mathrm{kg} / \mathrm{m} \cdot \mathrm{s})$ \\
\hline$v_{\text {air }}$ & Kinematic viscosity $\left(\mathrm{m}^{2} / \mathrm{s}\right)$ \\
\hline$\rho_{p v t}$ & Density of BIPV/T-BISAH outlet air $\left(\mathrm{kg} / \mathrm{m}^{3}\right)$ \\
\hline$\rho_{x}$ & $\begin{array}{l}\text { Reflectance for a particular radiation component (beam, sky diffuse, } \\
\text { ground diffuse) (-) }\end{array}$ \\
\hline$\sigma$ & Stefan-boltzman constant $\left(\mathrm{W} / \mathrm{m}^{2} \mathrm{~K}^{4}\right)$ \\
\hline$\tau_{a, x}$ & $\begin{array}{l}\text { Transmittance considering only absorptance for a particular } \\
\text { radiation component (beam, sky diffuse, ground diffuse) (-) }\end{array}$ \\
\hline$\tau_{\mathrm{g}}$ & Transmittance through the glass (-) \\
\hline$\tau_{\mathrm{g}, \mathrm{b}}$ & $\begin{array}{l}\text { Transmittance through the glass for the beam component of radiation } \\
(-)\end{array}$ \\
\hline$\tau_{\mathrm{g}, \mathrm{gr}}$ & $\begin{array}{l}\text { Transmittance through the glass for the ground diffuse component } \\
\text { of radiation (-) }\end{array}$ \\
\hline$\tau_{\mathrm{g}, \mathrm{s}}$ & $\begin{array}{l}\text { Transmittance through the glass for the sky diffuse component of } \\
\text { radiation (-) }\end{array}$ \\
\hline$\tau_{g, x}$ & $\begin{array}{l}\text { Transmittance through the glass for a particular radiation component } \\
\text { (beam, sky diffuse, ground diffuse) (-) }\end{array}$ \\
\hline$(\tau \alpha)_{B}$ & $\begin{array}{l}\text { Transmittance-absorptance product for beam component of the } \\
\text { radiation (-) }\end{array}$ \\
\hline$(\tau \alpha)_{G R}$ & $\begin{array}{l}\text { Transmittance-absorptance product for ground diffuse component of } \\
\text { the radiation (-) }\end{array}$ \\
\hline$(\tau \alpha)_{S}$ & $\begin{array}{l}\text { Transmittance-absorptance product for sky diffuse component of the } \\
\text { radiation (-) }\end{array}$ \\
\hline$(\tau \alpha)_{T}$ & $\begin{array}{l}\text { Transmittance-absorptance product for the total radiation on a } \\
\text { surface (-) }\end{array}$ \\
\hline
\end{tabular}




\subsection{Introduction and objectives}

In Canada, space heating constitutes $63 \%$ of the energy consumed in residential buildings, due to cold and extended winter conditions and natural gas provides approximately $45 \%$ of this energy (NRCan, 2016). A reduction in the energy consumption of residential buildings can therefore greatly reduce greenhouse gas (GHG) emissions; net-zero energy (NZE) or near NZE homes can achieve this. Kamel and Fung (2014) demonstrated that variable capacity air source heat pumps (ASHP) effectively can satisfy space heating demands without additional auxiliary heat sources, if the ASHP is coupled with a building integrated photovoltaic/thermal (BIPV/T) system. BIPV/T systems are rows of PV panels equipped with a duct or tubing that circulate and heat up a fluid, while the entire array is embedded into the façade or roof of a building; thus, it simultaneously generates thermal (by heating air) and electrical energy. The result is that preheated air from the BIPV/T system can be used as a source by the ASHP and the ASHP can be powered by the electricity generated by the PV panels. The preheated air source allows the ASHP to operate during extremely cold weather conditions and increases the COP of the system itself. Thus, an integrated BIPV/T coupled ASHP system can supply space heating for residential buildings in Canada, without natural gas and the electricity generated can reduce reliance on grid supplied electricity that is partially generated from combustibles. Kamel and Fung (2014) determined that the utilizing an integrated BIPV/T coupled ASHP system could reduce up to $1959 \mathrm{~kg}$ of $\mathrm{CO}_{2}$ over the year.

Enhancements to BIPV/T systems can reduce energy consumption and result in further decrease in GHG emissions and the pay back period for the system. Many studies have focused on the enhancements of photovoltaic thermal (PVT) and solar air thermal collectors; and many of these modifications are applicable to BIPV/T systems. However, many of these enhancements introduce increased air flow restrictions in the air channel (e.g., fins, double pass flow, increasing surface roughness) and would decrease the overall energy savings of an integrated BIPV/T coupled ASHP system. Therefore, the objective of this work is to present enhancements that would increase the efficiency of the overall integrated BIPV/T coupled variable capacity ASHP systems.

An analysis of the different parameters of collectors was conducted and its effect on individual collectors and as an overall system are presented in this work. These parameters affect the thermal performance of the collectors under study and the electrical efficiency of the PV cells indirectly. The analysis quantifies the changes in the performance of the collectors (thermal and 
electrical generation) with respect to the range of the values of the parameters examined. These optimized parameters increase flow resistance on a negligible level and are therefore in line with the goal of enhancing the performance of the integrated system.

In addition to analyzing enhancements of BIPV/T systems on an individual collector basis, arrangement analyses were also conducted. These results show that different levels of performance could be obtained based on placements of specific collectors. Array systems are generally limited by the area available for surface integration and smaller BIPV/T systems with its arrangement optimized can perform as well as larger systems.

To quantify these enhancements, simulations of these enhanced arrays were coupled with a multispeed heat pump (MSHP) were conducted using a NZE and an energy efficient house. The system on these two houses introduced similar levels of savings; analysis of the results also depicted areas of strength and limitations of these systems. 


\subsection{Literature Review}

Building integrated photovoltaic/thermal (BIPV/T) systems are PV panels directly integrated into the building envelope, displacing conventional roofing material (e.g., shingles), that are equipped with a duct/channel or tubing behind it with a circulating heat transfer fluid (e.g., air or water) to collect thermal energy. Thus, a BIPV/T system generates both electricity and thermal energy. Originally developed from photovoltaic thermal (PVT) panels with research dating back to the 1970's, application of PV for residential usage were not economically viable until in recent years when the cost of PV panels had dropped significantly (Ibrahim et al., 2014). Benefits of BIPV/T systems including offsetting the cost of the construction of new buildings by making conventional roofing material obsolete, increasing the electrical efficiency of the solar cells of the PV panels, and providing an efficient heat source for air source heat pumps (ASHP).

Enhancements that increase the overall thermal energy and temperature output of solar thermal and PVT collectors are applicable for BIPV/T systems. Enhancements such as fins, selective absorbers, collector flow arrangement, collector dimensional ratio (e.g., aspect ratio) surface roughening/modifications, and porous media have been proposed. Generally, these enhancements can be classified as collector design based (does not require additional components, e.g., reconfiguration of a collectors absorbing plate) and component based (e.g., utilizes additional devices). These modifications have been examined and significant improvements over base case results have been proven.

Air based solar thermal collectors (also referred to as solar air heaters, $\mathrm{AH}$ ) are devices that are intended to convert solar radiation into useful thermal energy. This is accomplished by using a collecting surface, which radiation strikes, and uses moving air to extract the thermal energy (Duffie \& Beckman, 2006), either passively (e.g., natural convection of air) or actively (fan to induced forced flow). In general, these collectors consist of an absorbing/receiving surface and a system that allows fluid to extract the thermal energy (e.g., tubes, channels). In application, these collectors can be flat plate or concentrating collectors; flat plate uses a flat absorbing plate to absorb radiation and concentrators have additional features that optically enhance the total amount of radiation incident on the absorbing surface. With respect to residential application, flat plate collectors are of interest as they are mechanically simple, produce high temperature outputs that are suitable for residential use (up to $100^{\circ} \mathrm{C}$ above ambient) (Duffie \& Beckman, 2006) and, in contrast to concentrating collectors, do not require solar tracking. 


\subsection{Fluid flow configuration}

Othman et al. (2005) constructed a double pass PVT with the top air stream flowing between the glass cover and the PV cells, and then between the underside of the PV cells and the lower surface of the collector. In the top layer, compound parabolic concentrators were placed around the PV cells in order to concentrate the radiation onto the glass cover; on the lower surface longitudinal plate fins were installed behind the PV cells within the bottom pass. The numerical model was based on steady-state energy balances and the experimental data were obtained in a controlled environment with artificial solar radiation. Othman et al. (2005) presented theoretical and experimental electrical, air temperature rise, and efficiency (thermal, electrical, combined) results. These results all reflect that casual effect of mass flow rate and radiation on their PVT; an increase mass flowrate will increase the efficiency (thermal and electrical) and decrease the temperature rise of the PVT (Othman et al., 2005).

Figure 2-1 depicts the temperature rise obtained from the theoretical model and experimental work, where $T_{i}$ and $T_{o}$ are the inlet temperature and outlet temperature, respectively (Othman et al., 2005). There is a high level of agreement between the two results in the lower and higher range of the mass flowrates, but a larger discrepancy (approximately $1^{\circ} \mathrm{C}$ ) occurs between mass flowrates of 0.05 and $0.01 \mathrm{~kg} / \mathrm{s}$. In Figure 2-2, the efficiencies obtained, theoretically and experimentally, by Othman et al. (2005) are presented; from this figure, it can be seen that the theoretical model's thermal efficiency results greatly differ from those obtained experimentally; this suggest their steady-state model is incapable of accurately modelling their double pass PVT with compound parabolic concentrators.

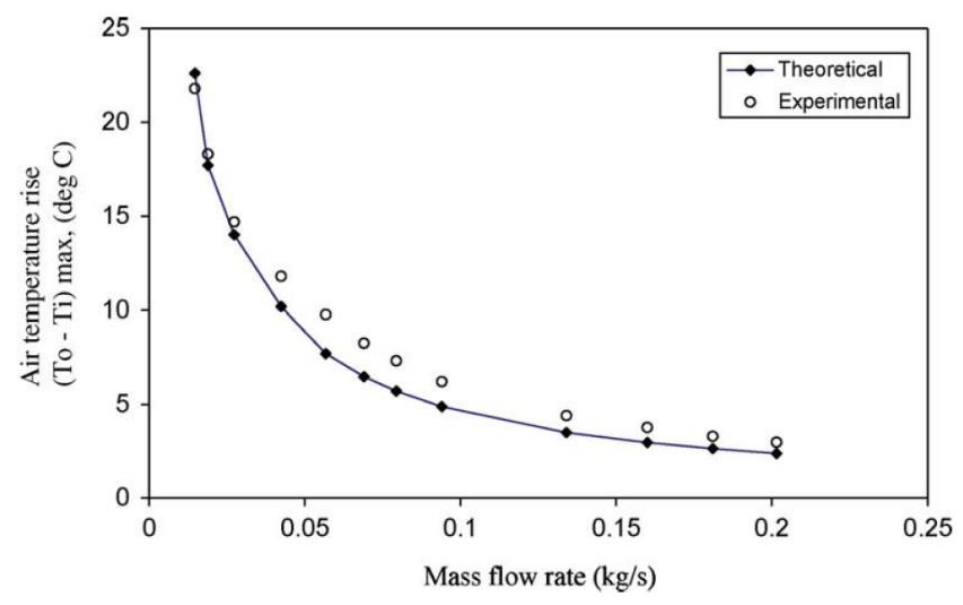

Figure 2-1 Theoretical and experimental temperature rise for different flowrates (Othman et al., 2005) 


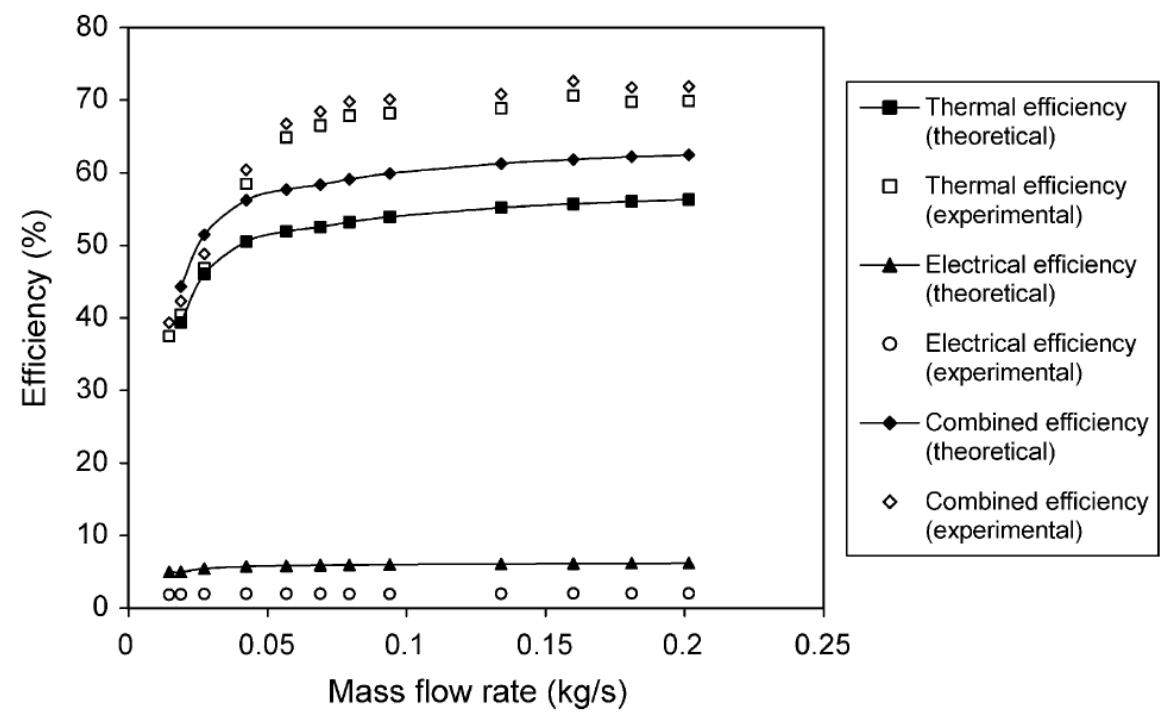

Figure 2-2 Efficiency for various mass flowrates (Othman et al., 2005)

Vaziri, Ilkan and Egelioglu (2015) experimentally investigated the performance of perforated glazed solar air heaters with colored collector surfaces and unglazed transpired metal sheet absorber collectors. Shown schematically in Figure 2-3, air is drawn through the perforated glass and exits through the opening on the collector bottom surface; the same design was used for the perforated metal collectors.

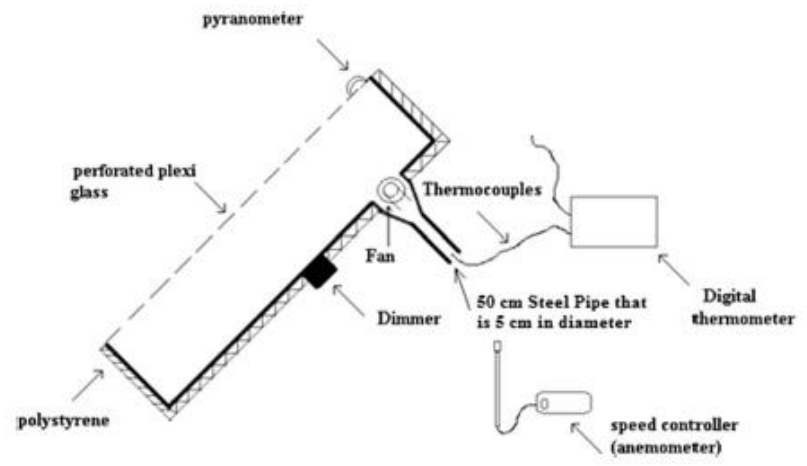

Figure 2-3 Schematic of perforated collector (Vaziri, Ilkan, \& Egelioglu, 2015)

In their study, perforated glazing collectors with dark green, blue, yellow, and white collector surfaces were examined and compared with the unglazed transpired metal sheet collector. For a mass flowrate of $0.024 \mathrm{~kg} / \mathrm{s}$, perforated glazed collectors with a green or blue coloured surface 
consistently performed better than the metal sheet collector, as shown in Figure 2-4. On the other hand, in Figure 2-5 the perforated glazed collectors with a white or yellow collector surface performed similarly to the metal transpired collector. Although, the collectors presented by Vaziri, Ilkan and Egelioglu (2015) are unorthodox, their results support the design of using glazed covers on top of an absorbing surface.

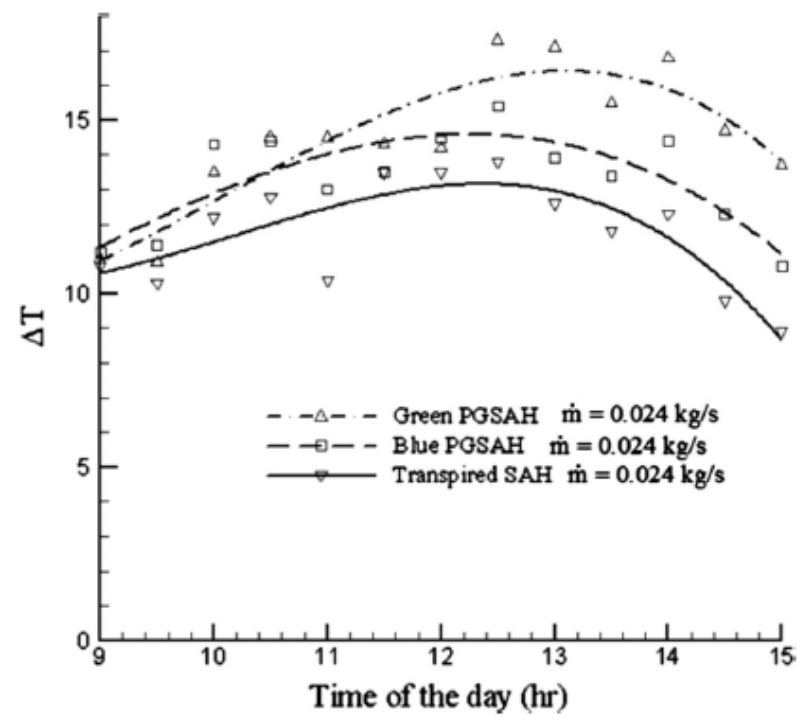

Figure 2-4 Temperature rise for green, blue and transpired collectors throughout the day (Vaziri, Ilkan, \& Egelioglu, 2015)

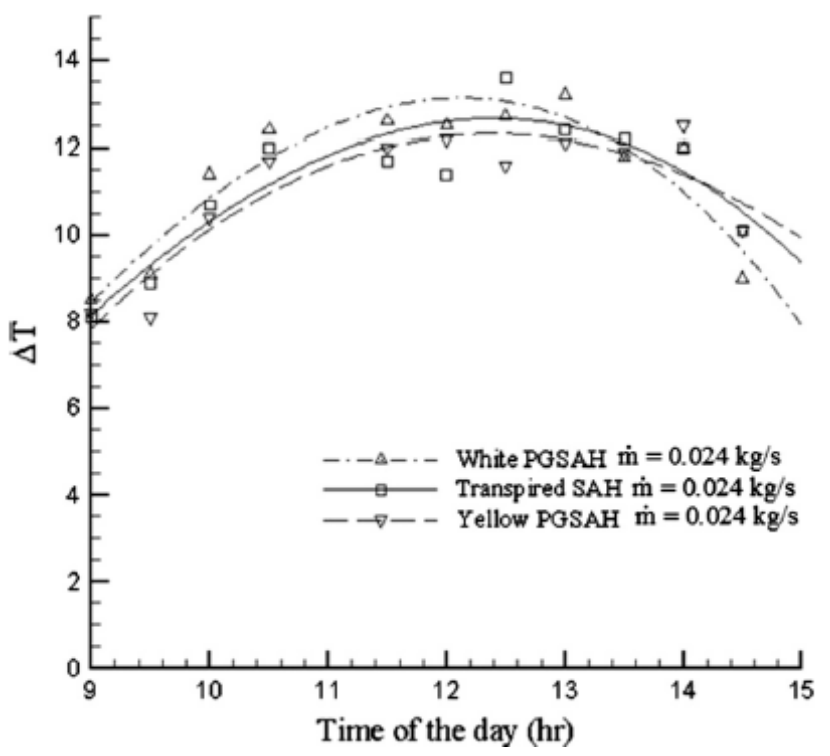

Figure 2-5 Temperature rise for white, yellow, and transpired collectors throughout the day (Vaziri, Ilkan, \& Egelioglu, 2015) 


\subsection{Absorber plate configuration}

Koyuncu (2006) examined the performance of six different designs of solar air heaters (modifications of model-1 shown in Figure 2-6). Three different absorber plates were examined and each were configured in two different air flow configurations for a total of six designs, referred to as model-1, model -2, etc. The first three absorber plates included a flat black painted hardboard absorber plate, flat black painted aluminum plate, and a zigzag black painted aluminum plate with the air flowing between the plastic cover and the plates. For each plate, the air flow was configured to flow between the absorber plate and glass cover in one setup and then to flow beneath the absorber plate in another. With the exception of the flat plate absorber, when the air flow was configured to flow beneath the plate, two covers above the plate were installed, whereas all other collectors was equipped with a single cover layer. In the experimental setup, all six designs operated simultaneously at Samsun, Turkey with a constant mass flowrate.

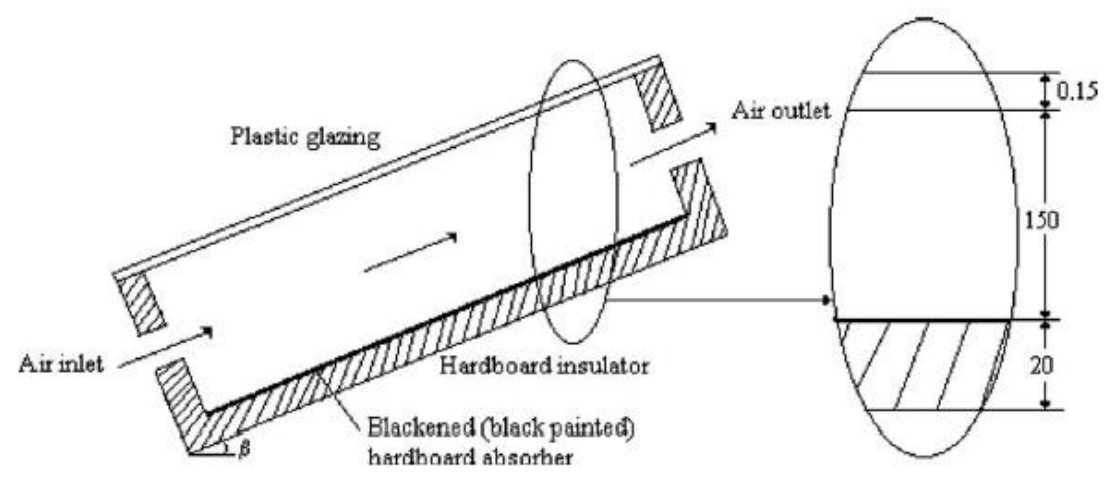

Figure 2-6 Model 1 (dimensions in mm) (Koyuncu, 2006)

The results indicated that the most efficient design was found to be model-2, shown in Figure 2-7 (dimensions in mm), while model-6 was the least efficient (Figure 2-8) (Koyuncu, 2006). The average change in temperature of model-2 and model- 6 were $10.92{ }^{\circ} \mathrm{C}$ and $8.85{ }^{\circ} \mathrm{C}$, respectively; as all the collectors drew ambient air through the inlet, model-2 also had the highest outlet air temperature. 


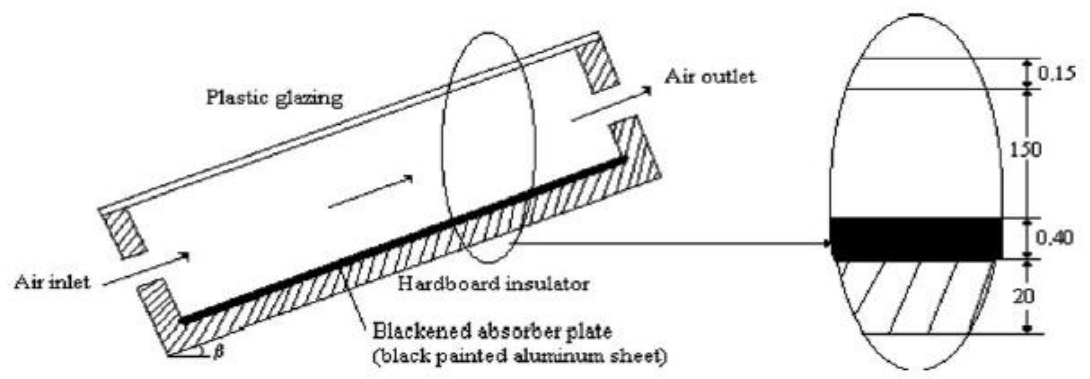

Figure 2-7 Model 2 (dimensions in mm) (Koyuncu, 2006)

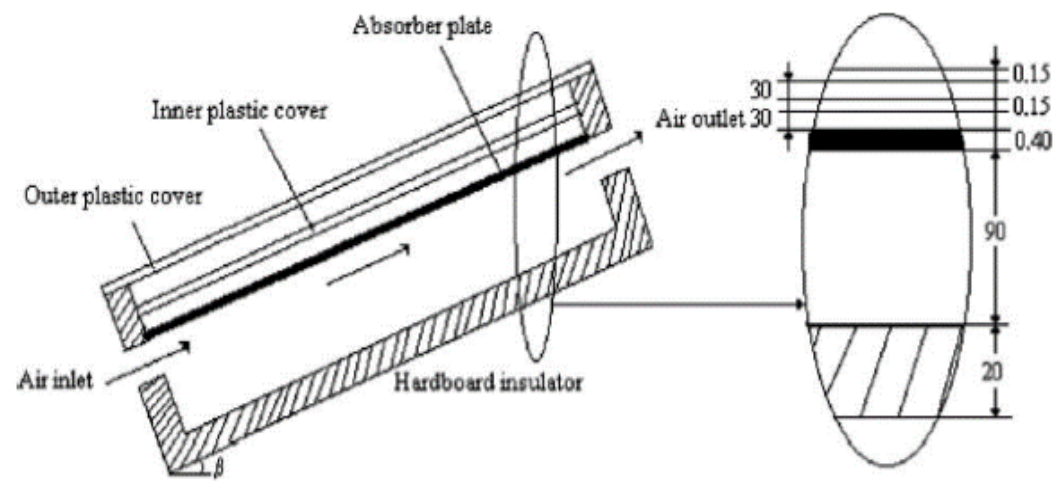

Figure 2-8 Model 6 (dimensions in mm) (Koyuncu, 2006)

Although model-2 generated the highest outlet air temperature, its plate temperature was not the highest (Koyuncu, 2006). Model-4 (shown in Figure 2-9) had the highest average plate temperature and Koyuncu (2006) attributed this to the model's design parameters and because the air flowed behind the plate. When the airflow is located behind the absorber plate, the energy gain was less than when the flow path was located between the cover and absorber plate.

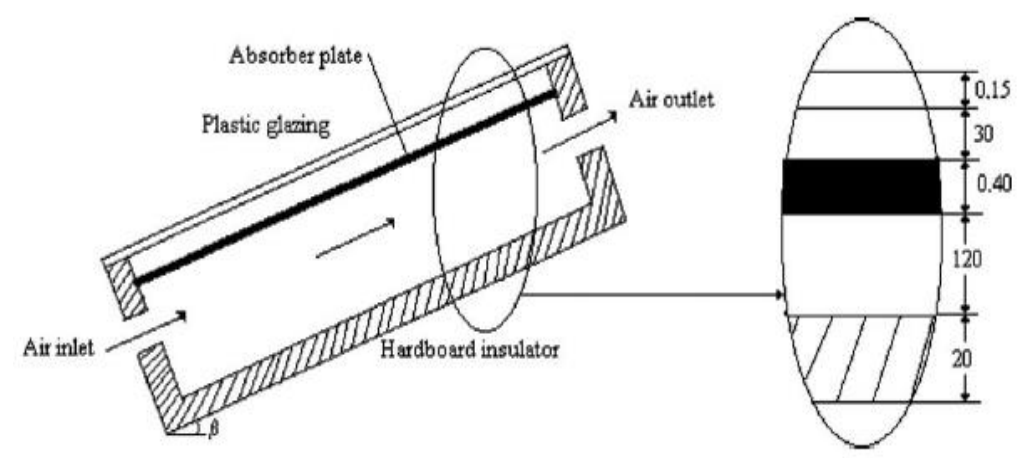

Figure 2-9 Model 4 (dimensions in mm) (Koyuncu, 2006) 
Njomo \& Daguenet (2006) conducted a sensitivity analysis with a focus on the outlet air temperature and temperature rise through collectors, in response to irradiance, thermal efficiency and a dimensionless number termed the thermal performance factor. The thermal performance factor relates the useful thermal energy gain to the heat loss of the collector. In the study, four different collector designs were developed, assuming at steady state operation. Their results showed that for the collectors considered, small channel depths resulted in large temperature rises and correspondingly higher outlet temperatures; there is also a diminishing margin of return for increasing the mass flowrate. They also examined the use of adding a glass cover underneath a top cover of plexiglass to reduce thermal losses. The base case, where the collector only had a single plexiglass layer, the thermal efficiency was $24.71 \%$; on the other hand, the collector with the additional glass layer had an efficiency of $35.49 \%$.

Yeh, Ho and Lin (2000) found that increasing the collector aspect ratio (ratio between the dimension along the flow direction to the dimension perpendicular to), while maintaining the collector area, increases collector thermal efficiency. They attributed this to the reduced crosssectional area which increases fluid velocity for a constant mass flowrate. Their work also examined the effect of aspect ratio on collectors with fin and baffles; the results showed that increasing the aspect ratio had a larger effect on collectors without fins and baffles than collectors equipped with them did. Based on this observation, the optimal collector aspect ratio should be selected, not just to maximize the thermal performance of a finned collector, but to consider the pressure drop through the collector.

\subsection{Solar absorption characteristics of air thermal and photovoltaic collectors}

Another important consideration in BIPV/T, PVT, and air heater performance, is the absorbed solar radiation available to a particular PV/absorber layer. Candanedo, Athienitis, and Park (2011) and asserted the importance of the incidence angle in regard to modeling the solar radiation during early morning hours.

Radiation often travel through a combination of air, glass, encapsulants (for PV cells), and antireflection coating (McIntosh et al., 2009), while simultaneously being reflected, refracted, absorbed, and transmitted by the material (which often have wavelength dependent properties). Hence, the precise optical path travelled by the shortwave radiation differs between PV or PVT panels and solar thermal collectors. 
Most PV panels use ethylene vinyl acetate (EVA) as the encapsulant that adheres the PV cells to the glass cover and back surface for its optical, mechanical, and electrical properties (McIntosh et al., 2009). A potentially superior encapsulant, one that results in higher electrical performance, is silicone.

In solar thermal collectors, absorbers with high solar absorptance and low long wave emittance are sought after since they convert a larger proportion the incident solar radiation while emitting less of it to the ambient as losses. Absorbers exhibits a combination of high absorptance and low emittance are termed selective surfaces (Agnihotri \& Gupta, 1981). The absorptance of materials are dependent on the chemical composition and molecular phase structure. For high temperature applications, transition metal and transition metal alloys (e.g., NbN, TiON, TiMON) are favoured for their low costs and stability at high temperatures (Liu, Wang, Lei, \& Wang, 2014). Examples of these include the selective absorbing $\left.\mathrm{SS}\left(\mathrm{Fe}_{3} \mathrm{O}_{4}\right) / \mathrm{Mo} / \mathrm{TiZrN} / \mathrm{TiZrON} / \mathrm{SiON}\right)$ coating developed by Liu et al. (2014) which has an absorptance of 0.95 and emittance of 0.08 at $80^{\circ} \mathrm{C}$. On the other hand, lower temperature solutions included a novel absorber developed by Wang et al. (2016), which has a solar absorptance of 0.92 and thermal emittance of 0.12 at $300 \mathrm{~K}$.

Tesfamichael and Wackelgard (2000) characterized the solar absorptance of two types of selective absorbers, nickel pigmented aluminum oxide $\left(\mathrm{Ni}-\mathrm{Al}_{2} \mathrm{O}_{3}\right)$ and sputtered nickel/nickeloxide $\left(\mathrm{Ni}-\mathrm{Ni}_{\mathrm{x}}\right)$. They examined the two absorbers experimentally with and without glazing and presented their fitted results, absorptance as a function of incidence angle using Equation 2-1,

$$
\operatorname{IAM}(\theta)=\text { Normalized absorptance }=1-b_{0}\left(\frac{1}{\cos \theta}-1\right)^{c}
$$

which is a modified version of the equation presented in ASHRAE/ANSI Standard 93-2003 (2003) and was presented by Ronnelid (1998).

Based on their experimental results on the characterization of the solar absorptance and using Equation 2-1, Tesfamichael and Wackelgard (2000) reported $b_{0}=0.017$ and $c=1.8$ for $\mathrm{Ni}-\mathrm{Al}_{2} \mathrm{O}_{3}$ and $b_{0}=0.057$ and $c=1.2$ for $\mathrm{Ni}-\mathrm{NiO}_{\mathrm{x}}$ without glazing (this is graphically presented in Figure 2-10). As a comparison, Tesfamichael and Wackelgard (2000) conducted a theoretical analysis of same absorbers under a $4 \mathrm{~mm}$ thick low iron glass cover. They presented their findings in Figure 2-11; they noted that the exponential parameter $c$ in this case was near unity, which 
would revert back to the original equation where, $c=1$, (ASHRAE/ANSI Standard 93-2003, 2003). Furthermore, they found that at higher incidence angles, the IAM is more heavily influenced by the properties of the cover.

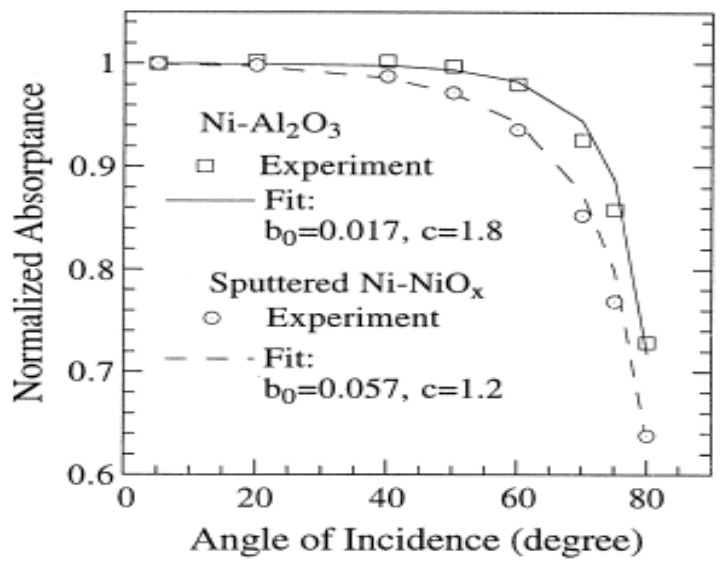

Figure 2-10 Unglazed IAM (Tesfamichael and Wackelgard, 2000)

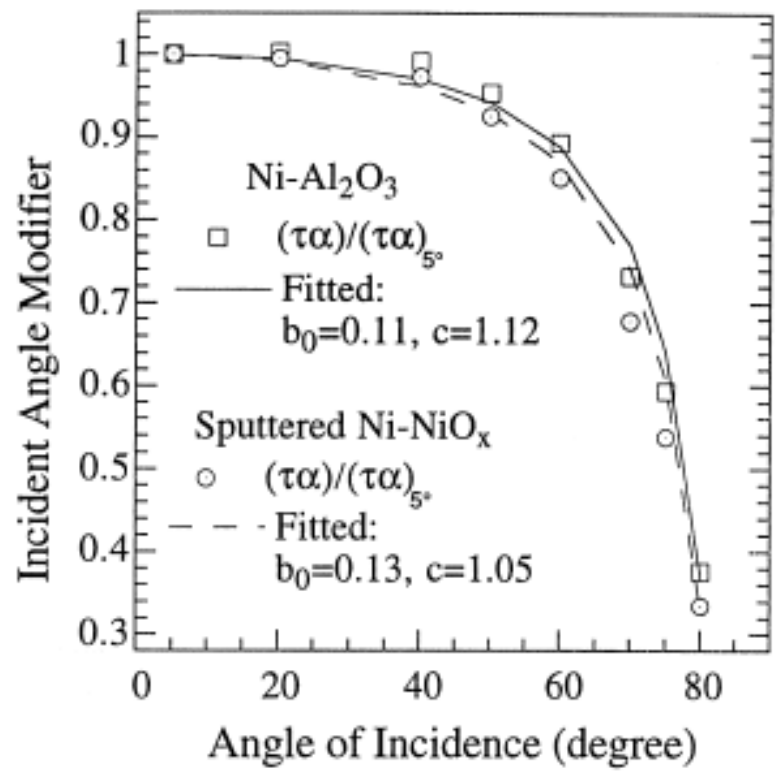

Figure 2-11 4 mm glazed IAM (Tesfamichael and Wackelgard, 2000)

\subsection{Internal channel fins}

The performance of finned solar thermal collectors have been examined theoretically by Naphon (2005), experimentally by Peng, Zhang, Dong, and Lv (2010), and both theoretically and 
experimentally by Fudholi et al. (2013) and Karim and Hawlader (2006); Othman et al. (2005) conducted a theoretical and an experimental study on a PVT collector with fins. In these papers, the authors examined the effect of various fin parameters on the collector's performance, and/or validated their theoretical model results based on experimental data. Furthermore, in each of these studies, the collectors were tested under laboratory conditions or ambient conditions of a warm climate region, the coldest collector inlet temperature used in these studies was approximately $11^{\circ} \mathrm{C}$, by Peng et al. (2010).

Enhancement in heat transfer by fins on PV, and PVT have been proposed and examined. Finned surfaces are "practical modifications that enhance the heat transfer in the air channel" (Tripanagnostopoulos, 2007). According to Tahat, Kodah, Jarrah, and Probert (2000), the addition of fins introduce additional parameters for the system: fin geometry, fin and base material thermal properties, and fin array orientation. Although fins have been installed on the rear surfaces of PVs and on the inner channel surfaces (Garg \& Datta, 1989) and (Garg, Jha, \& Datta, 1991), optimal placement depends on the type of PV panels; for example, Tripanagnostopoulos (2007) suggested fins to be installed on the rear surfaces of opaque PV panels, in order to effectively conduct heat from the panels. However, Tripanagnostopoulos (2007) also pointed to the impracticality of storage and transportation of panels with protrusions.

Naphon (2005) developed a numerical solar air collector model with longitudinal fins and used it to examine the effect of air mass flow rate, fin height, and the number of fins on the collector's outlet temperature, thermal efficiency, and entropy generation rate. Using a numerical model, Naphon (2005) theoretically determined for a constant flowrate and inlet air condition, the entropy increases inversely with the length of the fins. This agreed with the phenomenon that increased fin length leads to enhanced heat transfer and outlet temperature. Furthermore, Naphon (2005) also examined the entropy generation of a double-pass solar air heater with fins. In the analysis, entropy change was due to the heat transfer between the collector and the working fluid (air), incident solar irradiance, and stray heat losses to the environment.

Peng et al. (2010) examined 25 different solar collectors with circular pin fins experimentally (outdoor test). They obtained 25 mathematical correlation that estimated the thermal efficiency based on the air inlet temperature and the irradiance; these correlations are valid only for a specific fin configuration. They also presented an experimentally determined Nusselt correlation for a specific collector. 
Fudholi et al. (2013) developed a steady-state double pass solar collector model with longitudinal plate fins. Their theoretical results closely matched their experimental results. They reported their theoretical and experimental results for three different solar irradiances, 425, 575, and $790 \mathrm{~W} / \mathrm{m}^{2}$ for each mass flowrates of $0.04,0.07,0.08$, and $0.09 \mathrm{~kg} / \mathrm{s}$.

Naphon (2005), Fudholi et al. (2013), and Karim and Hawlader (2006) developed steadystate models for solar collectors and (Othman et al., 2005) developed a steady-state model for PVT collectors. For their finned channel's Nusselt correlation, Naphon (2005) and Fudholi et al. (2013) referenced the work of Ong (1995), who in turned applied correlations for the flow between parallel plates and flat plate solar collectors that were developed by Heaton, Reynolds, and Kays (1964) and Tan and Charters (1970), respectively. Although these correlations were not developed for flow along finned surfaces, according to the results obtained by Fudholi et al. (2013), there was a level of agreement between the theoretical and experimental data. As shown in Table 2-1, for the outlet temperature the absolute errors ranged from $0.11-9.46 \%$ with the greatest errors consistently obtained for an irradiance of $575 \mathrm{~W} / \mathrm{m}^{2}$, regardless of the flowrate applied.

Table 2-1 Outlet temperature and thermal efficiency results (Fudholi et al. 2013.)

\begin{tabular}{|c|c|c|c|c|c|c|c|c|c|}
\hline \multirow{2}{*}{$\begin{array}{l}\text { min } \\
(\mathrm{kg} / \\
\mathrm{s})\end{array}$} & \multirow[t]{2}{*}{$\begin{array}{l}I(\mathrm{~W} / \\
\left.\mathrm{m}^{2}\right)\end{array}$} & \multicolumn{3}{|c|}{$\begin{array}{l}\text { Outlet temperature, } \\
T_{o}\left({ }^{\circ} \mathrm{C}\right)\end{array}$} & \multicolumn{3}{|c|}{ Efficiency, $\eta(\%)$} & \multicolumn{2}{|c|}{ Accuracy (\%) } \\
\hline & & Theo. & Exp. & $\begin{array}{l}\% \\
\text { error }\end{array}$ & Theo. & Exp. & error & $T_{o}$ & $\eta$ \\
\hline 0.04 & $\begin{array}{l}425 \\
575 \\
790\end{array}$ & $\begin{array}{l}43.55 \\
49.88 \\
61.44\end{array}$ & $\begin{array}{l}43.50 \\
52.20 \\
62.70\end{array}$ & $\begin{array}{l}0.11 \\
4.65 \\
2.01\end{array}$ & $\begin{array}{l}55 \\
56 \\
58\end{array}$ & $\begin{array}{l}54 \\
55 \\
56\end{array}$ & $\begin{array}{l}1.90 \\
1.79 \\
3.45\end{array}$ & $\begin{array}{l}99.89 \\
95.35 \\
97.99\end{array}$ & $\begin{array}{l}98.10 \\
98.21 \\
96.55\end{array}$ \\
\hline 0.06 & $\begin{array}{l}425 \\
575 \\
790\end{array}$ & $\begin{array}{l}39.52 \\
44.46 \\
54.24\end{array}$ & $\begin{array}{l}40.27 \\
47.77 \\
55.41\end{array}$ & $\begin{array}{l}1.90 \\
7.44 \\
2.11\end{array}$ & $\begin{array}{l}62 \\
64 \\
67\end{array}$ & $\begin{array}{l}60 \\
61 \\
62\end{array}$ & $\begin{array}{l}3.30 \\
4.69 \\
7.76\end{array}$ & $\begin{array}{l}98.10 \\
92.56 \\
97.89\end{array}$ & $\begin{array}{l}96.70 \\
95.31 \\
92.24\end{array}$ \\
\hline 0.07 & $\begin{array}{l}425 \\
575 \\
790\end{array}$ & $\begin{array}{l}38.07 \\
42.50 \\
51.57\end{array}$ & $\begin{array}{l}39.20 \\
46.24 \\
54.21\end{array}$ & $\begin{array}{l}2.97 \\
8.80 \\
4.87\end{array}$ & $\begin{array}{l}64 \\
66 \\
70\end{array}$ & $\begin{array}{l}62 \\
64 \\
65\end{array}$ & $\begin{array}{l}3.40 \\
2.59 \\
7.71\end{array}$ & $\begin{array}{l}97.03 \\
91.20 \\
95.13\end{array}$ & $\begin{array}{l}96.60 \\
97.41 \\
92.29\end{array}$ \\
\hline 0.08 & $\begin{array}{l}425 \\
575 \\
790\end{array}$ & $\begin{array}{l}36.97 \\
41.00 \\
49.57\end{array}$ & $\begin{array}{l}37.70 \\
44.88 \\
52.64\end{array}$ & $\begin{array}{l}1.97 \\
9.46 \\
5.83\end{array}$ & $\begin{array}{l}66 \\
68 \\
73\end{array}$ & $\begin{array}{l}65 \\
66 \\
70\end{array}$ & $\begin{array}{l}1.10 \\
2.22 \\
3.97\end{array}$ & $\begin{array}{l}98.03 \\
90.54 \\
94.17\end{array}$ & $\begin{array}{l}98.90 \\
97.78 \\
96.03\end{array}$ \\
\hline 0.09 & $\begin{array}{l}425 \\
575 \\
790\end{array}$ & $\begin{array}{l}35.20 \\
39.65 \\
47.71\end{array}$ & $\begin{array}{l}36.42 \\
42.23 \\
50.14\end{array}$ & $\begin{array}{l}3.47 \\
6.51 \\
4.85\end{array}$ & $\begin{array}{l}67 \\
70 \\
75\end{array}$ & $\begin{array}{l}67 \\
72 \\
79\end{array}$ & $\begin{array}{l}0.90 \\
2.86 \\
5.33\end{array}$ & $\begin{array}{l}96.53 \\
93.49 \\
95.15\end{array}$ & $\begin{array}{l}99.10 \\
97.14 \\
94.67\end{array}$ \\
\hline \multicolumn{2}{|c|}{ Average } & & & 4.46 & & & 3.53 & 95.54 & 96.47 \\
\hline
\end{tabular}

Karim and Hawlader (2006) also applied flat plate collector correlations in their steadystate model. For laminar flow, they applied a correlation obtained by Sherwin (1985) and for turbulent flow they applied a correlation determined by Niles, Caxnegie, Pohl, and Cherne (1979). Although these were also flat plate correlations, the results obtained experimentally were in good 
agreement with those determined theoretically. This is shown in Figure 2-12, where the thermal efficiencies were plotted for different mass flowrates. Although Karim and Hawlader (2006) did not explicitly quantify the errors, given the slight differences, their flat plate correlations and their steady-state models accurately estimated the performance of their collector.

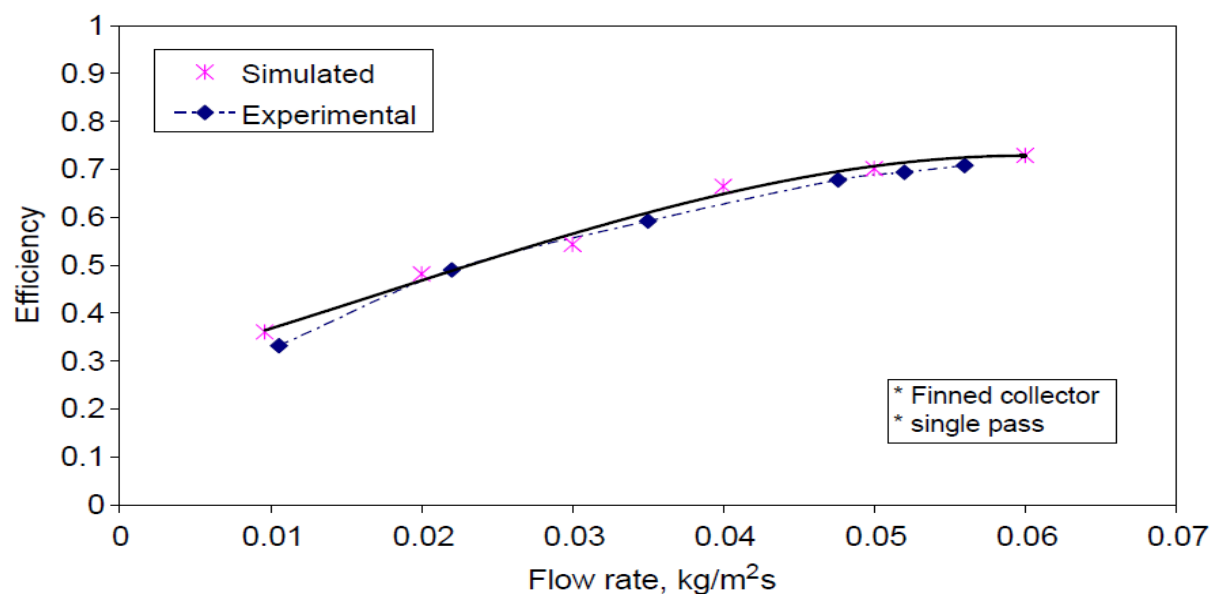

Figure 2-12 Thermal efficiency of a finned collector for different flowrates for irradiance of $500 \mathrm{~W} / \mathrm{m} 2$ (Karim and Hawlader, 2006)

\subsection{Thermal storage}

Aboul-Enein, El-Sabii, Ramadan and El-Gohary (2000) experimentally examined the performance of solar heaters with and without thermal storage attached behind a flat absorber plate and developed a validated model; the numerical results were found to be within $4.5 \%$ of the experimentally observed values. In the model, the capacitance of the physical collector was negligible as they kept the material thickness to a minimum. The transient nature of the material was retained when modelling the air flowing through the collector and storage material. AboulEnein et al. (2000) found that increasing length and width increases outlet temperature and that it is a design parameter with a diminishing margin of return- increasing the area increase the amount of absorbed energy but it also increases overall heat losses to the ambient environment (convective and radiative losses).

In the study, the storage was attached directly behind the absorber plate as shown in Figure 2-13 (Aboul-Enein et al., 2000). They determined that the outlet temperature of the sytem, when equipped with thermal storage, was much higher for most of the day, as shown in Figure 2-14. The 
addition of the thermal storage material behind the plate lowered the heat losses from the back, compared to the case without storage material.

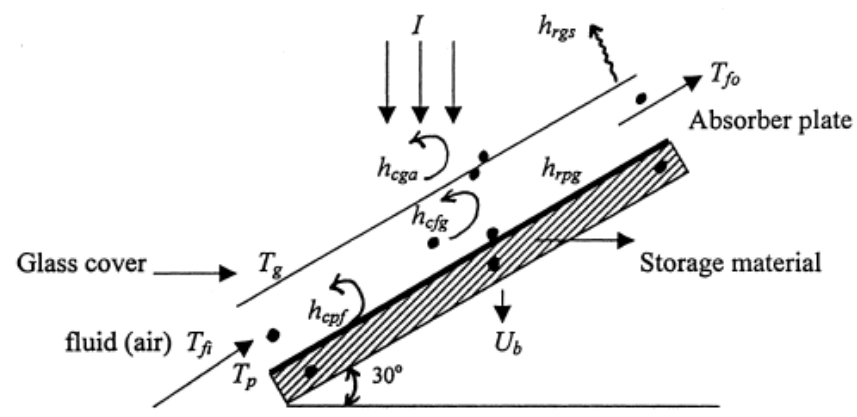

Figure 2-13 Solar collector with thermal storage (Aboul-Enein et al., 2000)

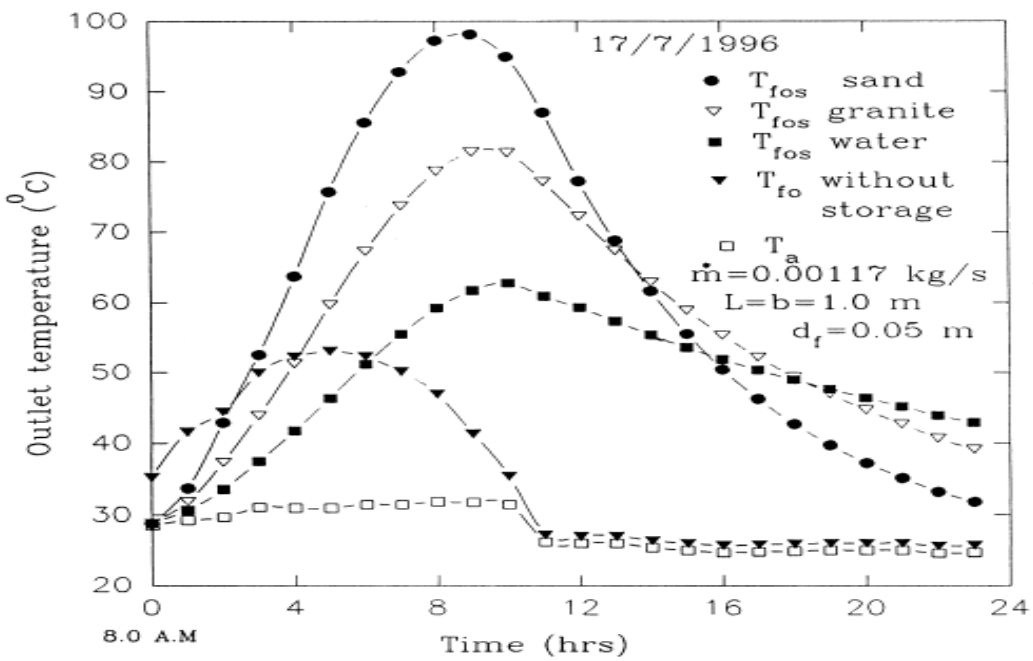

Figure 2-14 Hourly outlet temperature of solar collector with different types of thermal storage material (Aboul-Enein et al., 2000)

Fath (1995) identified that solar air heaters are limited by their low efficiencies and lack of storage options; however, compared with liquid based solar heaters, air heaters avoid issues such as "corrosion, boiling, freezing, salt deposits and leaks". Fath (1995) also listed some ways to improve the performance of air heaters, such as, enhancing heat transfer coefficient, enlarging the heat transfer area, and lowering heat losses to the ambient. Fath (1995) conducted a transient analysis of the collector performance after replacing the absorber plate of a flat plate air heater with rows of tubes filled with thermal storage material. The purpose was to extend the hours of 
when the collector can be used for heating purposes beyond the hours when the sun is shining. In the study, empty smooth tubes, corrugated tubes filled with sand, and corrugated tubes filled with paraffin wax were examined. The results showed that the use of a sensible material (sand) in the study delayed the temperature and heat transfer rate profiles by approximately 30 min when compared to the empty tubes. This was attributed to the higher heat capacitance of the sand. The use of a latent medium noticeably lowered the outlet temperature and heat transfer rate of the air but extended the hours when the outlet temperature is higher than the ambient by $5^{\circ} \mathrm{C}$ by four hours after sunset and increased the thermal efficiency to $63.35 \%$ compared to the $59 \%$ thermal efficiency of sand.

\subsection{Non-finned heat transfer surface modification}

Karim and Hawlader (2006) examined the efficiency of flat plate, V-grooved, and platefinned collectors theoretically and experimentally. They used steady-state efficiency factors to evaluate for expected efficacies based on mass flow rates, inlet temperature, and ambient temperature conditions. Their experimental data were derived from an outdoor test facility that was constructed according to ASHRAE 93-77 guidelines. For each of the three the collectors, Karim and Hawlader (2006) used $1.8 \times 0.7 \mathrm{~m}^{2}$ absorbers with a $0.0175 \mathrm{~m}^{2}$ flow area. Their results showed that their V-grooved collector was the most efficient; the grooved collector's efficiency was $5-11 \%$ greater than the flat pate and $2-5 \%$ greater than the finned collector was. There was a great level of agreement between their simulated and experimental results, based on the graphical representation of the thermal efficiency for different flow rates for each of the three types of collectors. The authors also noted that their study did not examine the effect of the fan's power consumption on the efficiency. Karim and Hawlader (2006) argued that the additional fan power consumption that the grooved and finned collector would require is negligible.

Saini and Verma (2008) experimentally investigated the performance of solar air heaters with an artificially roughened absorber plate for Reynolds numbers from 2000-12,000 and a range of relative roughness height (ratio of height of the element to the hydraulic diameter) and relative pitch (ratio roughness pitch to height of the element). Nusselt and friction factor correlations were developed based on their experimental set up. 


\subsection{Porous media}

Metal foams, a type of porous media, have been applied in experimental and analytical studies as heat transfer enhancement modifications. In particular, for solar collector applications, Wang, Shuai, Tan, and Yu (2013) and Xu, Gong, Huang, and Xu (2014) found metal foams to have greatly enhanced the thermal performance of solar collectors, based on their analysis. In several analyses of solar collectors with metal foams, the Darcy, Brinkman, and Forchheimer models were employed to model flow through a porous media. The Darcy equation is the governing equation of the flow through a porous media, the Brinkman model is formed by including viscous dissipation effect to the Darcy model (used when the flow is slow or if the fluid has a low viscosity) and the Forccheimer model is the Darcy equation with an inertial term (used for high velocity flows).

Xu et al. (2014) analytically and numerically examined the effect of porosity, pore density (measured in pores per in, PPI), channel height, and Reynolds number on the thermal performance of a solar collector; the air channel enveloped block of metal foam. With respect to the velocity profile, they found that applying the Forccheimer resulted in a more uniform profile, than the Darcy or Brinkman model; this is due to the inertial term which would also result in a greater pressure drop Xu et al. (2014). This loss can be prevented by increasing the permeability (e.g., lowering foam density) (Xu et al., 2014). When dealing with a small scale problem, the viscous effects are more prominent which would affect the overall heat transfer (Xu et al., 2014). This is a consideration when applying the Brinkman model (with viscous dissipation) and the Darcy model; $\mathrm{Xu}$ et al. (2014) found that the heat transfer coefficient of the two model differed greatly when the scale of the problem was small, and the difference decreased when the channel height was increased.

A study conducted by Calmidi and Mahajan (2000) of aluminum foams with 5-40 PPI and 0.89- 0.97 porosity found that for a constant velocity, heat transfer coefficient decreased with an increase in porosity. An increase in porosity implies a decrease in the surface area to volume ratio of the block, resulting in less turbulent flow for a constant velocity. These results are further supported in a study completed by Mancin, Zilio, Cavallini, and Rossetto (2010) with air and a metal foam. A separate study by Kim, Paek and Kang (2000), determined that the pore density (measured in PPI) also exhibited an inverse relationship with respect to the heat transfer 
coefficient; for a constant Reynolds number, the heat transfer coefficient decreased as the PPI was increased.

The results of experimental heat transfer work on air and metal foams have sometimes varied. Mancin et al. (2010) conducted a study of the average heat transfer coefficient as it is influenced by pore density, porosity and flow. Mancin et al. (2010) employed a model developed by Ghosh (2009) and found that their experimental results greatly differed from their theoretical results; there was a $36.4 \%$ mean absolute deviation and $35.3 \%$ standard deviation between the two set of results on the heat transfer coefficient. However, using a second model, Mancin et al. (2010) found an $8 \%$ mean absolute deviation and $8 \%$ standard deviation between the two set of results.

The inclusion of a matrix material (e.g., wire mesh) increases the thermal performance of solar air heaters because it encourages a turbulent airflow regime, increases heat transfer area (Rajarajeswari \& Sreekumar, 2016) and because of the high thermal conductivity of the material. However, it is because of this enhanced turbulent flow, that the inclusion of the hydrodynamics is required and overall thermohydraulic performance should be considered. Based on numerous studies, the addition of matrix material in solar air heaters have shown improvements over conventional solar air heaters (Rajarajeswari \& Sreekumar, 2016). The thermohydraulic performance of a solar air heater with a matrix substance were found to have improved when mass flowrate was increased, up to a point; further increase in flow resulted in lower efficiency, as Rjarajeswari and Sreekumar (2016) cited based on the work of Varma, Ahmad and Saini (1996).

Wired meshes can be stacked in parallel at discrete intervals of distance between adjacent layers. Mittal and Varshney (2006) numerically examined the performance of collectors with a mass flowrate of $0.005 \mathrm{~kg} / \mathrm{s}$ to $0.05 \mathrm{~kg} / \mathrm{s}$ with and without wired mesh screens. It was determined that the effective efficiency of the collector, with a specific wired mesh, increased as Reynolds number increases, until a maximum performance, after which further increase in Reynolds number reduced the efficiency of the collector. This was observed by Mittal and Varshney (2006) because the Reynolds number is strongly correlated to the pumping power. In addition to porosity of the mesh, the geometry (wire diameter and pitch) also contributes to enhancing or degrading the performance of the collector.

Studies have also been conducted on applying pulsating flow with metal foams and investigating its effect on the heat transfer coefficient. A computational fluid dynamics (CFD) analysis was used to investigate a metal foam enclosed in a channel with an oscillating air flowrate 
and the results were experimentally validated (Ghafarian, Mobebbi-Kalhori, \& Sadegi, 2013). They determined a proportional relationship between the Nusselt number and the amplitude and frequency of the flow; the increase of these two parameters correlates with an increase in the flow rate. However, the level of enhancement due to increasing amplitude and frequency eventually diminishes. Further increase in amplitude/ frequency results in negligible increase in the Nusselt number (Ghafarian et al., 2013). They achieved an increase in the Nusselt number from 170 to 195 when the amplitude was increased from 1.8 to $2.0 \mathrm{~m} / \mathrm{s}$; however, when the amplitude was further increase from 2.4 to $2.6 \mathrm{~m} / \mathrm{s}$, the Nusselt number only increased from 215 to 220 (Ghafarian et al., 2013).

\subsection{Coupling PVT systems with air source heat pumps}

ASHP perform poorly (e.g., COP less than 2) when operating with low temperature ambient sources (Chen, Athienitis, \& Galal, 2010), as is the case in Canada during winter. This problem can be alleviated by allowing the ASHP to use the preheated air from a BIPV/T system. Kamel, Fung and Dash (2015) classified solar assisted heat pumps as either direct or indirect expansion solar assisted heat pumps. In direct expansion, the solar collector acts as the evaporator; in indirect expansion systems, the thermal energy of the collector is transported via a heating medium and then the energy is transferred to the HP. These indirect expansion systems are further categorized by their arrangements. A series arrangement, thermal energy from the collector is diverted to the HP as a source, however, if the temperature of the heating medium is high enough, they may be used directly and the heat pump is bypassed. In a parallel arrangement, the collector and heat pump are independent systems, the overall integrated system chooses to either operate the collector and utilize its thermal energy directly or operate the HP using ambient air. The last arrangement is the dual source configuration, where the HP is able to choose to operate using the thermal energy from a collector or to use ambient air, depending on which condition is favourable.

Regardless of how the heat pump is to be used (for space heating or domestic water heating), coupling PVT or solar collector with a heat pump (directly or indirectly) will provide a greater increase in the overall energy efficiency of the integrated system, due to the additional heat energy being collected and utilized. According to a study performed by Kuang, Wang and Yu (2003) a solar assisted heat pump collector system could reach efficiencies of $67.2 \%$. For a different configuration set up, a COP of up to 8 could be obtained (Ji, et al., 2008). 
Badescu (2002) developed a model that couples a HP with a solar thermal collector system and an operation scheme. If the solar radiation exceeded a critical value, the system would couple the collector system and assist the heat pump, at other times, the heat pump operates independent of the collectors. The results indicate that the heat pump satisfied the same heating demand as in the base case using $8 \%$ less electricity.

Hailu, Dash and Fung (2015) used TRNSYS to theoretically examined the potential energy savings of a two staged variable capacity ASHP coupled with a BIPV/T system installed in a single family two storey house; these results were compared with a base case where the ASHP was operating with ambient air. The simulation was conducted using Anchorage, Alaskan weather (TMY2) for the heating season. Their results showed that the ASHP coupled BIPV/T system had higher COP compared to the base case for the months of February to April; for December to January, they reported the integrated system did not perform more efficiently than the base system. For a particular day where the ambient temperature was $4.4^{\circ} \mathrm{C}$ in February, the COP of the integrated system was 5.31 and the base system's COP was 4.2. They concluded that improved performances could be obtained using the integrated system during mild winter conditions.

Tardif, Tamasauskas, Delisle and Kegel (2017) used TRNSYS and examined the performance of a BIPV/T system coupled with an ASHP that serviced a $284 \mathrm{~m}^{2}$ two storey single detached house that was intended to be an archetype of the current stock of typical houses in Canada. These simulation results were obtained using Montreal weather. Their case studies included the same house in operation with a standalone electric furnace, electric furnace and $\mathrm{BIPV} / \mathrm{T}$, standalone ASHP, and an integrated ASHP coupled BIPV/T system. In their simulation, the BIPV/T provided $30 \%$ of the ASHP's required source air flowrate and the remaining $70 \%$ was sourced from ambient air. They determined that the house with the integrated ASHP and BIPV/T system yielded the most savings, largely due to a reduction in space and water heating demand and the electricity generated by the PV. In a comparison of the energy consumption of the house equipped with a standalone ASHP and the house equipped with the integrated ASHP and BIPV/T system, their results showed a reduction of $205 \mathrm{kWh}$ in space and water heating energy consumption over the year.

In flow optimized collector systems, heat pumps may be required to operate with varying flow rates as part of an optimization scheme that is balancing multiple variables (e.g., temperature, flowrate, availability of solar sources, cost etc.). However, there has been limited research on the 
effect of varying the source flowrate (e.g., evaporator flowrate in the winter and condenser flowrate in the summer) as in many current ASHP installations, the outdoor flowrate are establsihed by manufacturers by design.

Li, Cao, Feng, Zhang and Huang (2015) conducted a CFD analysis of the impact of air flow velocity of a BIPV/T system on an ASHP's COP. In their work, the velocity was varied and the results are shown in Figure 2-15. They determined that as the flow increased, the temperature exiting the collector system decreased but the ASHP COP increased. For their system, they found that when the velocity was between $2 \mathrm{~m} / \mathrm{s}$ and $4 \mathrm{~m} / \mathrm{s}$ the COP increased from 3.72 to 4.6 .

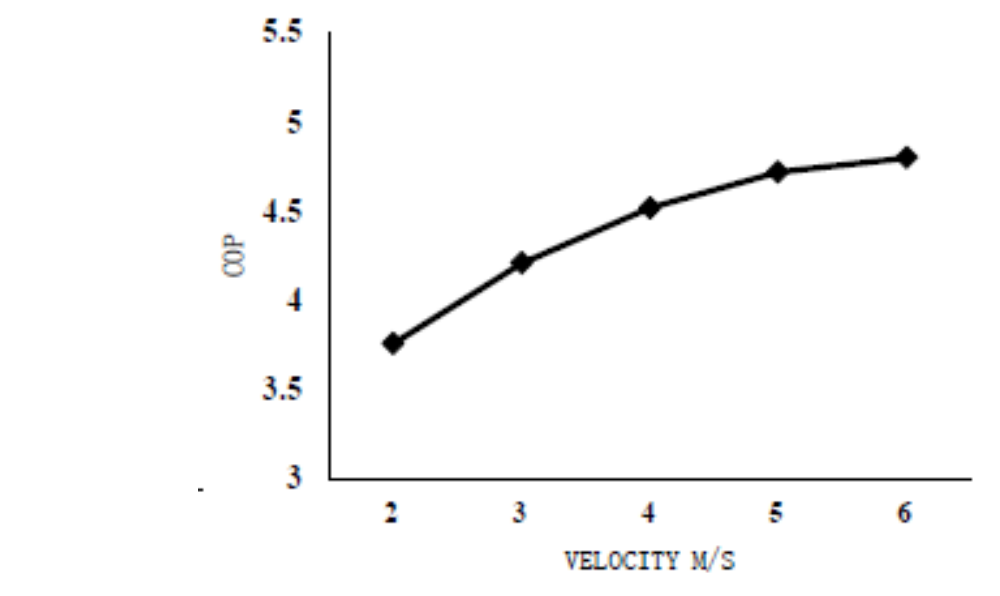

Figure 2-15 ASHP COP for various flow velocities (Li, Cao, Feng, Zhang and Huang, 2015)

Payne, Yoon and Domanski (2009) conducted experimental studies on the performance of a residential heat pump with faults. One of these faults was improper air flow at the outdoor unit (evaporator) during heating mode. The heat pump under study was a "R410A split residential heat pump with an $8.8 \mathrm{~kW}$ nominal cooling capacity", SEER 13 and HSPF 7.8 and was equipped with two finned-tube heat exchangers and a TXV; it is shown schematically in Figure 2-16 (Payne et al., 2009). Experimental work was carried out in an environmental chamber and solid ribbons of paper were placed "across the bottom edge face of the coil", this increased air flow resistance and limited the air flowrate as well and is shown in Figure 2-17 (Payne et al., 2009). 


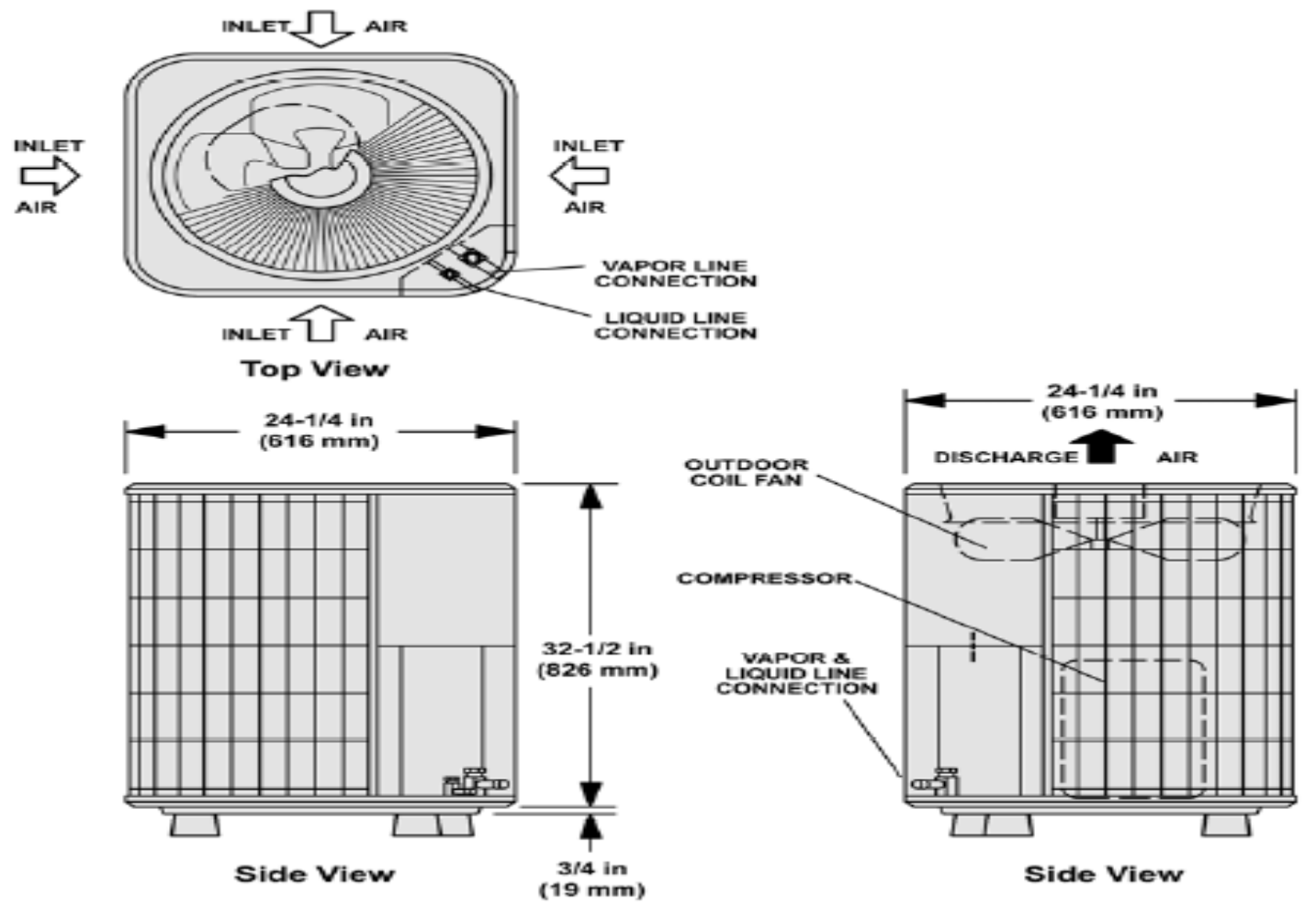

Figure 2-16 R410A split residential heat pump (Payne et al., 2009)

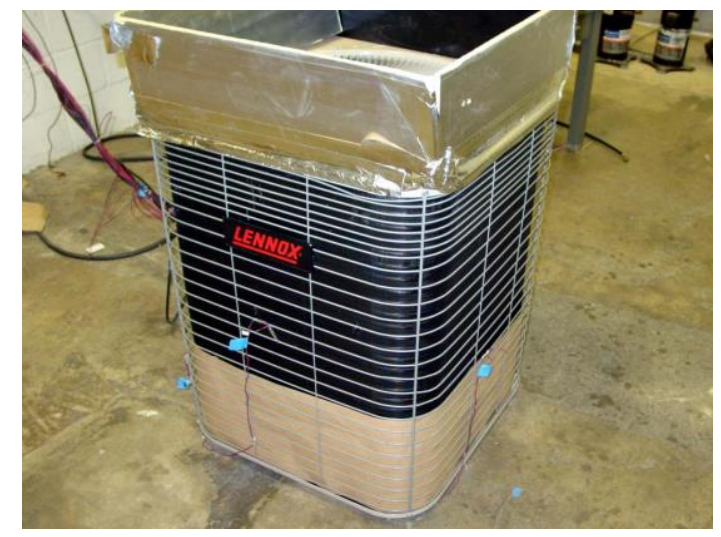

Figure 2-17 Heat pump setup with improper flow fault (Payne et al., 2009)

In Figure 2-18, the air heating capacity and COP are presented along with other performance indicators of the HP under various levels of blockage (coil area blocked as a percentage) for an indoor and outdoor temperature of $21.1^{\circ} \mathrm{C}$ and $-8.3^{\circ} \mathrm{C}$, respectively. The results show an inverse correlation between blocked area (limited air flow) and heating capacity and COP (Payne et al., 2009). As the blocked area increased linearly, the heating capacity and COP degraded in a non-linear fashion. The same test was performed a second time with an indoor and outdoor 
temperature of $21.1^{\circ} \mathrm{C}$ and $8.3^{\circ} \mathrm{C}$, respectively, and the results were presented in Figure 2-19. It is interesting to note that at the colder outdoor condition, at $30 \%$ blockage, the HP heating capacity and COP dropped by $23.7 \%$ and $23.5 \%$, respectively, while under the warmer condition, at $30 \%$ blockage, the heating capacity and COP decreased by $18 \%$ and $14 \%$, respectively. It should be noted that the percentage blocked area does not directly correlate to the percentage flowrate lowered; as Payne et al., (2009) explained, the block increased resistance.

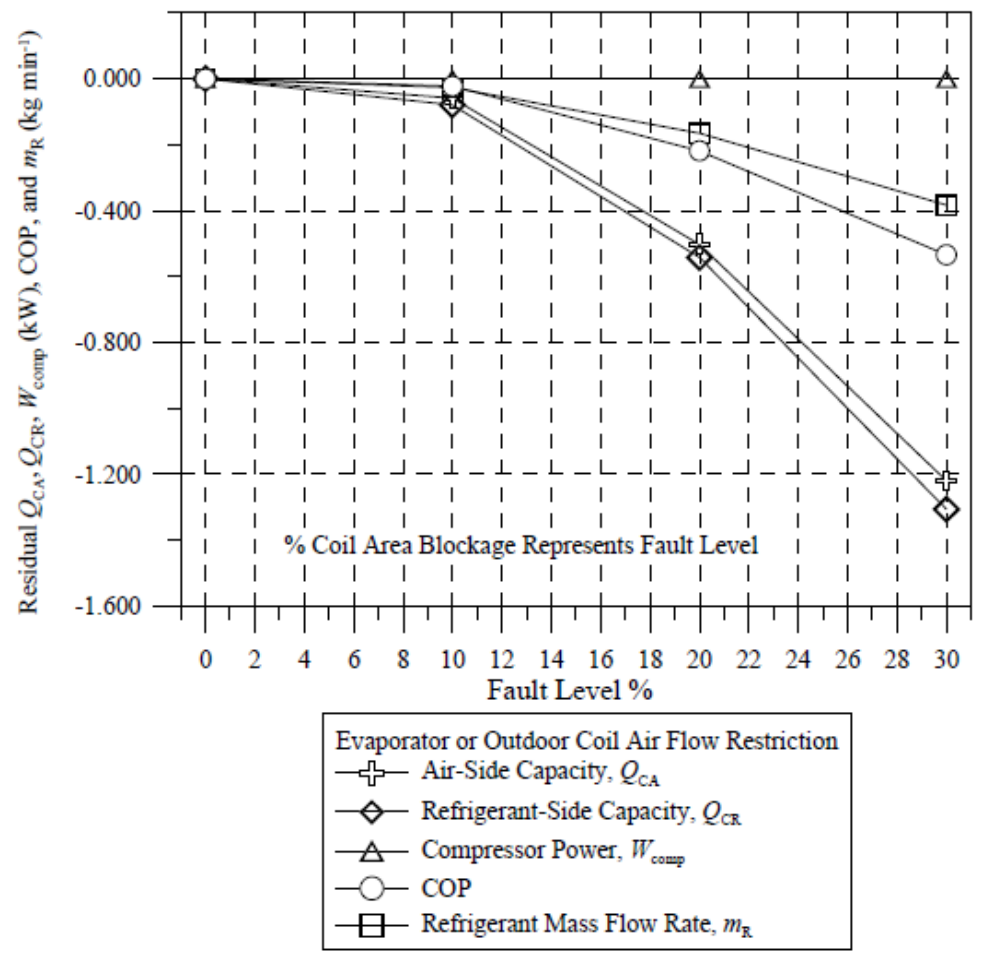

Figure 2-18 Heat pump performance at different fault levels at indoor and outdoor temperature of 21.1 OC and -8.3 OC (Payne et al., 2009) 


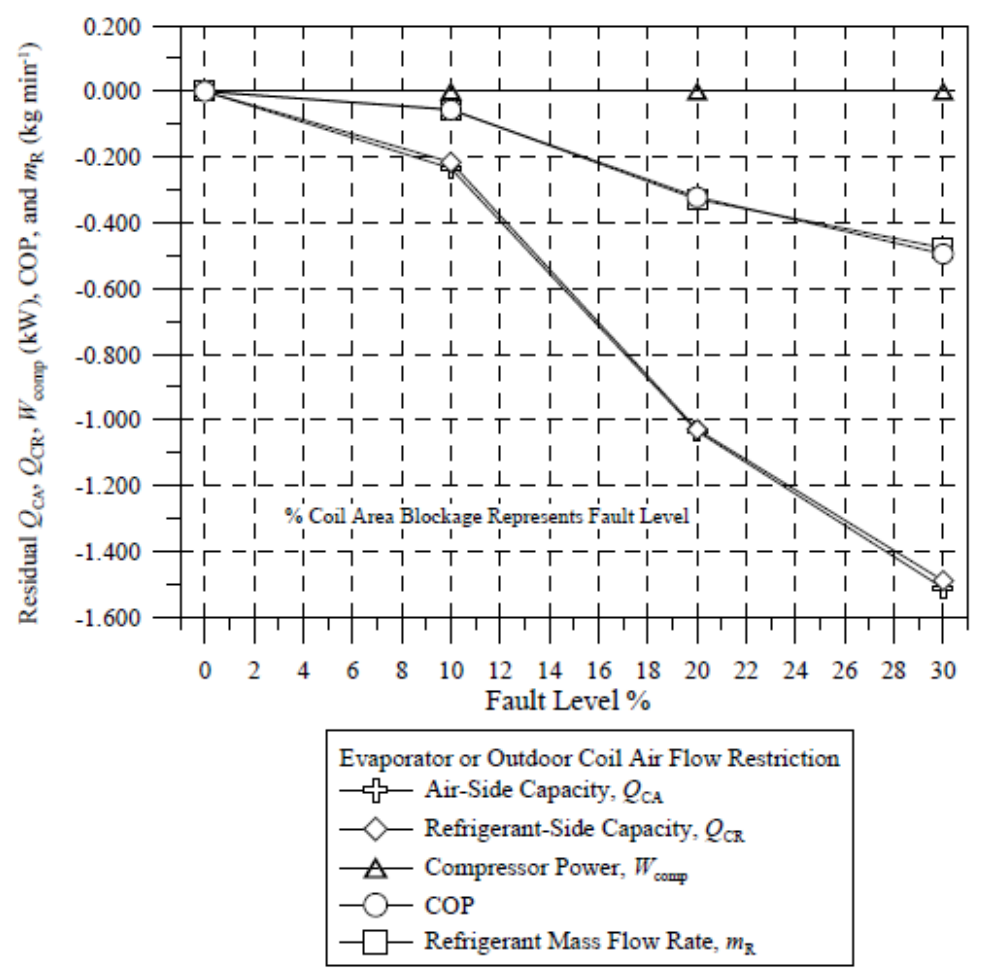

Figure 2-19 Heat pump performance at different fault levels at indoor and outdoor temperature of 21.1 oC and 8.3 oC (Payne et al., 2009)

\subsection{Literature review conclusion}

Numerous studies have examined the energy savings of improving PVT and solar air collector performance with thermal enhancements; although some have shown significant improvements, these systems were not operating under Canadian winter conditions. Hence, it is uncertain how beneficial these enhancements are under long-term cold weather applications. In addition, many of these studies have presented their improved results without regard to the pumping power required to achieve them; in a few studies, the pump power greatly diminished savings. Furthermore, there has been limited research on coupling PVT/solar collector systems with ASHP to form an integrated system; among the literature available, the flowrate has been held constant throughout the study period, which is inefficient when solar irradiance is at a minimum during the day.

This research aims to present the performance of an enhanced BIPV/T system coupled with an ASHP under Canadian climatic conditions, with consideration to the fan power consumption. The analysis was completed using a modified version of EnergyPlus with custom BIPV/T and HP models incorporated. In the literature, studies have shown PVT and solar collectors with 
enhancements to perform well under milder conditions; in colder climates, these systems face limited solar resources and colder air temperatures which make it difficult to obtain comparable results as those presented in the literature for mild climates. Therefore, enhancements used for integrated BIPV/T and ASHP systems under Canadian winter conditions should be able to elevate thermal gains under low irradiance and cold ambient conditions and require minimal additional fan power (compared to an unmodified BIPV/T system). 


\subsection{Methodology}

In this work, the objective is to develop and examine the potential benefit of different enhancements that improves thermal production but does not decrease hydraulic performance; enhancements in this work refer to improvements on the base case-opaque BIPV/T (OBIPV/T) systems. These modifications include adjusting for internal air channel surface emissivities, cover emissivity, inclusion of transparent BIPV/T (TBIPV/T) collectors, building integrated solar air heaters (BISAH), and collector arrangements (e.g., combining PVT collectors and SAH collectors in the same array system to form BIPV/T-BISAH systems). Additionally, flowrate modulation of the BIPV/T-BISAH system was also examined as an option to increase the overall efficiency of the overall integrated BIPV/T-BISAH-ASHP system.

A modified version of EnergyPlus V8.0 was developed and numerical models for OBIPV/T, TBIPV/T, BISAH collectors, and a multispeed ASHP model that estimates the performance of an air flow modulated BIPV/T-BISAH were incorporated into the source code. The original version 8.0 of EnergyPlus did not contain any BIPV/T models or variable capacity ASHP models that could model variable source flowrate (i.e., variable outdoor unit air flowrate). This modified version of EnergyPlus V8.0 was used in the simulation of individual, rows, and arrays of collectors as standalone units and as an integrated system (BIPV/T-BISAH-ASHP system). This chapter presents:

- the numerical models used in the simulation,

- modifications to the original components of the original EnergyPlus V8.0 to facilitate the incorporation of these new models, and

- the assumptions made in the development of the modifications to the code.

\subsection{Transient and quasi-steady state collector models}

Due to the advantages of BIPV/T systems, with respect to system energy and exergy efficiencies, BIPV/T is an attractive system for low energy solar house (Chen, Athienitis, \& Galal, 2010) or net-zero energy buildings (NZEB). In either case, the full benefits of BIPV/T systems are obtained when coupled with a thermal storage and/or ASHP. Therefore, simulation models $\mathrm{BIPV/T}$ systems are required for the design, analysis, and predictive control strategy. There are 
two ways of modeling such a complex system; through steady state analysis, transient analysis, or a combination of the two.

Steady state models of BIPV/T systems dominate current research as the most common because they require much less computing power (Bilbao \& Sproul, 2015) and the "error made by ignoring the dynamical effects is very small” (Zongdag et al., 2002). Furthermore, most models employed in the literature, are used as design or analysis tools (Bilbao \& Sproul, 2015) (Candanedo et al., 2010), (Kamel \& Fung, 2014); these tools rely upon collected weather data to provide applicable results, which are usually provided in hourly intervals. This implies that the transient effect cannot be seen with a transient model (Klein, 1975); hence, steady state models are preferred. However, as suggested by Candanedo et al. (2010) and Bilbao and Sproul (2015), steady state models are not as accurate in modeling the effect of rapid fluctuations in the weather; hence, the development of transient models are necessary in this respect.

Transient BIPV/T models are good for "[modeling of] thermal shocks, new and optimized control strategies, cloud effects on the electric and thermal performance, changes in flow rate for improved temperature output, and even the possibility to produce a synthetic characterization of a PVT collector (efficiency curve) only by knowing the design and used materials" (Bilbao \& Sproul, 2015). In addition, the inclusion of the capacitance of the material would be of importance when considering the sudden changes due to weather (Candanedo et al., 2010).

Bilbao and Sproul (2015) developed a 1-D dynamic thermal network for a water based PVT system and compared its results to data retrieved from an experimental set up every one minute intervals. They used an electrical circuit program, Micro-Cap, to simulate the dynamic model (Bilbao \& Sproul, 2015). Bilbao and Sproul (2015) suggested that the result of their dynamic model were exact enough to be used as a "diagnostic tool for a PVT collector not performing as expected". By comparing the model's results (using the original performance parameter) with the PV panel's measured electrical output, a conclusion can be drawn on the "state of degradation of the solar cells". Their suggestion was based on their model's outlet temperature and thermal power results closely matching experimentally determined results (an almost negligible mean bias error, and with $\mathrm{R}^{2}$ greater than 90\%); while the difference between the electrical power of the model and the experiment varied a bit more. (Bilbao \& Sproul, 2015).

Candanedo et al. (2010) developed a transient model, employing an explicit scheme, with capacitance only considered for the top portion of the BIPV/T system. Their argument is based on 
the volatility of the weather having a pronounced effect on the temperature of the PV and its adjacent layers. They concluded that their transient model results were a better fit than their steady state model. Along with Bilbao and Sproul (2015), Candanedo et al. (2010) also suggested the use of transient models for the determination of capacitance, and as part of a control strategy in development.

With the intended goal of enhancing BIPV/T systems on an annual basis, quasi-steady state models were developed and used to determine long term trends that are the result of different modifications to BIPV/T systems and BIPV/T systems enhanced with TBIPV/T collectors or BISAH collector (BIPV/T- BISAH systems). The use of transient model for diagnostic purposes or real-time control strategies are justified by Bilbao and Sproul (2015) and Candanedo et al. (2010). However, for the purpose of quantifying and qualifying improvements on a relative scale, quasi-steady state models provide a reliable (due to weather data limited to hourly intervals) and computationally inexpensive option.

3.2 Modelling of an Opaque Building Integrated Photovoltaic/ Thermal (OBIPV/T) system The quasi-steady OBIPV/T model presented below is from TRNSYS Type 298 which was developed by Kamel and Fung (2014). Presently, the model has been modified to include a PV cell packing factor to parameterize the effect of PV cell to collector area ratio. The following assumptions are made in the development of the model:

1. Steady state heat transfer throughout the collector is one dimensional (stray losses through the sides of the PV are negligible)

2. Air and solid material properties are constant during each timestep

3. Capacitance of the air is considered

4. The convective heat transfer coefficients for the top and bottom surfaces are identical

5. The longwave radiation between the glass cover and the surrounding environment are negligible because the temperature difference is insignificant.

\subsubsection{Energy balance of the OBIPV/T model}

The following energy balances are written and in reference to the schematic of an OBIPV/T collector shown in Figure 3-1. 

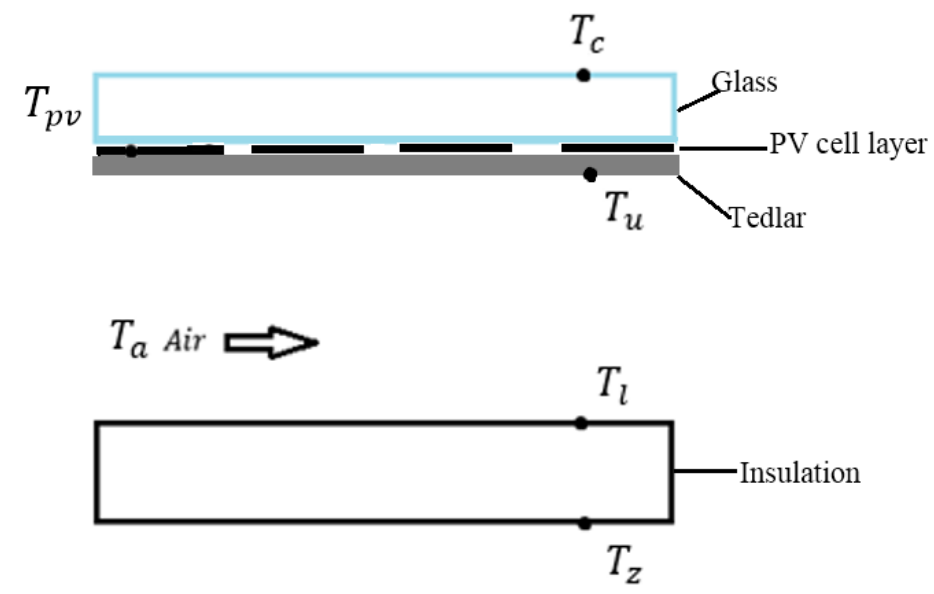

Figure 3-1 Schematic of an OBIPV/T collector

For the top glass cover surface:

$$
\frac{T_{p v}-T_{c}}{R_{g}}=h_{c}\left(T_{c}-T_{a m b}\right)+h_{r s}\left(T_{c}-T_{s k y}\right)
$$

For the PV cell layer:

$$
S=\frac{T_{p v}-T_{c}}{R_{g}}+\frac{T_{p v}-T_{u}}{R_{p v-u}}
$$

For the upper surface of the air channel:

$$
\frac{T_{p v}-T_{u}}{R_{p v-u}}=h_{a}\left(T_{u}-T_{a}\right)+h_{r a d, u-l}\left(T_{u}-T_{l}\right)
$$

For the air flow:

$$
q=h_{a}\left(T_{u}-T_{a}\right)-h_{a}\left(T_{a}-T_{l}\right)
$$


For the lower surface of the air channel:

$$
h_{a}\left(T_{a}-T_{l}\right)+h_{r a d, u-l}\left(T_{u}-T_{l}\right)=\frac{T_{l}-T_{z}}{R_{\text {ins }}}
$$

The estimation of the net absorbed solar thermal irradiance, $S$, is the flux of thermal power available after a portion has been deducted for PV electricity generation, $E_{p v}$. An algebraically simplified version of the original equation for $S$ and $E_{p v}$, as it was written by Kamel and Fung (2014) for Type 298, is shown below in Equation 3-6 and 3-7.

$$
\begin{gathered}
E_{p v}=(\tau \alpha)_{T} I_{T} A_{p a n e l} \eta_{p v} \\
S=(\tau \alpha)_{T} I_{T}\left(1-\eta_{p v}\right)
\end{gathered}
$$

The term $(\tau \alpha)_{T} I_{T}$ is the solar radiation absorbed by the panel after transmission through a single glazed layer (before deducting for electrical generation) and is presented as:

$$
(\tau \alpha)_{T} I_{T}=(\tau \alpha)_{B} I_{B}+(\tau \alpha)_{S} I_{S}+(\tau \alpha)_{G R} I_{G R}
$$

where $(\tau \alpha)_{B},(\tau \alpha)_{S}$, and $(\tau \alpha)_{G R}$ is the absorbed solar radiation fraction for the beam, sky diffuse, and ground diffuse component of the solar radiation; each component is estimated using Equation 3-9 (Duffie \& Beckman, 2006).

$$
(\tau \alpha)_{x}=e^{-\left(K l_{g} / \cos \theta_{r, x}\right)}\left[1-\frac{1}{2}\left(\frac{\sin ^{2}\left(\theta_{r, x}-\theta_{x}\right)}{\sin ^{2}\left(\theta_{r, x}+\theta_{x}\right)}+\frac{\tan ^{2}\left(\theta_{r, x}-\theta_{x}\right)}{\tan ^{2}\left(\theta_{r, x}+\theta_{x}\right)}\right)\right]
$$

\subsubsection{Modification of the electrical and solar optical model of the OBIPV/T model}

Including the effect of panel's PV cell packing factor (the ratio of PV cell to panel area), $P F$, will allow a balanced comparison between opaque and transparent BIPV/T systems. When both opaque and transparent PV panels are of the same area and contain the same number of PV 
cells, it can be shown that transparent panels perform more efficiently in terms of thermal and electrical generation. A comparison of this is presented later in Chapter 4.

The electricity generated and the net absorbed solar thermal irradiance are rewritten as:

$$
\begin{gathered}
E_{p v}=(\tau \alpha)_{T} I_{T} A_{P V \text { cell }} \eta_{p v} \\
S=(\tau \alpha)_{T} I_{T}-(\tau \alpha)_{T} I_{T} \eta_{p v} \mathrm{PF}
\end{gathered}
$$

where $A_{P V}$ cell is the area of the PV cells. In Equation 3-11, the first term, $(\tau \alpha)_{T} I_{T}$, assumes the PV cell and the absorber (PV cells are placed on an absorber plate) absorb the radiation together in the same manner; the second term is the electrical energy generated (for a given cell area) per PV panel area. Thus, the OBIPV/T is now equipped to model different PV panels of the same area but contain varying number of PV cells.

\subsubsection{Estimation of the PV cell efficiency}

The PV cell efficiency as estimated by Kamel and Fung (2014) was based on linear modifying factors. These relationships were obtained from TRNSYS17 (2012).

$$
\eta_{p v}=\eta_{\text {nominal }}\left[1+E f f_{T}\left(T_{p v}-T_{r e f}\right)\right]\left[1+E f f_{I}\left(I_{T}-I_{r e f}\right)\right]
$$

where, $E f f_{T}$ and $E f f_{I}$ are the dimensionless linear modifying factors; $T_{\text {ref }}$ and $I_{\text {ref }}$ are reference temperature and irradiance level when the cell efficiency is at the nominal level $\left(\eta_{\text {nominal }}\right)$.

\subsubsection{Estimation of heat transfer coefficients}

The following correlations were used in Type 298 and for the present work remains unchanged.

The sky and cover exchange heat radiatively, and the radiative heat transfer coefficient is

$$
\mathrm{h}_{\mathrm{rs}}=\sigma \epsilon_{c}\left(\mathrm{~T}_{\mathrm{c}, \text { kelvin }}+\mathrm{T}_{\mathrm{sky}}\right)\left(\mathrm{T}_{\mathrm{c}, \text { kelvin }}^{2}+\mathrm{T}_{\mathrm{sky}}^{2}\right)
$$


The upper and lower surfaces of the air channel also exchange heat with each other and the linearized coefficient is

$$
h_{\text {rad }, u-l}=\frac{\sigma\left(\mathrm{T}_{\mathrm{u}, \text { kelvin }}^{2}+\mathrm{T}_{\mathrm{l}}^{2}\right)\left(\mathrm{T}_{\mathrm{u}, \text { kelvin }}+\mathrm{T}_{\mathrm{l}}\right)}{\frac{1}{\epsilon_{\mathrm{u}}}+\frac{1}{\epsilon_{\mathrm{l}}}-1}
$$

The Reynolds number of the air channel is estimated as

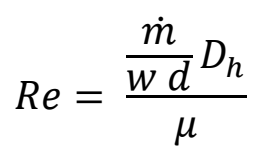

In the case of forced air laminar flow (Re < 2300), according to TRNSYS17 (2012), the Nusselt correlation is

$$
\mathrm{Nu}=4.9+\frac{0.0606\left(\operatorname{Re} \operatorname{Pr} D_{h} / L\right)^{1.2}}{1+0.0909\left(\operatorname{Re} \operatorname{Pr} D_{h} / L\right)^{0.7} \operatorname{Pr}^{0.17}}
$$

For turbulent flow $(\operatorname{Re}>2300)$,

$$
\mathrm{Nu}=0.0158 \mathrm{Re}^{0.8}
$$

Furthermore, for the first collector with turbulent flow, an additional term is included for abrupt contraction, thus for the first collector in a row where the air first enters the array, the Nusselt correlation, as was used by Kamel and Fung (2014), is written as:

$$
\mathrm{Nu}=0.0158 R e^{0.8}\left[1+\frac{\mathrm{C}_{\mathrm{x}}}{\mathrm{L} / \mathrm{D}_{\mathrm{h}}}\right]
$$


For the case where the flowrate is set to $0 \mathrm{~kg} / \mathrm{s}$, following natural convection was used (TRNSYS17, 2012).

$$
\begin{aligned}
N u=1+1.44 & {\left[1-\frac{1708\left(\sin (1.8 \text { slope })^{1.6}\right)}{R a \cos (\text { slope })}\right] \cdot \operatorname{MAX}\left[0,\left(1-\frac{1708}{R a \cos (\text { slope })}\right)\right] } \\
+ & \text { MAX }\left[0,\left(\frac{R a \cos (\text { slope })^{\frac{1}{3}}}{5830}\right)-1\right]
\end{aligned}
$$

where,

$$
R a=\operatorname{MAX}\left[0,\left(\frac{g \Delta T_{u-l} d^{3}}{\left(\frac{T_{u}+T_{l}}{2}\right) v_{a i r} \alpha_{a i r}}\right)\right]
$$

For the heat transfer between the cover and the ambient air, the following correlation for the convective heat transfer correlation is used,

$$
h_{c}=2.8+3 V_{W}
$$

The heat transfer coefficient, $h_{c}$, is in units of $\mathrm{W} /\left(\mathrm{m}^{2} \cdot \mathrm{K}\right)$ and the velocity, $V_{W}$, is in units of $\mathrm{m} / \mathrm{s}$.

\subsection{Modelling of a Transparent Building Integrated Photovoltaic/Thermal (TPBIPV/T) system}

The quasi-steady TBIPV/T model presented below is derived from TRNSYS Type 289 developed by (Kamel and Fung, 2015) which in turn, was developed based on TRNSYS Type 298. In the present work, the TBIPV/T model's solar optical relationship was modified to provide a balanced comparison of the two different collectors performance. The assumptions of the OBIPV/T model described in Section 3.2.1 hold.

\subsubsection{Energy balance of the TBIPV/T model}

In the OBIPV/T model, a glazing layer covered the PV cells, which were adhered to an absorber plate, that is then placed on a layer of tedlar. In the TBIPV/T model, the PV cells are 
placed in between two glass layers, forming pockets of transparent glass and opaque PV cells and the back of the second glass layer forms the upper surface of the air channel. This infers that the thermal resistance between the PV layer and the upper air channel surface between the OBIPV/T and TBIPV/T have different values and that the TBIPV/T model allows short wave (solar) radiation to strike the lower surface, while preventing long wave radiation from transmitting through the collector from the same surface. The following energy balances were developed in reference to the associated schematic shown in Figure 3-2.

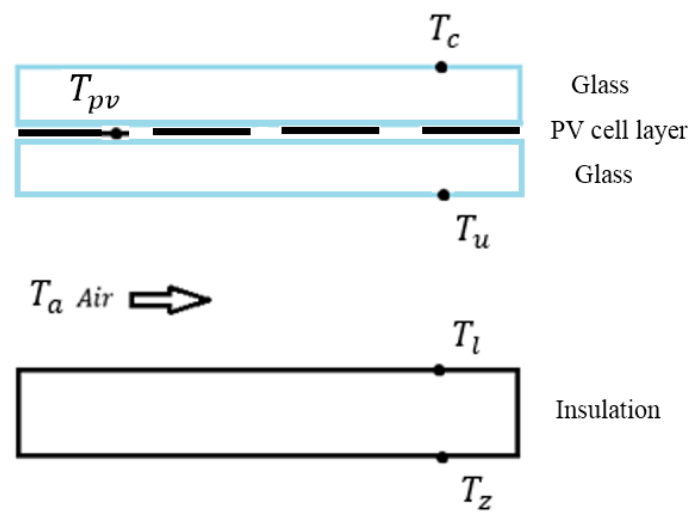

Figure 3-2 Schematic of a TBIPV/T collector

For the energy balance about the cover surface,

$$
\frac{T_{p v}-T_{c}}{R_{g}}=h_{c}\left(T_{c}-T_{a m b}\right)+h_{r s}\left(T_{c}-T_{s k y}\right)
$$

For the energy balance about the PV layer,

$$
S_{1}=\frac{T_{p v}-T_{c}}{R_{g}}+\frac{T_{p v}-T_{u}}{R_{p v-u}}
$$

For the energy balance about lower channel surface,

$$
\frac{T_{l}-T_{z}}{R_{\text {ins }}}=h_{a}\left(T_{a}-T_{l}\right)+h_{\text {rad }, u-l}\left(T_{u}-T_{l}\right)+S_{2}
$$


For the energy balance about the upper channel surface,

$$
\frac{T_{p v}-T_{u}}{R_{p v-u}}=h_{a}\left(T_{u}-T_{a}\right)+h_{r a d, u-l}\left(T_{u}-T_{l}\right)
$$

For the energy balance of the air flowing through the collector,

$$
q=h_{a}\left(T_{u}-T_{a}\right)+h_{a}\left(T_{l}-T_{a}\right)
$$

The net absorbed thermal radiation at the PV layer and at the lower surface of the air channel as written by Kamel and Fung (2015) are:

$$
\begin{gathered}
S_{1}=\tau_{\mathrm{g}} \alpha_{\mathrm{pv}} \mathrm{I}_{\mathrm{T}}(\mathrm{PF})-\eta_{\mathrm{pv}}(\mathrm{PF}) \tau_{\mathrm{g}} \mathrm{I}_{\mathrm{T}} \\
S_{2}=\alpha_{\mathrm{l}}(1-\mathrm{PF}) \tau_{\mathrm{g}}^{2} \mathrm{I}_{\mathrm{T}}
\end{gathered}
$$

In Equation 3-27, the first term, $\tau_{\mathrm{g}} \alpha_{\mathrm{pv}} \mathrm{I}_{\mathrm{T}}(\mathrm{PF})$, is the solar irradiance absorbed by the PV layer; the second term, $\eta_{p v}(P F) \tau_{g} I_{T}$, is the electrical energy generated per panel area. In Equation 328 , the solar irradiance travels through two glazing layers (hence, the $\tau_{g}^{2} I_{T}$ term), and only through the pockets of glass (hence the $1-\mathrm{PF}$ term).

Lastly, $\tau_{\mathrm{g}}$ is estimated using the following Equations:

$$
\begin{gathered}
\tau_{\mathrm{g}}=\frac{\tau_{\mathrm{g}, \mathrm{b}} I_{B}+\tau_{\mathrm{g}, \mathrm{s}} I_{S}+\tau_{\mathrm{g}, \mathrm{gr}} I_{G R}}{I_{T}} \\
\tau_{g, x}=\frac{\tau_{a, x}\left(1-\rho_{x}\right)^{2}}{1-\left(\rho_{x} \tau_{a, x}\right)^{2}} \\
\tau_{a, x}=e^{-\left(K l_{g} / \cos \theta_{r, x}\right)}
\end{gathered}
$$




$$
\rho_{x}=\frac{1}{2}\left(\frac{\sin ^{2}\left(\theta_{r, x}-\theta_{x}\right)}{\sin ^{2}\left(\theta_{r, x}+\theta_{x}\right)}+\frac{\tan ^{2}\left(\theta_{r, x}-\theta_{x}\right)}{\tan ^{2}\left(\theta_{r, x}+\theta_{x}\right)}\right)
$$

\subsubsection{Modification of the solar transmittance-absorptance of the PV layer of TBIPV/T model}

To compare the performance of the TBIPV/T model and the OBIPV/T model on a common datum, the solar transmittance-absorptance model should be the same, as deviation in this respect would biasedly reflect one system as more favourable over the other. Therefore, Equation 3-27 is rewritten as:

$$
S_{1}=(\tau \alpha)_{T} I_{T}(P F)-(\tau \alpha)_{T} I_{T}(P F) \eta_{\mathrm{pv}}
$$

Where, the $(\tau \alpha)_{T} I_{T}$ term is the same one found in Equation 3-8 of the OBIPV/T model. The modified TBIPV/T model with Equation 3-33 models the absorption of the solar irradiance at the PV layer in the same manner as the OBIPV/T. This same relationship can be applied to TBIPV/T even with its pockets of glass and PV cell area, because inherent to Equation 3-8 is the assumption that all radiation transmitted through the glass is absorbed at the PV layer (i.e., no reflection). Furthermore, because the transmittance-absorptance by the PV layers is different from Type 289, the modification extends to estimating the electrical power per panel area,

$$
\frac{E_{p v}}{A_{\text {panel }}}=(\tau \alpha)_{T} I_{T}(P F) \eta_{\mathrm{pv}}
$$

\subsubsection{Estimation of heat transfer coefficients}

All convective and radiative coefficients of the TBIPV/T are estimated in the same manner as presented in Section 3.2.4.

\subsection{Modelling of a Building Integrated Solar Air Heater (BISAH)}

The BISAH model employed in this work is a quasi-steady state model that was developed in the same manner which Type 567, Type 298, and Type 289 were established. The SAH modelled contains a single glazing layer and an absorbing plate that is coupled to the roof of a 
building; it is shown schematically in Figure 3-3. The following assumptions were made in developing the model:

1. Air flow is one-dimensional

2. The capacitance of the air is considered

3. Temperature gradients only exist in the direction of the flow

4. Material properties (solid and fluid) are uniform

5. Steady state heat transfer is one dimensional

6. The top and bottom surfaces of the air channel share a common heat transfer coefficient based on the average air temperature through the collector

7. The longwave radiation between the glass cover and the surrounding environment are negligible because the temperature difference is insignificant.

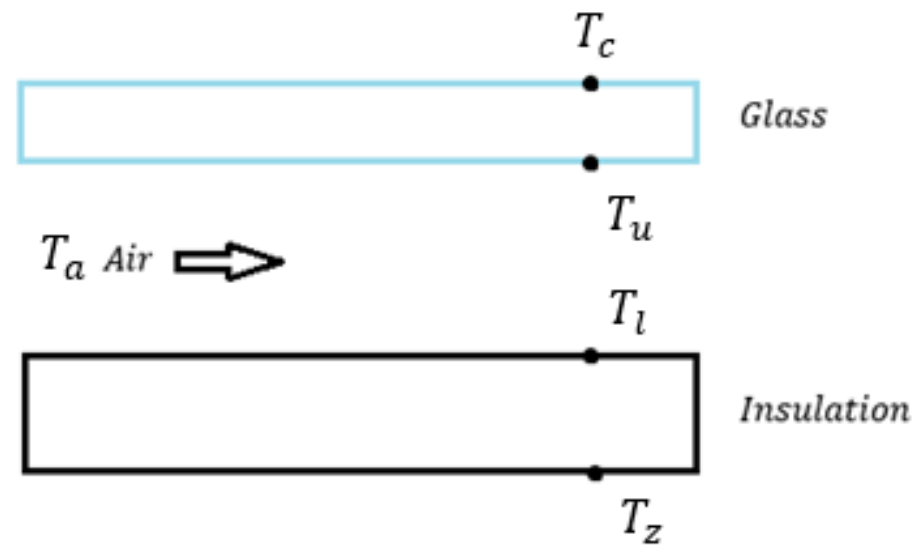

Figure 3-3 Schematic of a BISAH

\subsubsection{Energy balance of the BISAH model}

An energy balance about the top surface of the glass cover is as follows and a schematic is shown in Figure 3-4.

$$
\frac{T_{u}-T_{c}}{R_{g}}=h_{r s}\left(T_{c}-T_{s k y}\right)+h_{c}\left(T_{c}-T_{a m b}\right)
$$




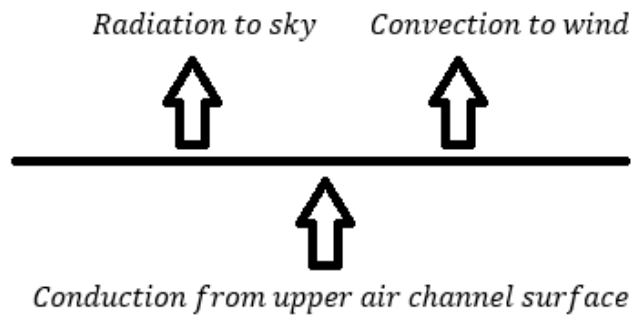

Figure 3-4 Energy balance of the top surface of the glass cover

An energy balance of the upper surface of the air channel is as follows and is based on Figure 35.

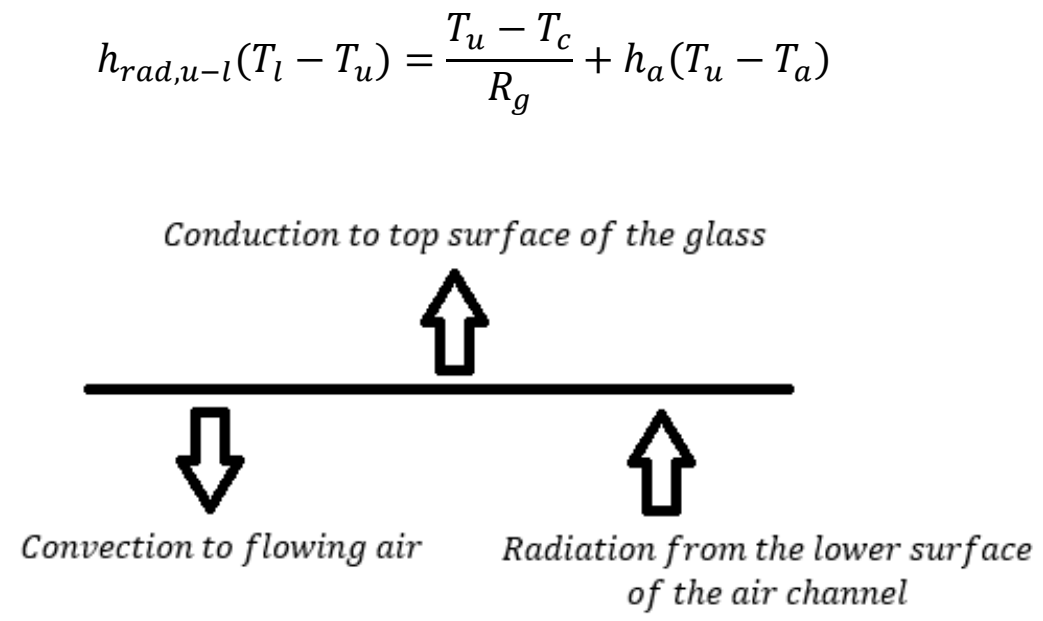

Figure 3-5 Energy balance of the upper surface of the air channel

An energy balance of the control volume of air flowing through the collector is as follows and is based on Figure 3-6.

$$
q=h_{a}\left(T_{u}-T_{a}\right)+h_{a}\left(T_{l}-T_{a}\right)
$$




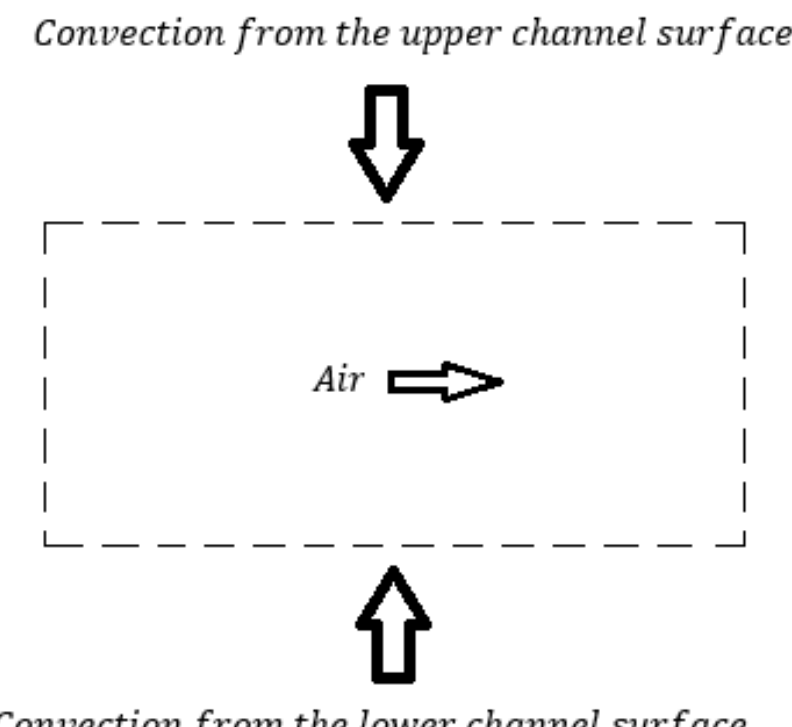

Figure 3-6 Energy balance of the air flow

An energy balance of the lower surface of the air channel is as follows, based on Figure 3-7.

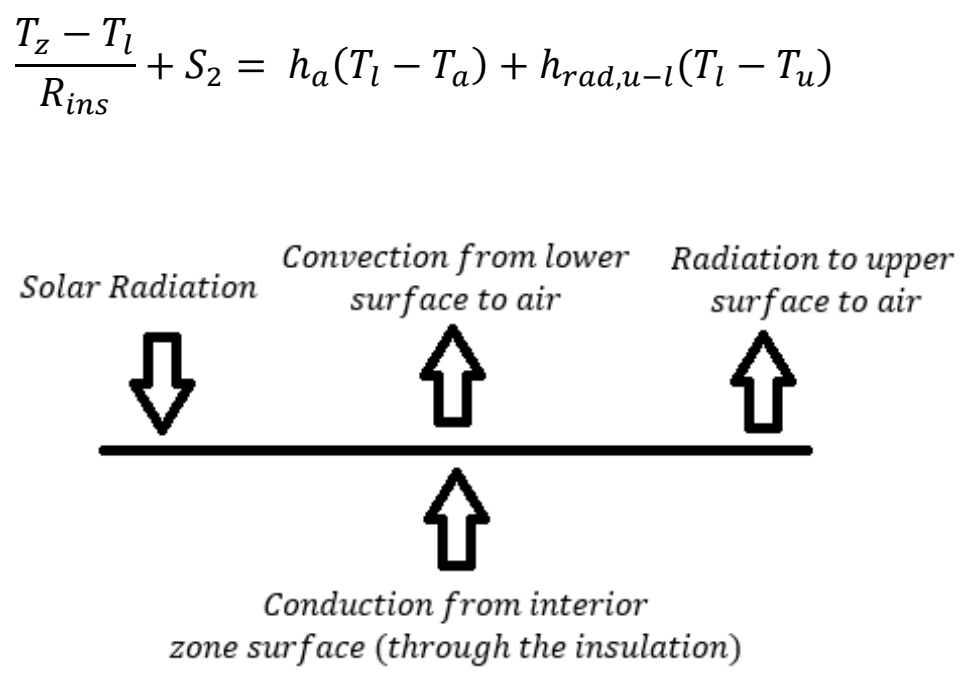

Figure 3-7 Energy balance of the lower surface of the air channel

\subsubsection{Estimation of heat transfer coefficients}

All convective and radiative coefficients of the BISAH are estimated in the same manner as presented in Section 3.2.4. 


\subsection{Differential control volume energy balance}

The models for the OBIPV/T, TBIPV/T, and BISAH are solved in the same manner and is shown in the TRNSYS manual (TRNSYS17, 2012); average air temperature through the collector and air outlet temperature are presented. For each of the three collectors, by solving for the heat flux, $q$, as a function of the average air temperature, the following form can be obtained for each of the three collector models.

$$
q=a T_{a}+b
$$

Where $a$ and $b$ are algebraic grouped terms that are obtained algebraically and are unique for each of the three collectors; these terms for the BISAH collector can be found in Appendix A. Afterwards, by taking a differential control volume of the air in the channel, an energy balance would result in a linear differential equation that can be solved to yield,

$$
\begin{gathered}
T_{a}=\left(T_{\text {in }}+\frac{b}{a}\right)\left(\frac{\dot{m}_{P V T, \text { row }} c_{p}}{a A_{\text {panel }}}\right)\left(e^{\frac{a A_{\text {panel }}}{\dot{m}_{P V T, \text { row }} c_{p}}}-1\right)-\frac{b}{a} \\
T_{\text {out }}=\left(T_{\text {in }}+\frac{b}{a}\right) e^{\frac{a A_{\text {panel }}}{\dot{m}_{P V T, \text { row }} c_{p}}}-\frac{b}{a}
\end{gathered}
$$

For each of the three collectors, the form Equation for the average air temperature, $T_{a}$, and the outlet temperature, $T_{\text {out }}$, are the same as those in Equation (3-40) and Equation (3-41), respectively, while the specific formulation for $a$ and $b$ are different. With Equation (3-40) and Equation (3-41), and explicit expressions for $T_{l}, T_{u}, T_{c}, T_{p v}$, the steady state solution can be obtained through a successive substitution scheme.

\subsection{EnergyPlus V8.0: a quasi-steady state building energy simulation program}

EnergyPlus V8.0 is an open source quasi-steady state building energy simulation program developed by the US Department of Energy. The program is capable of modeling air temperature and moisture in a building, in response to HVAC equipment and other equipment and their impact on the thermal performance of the zone (e.g., heat transfer to due coupled solar collectors). Unlike 
TRNSYS, which can simulate standalone HVAC or other residential equipment, EnergyPlus revolves around the energy simulation of the zone of a building. At the core of the program, at every timestep,

- heating/cooling loads are estimated based on current building heat transfers with the ambient environment (e.g., external heat sources from a solar collector, convection with the wind, radiation with the environment, etc.) and user defined setpoints,

- which are then taken as demands by the HVAC (e.g., heat pump system),

- the HVAC system is simulated based on equipment parameters and environmental conditions (e.g., outside air temperature for an ASHP) and the actual output of the system computed,

- the actual output of the system and the heating/cooling loads are summed and the final conditions of the air is computed.

EnergyPlus V8.0 is a robust opens source program that is widely used by many users from public and private organizations. It has an active community that regularly contributes to it and contains an extensive list of residential equipment that can flexibly model current and innovative building designs. Thus, for these reasons, EnergyPlus V8.0 was used to study enhanced BIPV/T systems.

It is important to note that the original EnergyPlus V8.0 does not contain BIPV/T systems or ASHP models intended for coupling with BIPV/T system. The models presented in this work were developed into FORTRAN code and added as modules to EnergyPlus V8.0's source code (hence referred to as the modified EnergyPlus V8.0). The addition of OBIPV/T, TBIPV/T, BISAH, and the integration of these systems with an ASHP to the program involved detailed integration of the collector systems with the building surface heat transfer managing modules, as well as the heat pump simulation modules. The OBIPV/T and TBIPV/T models were based on models that were used for analysis in peer review articles and the BISAH model was developed using similar energy balances. All the models incorporated were validated by comparing an iteration of results with a set of results computed using excel. 
3.7 Modelling of an Air Source Heat Pump coupled with a photovoltaic/thermal and solar air collector system

Hailu, Dash and Fung (2015) studied the coupling of BIPV/T systems with ASHP in Alaskan climate and found the integrated system had difficulty in providing consistent benefit throughout the heating season. This can be partially explained by the fluctuation of solar irradiance. For a collector system, if the irradiance decreases and the flowrate through the system remains constant, the outlet temperature would decline and result in a lower COP. Furthermore, Tardif et. al (2017) found that over their study period, the fan power used to operate the BIPV/T coupled ASHP system greatly diminished their heating consumption savings largely due to the use of supplying a constant $30 \%$ of the HP's required air flow from the PVT; hence, the source temperature was low (close to the ambient). In these studies, air flowrate through the BIPV/T could have been modulated under then current environmental condition to achieve better performance (e.g., increase the flowrate to achieve a larger thermal gain at favourable conditions).

Modelling an integrated BIPV/T coupled ASHP system that modulates the air flowrate through the BIPV/T system with the end goal of assisting the ASHP system infers that the HP system decides on the flowrate to use and the need for a HP model that accept a variable source flowrate (i.e., the air flowrate at the outdoor unit/evaporator in heating mode) as an independent variable. However, as a review of the literature has shown, there has been a limited number of studies on varied air source flowrate for ASHPs; therefore, a pertinent HP model that estimates HP heating rate and electrical power consumption is unavailable in EnergyPlus V8.0. This is largely due to the lack of a reason to need to model variable source flowrates in the past. Manufacturers of HPs set outdoor fan RPM to predetermined flows based on design conditions without the need to consider the source temperature, since the air temperature is effectively independent of the fan speed (fan heat losses are negligible). Hence, the need for, and the present lack of, data of HPs operating with variable source flowrates.

Heat pump models can be grouped into three types: numerical approximations (regression fit performance curves), general thermodynamic (correlates physical HP with idealized references), and detailed thermodynamic (detailed component parameter input, e.g., hardware based models) (Scarpa, Emmi, \& De Carli, 2012). Examples of regression fitted models are found in EnergyPlus V8.0, the single, multi, and variable speed air to air HP are all regression fitted models that depend on detailed manufacturer provided data. Furthermore, Scarpa et al. (2012) 
presented a few examples for the latter two types (Domanski \& Didion, 1984), (Cecchini \& Marchal, 1991), (Bourdouxhe et al., 1994) and (Stefanuk, Aplevich, \& Renksizbulut, 1992).

Scarpa et al. (2012) developed a numerical vapor compression based air-water/water-water HP, that uses a combination of basic manufacturer catalog data (e.g., rated capacity, rated input power, rated COP, rated air conditions, motor efficiency, etc.) to back trace a vapor compression thermodynamic cycle. Catalog information inputs are used to compute refrigerant side conditions; the model estimates a heat exchanger effectiveness based on the rated air conditions and capacities. This effectiveness is assumed to be constant, even for conditions outside of rated conditions. In phase 1, the model uses the input catalog data to estimate the HP parameters such as heat exchanger effectivenesses, refrigerant flowrate. Afterwards, in phase 2, the simulation takes operating inputs (such as inlet air flowrates and temperatures,referred to as the "secondary fluid", and traces the vapor compression cycle), in an iterative process, to compute the performance (heating rate, input power, COP).

The Oak Ridge National Laboratory (ORNL) developed a detailed hardware based HP tool, referred to as the ORNL Modulating Heat Pump Design Model (HPDM), to model steady state single or variable speed HP (Rice, 1991). It accepts inputs related to the physical design of the HP such as number of fins, fin sizes, tube diameters of heat exchangers, expansion device (TXV, capillary tube, fix orifice), compressor performance curves, refrigerant charge size. Using this input and a given set of operating conditions (e.g., air flowrates and temperature), along with information on evaporator superheating and condenser subcooling, the model estimates the operating states of the refrigerant for the inlet and outlet conditions of each component and the overall performance of the HP system. As the ORNL HPDM is capable of simulating HP performance over a range of outdoor air flowrates, however, as it is a detailed model, it requires an extensive list of parameters which makes it well suited for detailed HP design or as an experimental HP research tool.

As presented previously, there are several methods that can be used to model a HP with a variable source flowrate. Modeling a HP using empirical correlations derived from a regression analysis of the performance data is relatively simple and provides highly accurate performance modelling. However, since normal ASHP applications do not require a varied source air flowrate, this type of information is not available from manufacturers; the addition of an extra variable would require a compounded number of additional test and time. On the other hand, while 
performance curves could be obtained using the ORNL model, a lack of HP specific parameters makes it an impractical option. A simple and accurate method is needed.

\subsection{Modelling a source flowrate modulated ASHP in EnergyPlus}

The HP model developed in this work uses a regression fitted curve of performance data for a single source flowrate (i.e., the data set includes indoor flowrate, indoor temperature, and outdoor temperature as independent variables but excludes outdoor flowrate) and modulation of the air flow is provided by mixing varied proportions of preheated BIPV/T air and outdoor air, while the total flowrate remained constant. Tardif et al. (2017) used this approach in modeling their BIPV/T coupled ASHP system. They combined the flowrate of their BIPV/T system's preheated and ambient air together to form the required flowrate necessitated by their HP. However, in their work, the proportion of BIPV/T airflow was fixed at $30 \%$ of the total flowrate; by varying this proportion, the air flow through the BIPV/T can be modulated yet current commercial HP performance data (datasets that exclude the source flowrate as an independent variable) can be used.

The flow modulation scheme described above, of mixing preheated and outdoor air to supply the total HP manufacturer specified source flowrate, was added as a modification to an existing multispeed ASHP model in EnergyPlus V8.0, the Coil:Heating:DX:Multispeed object; it models ASHP with discrete compressor speeds. Technically, the Coil:Heating:DX:Multispeed object in EnergyPlus only represents the heating coil component, i.e., it computes the air conditions leaving the coil in the air handling unit. The control of the MSHP (e.g., compressor speed and run time) is determined by an overarching controller. Since the airflow from the BIPV/T is supplied to the ASHP, the ASHP system should modulate the flowrate to satisfy heating demands; therefore, it is important to understand the control of the MSHP itself and how it influences the selection of the BIPV/T flowrate. Section 3.8.1 describes how off rated performance is estimated from the performance data (referred to as nominal heating capacity and nominal input power if they are directly obtained from the performance curves and not adjusted for defrost or cycling inefficiencies); Section 3.8.2 describes the MSHP control scheme. 
3.8.1 Estimating nominal and defrost adjusted heating capacity and power input

\subsubsection{Estimating the modifying factors and nominal variables from performance curves}

The terms nominal heating capacity and power input refers to the direct values obtained from the performance data. These values are estimated from regression fitted curves and are adjusted for defrost and then for cycling/speed shifting (switching between two different compressors speeds to meet the heating load for a particular timestep may be required if the load is in between the two speed's capacity). For this work, the performance dataset of the Carrier 25VNA024A**30 (with indoor section FE4ANB006) variable speed HP was used and can be found in Appendix B and a resistive defrosting process is assumed.

The following model descriptions were obtained from the Engineering manual of EnergyPlus V8.0 (Ernest Orlando Lawrence Berkeley National Laboratory, 2013a). The performance data used contains heating capacity and its corresponding HP input power consumption for a specific indoor flowrate, and a range of indoor temperature and outdoor temperature for each speed. Four regression fitted curves were: two for estimating nominal heating capacity and two for estimating the nominal energy input ratio (EIR) (the EIRs is the inverse of the COP). Each of these four curves, provide an adjustment factor (based on indoor flowrate or indoor and outdoor temperature) that adjusts the rated nominal capacity and COP to the off-rated value. These curves were obtained by using an EnergyPlus provided Excel-based regression tool which normalizes the off rated value (capacity or EIR) to the rated value as function of temperature or flowrate.

The dimensionless heating capacity modifying factor as a function of temperature is obtained and adjusts the rated value of the nominal heating capacity based on the indoor and outdoor (source) temperature with a bi-quadratic curve (Equation 3-42).

$$
Q_{T}=c_{1, Q T}+c_{2, Q T} \cdot T_{i}+c_{3, Q T} \cdot T_{i}{ }^{2}+c_{4, Q T} \cdot T_{o}+c_{5, Q T} \cdot T_{o}{ }^{2}+c_{6, Q T} \cdot T_{i} \cdot T_{o}
$$

The dimensionless heating capacity modifying factor as a function of flow fraction (ratio of actual indoor flowrate to rated flowrate) is obtained and adjusts the rated value of the nominal heating capacity based on the indoor flowrate with a quadratic or cubic curve (Equation 3-43). 


$$
Q_{f}=c_{1, Q F}+c_{2, Q F} \cdot f+c_{3, Q F} \cdot f^{2}+c_{4, Q F} \cdot f^{3}
$$

where $f$ is the flow fraction.

The dimensionless EIR modifying factor as a function of temperature is obtained and adjusts the rated value of the nominal EIR based on the indoor and outdoor (source) temperature with a bi-quadratic curve (Equation 3-44).

$$
E I R_{T}=c_{1, E T}+c_{2, E T} \cdot T_{i}+c_{3, E T} \cdot T_{i}^{2}+c_{4, E T} \cdot T_{o}+c_{5, E T} \cdot T_{o}{ }^{2}+c_{6, E T} \cdot T_{i} \cdot T_{o}
$$

The dimensionless EIR modifying factor as a function of flow fraction (ratio of actual indoor flowrate to rated flowrate) is obtained and is used to adjust the rated value of the nominal EIR based on the indoor flowrate with a quadratic or cubic curve (Equation 3-45).

$$
E I R_{f}=c_{1, E F}+c_{2, E F} \cdot f+c_{3, E F} \cdot f^{2}+c_{4, E F} \cdot f^{3}
$$

The nominal capacity (at off rated conditions) as estimated from the performance curves is calculated as:

$$
\dot{Q}_{\text {nom,off rated }}=\dot{Q}_{\text {rated }} \cdot Q_{f} \cdot Q_{T}
$$

The defrost adjusted heating capacity is calculated as follows:

$$
\dot{Q}_{\text {speed } x, \text { defrost adjusted }}=\dot{Q}_{\text {nom }, \text { off rated }} \cdot Q_{\text {defrost }}
$$

The off rated EIR at a timestep is evaluated as follows:

$$
E I R=E I R_{\text {rated }} \cdot E I R_{f} \cdot E I R_{T}
$$


The nominal input power (off rated input power) at a timestep is evaluated as follows:

$$
\dot{P}_{\text {nom,off rated }}=E I R \cdot \dot{Q}_{\text {nom }, \text { off rated }}
$$

The defrost adjusted input power (off rated input power) at a timestep is evaluated as follows:

$$
\dot{P}_{\text {speed } x, \text { defrost adjusted }}=\dot{Q}_{\text {speed } x \text {,defrost adjusted }} \cdot E I R \cdot P_{\text {defrost }}
$$

The defrost adjustments are factors that adjust the nominal heating capacity and input power to form the defrost adjusted heating and input power capacities.

\subsubsection{Assumptions in simulating with the performance data}

The HP input power specified in the performance data used in the simulation also include fan power. However, the exact fan power required cannot be determined at different temperatures. Hence, it is assumed that for the simulation of the HP as standalone system (not using BIPV/T), the total HP power is simply the input power obtained from the performance curves. On the other hand, when the HP is coupled with a BIPV/T system, the value of the external fan power associated with the outdoor unit is simply considered as just the compressor power and the fan power required to operate the BIPV/T are considered separate. In the end, this would result in an underestimation of the energy saving.

The performance data used only provided the HP performance at a single indoor flowrate for the high speed (900 CFM) and low speed (500 CFM), thus, in the simulation, the MSHP object was set to provide supply air flow at the rated flowrate, $900 \mathrm{CFM}\left(0.425 \mathrm{~m}^{3} / \mathrm{s}\right)$ or $500 \mathrm{CFM}(0.236$ $\mathrm{m}^{3} / \mathrm{s}$ ) when operating. Furthermore, in EnergyPlus V8.0 the supply flowrate and the rated flowrate are converted into mass flowrates and used for computations by using a barometric adjusted density, assumed for different definitions of standard air $\left(20^{\circ} \mathrm{C}\right.$ and $21^{\circ} \mathrm{C}$, respectively). This implies that the supply air flowrate to rated flowrate ratio (e.g., $f$, found in Equation 3-43 and 345 ) is only very close to 1 , even though the supply flowrate and rated flowrate are both specified as $0.425 \mathrm{~m}^{3} / \mathrm{s}$. Therefore, in the simulation, the flow ratio is assumed to be at unit for all time and 
the heating capacity factors as a function of indoor flowrate and EIR factor as a function of indoor flowrate are assumed to be equal to unity (i.e., $E I R_{f}=Q_{f}=1$ ).

\subsubsection{Control of the Multispeed Heat Pump in EnergyPlus}

A schematic of the MSHP representation is shown in Figure 3-8. In EnergyPlus V8.0, the overarching controller for the MSHP is the virtual object, AirLoopHVAC:UnitaryHeatPump:AirToAir:Multispeed (Ernest Orlando Lawrence Berkeley National Laboratory, 2013a), it effectively controls the operation (simulation) of the fan and conditioning coils. After the heating load is passed to the HVAC as a demand, the controller operates the MSHP to output a total heating rate that satisfies the demand. In EnergyPlus V8.0, heating of the supply air in the air handling unit is performed by both the fan (fan heat) and heating coil, therefore, the total heating rate is the summation of the fan's heat addition and the coil's heating rate. In a cycling fan cycling compressor configuration (fan cycles in tandem with the compressor) the, controller carefully selects the MSHP run time and compressor speed level, so that the total fan heat addition and heating coil's heating rate matches the heating load; this is accomplished with an iterative scheme.

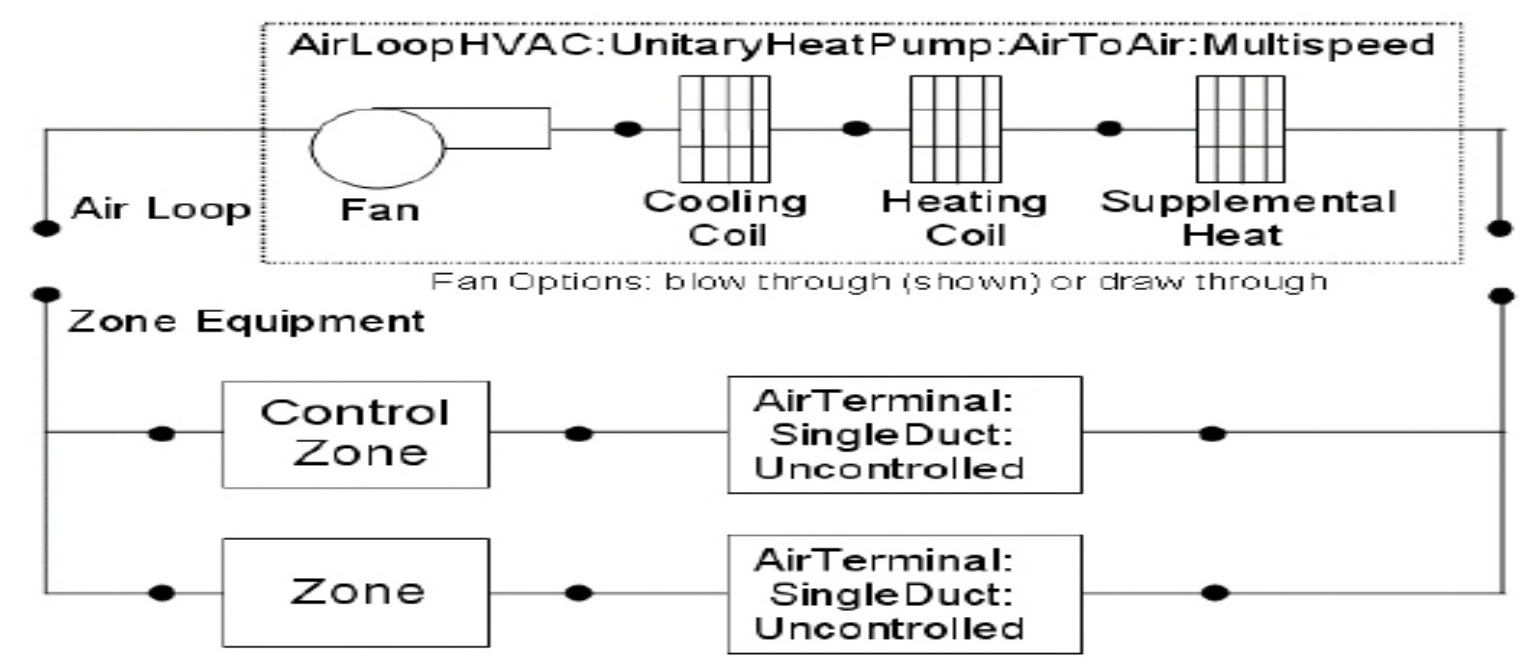

Figure 3-8 Schematic of the AirLoopHVAC:UnitaryHeatPump:AirToAir:Multispeed object and the HVAC system (Ernest Orlando Lawrence Berkeley National Laboratory, 2013a)

For a given timestep, assuming the heating load can be satisfied and a resistive defrosting scheme, the controller first decides on whether or not to cycle and then establishes the exact run 
time at a specific speed. The controller first checks whether the lowest speed's (speed 1's) defrost adjusted heating capacity is greater than the heating load; if it is greater, then the MSHP will need to cycle. On the other hand, if it is less, the controller checks which of the higher speed levels or combination of them (e.g., run a portion of the timestep at speed 2 and the rest of the timestep at speed 3) will satisfy the load. An overall flow diagram summarizes the control of the MSHP as it attempts to satisfy the zone heating load at every timestep is shown in Figure 3-9; a detailed breakdown of the process for speed 1 (iterative solver for speed 1 operation) and higher speed operations (iterative solver for higher speed operation) are found in Figure 3-10 and Figure 3-11.

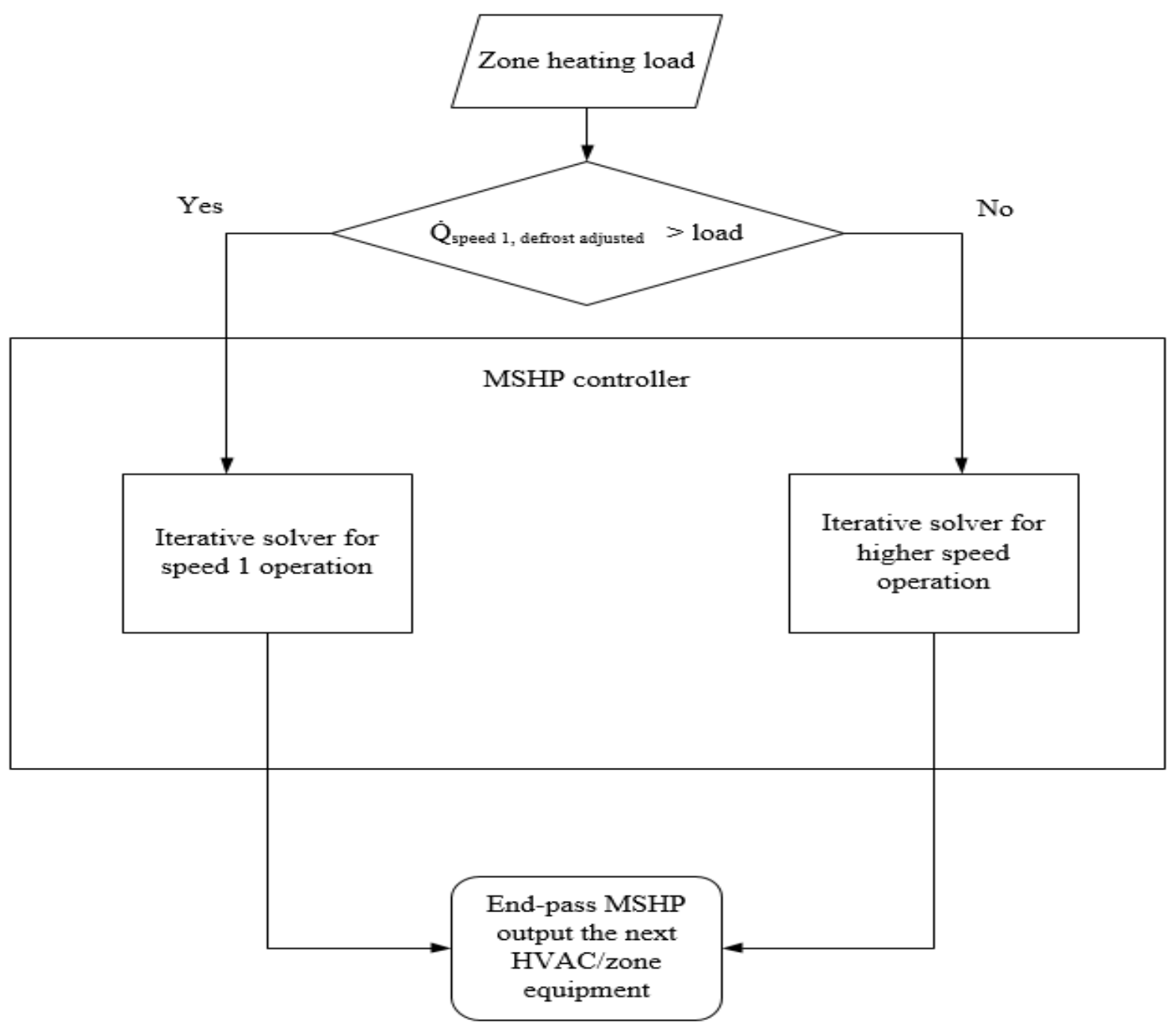

Figure 3-9 Flow diagram of the MSHP controller, in relation to the rest of the HVAC simulation process 


\subsubsection{Speed 1 (lowest speed) operation}

In the first option, if the MSHP needs to cycle, the controller selects the coil's heating rate using the part load ratio, PLR. The PLR is defined in Equation 3-51 and is estimated through successive iteration.

$$
P L R=\frac{H P \text { heating rate when cycling }}{H P \text { heating rate at speed } 1 \text { without cycling }}
$$

The "HP heating rate at speed 1 without cycling" is the MSHP's heating rate if the HP operated at speed 1 at steady state (i.e., continuously during the timestep). Therefore, it is the HP defrost adjusted heating capacity, described in Section 3.8.1. The PLR is used to adjusted the HP defrost adjusted capacity at speed 1 , in order to obtain the actual coil heating rate for the timestep, as shown in Equation 3-52.

$$
\dot{Q}_{M S H P \text { output }}=(P L R) \dot{Q}_{\text {speed } 1, \text { defrost adjusted }}
$$

The part load ratio is limited to $0 \leq P L R<1$ and higher values of $P L R$ implies longer compressor run time for the duration of the timestep; with a cycling fan cycling compressor configuration, the fan heat addition is also a function of the $P L R$ because longer compressor run times also result in more fan heat addition (more air flow). Hence, a direct substitution of the load as the actual averaged HP output, in order to estimate the PLR, would overheat the zone and the need for an iterative scheme to estimate the correct $P L R$ which is then used to estimate the actual coil heating rate.

The effect of the PLR is that for different values, the compressor operates with different levels of efficiency that is characterized by the part load fraction, $P L F$, defined in Equation 3-53 (Tang, 2003). As the compressor cycles, the equipment is less efficient than if it operated without cycling (steady state) and similar to the PLR, $0 \leq P L F<1$.

$$
P L F=\frac{C O P_{\text {cycling }}}{C O P_{\text {without cycling }}}
$$


As the compressor's electricity draw is almost instantaneous, the run time fraction, $R T F$, is defined as the fraction of the timestep the MSHP (compressor) is drawing electricity for operation $(0 \leq R T F \leq 1)$ and is calculated as follows:

$$
R T F=\frac{P L R}{P L F}
$$

The $R T F$ is used to adjust the HP defrost adjusted input power in the same manner the $P L R$ was used to adjust the defrosted adjusted heating capacity.

$$
\dot{P}_{M S H P \text { input }}=(R T F) \dot{P}_{\text {speed } 1, \text { defrost adjusted }}
$$

Lastly, the controller defines a residual (Equation 3-56) and varies the PLR using the false position (regula falsi) method, a numerical method (Chabert, 1999). The convergence criterion checks that the residual is less than 0.001, as found in the original EnergyPlus V8.0 source code (Ernest Orlando Lawrence Berkeley National Laboratory, 2013b). Physically, this means the PLR is varied until the combined heating from the fan and coil is within $0.1 \%$ of the heating load.

$$
M S H P_{\text {Residual }}=\frac{\dot{Q}_{\text {fan heat }}+\dot{Q}_{\text {MSHP output }}-\dot{Q}_{\text {zone load }}}{\dot{Q}_{\text {zone load }}}
$$

A summary of these steps can be found in the flow diagram in Figure 3-10. 


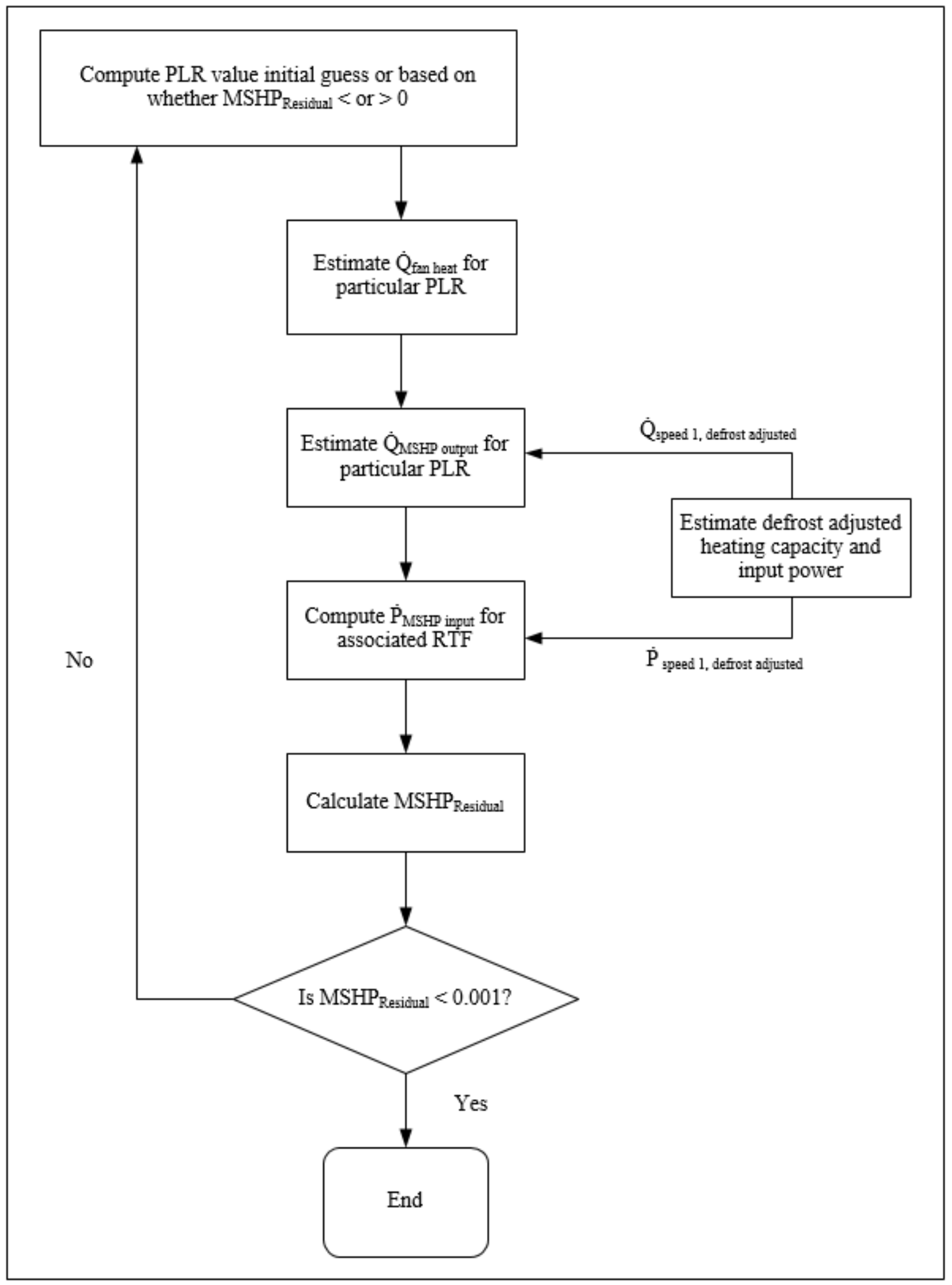

Figure 3-10 Flow diagram of the control process for speed 1 operation 


\subsubsection{Higher speed operation}

If the initial check determined that the HP operating speed 1 without cycling is incapable of satisfying the heating load, the controller iteratively checks for the lowest speed or lowest combination of speeds that would satisfy the heating load. The calculation is similar to the speed 1 operation, except the $P L R$ is replaced with the speed ratio, $S R$, and instead of cycling off, the HP is shifting between the higher speed (HS) and lower speed (LS). The $S R$ is used to estimate the coil heating output in a similar fashion as the PLR was used for in speed 1 operation, as shown in Equation 3-57.

$$
\dot{Q}_{M S H P \text { output }}=\dot{Q}_{L S, \text { defrost adjusted }}(1-S R)+\dot{Q}_{H S, \text { defrost adjusted }} S R
$$

Secondly, assuming speed shifting (e.g., speed 2 to speed 3) results negligible losses, the power input is also estimated using $S R$, without the need for a part load fraction:

$$
\dot{P}_{M S H P \text { input }}=\dot{P}_{L S, \text { defrost adjusted }}(1-S R)+\dot{P}_{H S, \text { defrost adjusted }} S R
$$

The controller iteratively varies $S R$ until Equation 3-56 is less than 0.001, just like for speed 1 operation. A summary of the higher speed operation can be found in a flow diagram in Figure 3 11. 


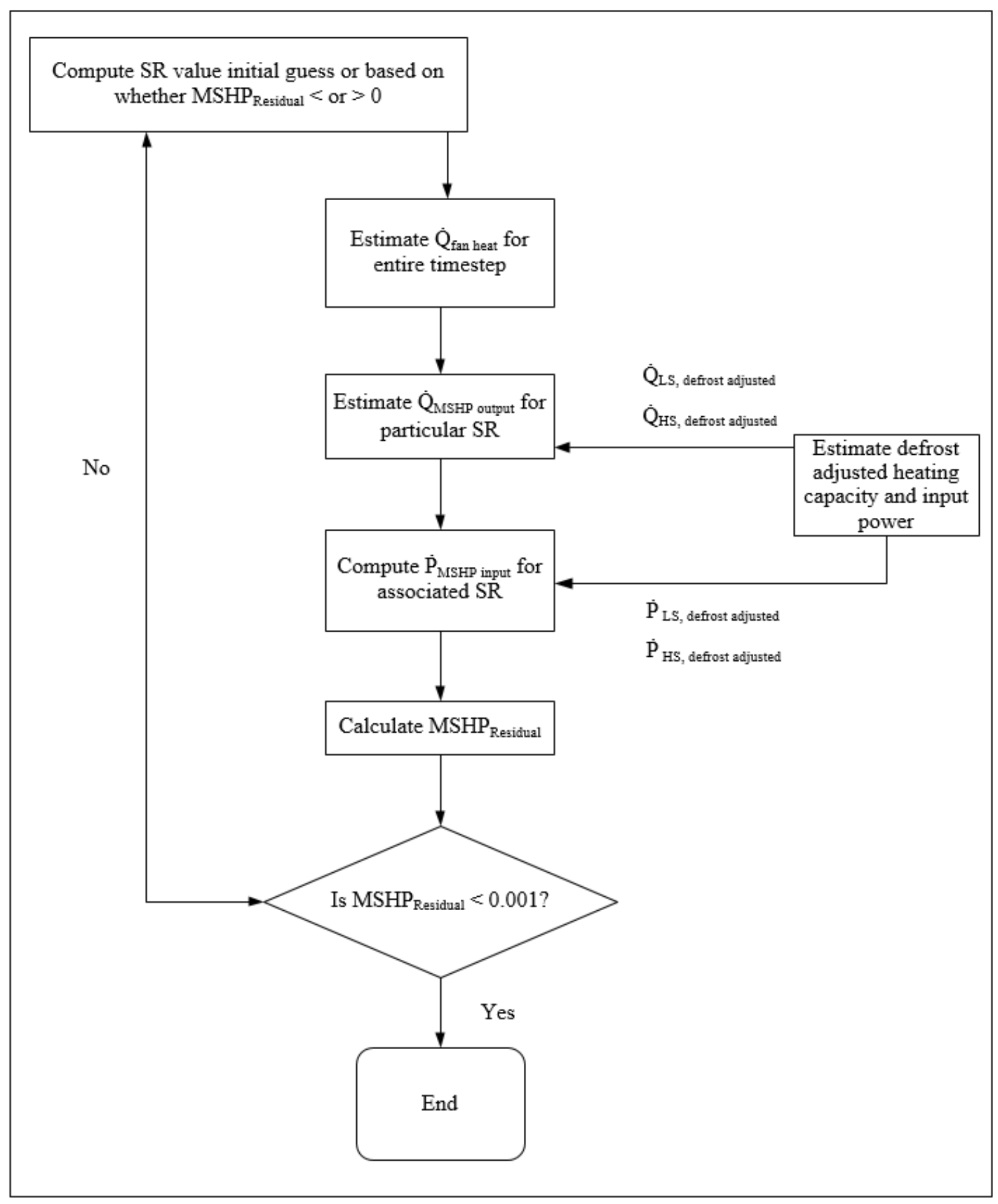

Figure 3-11 Flow diagram of the control process for higher speed operation 


\subsubsection{Flow modulation control scheme}

\subsubsection{Model of the flow modulation}

The flow modulation through the BIPV/T-BISAH system was achieved by keeping the total flowrate supplied to the ASHP constant while varying the proportion of the air flow that was to be supplied by BIPV/T-BISAH system. The flow modulation control scheme works within the controller of the MSHP as described in Section 3.8.2 and begins after the first $\dot{Q}_{M S H P \text { output }}$ and $\dot{P}_{M S H P \text { input }}$ are calculated (these are the heating rate and power input estimated based on outdoor air temperature at the timestep). Figure 3-12 and Figure 3-13 below depicts when the flow modulation begins and ends for speed 1 operation and higher speed operation, respectively. The flow modulation is described in more detailed steps following these figures. 


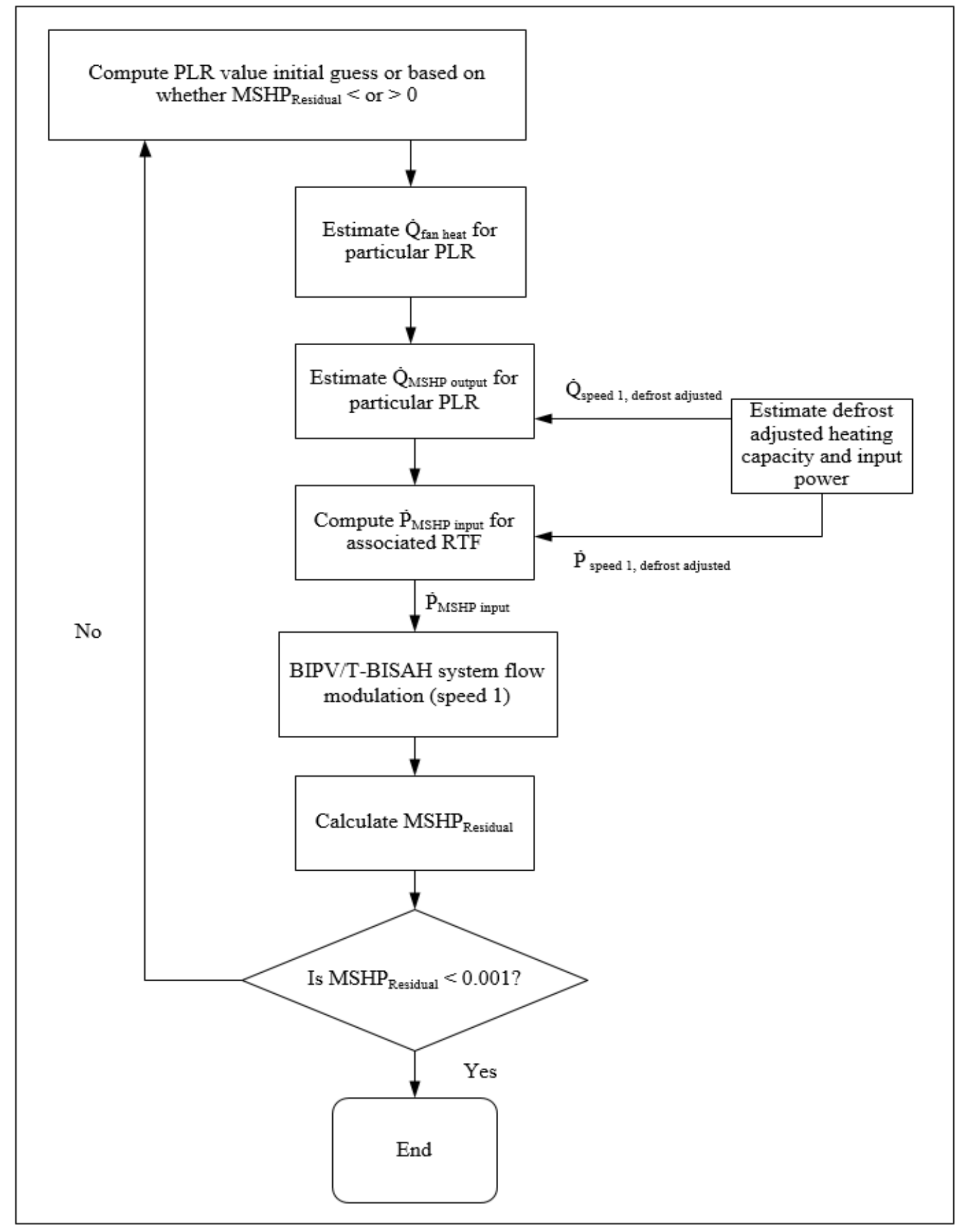

Figure 3-12 MSHP control process with a flow modulation step for speed 1 operation 


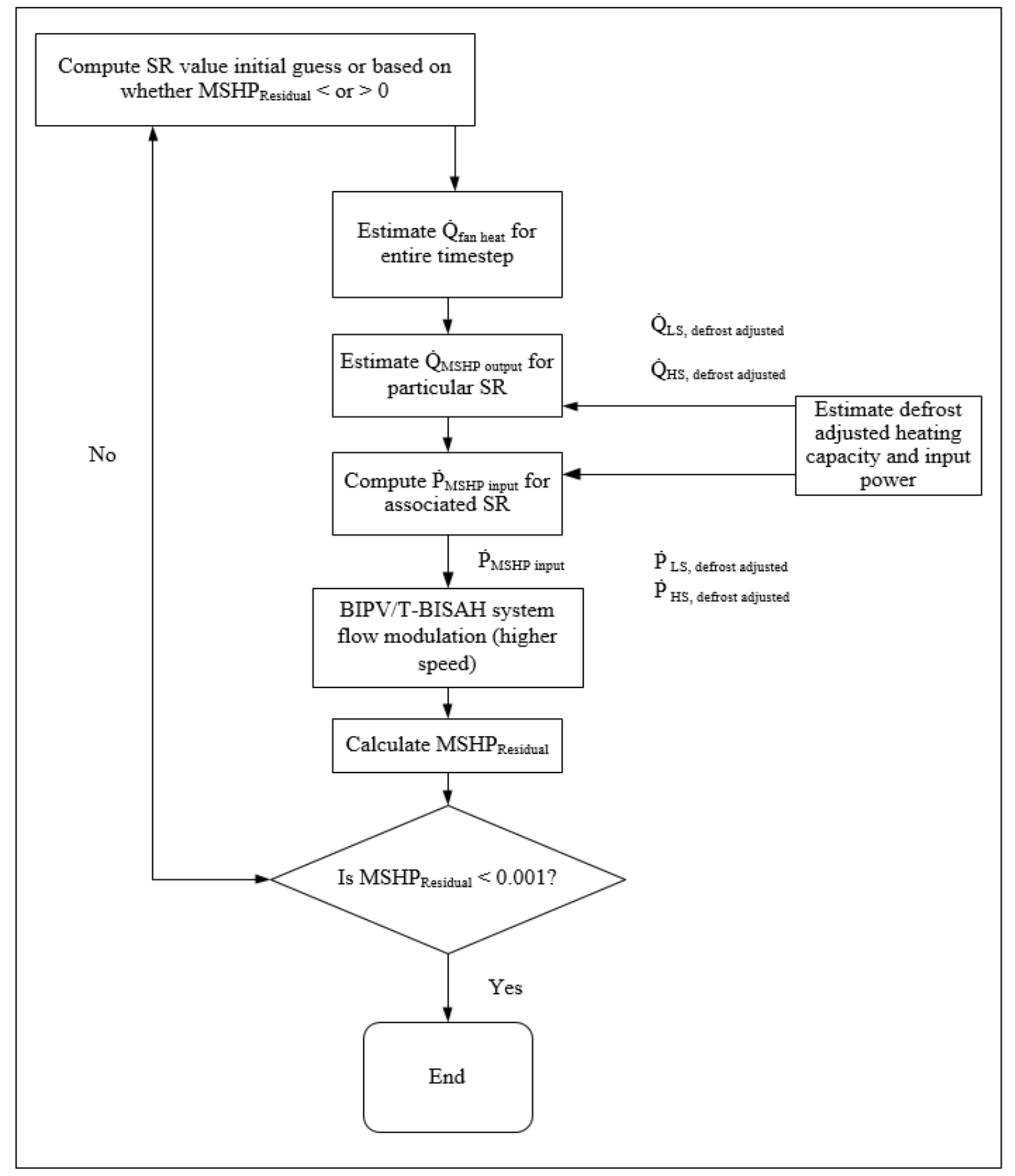

Figure 3-13 MSHP control process with a flow modulation step for higher speed operation

The flow modulation begins after the first set of $\dot{Q}_{M S H P \text { output }}$ and $\dot{P}_{\text {MSHP input }}$ are calculated because they are based on $100 \%$ outdoor air and they form the "base case scenario" 
which the flow modulation attempts to improve upon. Hence they are referred to with the subscripts "base", e.g., $\dot{Q}_{(\text {MSHP output),base }}$ and $\dot{P}_{(\text {MSHP input),base. The flow modulation is an }}$ iterative process that, for $\mathrm{i}^{\text {th }}$ iteration,

1. Selects a mass flowrate for the BIPV/T-BISAH system $\left(\dot{m}_{p v t, i}\right)$ and then combines it with enough outdoor air $\left(\dot{m}_{o a, i}\right)$ to satisfy the HP specified source flowrate $\left(\dot{m}_{H P}\right)$.

2. The outlet temperature of the BIPV/T-BISAH system, for a flowrate $\dot{m}_{p v t, i}$, is $T_{p v t, i}$; the outdoor air temperature is $T_{o a}$.

3. The temperature of the mixed air stream $\left(T_{m, i}\right)$ is estimated and substituted as the source temperature.

4. A new set of $\dot{Q}_{M S H P \text { output }, i}$ and $\dot{P}_{M S H P \text { input }, i}$ are estimated (using the same PLR or $S R$ as the base scenario, as the flow modulation occurs within the iterative solving scheme of the MSHP controller). For speed $1, \dot{P}_{\text {speed } 1, \text { defrost adjusted }}$ is based on the $T_{m, i}$ and for higher speed operation, $\dot{P}_{L S \text {, defrost adjusted }}$ and $\dot{P}_{H S, \text { defrost adjusted }}$ are both based on $T_{m, i}$.

5. Fan power used to draw BIPV/T air flow $\left(\dot{P}_{f a n-p v t, i}\right)$ and the outdoor air flow $\left(\dot{P}_{f a n-o a, i}\right)$ are calculated.

6. The summed total of the HP (compressor) and fan power required $\left(\dot{P}_{h p-f a n, i}\right)$, for this combination of $\dot{m}_{p v t, i}$ and $\dot{m}_{o a, i}$ is estimated and compared with $\dot{P}_{(M S H P \text { input }), b a s e}$ and the lowest $\dot{P}_{h p-f a n, l o w e s t}$ so far.

7. If $\dot{P}_{h p-f a n, i}<\dot{P}_{(M S H P \text { input }), b a s e}$ and $\dot{P}_{h p-f a n, i}<\dot{P}_{h p-f a n, l o w e s t}$, the newer $\dot{P}_{h p-f a n, i}$ is stored as the new $\dot{P}_{h p-f a n, l o w e s t}$ (new lowest combined compressor-fan power).

8. Steps 1-7 are repeated for 40 combinations (i.e., $\mathrm{i}=1,2,3, \ldots, 40$ ).

9. The $T_{m, i}$ that results in $\dot{P}_{h p-f a n, l o w e s t}$ is used to operate the MSHP at the given PLR or SR and the BIPV/T-BISAH /T runs with that specific $\dot{m}_{p v t, i}$. If none of the combination of flow results in $\dot{P}_{h p-f a n, i}<\dot{P}_{(M S H P \text { input }), \text { base }}$, the MSHP runs the base scenario, using $T_{o a}$ as the source temperature and the final $\dot{m}_{p v t}$ is set to $0 \mathrm{~kg} / \mathrm{s}$ (the BIPV/T-BISAH is not used for this particular $P L R$ or $S R)$. 
In more detail, the outdoor flowrate is estimated using Equation 3-59. $\dot{m}_{H P}$ was obtained from the HP specification, and each $\dot{m}_{p v t, i}$.

$$
\dot{m}_{o a, i}=\dot{m}_{H P}-\dot{m}_{p v t, i}
$$

The BIPV/T air and outdoor air are assumed to be well mixed and temperature of the mixed air is estimated using Equation 3-60. It assumes the humidity of the two air streams are the same. However, the BIPV/T model assumes dry air and hence, using Equation 3-60 results in underestimation of the humidity (the preheated BIPV/T air contains less moisture). The implication is that the defrost factors used to estimate the defrost adjusted input power in the MSHP model in the base case (based on ambient air) and in each iteration, are the same (i.e., preheating the air does not change the defrosting factors).

$$
T_{m, i}=\frac{\dot{m}_{o a, i}}{\dot{m}_{H P}} T_{o a}+\frac{\dot{m}_{p v t, i}}{\dot{m}_{H P}} T_{p v t, i}
$$

A variable speed fan model was used to estimate the fan power required to draw the air through the BIPV/T and from the ambient both. The following variable fan speed model was taken from EnergyPlus V8.0 (Ernest Orlando Lawrence Berkeley National Laboratory, 2013a); the variables used refer to the BIPV/T air flow, however, the same model was used in estimating the outdoor fan.

$$
\begin{gathered}
f_{P V T}=\frac{\dot{m}_{p v t, i}}{\dot{m}_{H P}} \\
f_{p l}=c_{1}+c_{2} f_{P V T}+c_{3} f_{P V T}^{2}+c_{4} f_{P V T}^{3}+c_{5} f_{P V T}^{4}{ }^{4} \\
\dot{P}_{\text {fan }-p v t, i}=\frac{f_{p l} \dot{m}_{H P} \Delta P_{\text {design }, P V T}}{\eta_{\text {fan }} \rho_{p v t}}
\end{gathered}
$$

In this work, the model assumes the BIPV/T air and the outdoor air stream are separate and only the main ductwork is included in the pressure drop. The main ductwork for the BIPV/T 
air is the air channel underneath the panels/glazing; the main duct for the outdoor air is a single straight duct. Additional duct work may be required but would be largely influenced by the architectural design of the house (e.g., placement of the mechanical room), hence for this work, only the fan power through the main ducts are considered. This identifies the amount of total savings available before additional duct work and will allow designers in the future to design the system to their needs.

\subsubsection{Limitation of the flow modulating model}

The flow modulation is an iterative process that, at a given timestep and particular $P L R$ or $S R$, would estimate the lowest possible BIPV/T-BISAH coupled MSHP power consumption; however are there limitations brought on by iterating within the controller as performs its own iterative procedure to select a $P L R$ or $S R$. The first is computational time and the second is the potential for non-convergent result in the controller's $P L R / S R$ selection process.

The simulations were conducted on a system using an Intel i7 core processor and 16 GB of ram and for the case studies took approximately one hour to complete. This is mainly due to the 40 iterations (comparing results for different BIPV/T-BISAH air flow proportion) within each iterative calculation for a trial $P L R / S R$.

Introducing the iterative flow modulation introduces the possibility that the $P L R / S R$ selection process may not converge. The $P L R / S R$ affects the fan heat addition, hence, it affects the inlet condition of the air entering the coil. Therefore, for each iteration of the $P L R / S R$, the $\dot{P}_{(\text {MSHP input),base }}$ is different and the lowest BIPV/T-BISAH coupled MSHP and fan power $\left(\dot{P}_{h p-f a n, l o w e s t}\right)$ may change. This is because the PLR/SR affects the inlet condition of the air and the efficiency of the system $(P L F, R T F)$ if it cycles. Hence, there could exist a case such that for the $\mathrm{j}^{\text {th }} P L R / S R$ the BIPV/T-BISAH is on and can provide savings but the total heating rate over satisfies the heating load; and for the $\mathrm{j}+1^{\text {th }} P L R / S R$, the BIPV/T-BISAH is turned off because it cannot provide any savings. The iterative method that the controller employs (false position method) would discover that at $\mathrm{j}^{\text {th }} P L R / S R$, the total heating rate is too high and with $\mathrm{j}+1^{\text {th }} \mathrm{s}$ $P L R / S R$, the heating rate is too low and it would attempt to find a $P L R / S R$ that is in between the $\mathrm{j}^{\text {th' }}$ s and the $\mathrm{j}+1^{\text {th }} \mathrm{s} P L R / S R$. In this case, it may not converge because there is a point where an increase or decrease for a specific $P L R / S R$ would result in the BIPV/T-BISAH not introducing 
any saving and hence it would be turn off, this would mean the $\dot{Q}_{M S H P ~ o u t p u t}$ when the BIPV/TBISAH is off could be much lower than when the BIPV/T-BISAH was on. This is effectively a discontinuity, there is a jump in the values of $\dot{Q}_{M S H P}$ output. Normally, this would not happen because without BIPV/T-BISAH coupling, for each iterative $P L R / S R$, the source temperature would not change (it would always be the temperature outdoor temperature) and thus as the PLR/SR converges, $\dot{Q}_{M S H P \text { output }}$ would change slightly and it would effectively be a continuous range of values.

The implication for this is that the controller's iteration would reach the maximum number of iteration and the MSHP would simply operate with the last PLR/SR, which may not be enough to satisfy the zone load or may over heat the zone. For the two case studies presented, there were only a maximum of 16.67 hours where the setpoint was not met.

\subsection{Modelling OBIPV/T, TBIPV/T, and BISAH in a building using EnergyPlus V8.0}

In EnergyPlus V8.0 (original and modified), the simulation process begins with

1. the heat transfer balance of different surfaces and allows the heating load to be estimated (these processes are referred to as the house model),

2. then the HVAC system are simulated,

3. and the zone conditions are updated.

In this work, the BIPV/T-BISAH system is a part of the "house model" because the system overlaps with the building surfaces physically (the insulation of the BIPV/T-BISAH is the actual roof insulation of the house). Hence, in reference to Figure 3-1, 3-2, and 3-3, $T_{l}$ is the outside temperature of the roof from the perspective of the house and each collector is associated with a unique surface (i.e., the roof is discretized into as many surfaces are there are collectors). However, the BIPV/T-BISAH system is controlled by the MSHP, thus making it part of the HVAC system as well. Thus, the BIPV/T-BISAH system in this modified version of EnergyPlus V8.0 interacts directly with both systems at any timestep.

In the modified version of EnergyPlus V8.0, the temperature $T_{l}$ is estimated at step 3 at the current timestep $\mathrm{k}$, however, it is not used in the house model's calculation until the next timestep, $\mathrm{k}+1$. Thus, there is a need for an iterative process to take place so that the house model can predict 
a new zone load for each iteration as the HVAC ASHP selects to operate the BIPV/T-BISAH system in a particular manner (with a specific flowrate, a specific $T_{l}$ is estimated).

However, as mentioned previously, the flow modulation process already includes an iterative procedure that greatly increases computational time, hence, there is a need to reduce simulation time. In this work, steps 1-3 above were completed once and an iterative procedure was avoided; effectively, only the first iteration of the procedure was completed. This would result in the $T_{l}$ estimated being not quite the actual steady state value. This was alleviated by using smaller timesteps so that the temperature could change gradually (as the timestep is shorten, temperature changes are reduced). And therefore, the need for an iterative process connecting steps 1-3 was eliminated.

A 20-min timestep was chosen (steps 1-3 were completed three times in one hour) based on a timestep sensitivity analysis using the results from simulating the energy efficient house with the BIPV/T-BISAH system in Section 4.3. Table 3-1 presents the temperature $T_{l}$ for the first OBIPV/T collector of a row and the last $\left(6^{\text {th }}\right)$ BISAH collector of the same row, on January $4^{\text {th }}$ at 2:00 pm. This particular day's results were used because the BIPV/T was constantly used (i.e., forced air through the BIPV/T) and the solar irradiance is relatively high.

Table 3-1 Tl at 1pm for two selected collectors

\begin{tabular}{|c|c|c|}
\hline Timestep & $\begin{array}{c}1^{\text {st }} \text { OBIPV/T } \\
\text { collector }\end{array}$ & $\begin{array}{c}6^{\text {th }} \text { BISAH } \\
\text { collector }\end{array}$ \\
\hline $60 \mathrm{~min}$ & $0.699836\left({ }^{\circ} \mathrm{C}\right)$ & $93.76766\left({ }^{\circ} \mathrm{C}\right)$ \\
\hline $30 \mathrm{~min}$ & $0.573738\left({ }^{\circ} \mathrm{C}\right)$ & $92.84896\left({ }^{\circ} \mathrm{C}\right)$ \\
\hline $20 \mathrm{~min}$ & $0.573679\left({ }^{\circ} \mathrm{C}\right)$ & $92.84894\left({ }^{\circ} \mathrm{C}\right)$ \\
\hline
\end{tabular}

At the 20 -min timestep, $T_{l}$ for the $1^{\text {st }}$ OBIPV/T collector changed by approximately $0.01 \%$ from the previous 30 min timestep, the BISAH collector changed by even less. 


\subsection{Results}

\subsection{Parametric sensitivity analysis}

Enhancements of the BIPV/T system can be obtained by selecting optimal parameters for individual collectors. As shown in the literature review, fan power used to draw the air through a BIPV/T system can greatly offset the energy savings introduced by BIPV/T systems that are installed in cold climate regions. Hence, in this work, the enhancements examined are ones that do not increase the fan power consumption, compared to the base case OBIPV/T system, as was studied by Hailu, Dash and Fung (2015) and Tardif et al. (2017).

In this work, the individual parameters examined were the internal air channel emissivity and the glass cover top emissivity, for OBIPV/T, TBIPV/T, and BISAH collectors. Changes to these parameters results in negligible changes to the surface smoothness, hence, there is no thermohydraulic trade off. In the analysis, parameter changes were applied to both individual collectors and collectors in a row configuration (connected in series) because it was determined that a common internal channel emissivity had different effects on the collector performance, depending on the type of collector and its location in the row. Afterwards, an examination of the effect of changes in these parameters and the mechanism behind was completed.

The analyses of collector parameters were examined under heating season (from October $1^{\text {st }}$ to May $21^{\text {st }}$ ) simulations using a CWEC weather file of Toronto, Canada, tilted $35^{\circ}$ from the horizontal and a constant $0.1 \mathrm{~kg} / \mathrm{s}$ flowrate for each row (collectors were arranged vertically from the bottom to the ridge of a roof to form a row; air flowed from the bottom upwards to the ridge). In the modified version of EnergyPlus V8.0, when the OBIPV/T, TBIPV/T, and BISAH systems are not coupled with the ASHP and operate at constant flowrate the air flowing through the collectors may lose heat, instead of gaining thermal energy. This occurs during some early morning or late afternoon hours when the irradiance is non-zero but relatively low (e.g., approximately < $70 \mathrm{~W} / \mathrm{m}^{2}$ ). In these cases, the thermal energy is not reported. However, the PV model assumes that the panels continue to generate electricity during these hours, so the electricity generated is included in the heating season results. Additionally, the collectors were examined as rows in addition to as individual collectors because the air increases in temperature as it flows through the row and the collectors are thermally different; the effect of particular parameter for one individual collector may not be applicable for an entire row of the same collectors. However, an analysis of 
the entire array is not necessary because the results of a single row can be applied to any array that combines multiple vertical rows.

\subsubsection{TBIPV/T-Internal channel emissivity}

The internal air channel emissivities refers to the emissivity values of the upper and lower surface of the TBIPV/T collector's air channel. For this analysis both the upper and lower emissivities varied were varied as part of a sensitivity analysis to determine its effect on the

performance of TBIPV/T systems. In this study, both the upper and lower surface's emissivity values were changed in unison (i.e., the emissivity of the upper and lower surface were the same for the entire analysis) and are referred to as the "internal emissivities". In this context, the performance refers to both thermal and electrical energy generation. The parameters used to model the TBIPV/T system for this analysis are presented in in Table 4-1.

Table 4-1 TBIPV/T collector parameters for internal emissivity analysis

\begin{tabular}{|c|c|}
\hline$K$ & $4 \mathrm{~m}^{-1}$ \\
\hline$l_{g}$ & $0.0032 \mathrm{~m}$ \\
\hline$n$ & 1.526 \\
\hline$k_{g}$ & $3.78 \mathrm{~kJ} / \mathrm{hr} \cdot \mathrm{m} \cdot \mathrm{K}$ \\
\hline$R_{p v-u}$ & $0.000847 \mathrm{~kJ} / \mathrm{hr} \cdot \mathrm{m}^{2} \cdot \mathrm{K}$ \\
\hline$w$ & $1.6 \mathrm{~m}$ \\
\hline$L$ & $1 \mathrm{~m}$ \\
\hline$d$ & $0.0635 \mathrm{~m}$ \\
\hline$R_{\text {ins }}$ & $1.9562 \mathrm{hr} \cdot \mathrm{m}^{2} \cdot \mathrm{K} / \mathrm{kJ}$ \\
\hline$\epsilon_{c}$ & 0.6 \\
\hline$P F$ & 0.9 \\
\hline$\alpha_{l}$ & 0.9 \\
\hline
\end{tabular}

A heating season (October $1^{\text {st }}$ to May $21^{\text {st }}$ ) simulation of one row of six TBIPV/T collectors was conducted. The collectors were arranged from the bottom of the roof to the ridge, the air flowed from the first collector upwards to the ridge and exits the last collector. For the case where the emissivities of each collector were the same, the results showed that a decrease in the emissivity resulted in diminished thermal gain and electrical generation. These results are shown Figure 4-1 and Table 4-2, for thermal generation and electrical generation, respectively. 


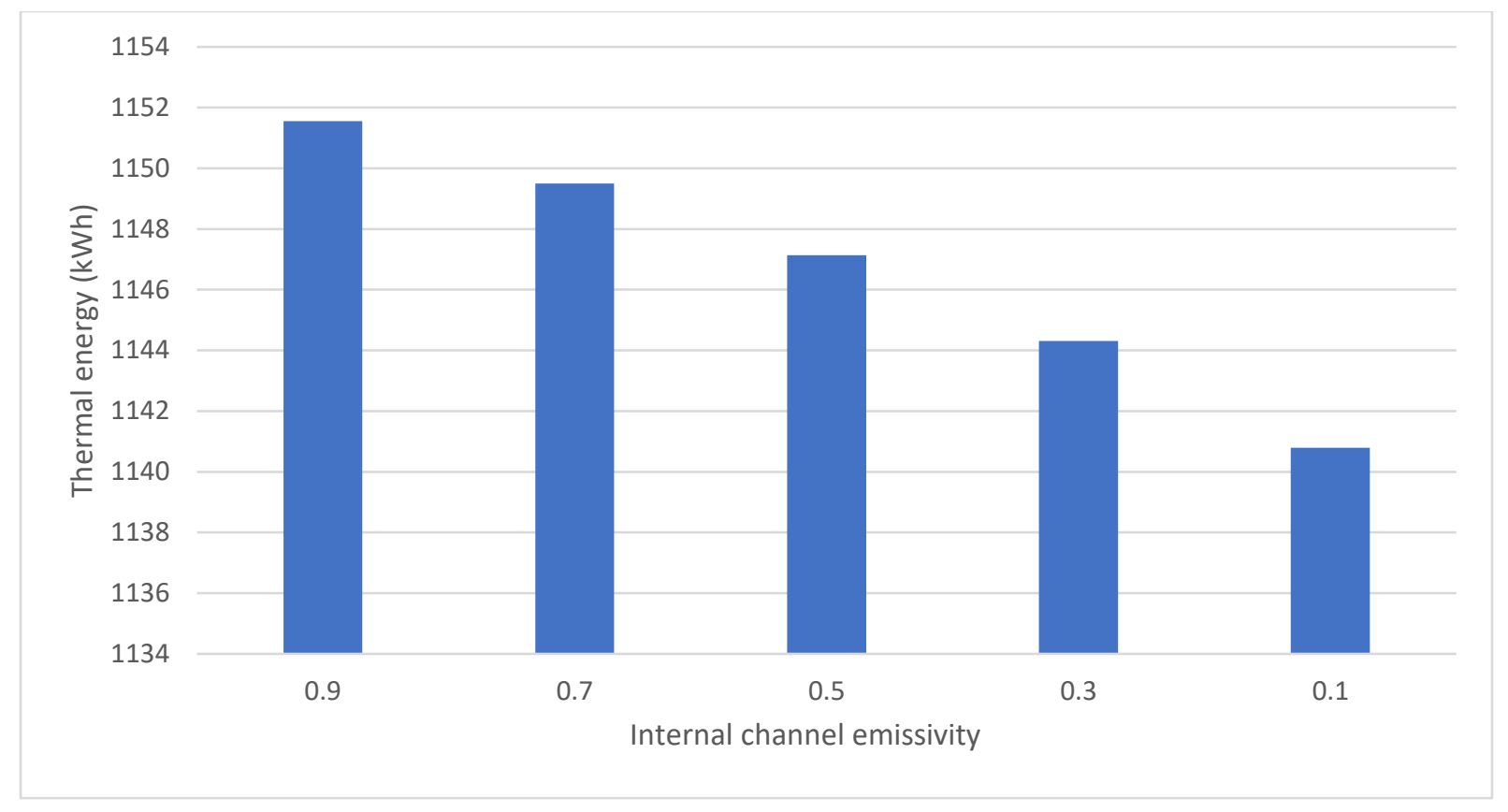

Figure 4-1 Annual thermal energy generation of a single row for different internal channel emissivity

Table 4-2 Annual electrical generation of a single row for different internal channel emissivity

\begin{tabular}{|c|c|}
\hline Emissivity & $\begin{array}{c}\text { Heating season electricity } \\
\text { generated }(\mathrm{kWh})\end{array}$ \\
\hline 0.9 & 964 \\
\hline 0.7 & 964 \\
\hline 0.5 & 964 \\
\hline 0.3 & 963 \\
\hline 0.1 & 963 \\
\hline
\end{tabular}

Over the heating season, the thermal energy decreases by $10 \mathrm{kWh}$ while the electricity decreases by approximately $1 \mathrm{kWh}$ when the internal emissivity decreases from 0.9 to 0.1 . That is, a high internal emissivity results in better TBIPV/T system performance. These changes are slight due to the small mass flowrate used in the analysis. However, these trends would still hold for increasing flowrate, up to a limit. Therefore, the trend presented in these results are applicable to future applications.

A detailed examination of the heating season thermal energy generated by each collector shows that not all of the individual collectors follow the same trends that Figure 4-1 and Table 4- 
2 exhibits. A comparison of the thermal energy generated by each collector shows that as the internal emissivity decreases from 0.9 to 0.1 (see Figure 4-2, where the collectors are in sequence from the first collector, A1, to the last collector, A6), it can be seen that the $1^{\text {st }}$ collector (A1), $2^{\text {nd }}$ collector (A2), and the $3^{\text {rd }}$ collector (A3), generated less thermal energy. On the other hand, as the emissivity decreases for collectors A4-A6, the thermal energy generated increases. These irregular results suggest that the effect of the internal emissivities on the thermal performance is dependent on the collector's position in the row. Since the inlet temperatures entering the collectors following the first (e.g., $2^{\text {nd }}$ to the $6^{\text {th }}$ collector) are different between the two rows with different internal emissivities, this could potentially contribute to the irregular trend. The effect of the internal emissivity on the collectors needs to be determined when the only difference between two individual collectors are their internal emissivities.

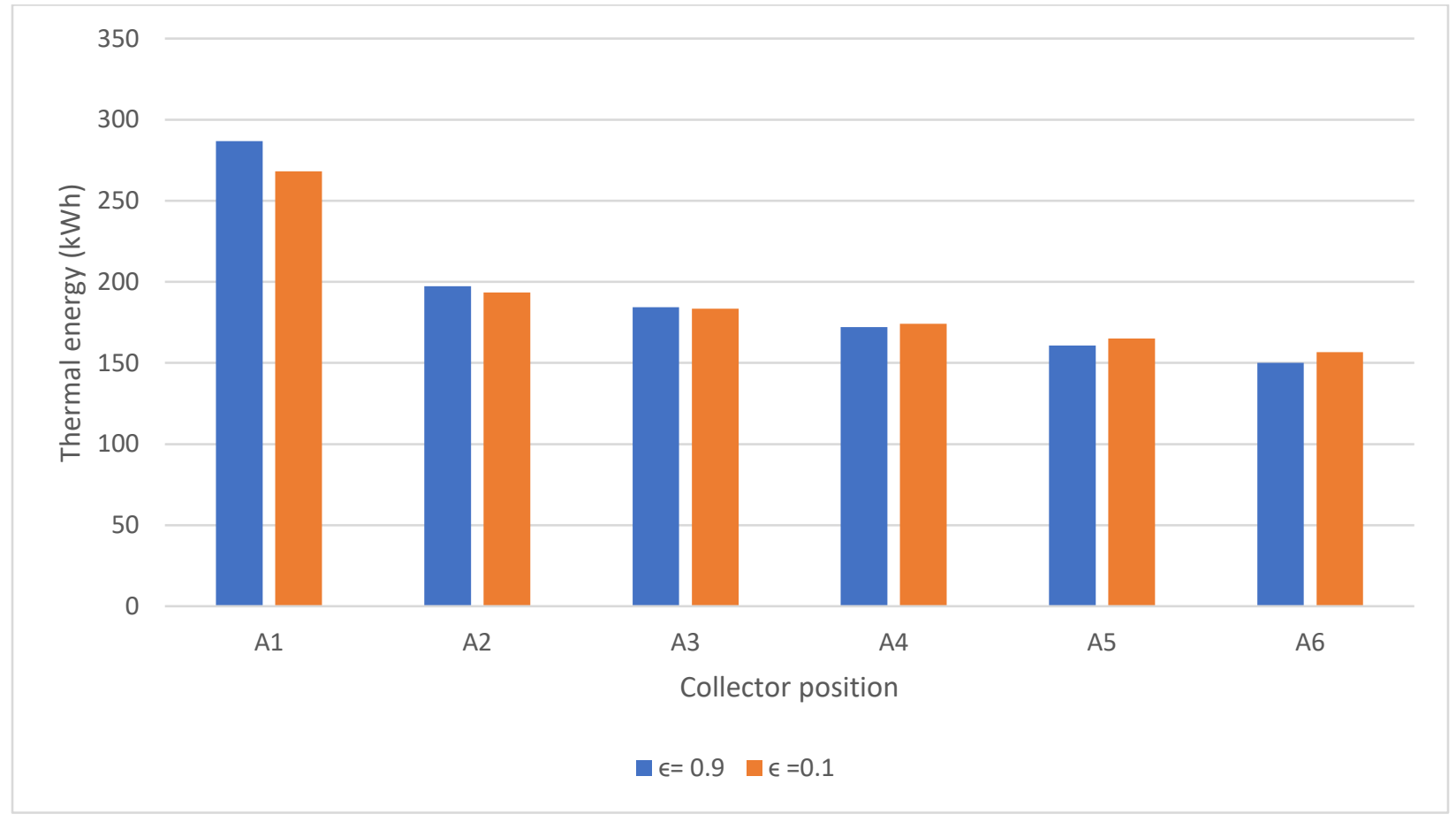

Figure 4-2 Heating season thermal energy generation for each collector of the row

\subsubsection{Detailed heat transfer analysis of a collector on January $8^{\text {th }}$}

A simulation of a single collector was completed using two internal emissivities of 0.1 and 0.9 , all other conditions were kept constant. Over the heating season, the collector with internal emissivities of 0.9 generated $184 \mathrm{kWh}$ of thermal energy, while the collector with 0.1 internal 
emissivity generated $182 \mathrm{kWh}$ of thermal energy. The hourly thermal generation is shown in Figure 4-3. The collector with internal emissivities of 0.9 generated more thermal energy than the collector with internal emissivities of 0.1 did for 7 hours out of the 9 hours when the collectors were irradiated (i.e., irradiance $>0 \mathrm{~W} / \mathrm{m}^{2}$ ). However, at 9 am and $5 \mathrm{pm}$, the collector with internal emissivities of 0.1 gained $3 \mathrm{Wh}$ and $17 \mathrm{Wh}$, respectively, more thermal energy than the collector with internal emissivities of $0.9 \mathrm{did}$. These are slight differences, but an examination of these hours will provide reasons that explain why higher emissivities do not always result in better performance.

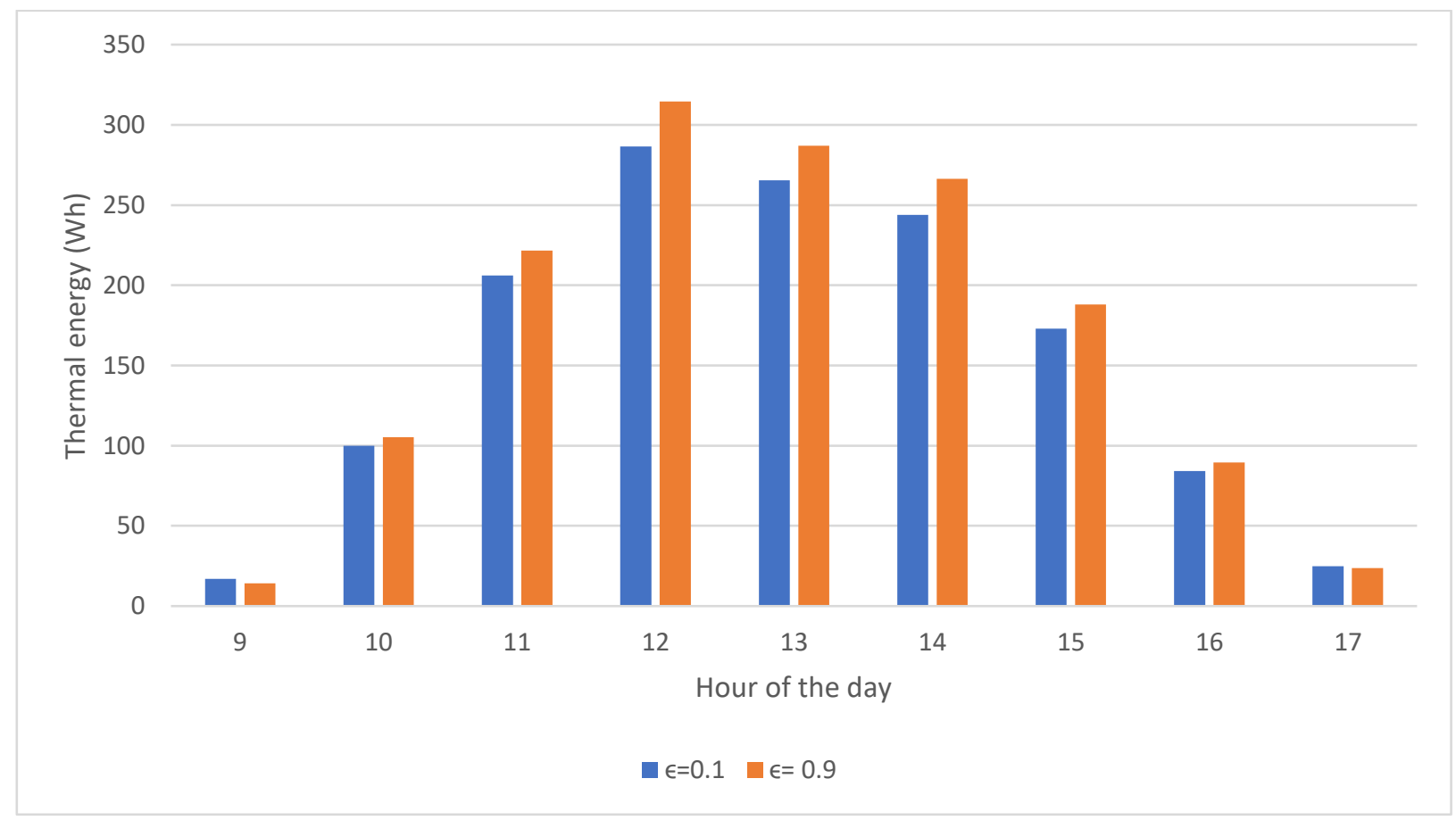

Figure 4-3 Hourly thermal generation of the collector on January $8^{\text {th }}$

For the 7 hours when the collector with 0.9 internal emissivities performed better than the collector with 0.1 internal emissivities, the upper surface temperature was always higher than the lower surface temperature. When the internal emissivities increases during these hours, the internal longwave radiation between the two surfaces improves. Thus, for these 7 hours, more heat flows from the upper surface (warmer) to the lower surface (colder). This resulted in the air stream gaining more thermal energy because more of the solar energy that was absorbed by the PV cells is conducted to the upper surface and less of it was lost through the cover to the ambient. The 
additional thermal energy that the lower surface received was mostly transferred to the air (a portion is transferred to the zone because for a few hours the temperature of the lower surface became higher than the zone surface temperature). Furthermore, because more of the thermal energy at the PV layer was transferred, it resulted in a drop of the PV temperature, hence an increase in electricity generation. This is corroborated below based on references to Figure 4-4 to Figure 4-7.

Figure 4-4, presents the upper and lower surface temperatures for the collector with an internal emissivity of 0.1 ; the upper surface is warmer than the lower surface $\left(T_{u}>T_{l}\right)$ from 10 am to $4 \mathrm{pm}$, which coincides with the hours when the thermal generation of the collector with 0.9 emissivity is greater. On the other hand, at 9 am and $5 \mathrm{pm}$, the thermal energy generated by the 0.1 emissivity collector is greater because during these two hours, the lower surface is warmer. At these two hours, the lower emissivities prevents radiation heat transfer from the lower surface to the upper surface. Higher emissivities would have increased the upper surface temperature, diminish the amount of heat conducted from the PV layer to the upper surface (because $T_{u}$ would have increased), and allow more of the net absorbed solar thermal irradiance to be transferred through the cold glass cover. Additionally, with less radiation heat transfer to the upper surface, the temperature of the PV remains lower, compared to the collector with internal emissivities of 0.9 at the same hour, and would thus generate more electrical energy comparatively.

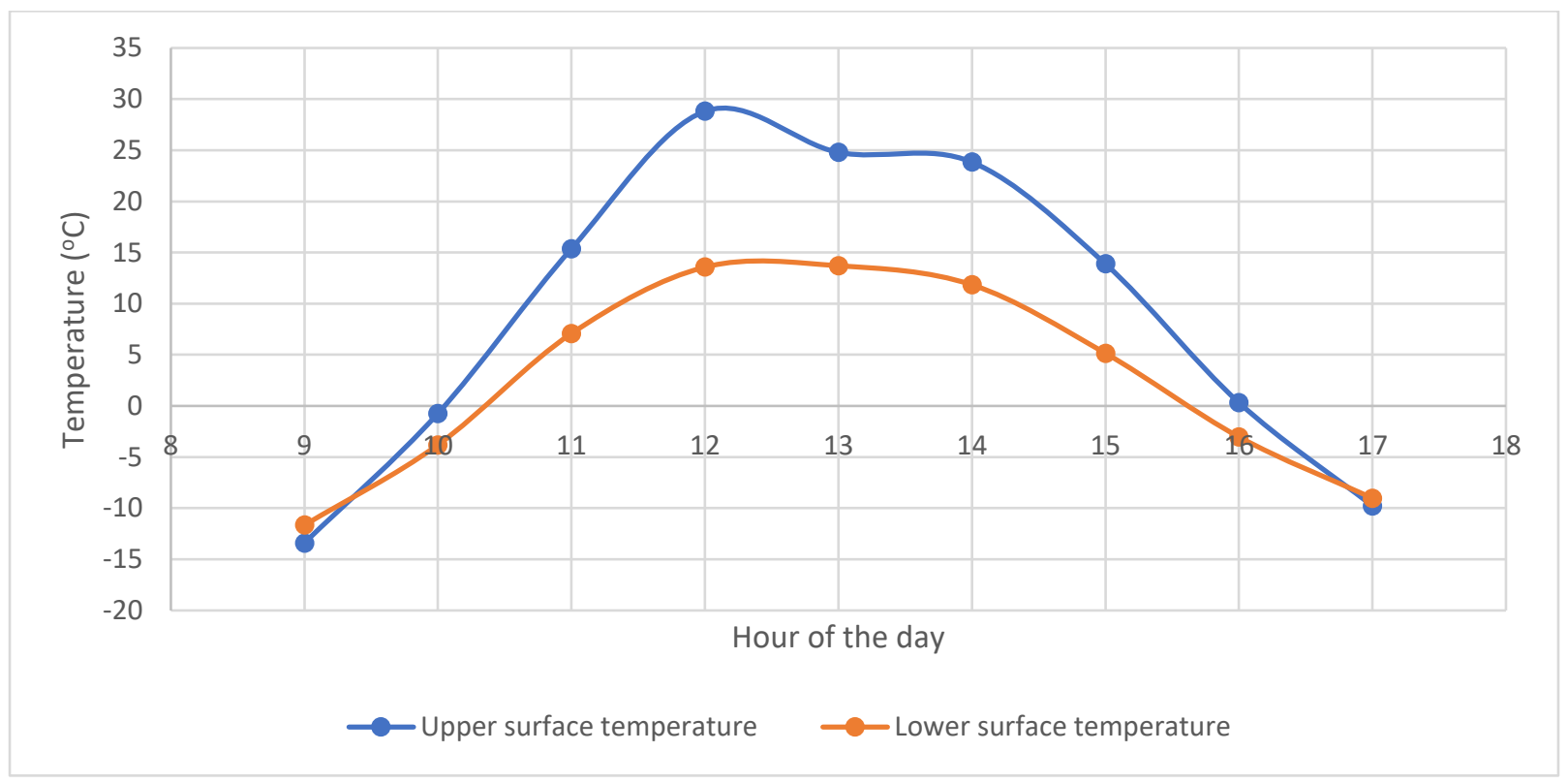

Figure 4-4 Upper and lower surface temperatures for collector with 0.1 internal emissivity on January $8^{\text {th }}$ 
From 10 am to $4 \mathrm{pm}$, increasing the internal emissivities from 0.1 to 0.9 augments the radiation heat transfer between the internal channel surfaces and the upper surface temperature decreases as Figure 4-5 shows. On the other hand, this results in an increase of the lower surface temperature as Figure 4-6 depicts.

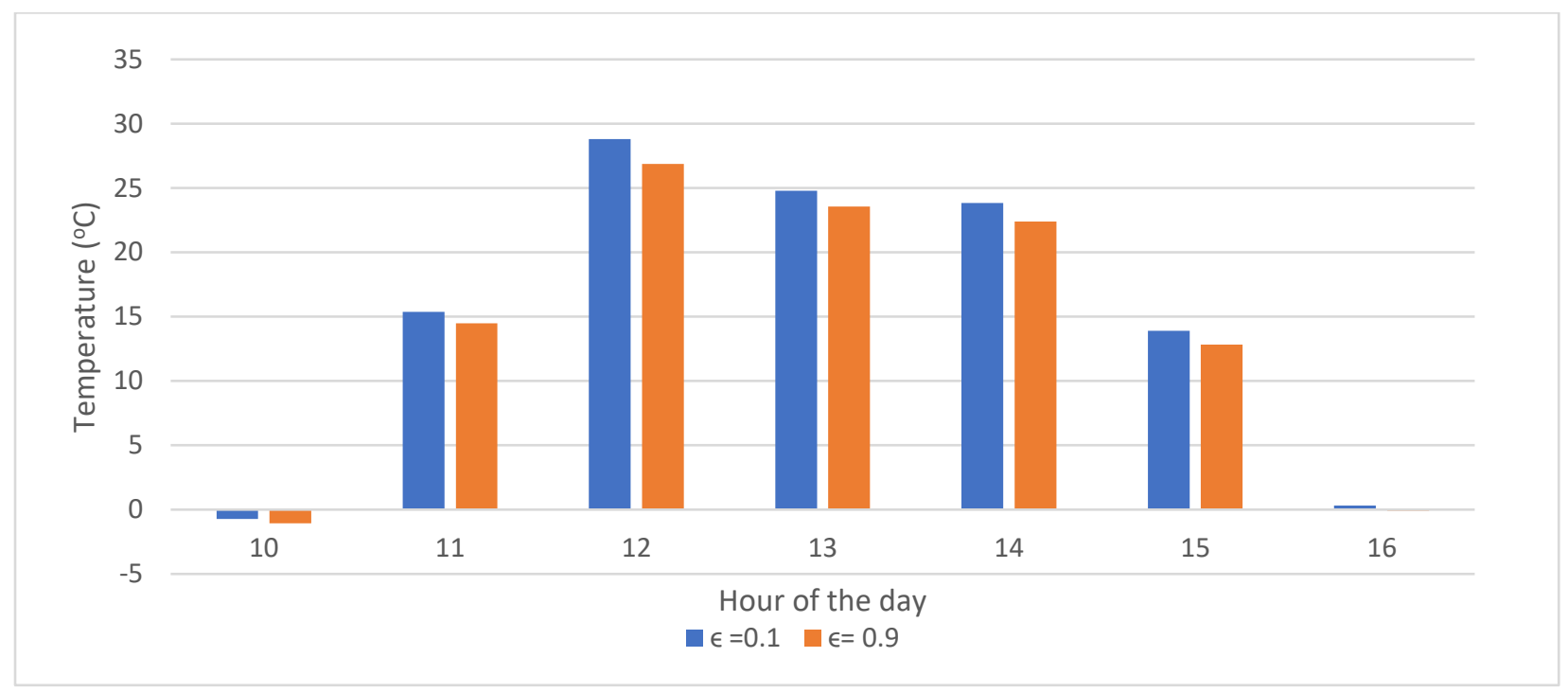

Figure 4-5 Upper surface temperature of the collector for different internal emissivity on January $8^{\text {th }}$

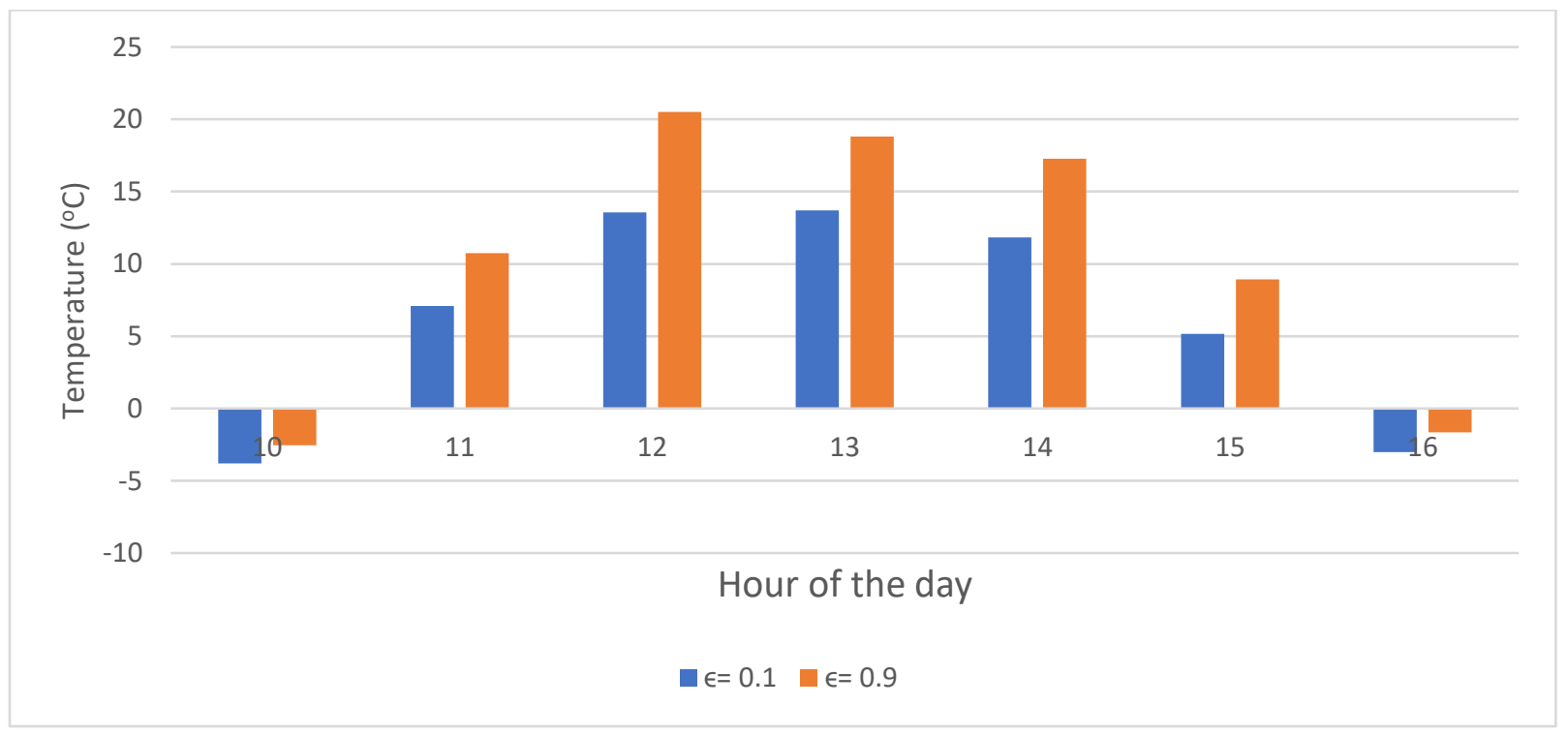

Figure 4-6 Lower surface temperature of the collector for different internal emissivity on January $8^{\text {th }}$ 
As the temperature of the upper surface drops, more thermal energy is transfers from the PV layer to the upper surface (due to a larger temperature difference). This results in less convective and radiative heat loss from the collector's glass cover. Shown in Figure 4-7, the collector with 0.9 internal emissivity experiences less environmental heat loss because more of the solar energy absorbed by the PV is transferred away from the cover. Thus, more solar energy is retained by the collector and distributed to the air stream.

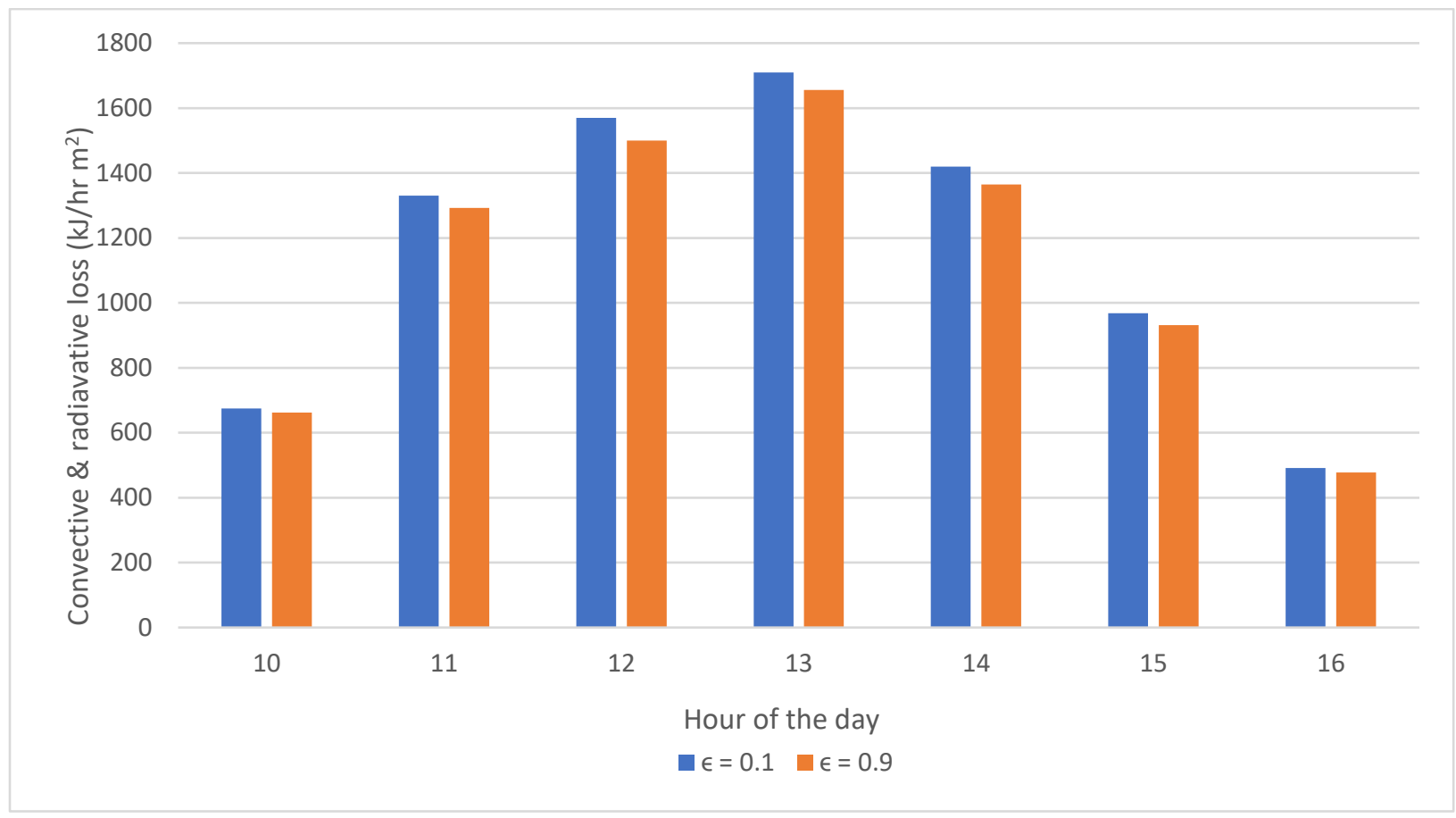

Figure 4-7 Total convective and radiative heat loss for the collector for different internal emissivities on January 8th

\subsubsection{Detailed heat transfer analysis of a collector on January 1st}

For January $8^{\text {th }}$, for 7 out of 9 hours the thermal energy generated by the collector with the 0.9 internal emissivities (higher emissivity) is greater than the thermal energy generated by the collector with 0.1 internal emissivities; on a different day (January $1^{\text {st }}$ ), the collector with 0.9 internal emissivity generates less thermal energy than the collector with 0.1 emissivity for the entire day, as Figure 4-8 depicts. 


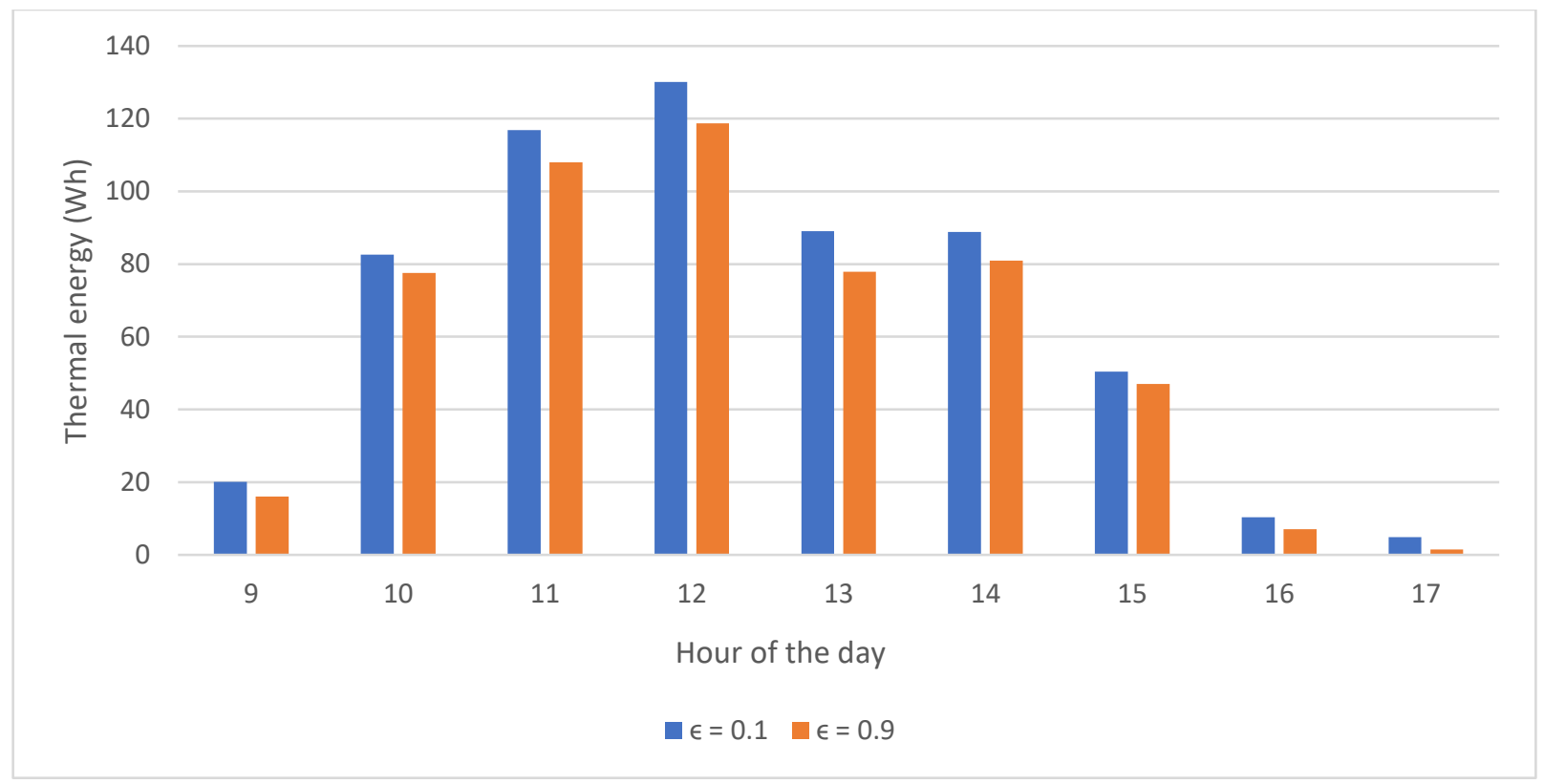

Figure 4-8 Thermal energy generation by a collector with two different internal emissivities on January $1^{\text {st }}$

On January $1^{\text {st }}$, a higher emissivity does not enhance the thermal energy generation. This occurs during these 9 hours, because $T_{u}<T_{l}$ for the collector with 0.1 internal emissivity, as Figure 4-9 depicts. In this case, increasing the emissivity removes energy from the lower surface (reducing its temperature as Figure 4-10 depicts), concentrates more thermal energy at the upper surface (increasing its temperature), lowers the heat transfer from the PV and allows more energy to escape the collector via convection and radiation to the environment (Figure 4-11).

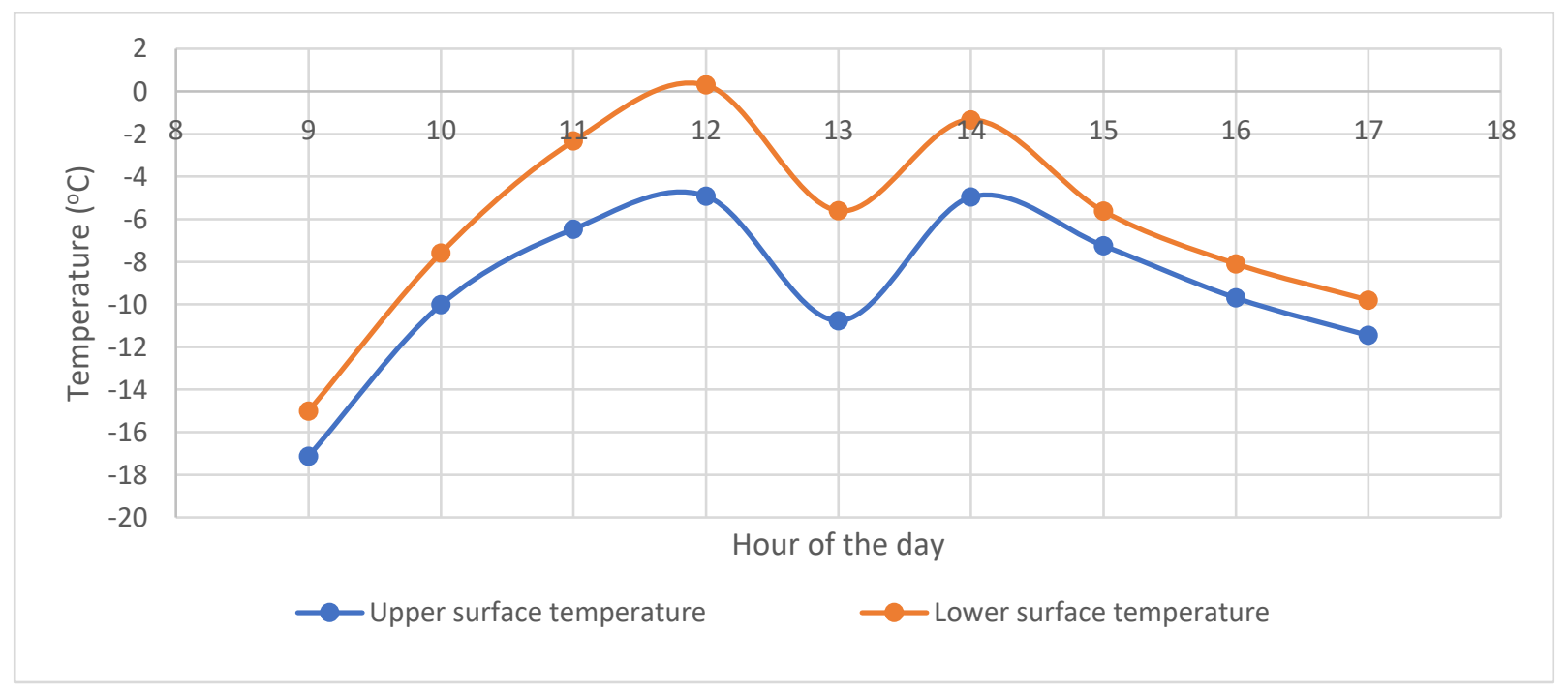

Figure 4-9 Hourly upper and lower surface temperature for the collector with 0.1 internal emissivities 


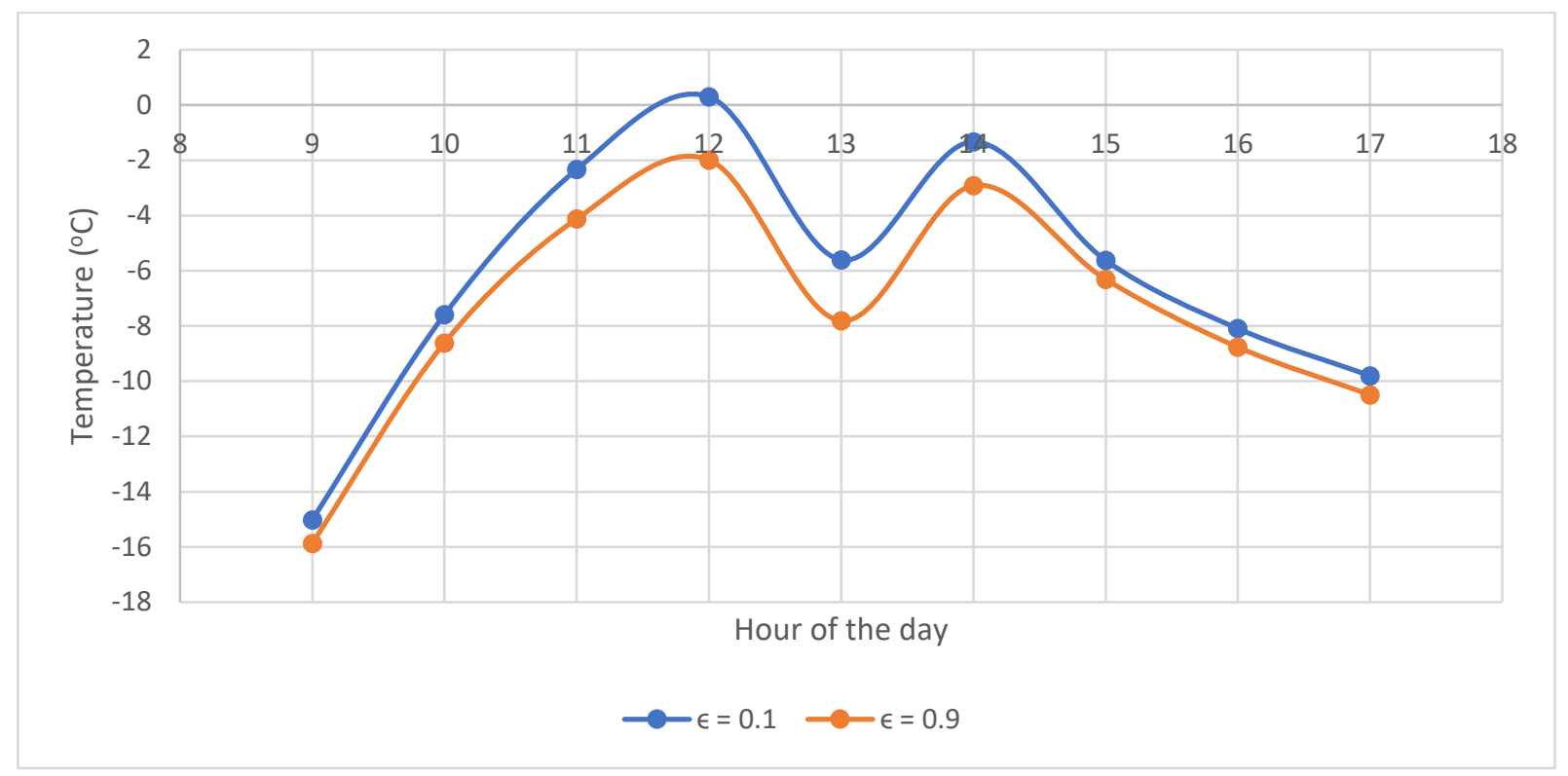

Figure 4-10 Lower surface temperature of the collector for two different emissivities

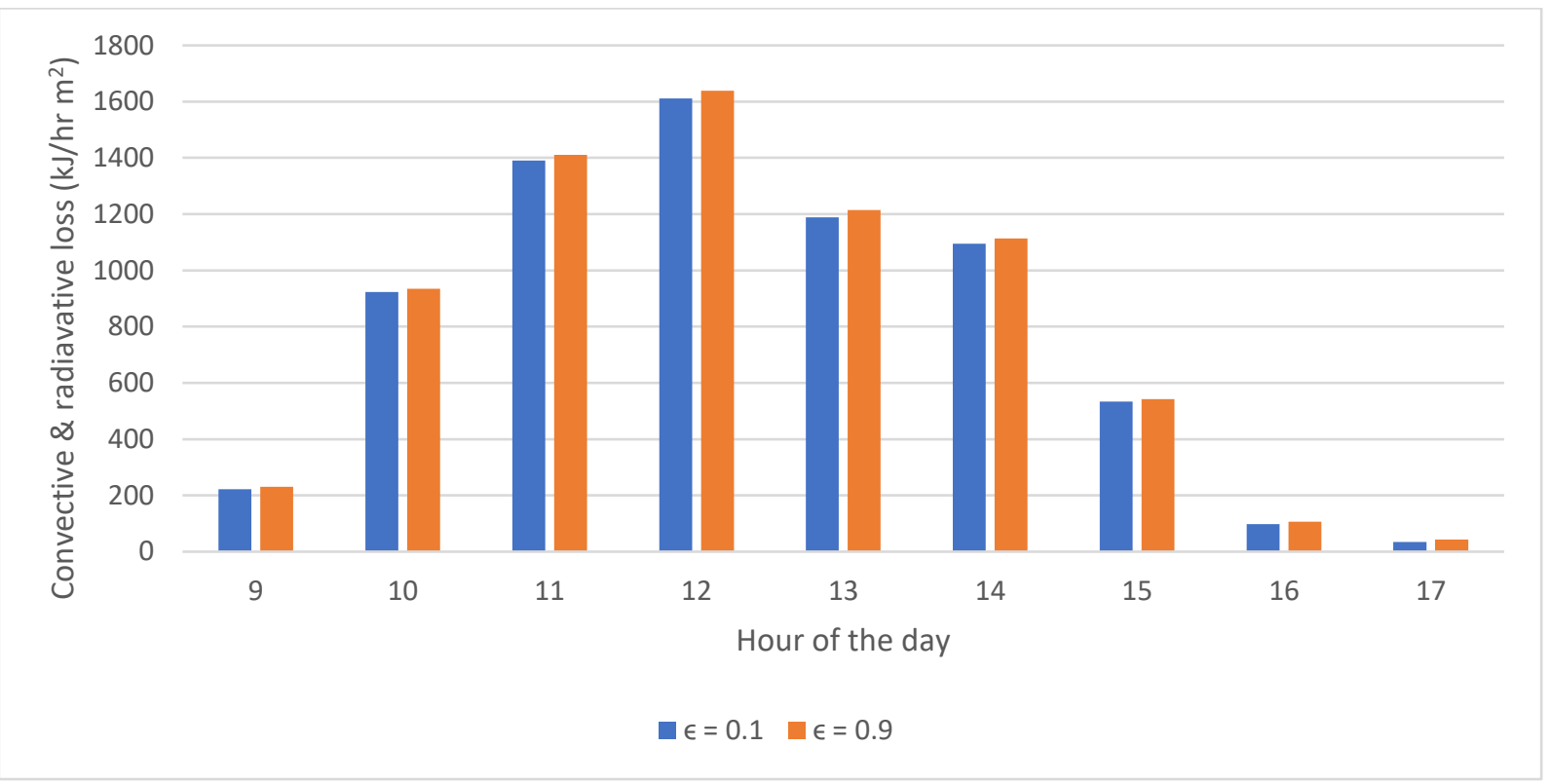

Figure 4-11 Convective and radiative heat loss for the collector for two different emissivities on January $1^{\text {st }}$

\subsubsection{Design option for internal emissivity for TBIPV/T system}

Whether a TBIPV/T collector should have a low or high emissivity depends on the frequency of $T_{u}>T_{l}$. For this weather file of Toronto, Canada, during the heating season, there are 2524 hours when the irradiance was greater than $0 \mathrm{~W} / \mathrm{m}^{2}$ (5592 hours total defines the heating 
season). The results from Figure 4-2 show that using a high emissivity value (0.9) improves the performance of collectors A1 - A3. Table 4-3 shows that for A1 there are 1689 hours or $67 \%$ of the hours with sunlight, where $T_{u}>T_{l}$ and thus using a high emissivity would enhance the thermal generation for these hours. However, for A2 and A3, $T_{u}>T_{l}$ for only 983 hours and 864 hours, respectively, which is less than $50 \%$ of the time with sunlight. This suggests that the time when $T_{u}>T_{l}$ (e.g., noon) occurs is also an important factor, in addition to the frequency. During the day when the irradiance is high, the thermal energy generated by the collectors at those hours would compensate for the reduced thermal gain at the morning and late afternoon hours (because the irradiance is low and the difference would have been small). therefore, for the heating season, the thermal energy generated by A2 and A3 improves with a high internal emissivity.

\section{Table 4-3 Frequency of when the upper surface was warmer than the lower surface for each collector in the row (for internal emissivities of 0.1)}

\begin{tabular}{|c|c|}
\hline Collector & No. of hours \\
\hline A1 & 1689 \\
\hline A2 & 983 \\
\hline A3 & 864 \\
\hline A4 & 722 \\
\hline A5 & 608 \\
\hline A6 & 494 \\
\hline
\end{tabular}

\subsubsection{Heating season results}

As Figure 4.1 and Table 4.2 depicts, the higher internal emissivity increases thermal and electrical performances, respectively; however, Figure 4-2 also shows, that not all collectors benefited from a higher emissivity. Thus, a simulation to examine which collectors would benefit from a high emissivity was conducted. Seven different row configurations were examined where each row consisted of six collectors. In the first row configuration, all the collectors had internal emissivities of 0.1 ; in the second row configuration, the first collector (A1) was equipped with internal emissivities of 0.9, while collectors A2-A6 remain unchanged (with internal emissivities of 0.1); in the third row, A1 and A2 were equipped with internal emissivities of 0.9, and A3-A6 were unchanged with internal emissivities of 0.1 . etc. The final configuration contained all six collectors with internal emissivities of 0.9. A summary of these configurations is presented in Table 4-4. Table 4-5 reports the heating season thermal energy generated for seven different row 
configurations. The heating season's electrical generation are excluded because the changes are insignificant; accuracy of the model is unlikely able to accurately estimate electrical generations on the order of $0.1 \mathrm{kWh}$ over a heating season.

Table 4-4 Row configuration with different collectors with different emissivity values

\begin{tabular}{|c|c|}
\hline Collectors with $\epsilon_{c}=0.9$ & Collectors with $\epsilon_{c}=0.1$ \\
\hline N/A & A1-A6 \\
\hline A1 & A2-A6 \\
\hline A1-A2 & A3-A6 \\
\hline A1-A3 & A4-A6 \\
\hline A1-A4 & A5-A6 \\
\hline A1-A5 & A6 \\
\hline A1-A6 & N/A \\
\hline
\end{tabular}

Table 4-5 Heating season thermal energy generated for incremental change in collectors with high internal emissivities changed to 0.9 .

\begin{tabular}{|c|c|c|}
\hline$\epsilon_{c}=0.9$ & $\epsilon_{c}=0.1$ & Thermal energy $(\mathrm{kWh})$ \\
\hline $\mathrm{N} / \mathrm{A}$ & $\mathrm{A} 1-\mathrm{A} 6$ & 1140.8 \\
\hline $\mathrm{A} 1$ & $\mathrm{~A} 2-\mathrm{A} 6$ & 1155.2 \\
\hline $\mathrm{A} 1-\mathrm{A} 2$ & $\mathrm{~A} 3-\mathrm{A} 6$ & 1159.3 \\
\hline $\mathrm{A} 1-\mathrm{A} 3$ & $\mathrm{~A} 4-\mathrm{A} 6$ & 1161.1 \\
\hline $\mathrm{A} 1-\mathrm{A} 4$ & $\mathrm{~A} 5 \mathrm{~A} 6$ & 1160.5 \\
\hline $\mathrm{A} 1-\mathrm{A} 5$ & $\mathrm{~A} 6$ & 1157.3 \\
\hline $\mathrm{A} 1-\mathrm{A} 6$ & $\mathrm{~N} / \mathrm{A}$ & 1151.6 \\
\hline
\end{tabular}

The results show an optimal configuration for adjusting the internal emissivities for the TBIPV/T systems considered. For the collectors under study and the number of collectors (six), the optimal configuration is to change the first three collectors to a high internal emissivities and to leave the other three with low internal emissivities. 


\subsubsection{TBIPV/T-Cover emissivity}

The cover emissivity refers to the emissivity of the glass cover's surface that is exposed to the wind and sky. For this study, the parameters of the TBIPV/T collector used for simulations are shown in Table 4-6.

Table 4-6 TBIPV/T collector parameters for cover emissivity analysis

\begin{tabular}{|c|c|}
\hline$K$ & $4 \mathrm{~m}^{-1}$ \\
\hline$l_{g}$ & $0.0032 \mathrm{~m}$ \\
\hline$n$ & 1.526 \\
\hline$k_{g}$ & $3.78 \mathrm{~kJ} / \mathrm{hr} \cdot \mathrm{m} \cdot \mathrm{K}$ \\
\hline$R_{p v-u}$ & $0.000847 \mathrm{~kJ} / \mathrm{hr} \cdot \mathrm{m}^{2} \cdot \mathrm{K}$ \\
\hline$w$ & $1.6 \mathrm{~m}$ \\
\hline$L$ & $1 \mathrm{~m}$ \\
\hline$d$ & $0.0635 \mathrm{~m}$ \\
\hline$R_{\text {ins }}$ & $1.9562 \mathrm{hr} \cdot \mathrm{m}^{2} \cdot \mathrm{K} / \mathrm{kJ}$ \\
\hline$\epsilon_{u}$ & 0.9 \\
\hline$\epsilon_{l}$ & 0.9 \\
\hline$P F$ & 0.9 \\
\hline$\alpha_{l}$ & 0.9 \\
\hline
\end{tabular}

\subsubsection{Heating season results for a single collector}

Heating season simulations were conducted for a single collector for three different cover emissivities (the inlet temperature was kept constant). The thermal and electrical energy generated for the heating season is shown in Figure 4-12 and 4-13, respectively. As the emissivity increases, total thermal energy generation increases as well; concurrently, however, the total electrical energy generated decreases. Decreasing the cover emissivity from 0.9 to 0.3 results in the thermal energy to increase by $47 \mathrm{kWh}$ (29\% increase) and the electrical energy to decrease by $3 \mathrm{kWh}(1.8 \%$ decrease). 


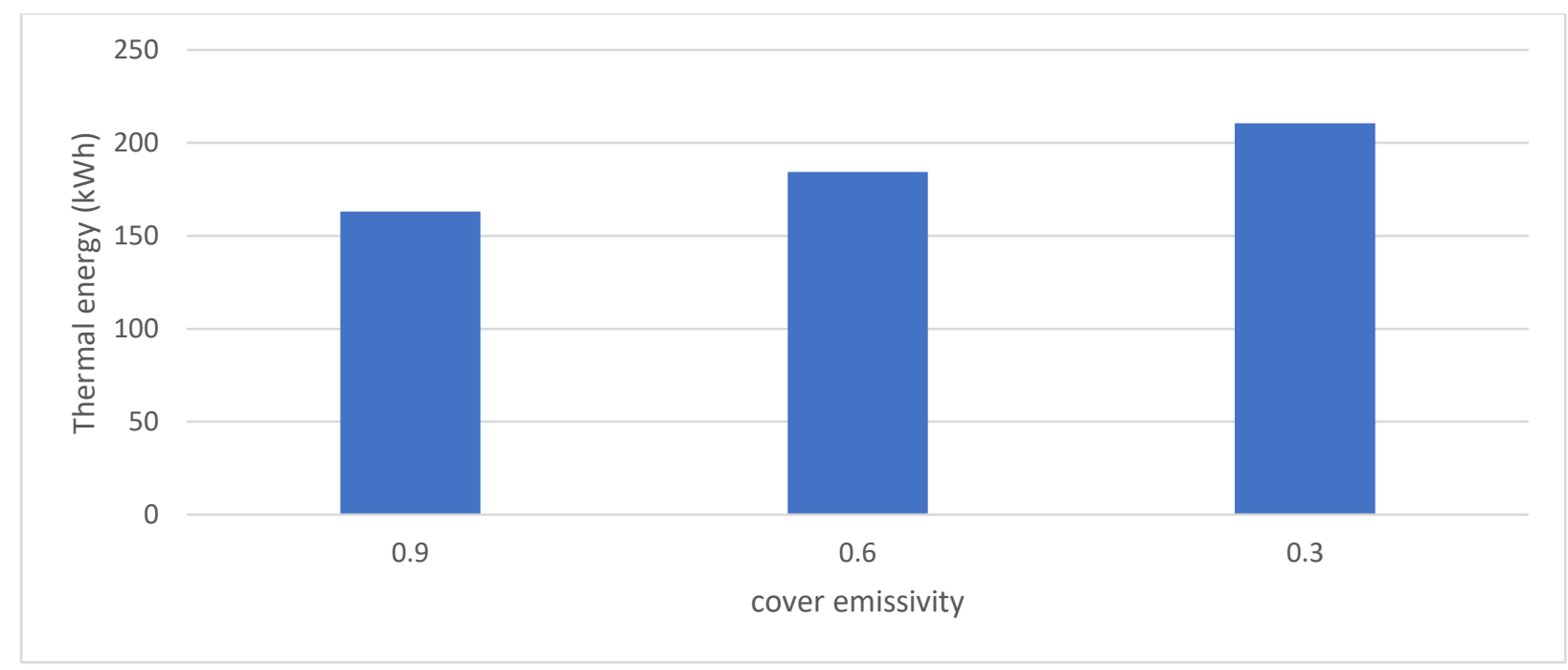

Figure 4-12 Heating season thermal energy generated by a collector for various cover emissivities

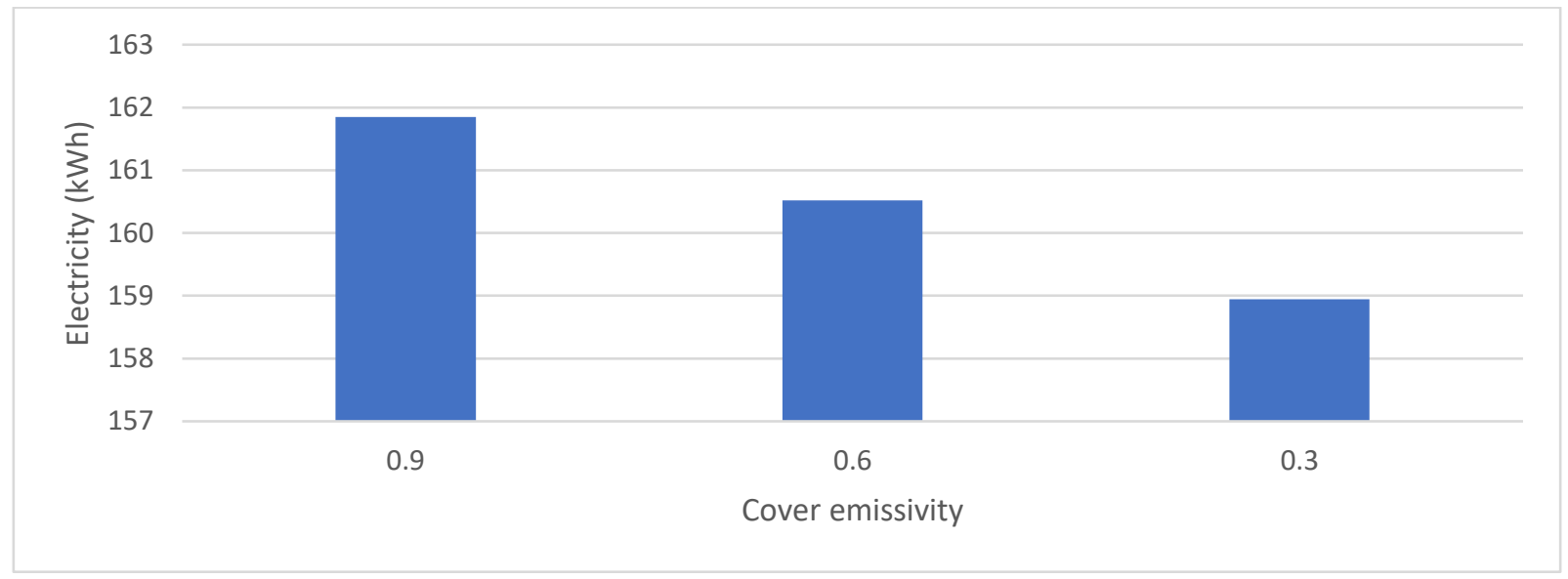

Figure 4-13 Heating season electrical energy generated by a collector for various cover emissivities

\subsubsection{Detailed heat transfer analysis of a collector on January $1^{\text {st }}$}

As the cover emissivity is reduced, the longwave radiation between the sky and the cover diminishes. An analysis of a single collector (where all conditions were constant including inlet temperature except for the change in cover emissivity) shows that the reduced sky radiation results in less radiative losses but higher convective losses; however, overall losses to the environment diminishes. The convective loss increases because a low cover increases the cover temperature. This change is shown Figure 4-14 for the collector with cover emissivities of 0.6 and 0.3 on January $1^{\text {st }}$ at $1 \mathrm{pm}$. Although the total losses are comparably similar, the collector with 0.3 cover emissivity does lose less heat to the environment. 


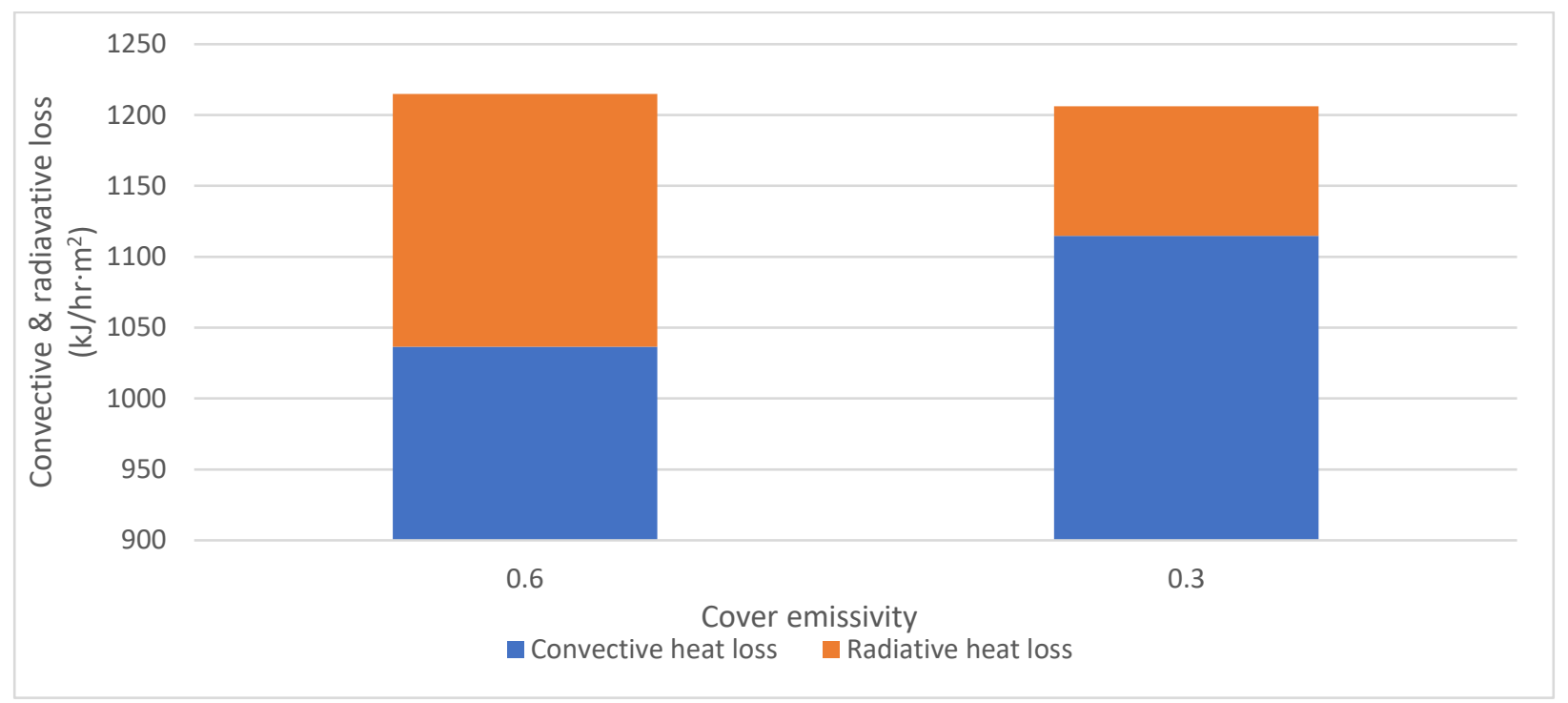

Figure 4-14 Total, convective, and radiative losses for a collector on January $1^{\text {st }}$ at 1 pm

Since the incident solar radiation for the two collectors at the same hours are the same and the collector with 0.3 cover emissivity loses less heat to the environment, it ends up transferring more of the net absorbed radiation to the upper surface. On January $1^{\text {st }}$ at $1 \mathrm{pm}$, the heat flux from the PV layer to the upper surface is shown in Figure 4-15, where the flux for the collector with 0.3 cover emissivity is greater than the same collector with 0.6 cover emissivity.

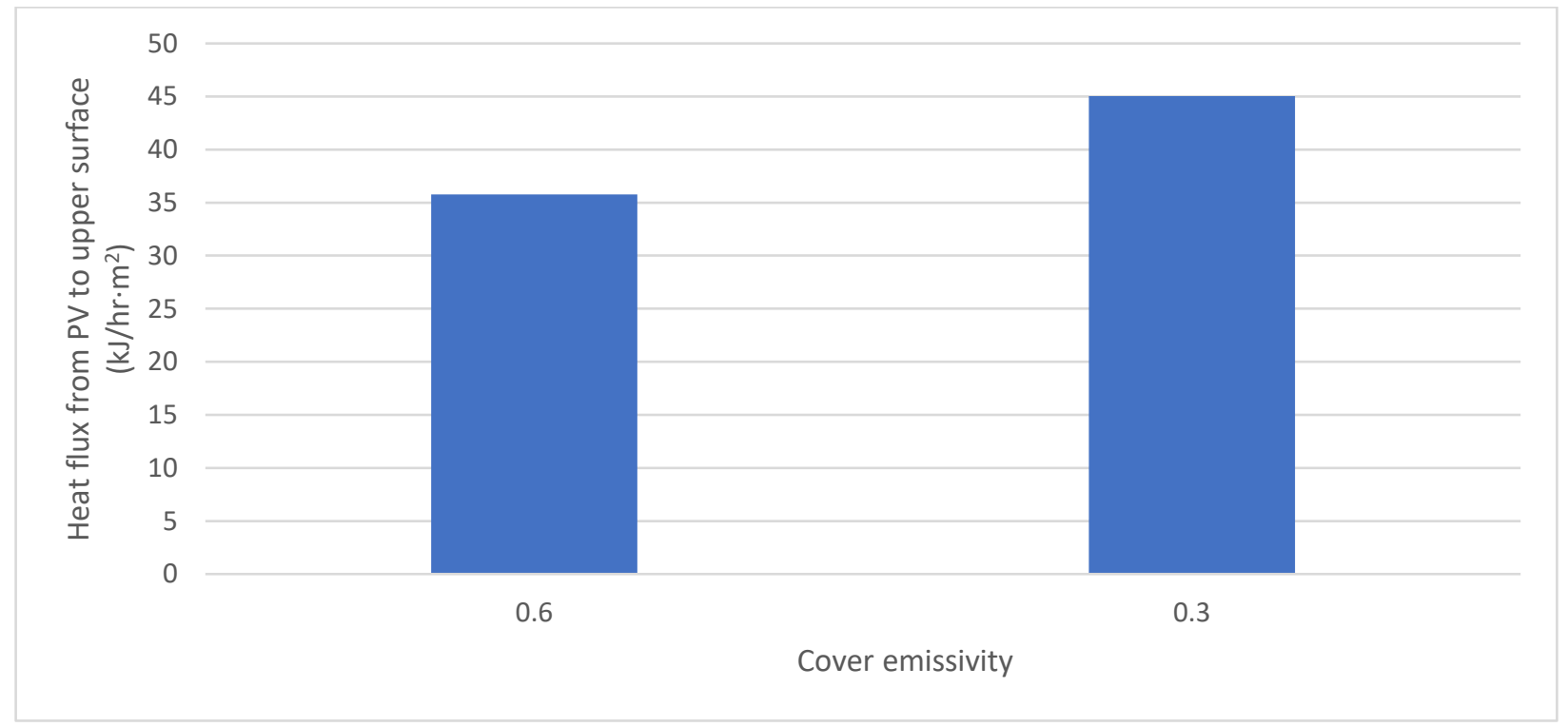

Figure 4-15 Heat flux from the PV layer to the upper surface for the collector on January $1^{\text {st }}$ at 1 pm 
It is interesting to note that in this case (for both cover emissivity of 0.6 and 0.3 ), $T_{u}<T_{l}$, if reducing the cover emissivity reduces thermal losses (hence PV temperature increases and electricity dropped by approximately $1 \mathrm{Wh}$ ), it would be convenient to increase the internal emissivity so that the extra thermal conducted to the upper surface can be further transferred to the lower surface more easily. However, that is not possible since after reducing the cover emissivity, the upper surface temperature remains colder (i.e., it become warmer but not warmer than the lower surface temperature) and increasing the internal emissivities will not help improve overall performance.

\subsubsection{Heating season results}

For the row configurations in Table 4-7, a heating season analysis was conducted for each configuration.

Table 4-7 Row configuration with different collectors with different cover emissivity values

\begin{tabular}{|c|c|}
\hline Collectors with $\epsilon_{c}=0.1$ & Collectors with $\epsilon_{c}=0.9$ \\
\hline N/A & A1-A6 \\
\hline A1 & A2-A6 \\
\hline A1-A2 & A3-A6 \\
\hline A1-A3 & A4-A6 \\
\hline A1-A4 & A5-A6 \\
\hline A1-A5 & A6 \\
\hline A1-A6 & N/A \\
\hline
\end{tabular}

These results are shown in Figure 4-16 for thermal energy and Figure 4-17 for electrical energy generated. The results show that the optimal configuration for the collectors is not to combine collectors with different cover emissivity. However, by combining some collectors with a low cover emissivity and others with high cover emissivity, a balanced trade-off between thermal and electrical performance for a TBIPV/T system is obtained. 


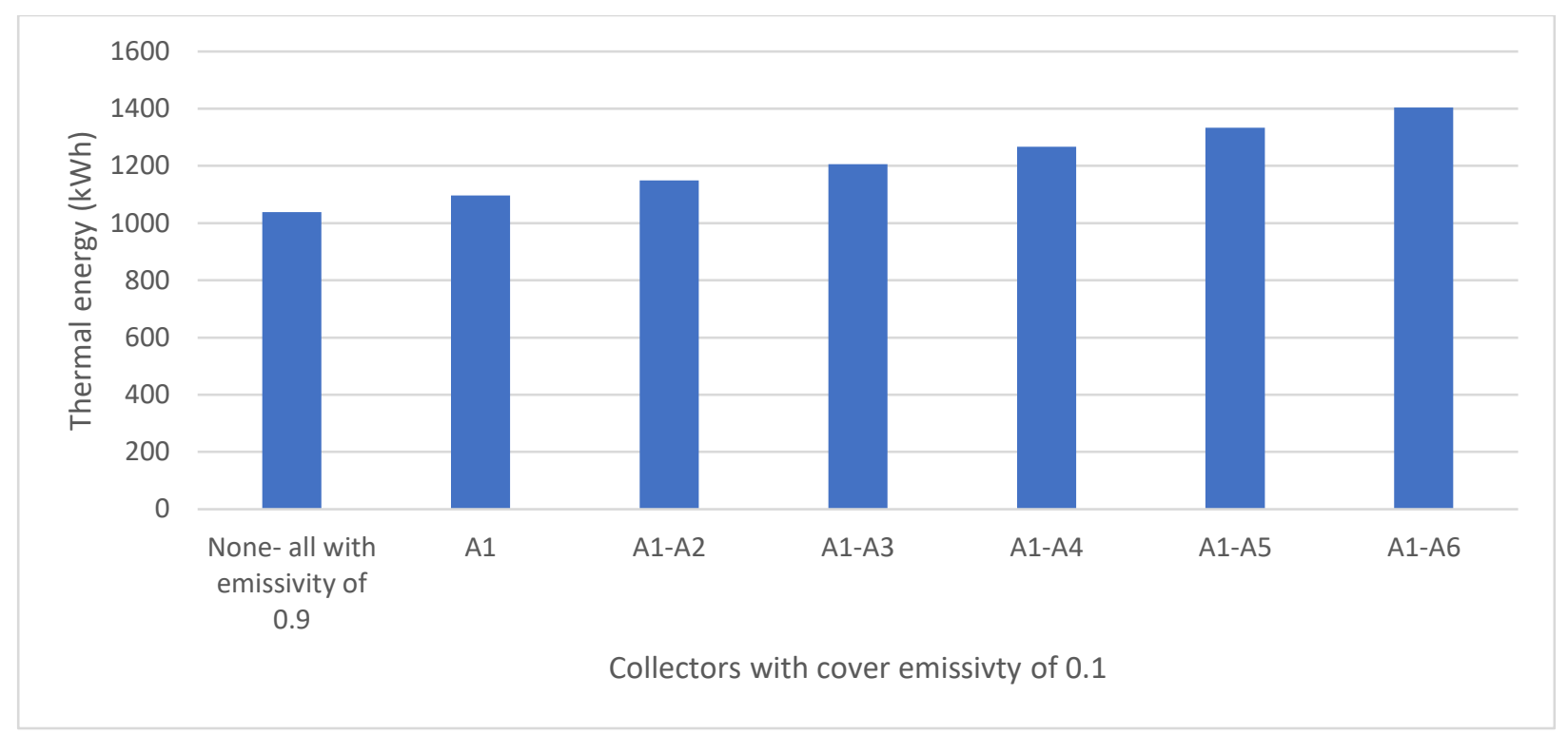

Figure 4-16 Heating season thermal energy generated for different row configuration

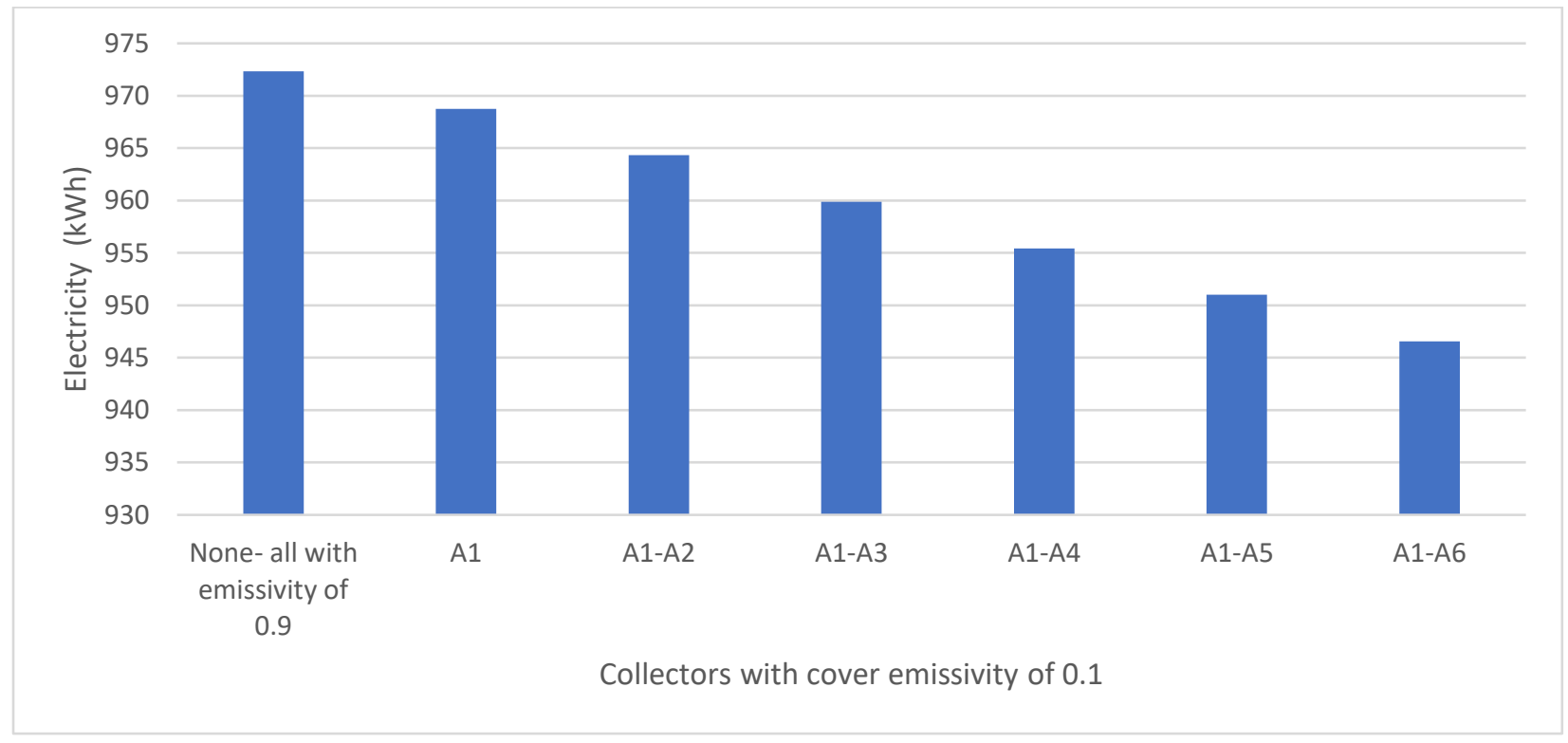

Figure 4-17 Heating season electrical energy generated for different row configuration

A heating season simulation where the cover emissivity of each collector was changed in unison (e.g., all collector shared the same cover emissivity as its value was varied) was conducted and the thermal and electrical energy generated is presented in Figure 4-18 and Figure 4-19. As the cover emissivity reduces, the environmental losses diminish, the collector retains more of the net absorbed solar energy and thermal energy generation increases. On the other hand, as more 
heat is retained and results in an increase in the PV temperature, the electrical energy decreases. Although electricity has a higher value exergy-wise, lowering the cover emissivity from 0.9 to 0.1 , over the heating season, increases the thermal energy by $367 \mathrm{kWh}$, while electrical generation decreases by $26 \mathrm{kWh}$, a ratio of approximately 14:1. Depending on the location of the system and the needs, reducing cover emissivity may be a viable design option. A case where this was applied is presented in Section 4.2.2.

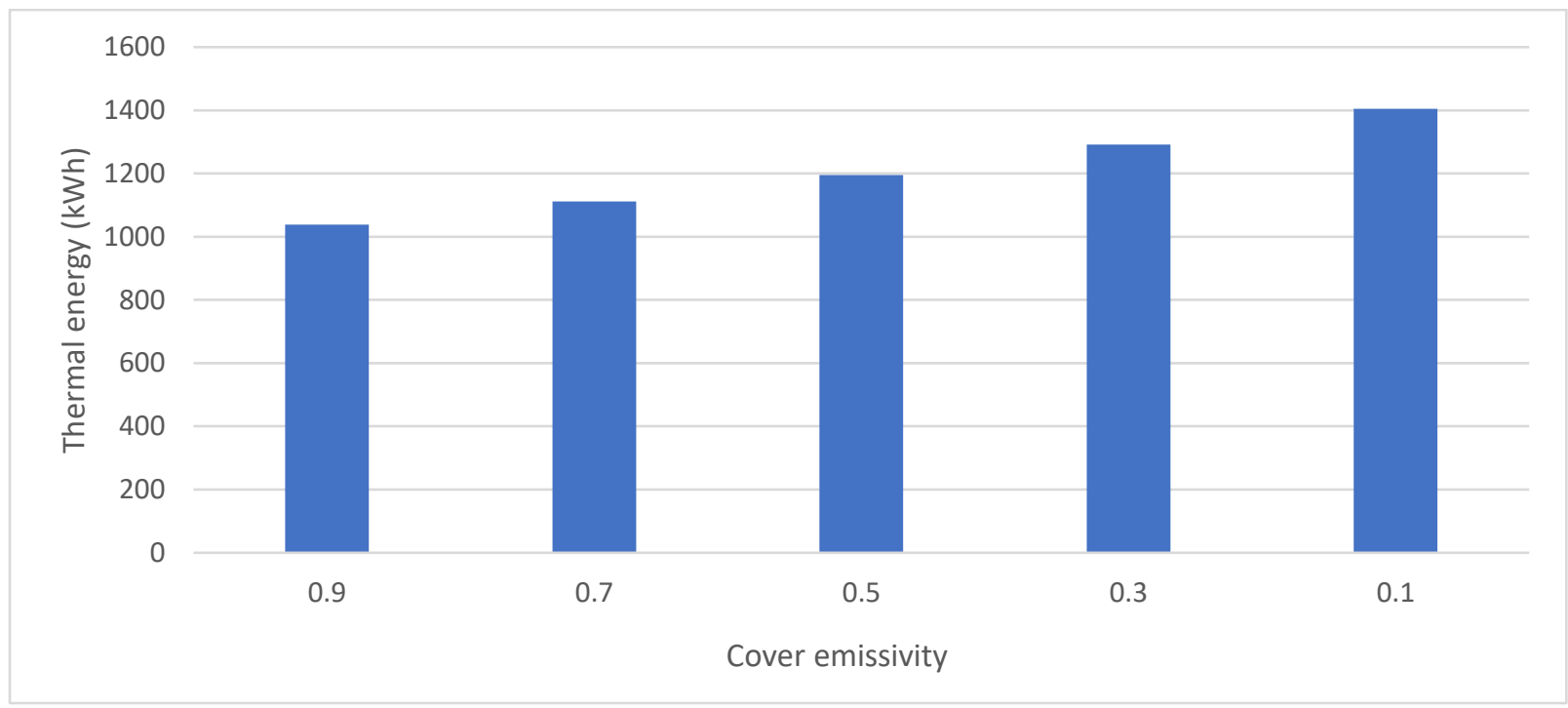

Figure 4-18 Heating season thermal energy generated by one row of TBIPV/T collectors where each collector had the same cover emissivity

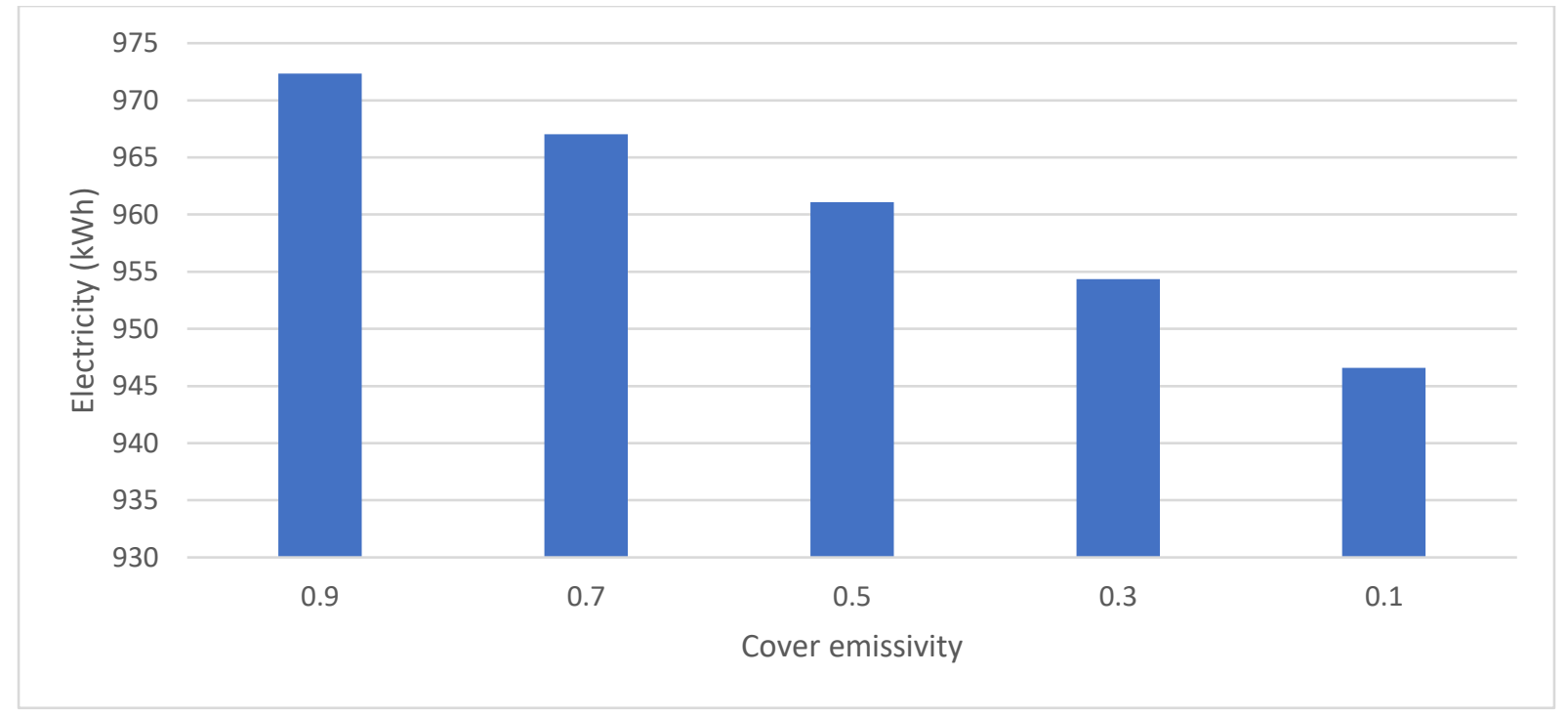

Figure 4-19 Heating season electrical energy generated by one row of TBIPV/T collectors where each collector had the same cover emissivity 


\subsubsection{BISAH-Internal channel emissivity}

In this section, the effect of the internal channel emissivities and the cover emissivity parameters on a BISAH system was studied and the results are presented. The parameters of the BISAH collector used for the analysis are shown in Table 4-8.

Table 4-8 BISAH collector parameters for internal channel emissivity analysis

\begin{tabular}{|c|c|}
\hline$K$ & $4 \mathrm{~m}^{-1}$ \\
\hline$l_{g}$ & $0.0032 \mathrm{~m}$ \\
\hline$n$ & 1.526 \\
\hline$k_{g}$ & $3.78 \mathrm{~kJ} / \mathrm{hr} \cdot \mathrm{m} \cdot \mathrm{K}$ \\
\hline$w$ & $1.6 \mathrm{~m}$ \\
\hline$L$ & $1 \mathrm{~m}$ \\
\hline$d$ & $0.0635 \mathrm{~m}$ \\
\hline$R_{\text {ins }}$ & $1.9562 \mathrm{hr} \cdot \mathrm{m}^{2} \cdot \mathrm{K} / \mathrm{kJ}$ \\
\hline$\epsilon_{c}$ & 0.6 \\
\hline$P F$ & 0.9 \\
\hline$\alpha_{l}$ & 0.9 \\
\hline
\end{tabular}

\subsubsection{Heating season results for a single collector}

The effect of the internal channel emissivities on a single BISAH collector was examined in a heating season simulation using various emissivity values. In Figure 4-20, the thermal energy generated by a single collector over the heating season are presented. By decreasing the internal emissivities from 0.9 to 0.3 , increases the thermal energy generation by $227 \mathrm{kWh}$ over the heating season. Part of this increase is due to an increased of the number of hours when the collector with internal emissivities of 0.3 could generate thermal energy while the collector with internal emissivities of 0.9 could not. 


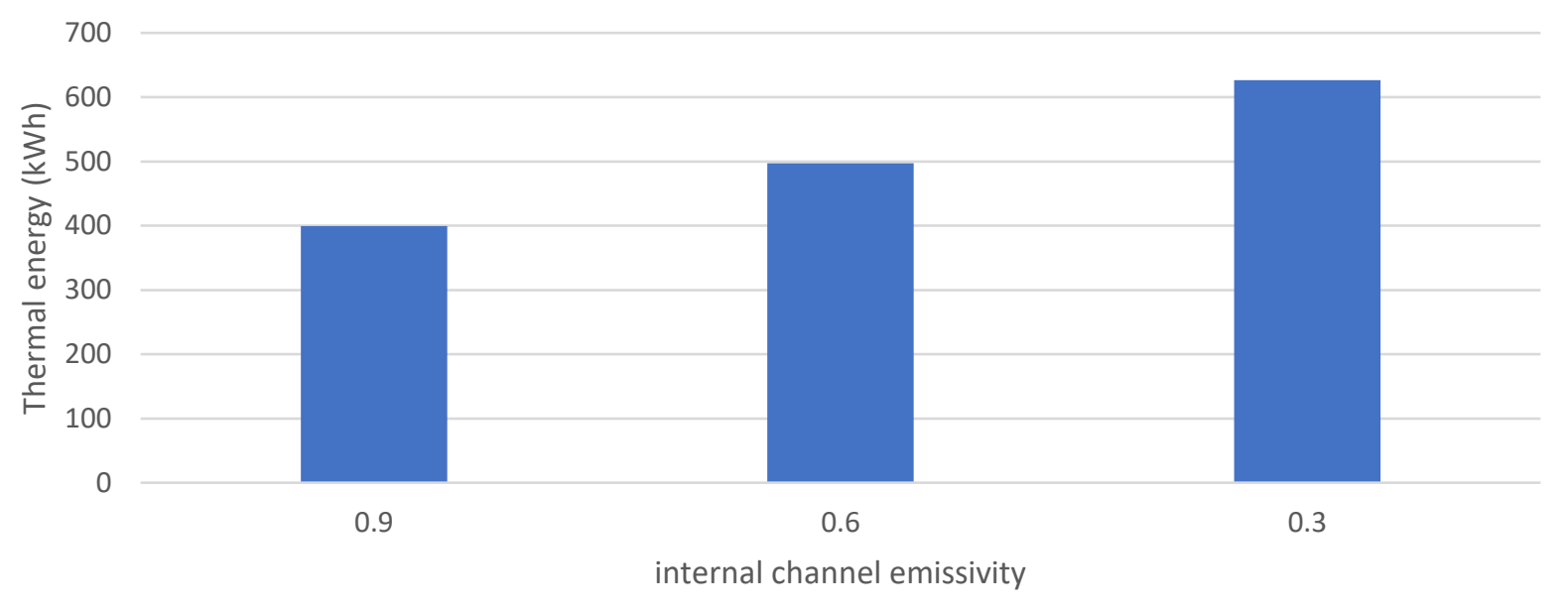

Figure 4-20 Heating season thermal energy generated by a collector for various internal channel emissivities

\subsubsection{Detailed heat transfer analysis of a collector on January $1^{\text {st }}$}

In Figure 4-21, the upper and lower temperature of the collector with internal emissivities of 0.9 is presented. For the entire day, the lower surface is warmer. This is because the incident radiation transmitted through the glazing strikes the lower surface. In the BISAH, the upper surface is the back surface of the second glass layer and it does not prevent solar radiation from transmitting through; in addition, it also loses a large amount heat to the front glass surface due to the low resistance of the glazing layer.

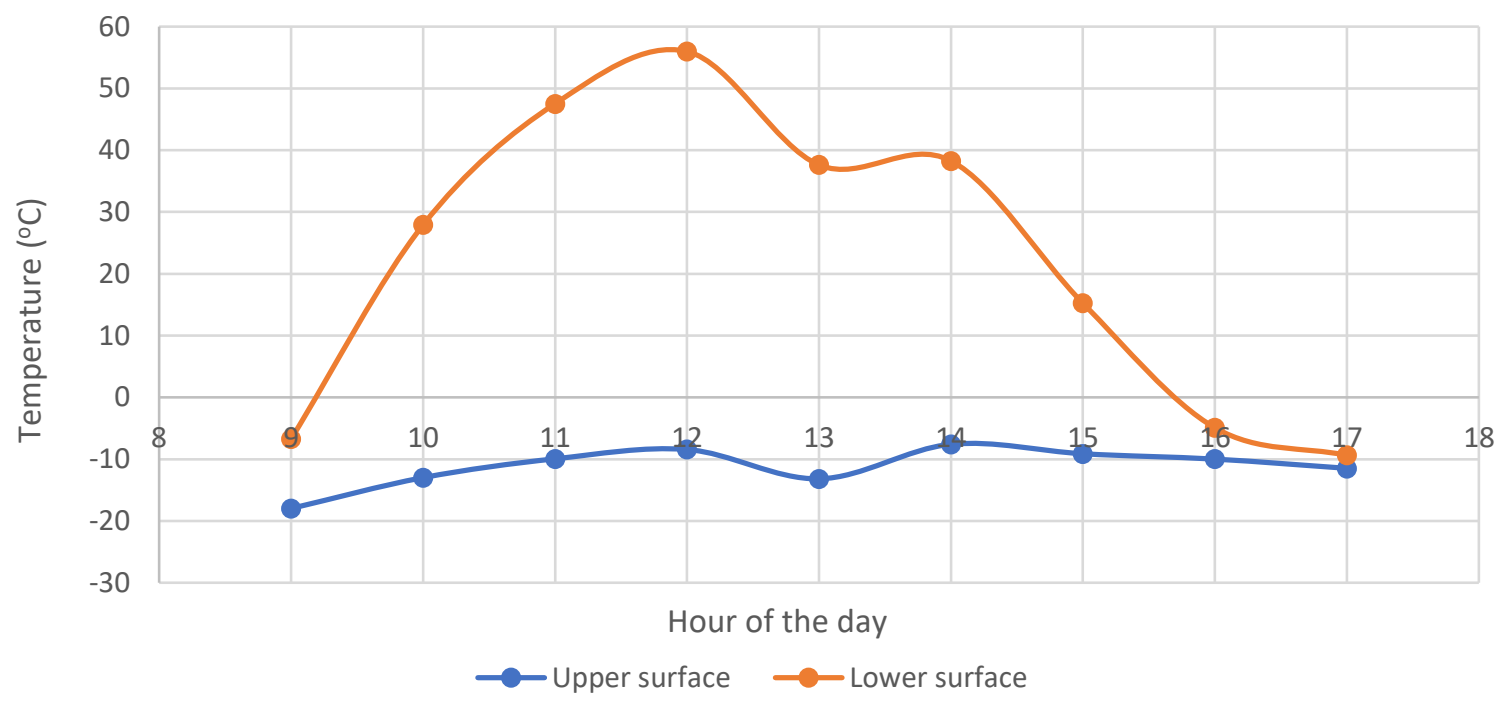

Figure 4-21 Upper and lower surface temperatures for a collector with internal emissivities of 0.9 on January $1^{\text {st }}$ 
The trend of the thermal energy generated by a single BISAH collector for decreasing internal emissivities is similar to the relationship exhibited by TBIPV/T collectors. In Figure 4-21, $T_{u}<T_{l}$ and based on the explanation from Sections 4.1.1.1 and 4.1.1.2, as the internal emissivities decrease, the internal long wave radiation heat transfer from the lower surface to the upper surface also decrease (as shown in Figure 4-22 where the heat flux is reduced by approximately 50\%). This diminishes heat loss to the environment as the upper surface does not end up at an elevated temperature and loses more heat through the low resistance glazing.

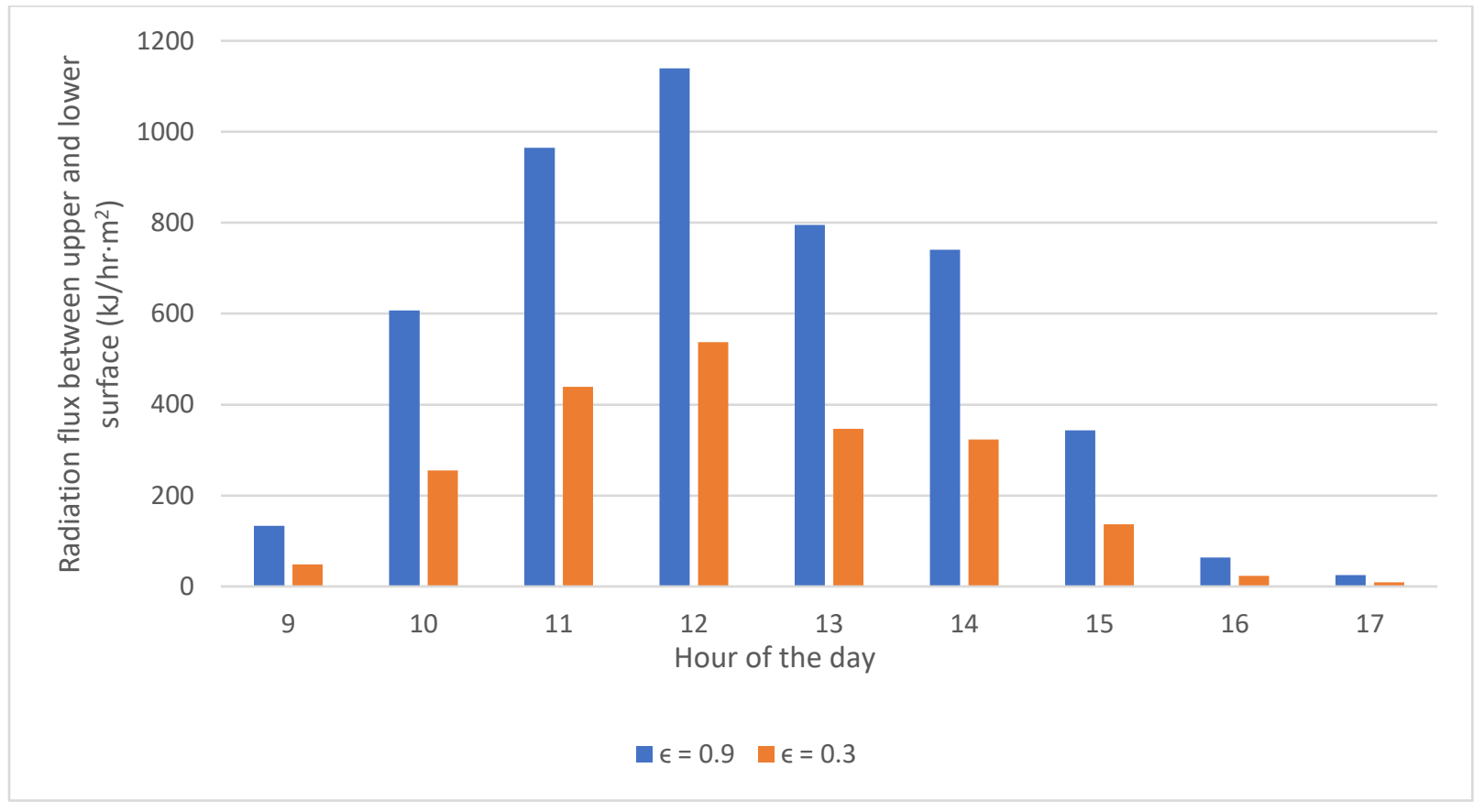

Figure 4-22 Internal longwave radiation heat transfer from the lower surface to the upper surface for the collector on January $1^{\text {st }}$

In the end, this results in a large increase in $T_{l}$ while $T_{u}$ decreases. The magnitude of the increment and decrement is presented in Figures 4-23 (upper surface) and Figure 4-24 (lower surface). The overall thermal energy generated increases because the increase in the magnitude of the lower surface temperature is much greater than the decrease in the upper surface's temperature (maximum approximately $5^{\circ} \mathrm{C}$ ). Furthermore, for BISAH collectors, it is better to have the thermal energy retained at the lower surface. This is because the upper surface is adjacent to a cold boundary condition (environmental wind and apparent sky temperature) with a low resistant layer of glazing in between, while the lower surface is adjacent to the interior zone surface with an 
insulation layer in between. Therefore, at the upper surface, the heat can be more easily conducted away to the cover surface compared to lower surface.

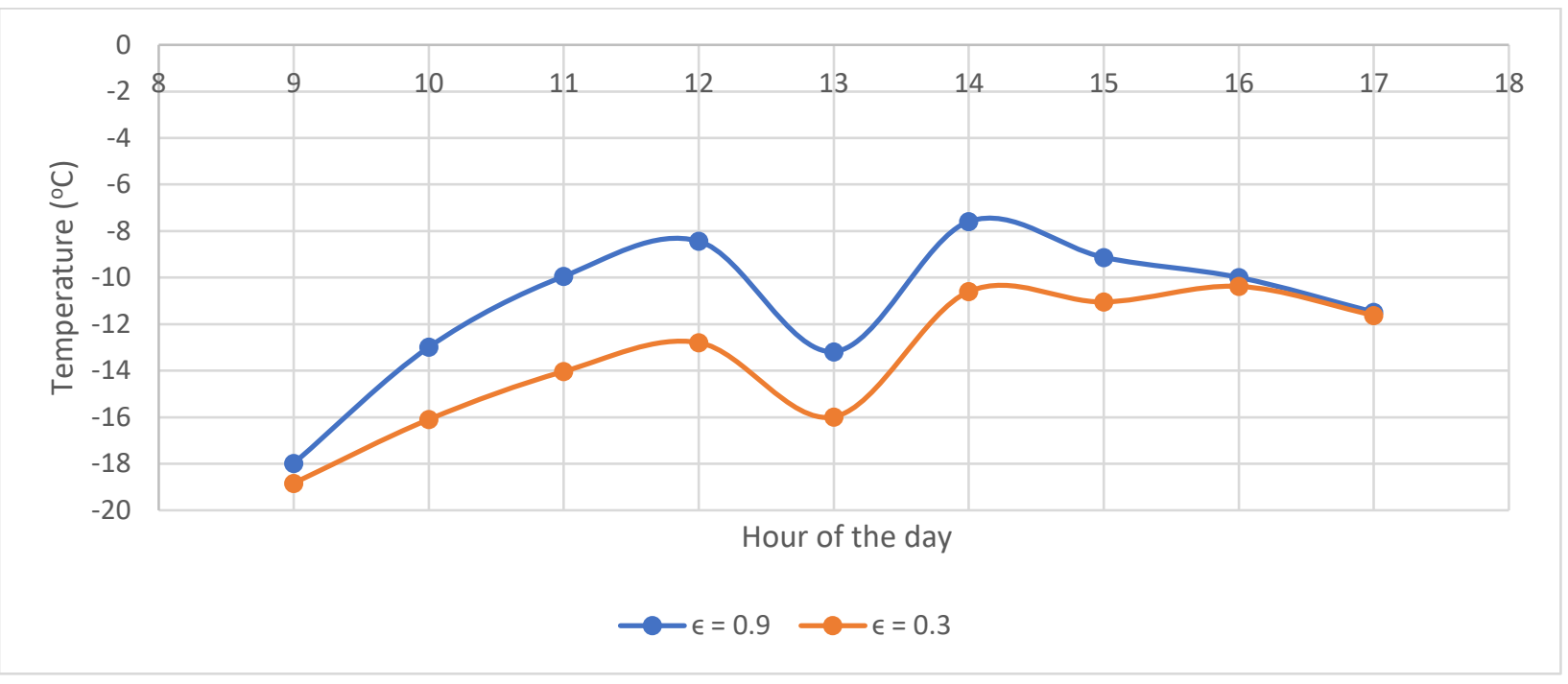

Figure 4-23 Upper surface temperature for the collector for two different internal emissivities on January $1^{\text {st }}$

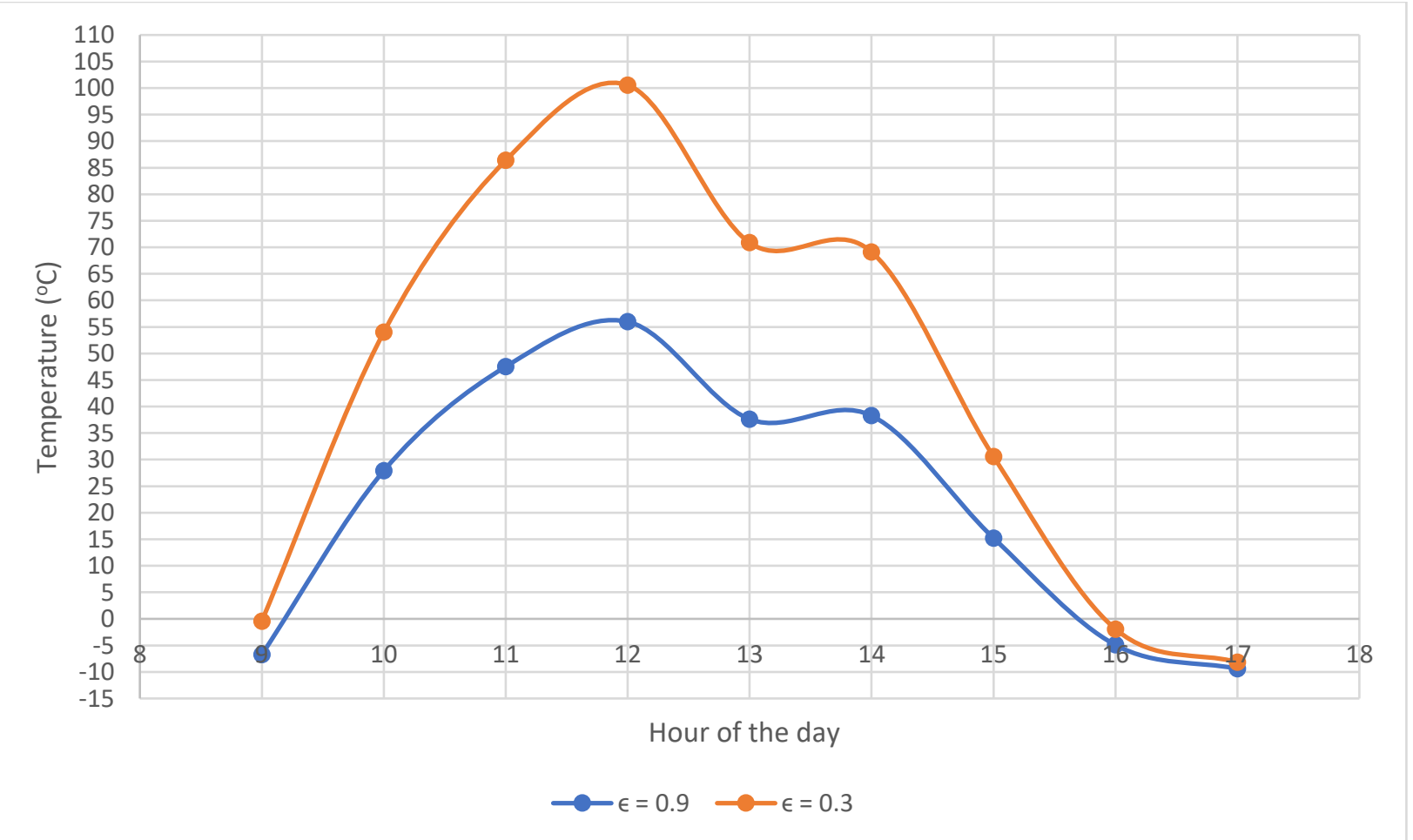

Figure 4-24 Lower surface temperature for the collector for two different internal emissivities on January $1^{\text {st }}$ 
Overall, as less heat is directed to the upper surface, the overall system loses less heat to the environment. This principle is applied in low-e coating for windows; reducing the long wave radiation so it does not escape the room but simultaneously allows low wavelength radiation (solar radiation) through. Reducing the emissivity greatly reduces the losses during the day, as shown in Figure 4-25. However, as the irradiance drops, the energy savings diminishes as the lower surface becomes colder.

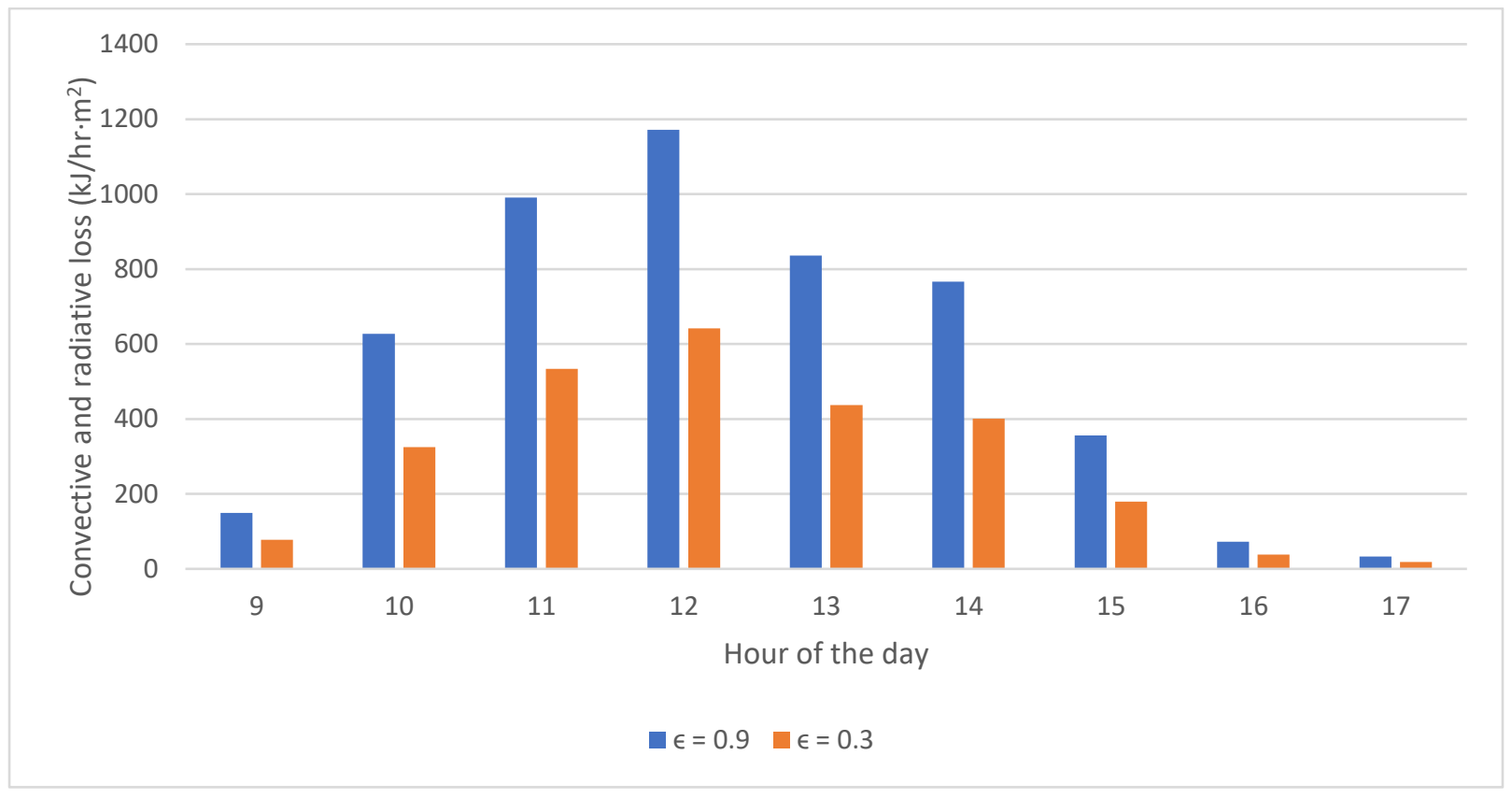

Figure 4-25 Convective and radiative heat loss by the collector for two different internal emissivities on Jan $1^{\text {st }}$

Additionally, heat loss to the zone lowers the heating load, which increases the level of savings introduced by the system. Figure 4-26 depicts the heat flux from the lower surface to the interior zone surface (heat transfer to the zone is positive, heat transfer from the zone is negative) and it can be seen that by lowering the internal emissivity the heat transfer from the warmer lower surface to the zone almost doubled for most hours. Furthermore, at $3 \mathrm{pm}$ when the zone is losing heat to the lower surface (for an internal emissivity of 0.9 ), by reducing the internal emissivity to 0.3 , the heat transfer reverses in direction and the surface contributes heat to the zone instead 


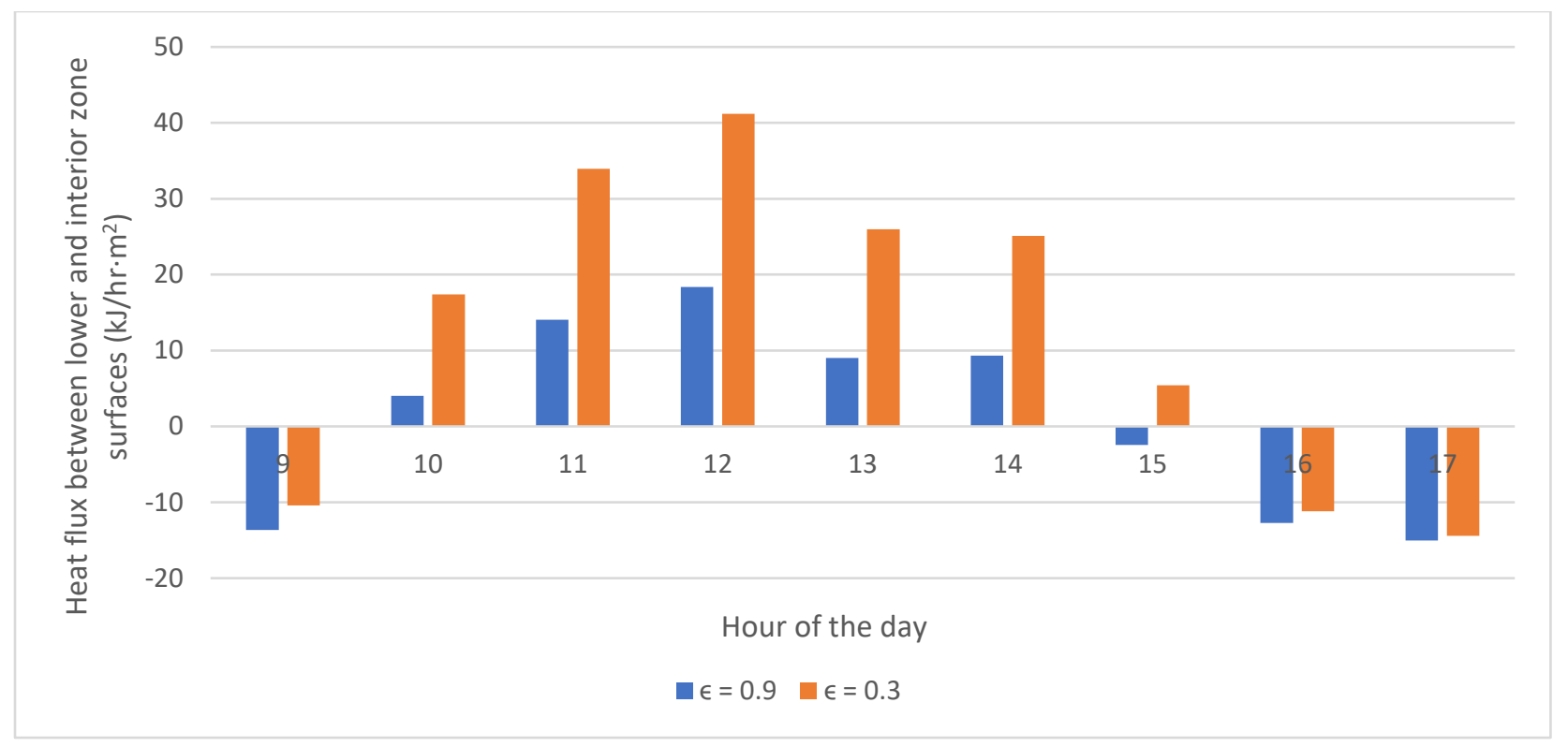

Figure 4-26 Heating flux from the lower surface to the interior zone surface for the collector for two different internal emissivities

\subsubsection{Heating season results}

Unlike the case for TBIPV/T, in the BISAH system, the lower surface is warmer than the upper surface for almost all hours during the day, regardless of collector position; thus, there was no need to do an analysis of rows that contained different collectors with different internal emissivities such as the one conducted in Section 4.1.1.4. A heating season long simulation of an entire row of BISAH collectors for two emissivities (where each collector shares the same internal emissivities as the emissivities' value were varied) was conducted and the results are presented in Figure 4-27. Unlike the trends from Figure 4-2, where a change in internal emissivity results in an increase in performance for some but a decrease in others, the trend is consistent throughout the row; there is not an optimal configuration in terms of performance by combining collectors with different internal emissivities. 


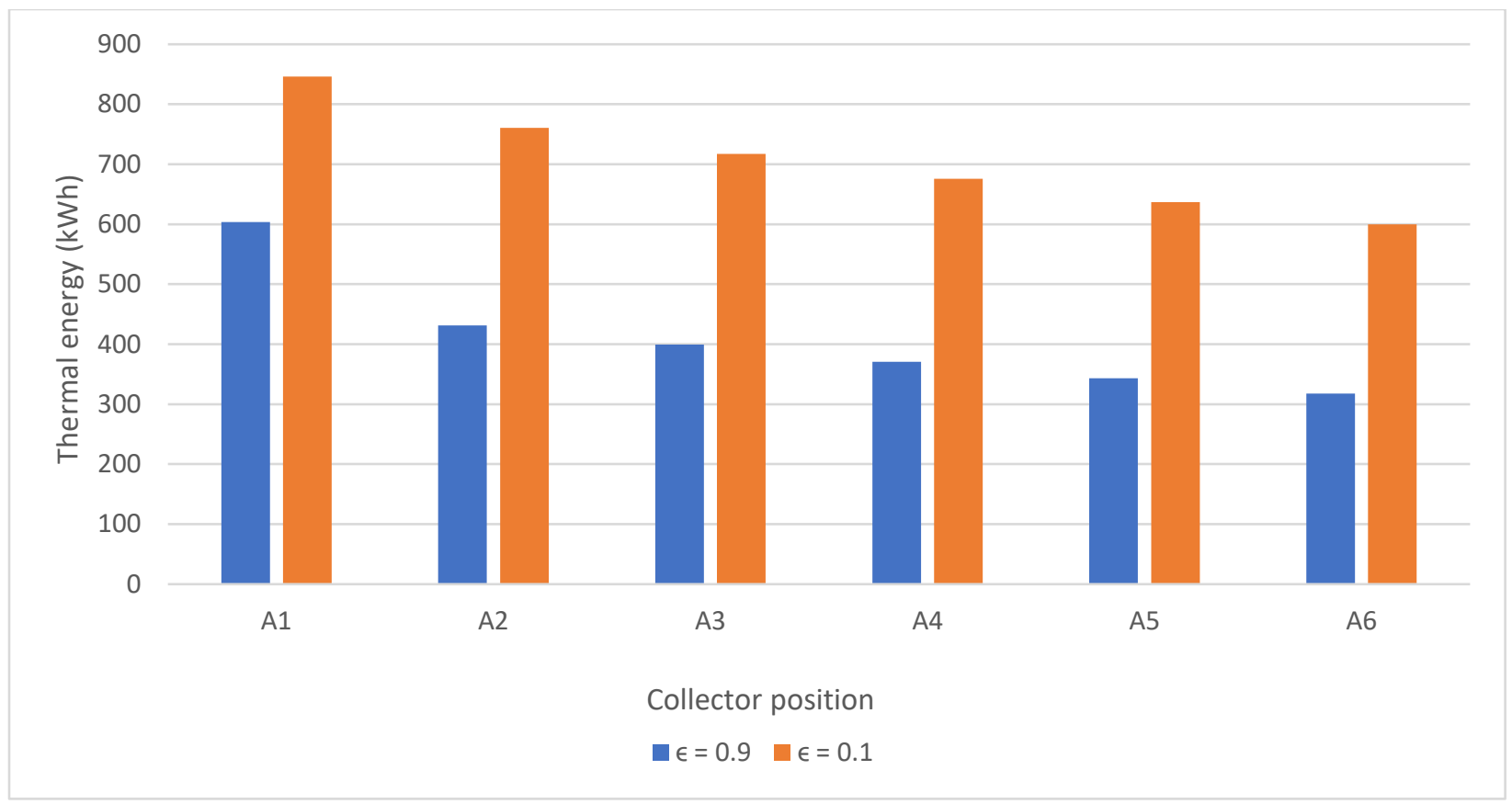

Figure 4-27 Heating season thermal energy generated for each collector based on position

The heating season thermal energy generated by one row of collectors (all with the same internal emissivities) is presented for various emissivities in Figure 4-28. The results show that decreasing the internal emissivities from 0.9 to 0.1 increases the thermal energy gained by 1771 $\mathrm{kWh}$ or a $72 \%$ increase in performance.

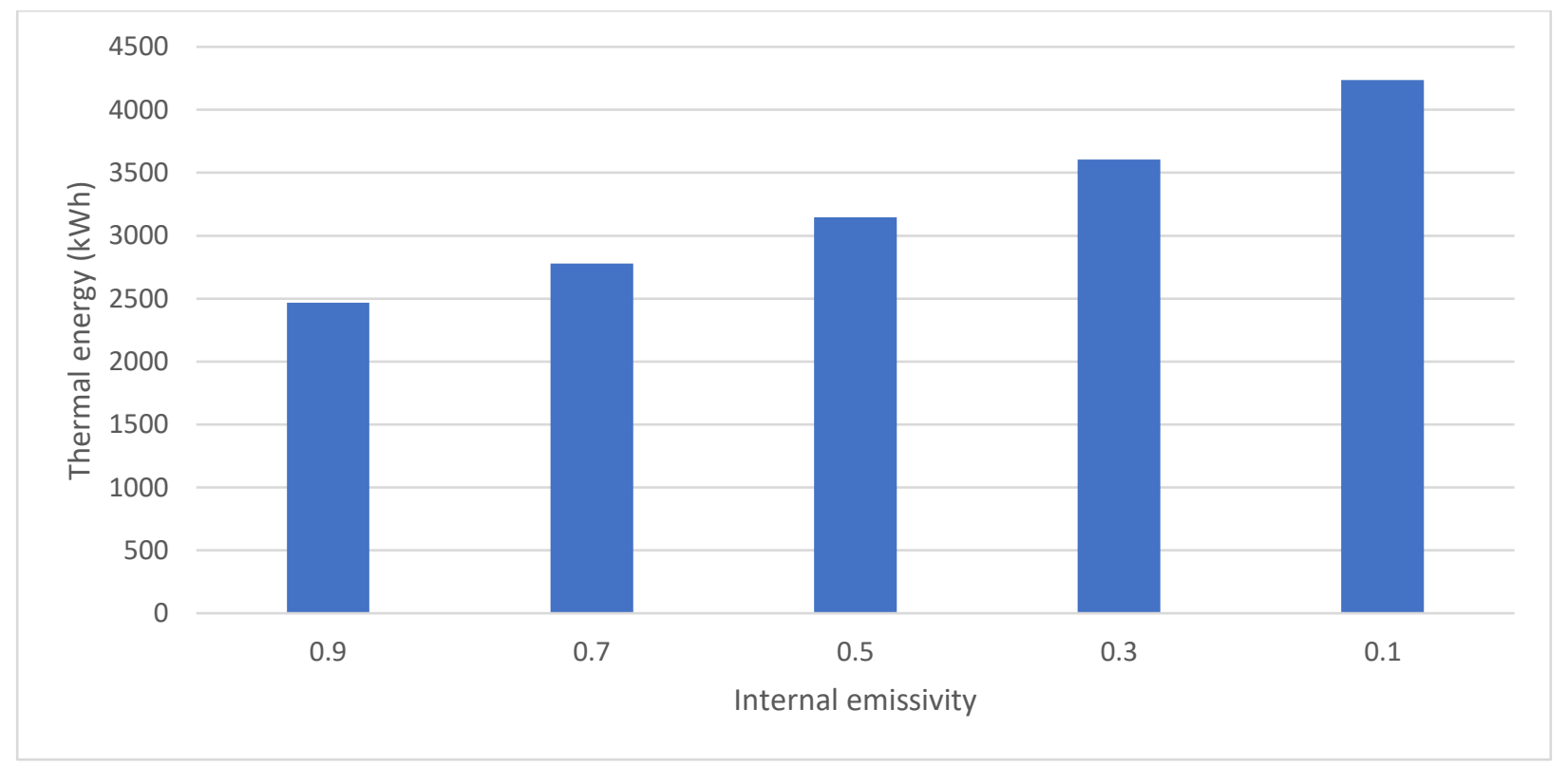

Figure 4-28 Heating season thermal energy generated by one row for various internal emissivities 


\subsubsection{BISAH-Cover emissivity}

For this study, the parameters of the BISAH system used for simulation are shown in Table $4-9$.

Table 4-9 BISAH parameters for cover emissivity analysis

\begin{tabular}{|c|c|}
\hline$K$ & $4 \mathrm{~m}^{-1}$ \\
\hline$l_{g}$ & $0.0032 \mathrm{~m}$ \\
\hline$n$ & 1.526 \\
\hline$k_{g}$ & $3.78 \mathrm{~kJ} / \mathrm{hr} \cdot \mathrm{m} \cdot \mathrm{K}$ \\
\hline$w$ & $1.6 \mathrm{~m}$ \\
\hline$L$ & $1 \mathrm{~m}$ \\
\hline$d$ & $0.0635 \mathrm{~m}$ \\
\hline$R_{\text {ins }}$ & $1.9562 \mathrm{hr} \cdot \mathrm{m}^{2} \cdot \mathrm{K} / \mathrm{kJ}$ \\
\hline$\epsilon_{u}$ & 0.9 \\
\hline$\epsilon_{l}$ & 0.9 \\
\hline$P F$ & 0.9 \\
\hline$\alpha_{l}$ & 0.9 \\
\hline
\end{tabular}

\subsubsection{Heating season results for a single collector}

Reducing the cover emissivity for the BISAH, increases thermal energy generation; the thermal energy generated by a single collector is shown in Figure 4-29. A decrease from 0.9 to 0.3 for the cover emissivity increases the collector's thermal energy generation by $10 \%$. A comparison

of the thermal generation shows that the using a lower emissivity value allows the collector to generate more heat during the day but also in the early and late afternoon hours. Decreasing the cover emissivity from 0.9 to 0.6 , extends the number of hours where the collector generated thermal energy. 


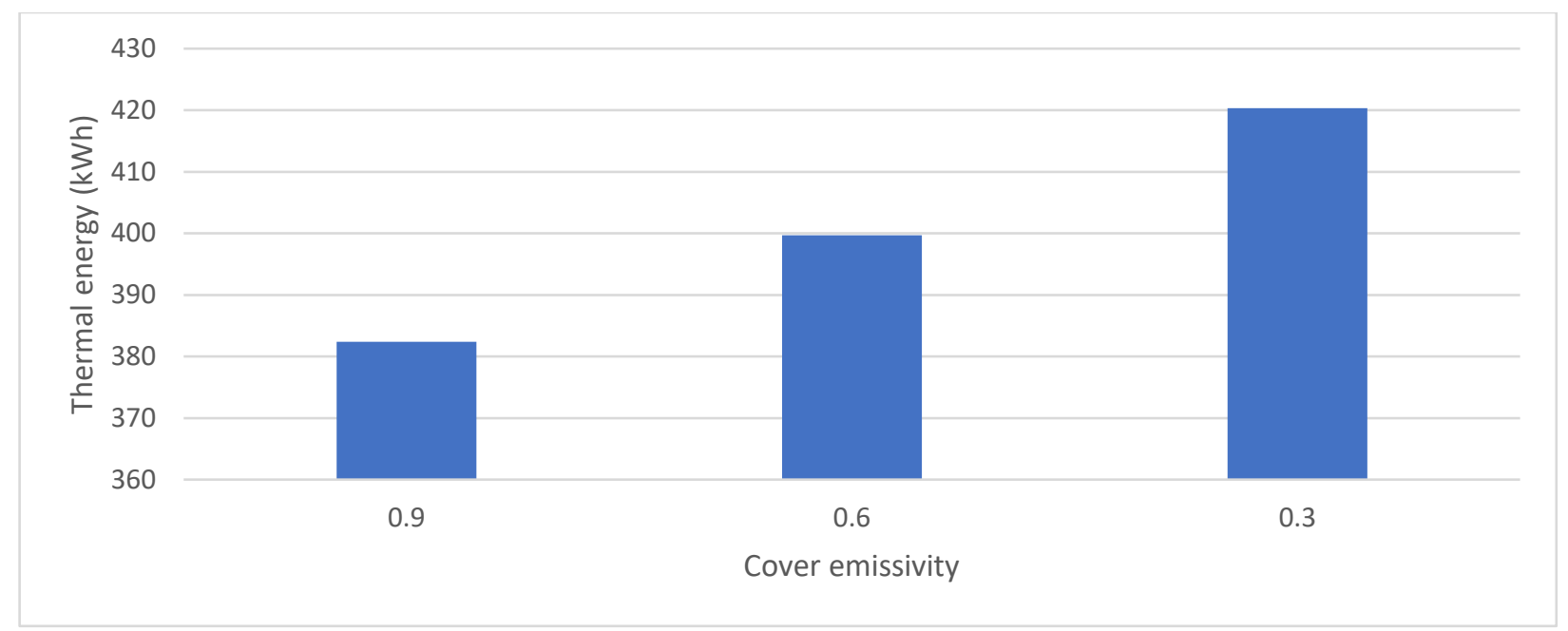

Figure 4-29 Heating season thermal energy generated by a collector for various cover emissivities

\subsubsection{Detailed heat transfer analysis of a collector on January $1^{\text {st }}$}

Similar to the effect that reducing the cover emissivity has TBIPV/T performance, a reduction in the cover emissivity of the BISAH collector reduces overall loses to the environment, Figure 4-30 depicts. However not all the savings is transferred to the air stream. Summing savings over the day shows that reducing the cover emissivity reduces heat loss by $249.25 \mathrm{~kJ}$ but the air stream only gains an additional $246.40 \mathrm{~kJ}$ and the zone gained an additional $2.85 \mathrm{~kJ}$. Although these are small, it shows that not all of the energy savings are transferred to the air stream.

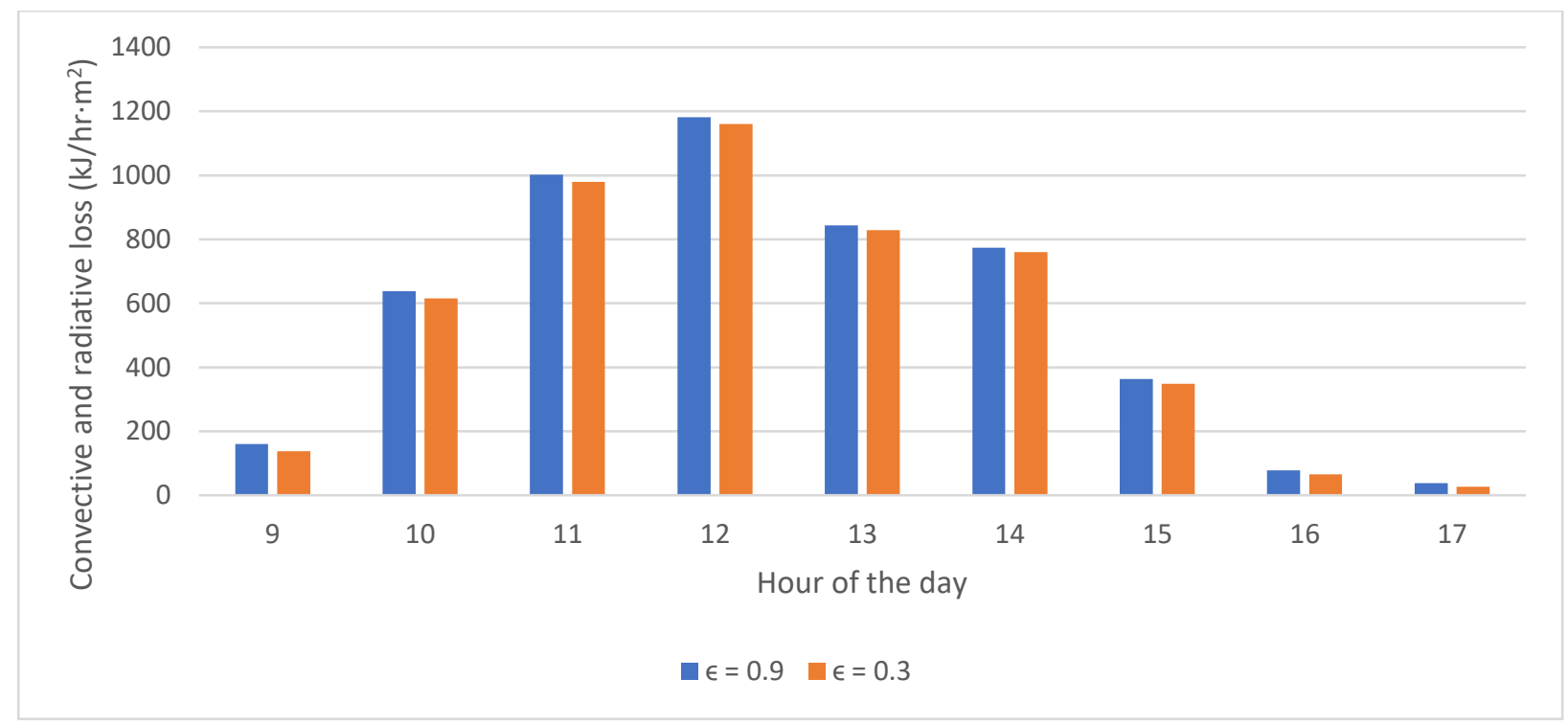

Figure 4-30 Convective and radiative heat loss for the collector for two different cover emissivities on January $1^{\text {st }}$ 


\subsubsection{Heating season results}

Under the same principle explained in Section 4.1.3.3 and as shown in Figure 4-31, changing the cover emissivity for the entire row does not improve the performance of some collectors and degrade others. In Figure 4-31, the trend is consistent, where reducing the emissivity for all collectors simultaneously increases heating season thermal generation.

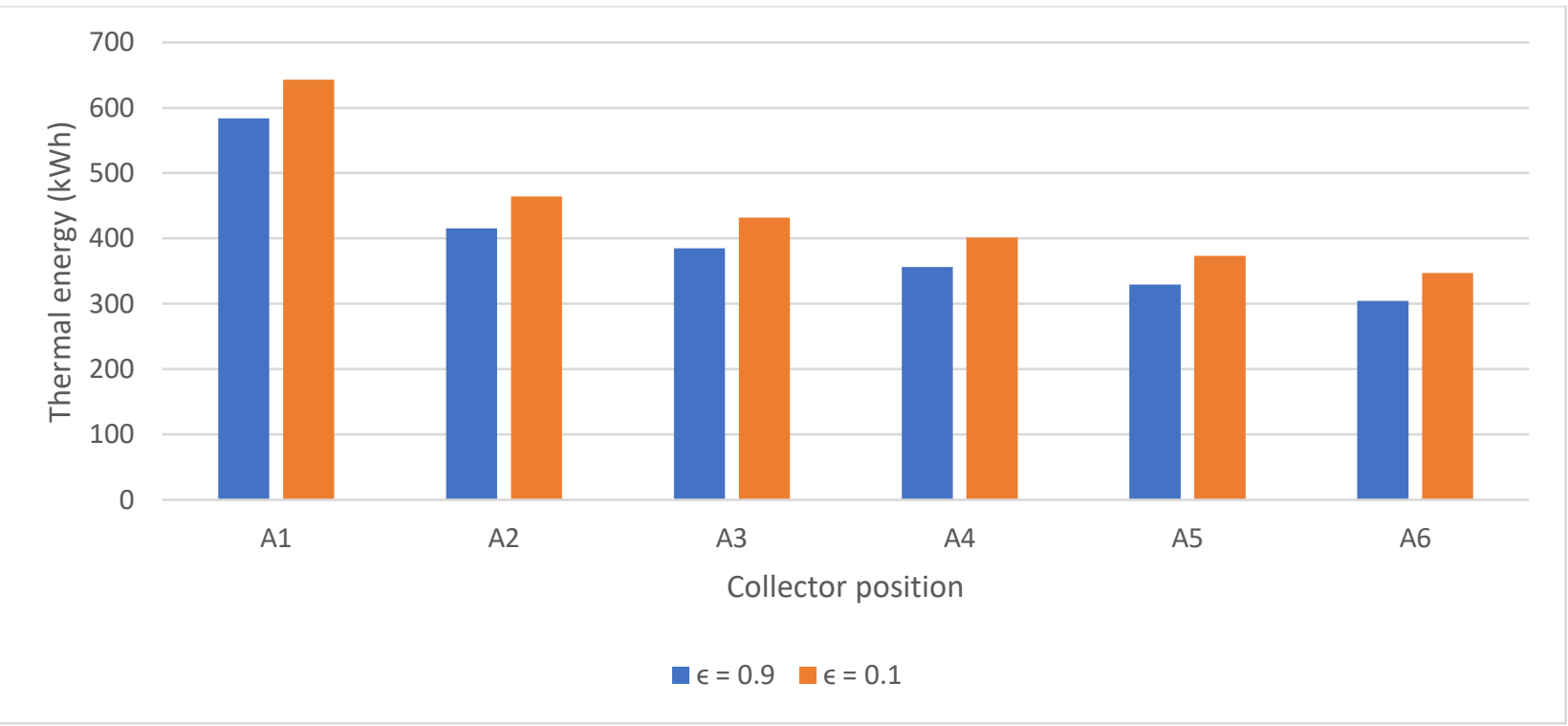

Figure 4-31 Heating season thermal energy generated for one row for two different cover emissivities

The results of varying the cover emissivity for all collectors in a row shows that the thermal energy increases by $12 \%$ from $2375 \mathrm{kWh}$ to $2662 \mathrm{kWh}$ when the cover emissivity reduces from 0.9 to 0.1 (see Figure 4-32). It is interesting to note that the rate at which the thermal energy changes for each 0.2 decrement in cover emissivity increases as the cover emissivity is reduced. This can be applicable design consideration if costs were considered and the margin in the increase in performance could justify costs. 


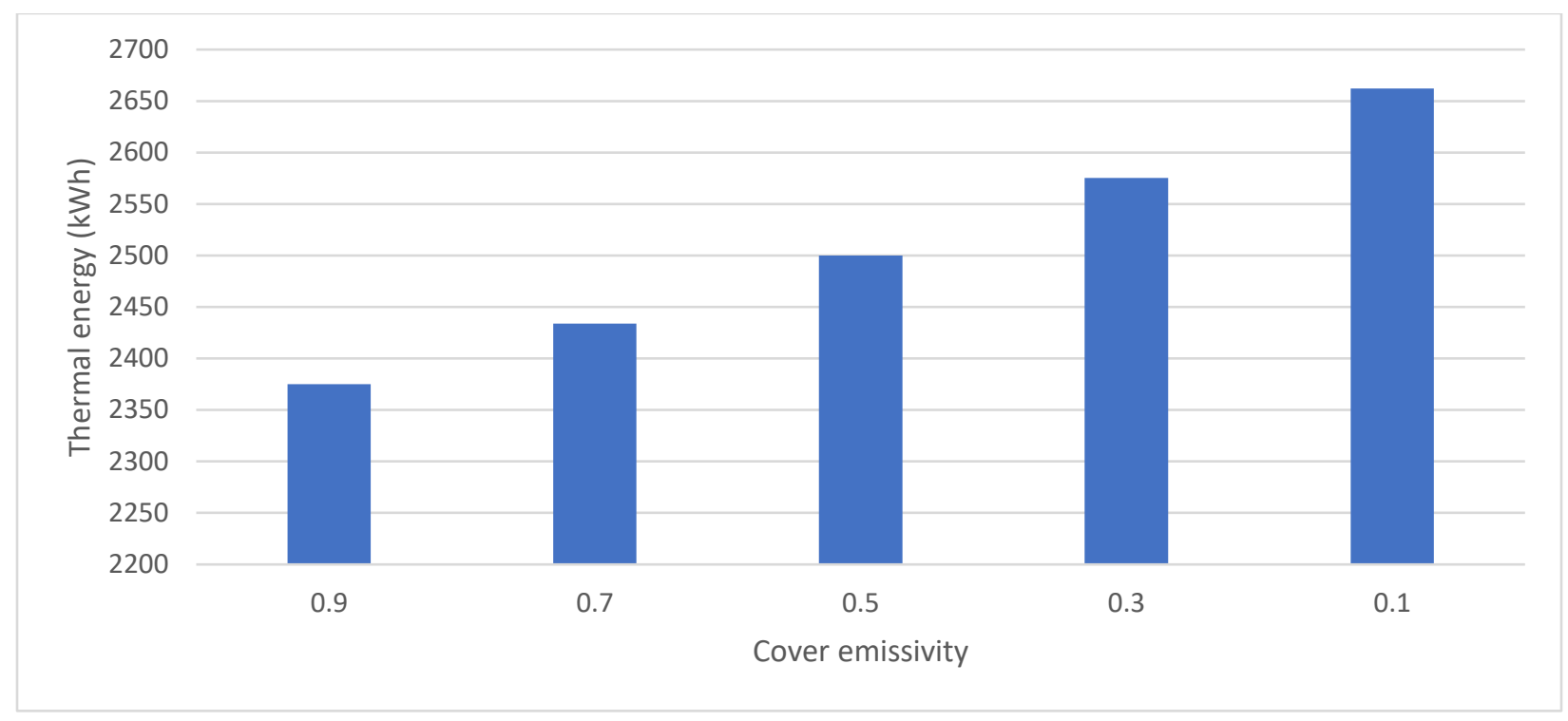

Figure 4-32 Heating season thermal energy generated by one row for various cover emissivities

\subsubsection{OBIPV/T-Internal channel emissivity}

This section presents the sensitivity analysis of the internal channel emissivities an OBIPV/T system. The parameters of the BISAH collected used for the analysis are shown in Table 4-10.

Table 4-10 OBIPV/T collector parameters for internal channel emissivity analysis

\begin{tabular}{|c|c|}
\hline$K$ & $4 \mathrm{~m}^{-1}$ \\
\hline$l_{g}$ & $0.0032 \mathrm{~m}$ \\
\hline$n$ & 1.526 \\
\hline$k_{g}$ & $3.78 \mathrm{~kJ} / \mathrm{hr} \cdot \mathrm{m} \cdot \mathrm{K}$ \\
\hline$R_{p v-u}$ & $0.01 \mathrm{~kJ} / \mathrm{hr} \cdot \mathrm{m}^{2} \cdot \mathrm{K}$ \\
\hline$w$ & $1.6 \mathrm{~m}$ \\
\hline$L$ & $1 \mathrm{~m}$ \\
\hline$d$ & $0.0635 \mathrm{~m}$ \\
\hline$R_{\text {ins }}$ & $1.9562 \mathrm{hr} \cdot \mathrm{m}^{2} \cdot \mathrm{K} / \mathrm{kJ}$ \\
\hline$\epsilon_{c}$ & 0.6 \\
\hline$P F$ & 0.9 \\
\hline
\end{tabular}

\subsubsection{Heating season results for a single collector}

For a single collector, decreasing the internal emissivities reduces the thermal and electrical performance as shown in Figure 4-33 and Figure 4-34, respectively. Similar to the effect that low 
internal emissivities allow the BISAH to collect thermal more energy more often than the same collector with high emissivities (Section 4.1.3.1), this OBIPV/T collector generates thermal energy for an additional 84 hours when its internal emissivities reduces to 0.3 . However, the overall results show a decline in thermal energy generation because the additional hours of thermal generation are in the early or late afternoon hours; the additional energy gained during those hours, over the heating season, are small relative to the reduction in thermal energy generation during most of the day.

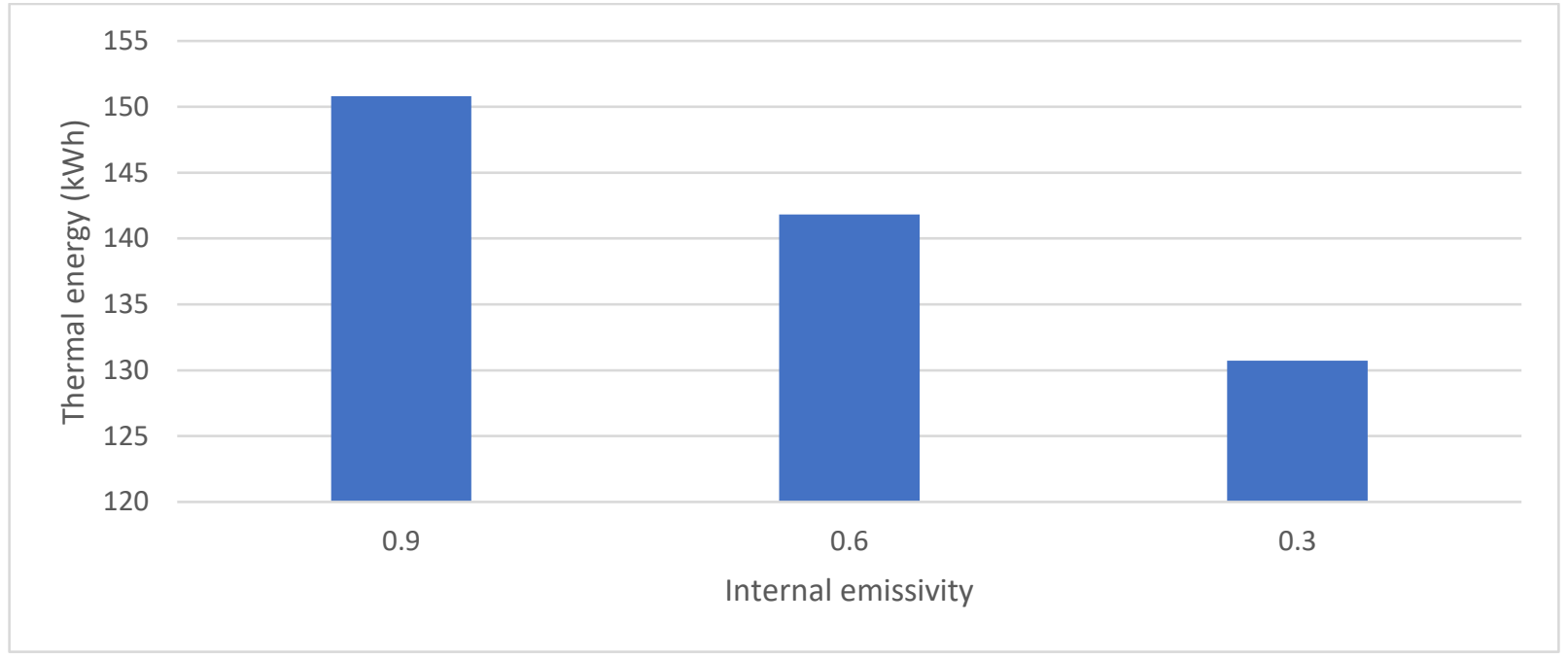

Figure 4-33 Heating season thermal energy generated by a collector for various internal channel emissivities

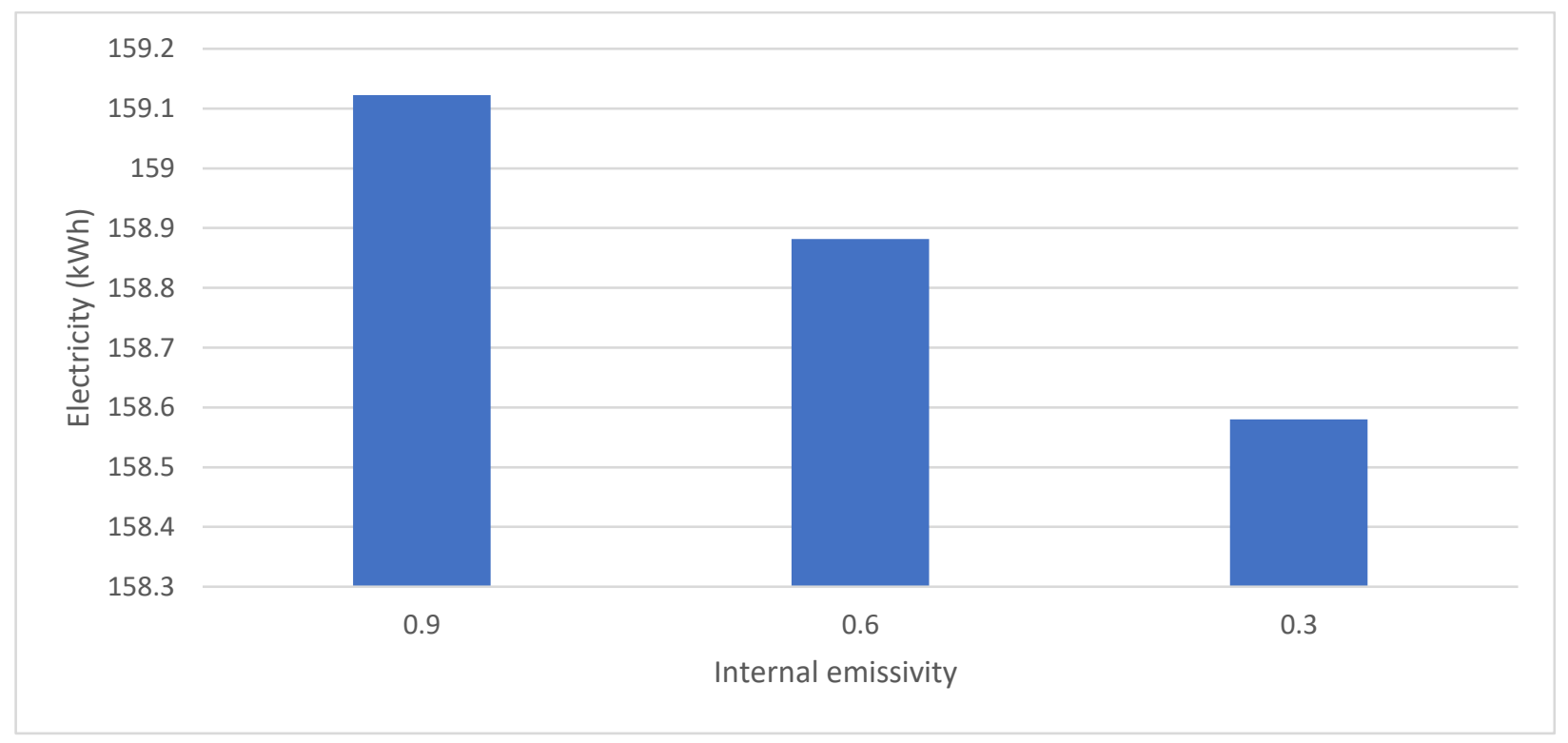

Figure 4-34 Heating season electrical energy generated by a collector for various internal channel emissivities 


\subsubsection{Detailed heat transfer analysis of a collector on January $1^{\text {st }}$}

With respect to the effect of internal emissivities on OBIPV/T system performance, the same conditions apply (Section 4.1.1.1 and 4.1.1.2). On an hourly basis, high internal emissivities increases performance whenever $T_{u}>T_{l}$. During this condition, longwave internal radiation transfers more heat to the lower surface, which increases the lower surface temperature and at the same time, allows the PV layer to cool down (generate more electricity) because more heat is transferred from the PV to the upper surface.

\subsubsection{Design option for internal emissivity for TBIPV/T system}

For TBIPV/T collectors, the optimal configuration was to set the internal emissivities of first three collectors to a 0.9 due to the frequency of $T_{u}>T_{l}$ occurring during the day with high irradiance levels, and set the last three collector's emissivities to 0.1, as determined in Section 4.1.1.4. For the OBIPV/T system, Table 4-11 presents the number of hours, during sunny hours, where $T_{u}>T_{l}$. Comparing Table 4-11 and Table 4-3, the upper surface is much more frequently warmer than its lower surface, throughout the row of OBIPV/T collectors. This is because the TBIPV/T had pockets of glass that allow radiation to strike the lower surface, in the OBIPV/T all the heat is concentrated at the PV/absorber layer and the thermal energy disperses from there.

Table 4-11 Frequency of when the upper surface was warmer than the lower surface for each collector in the row

\begin{tabular}{|c|c|}
\hline Collector & No. of hours $T_{u}>T_{l}$ \\
\hline A1 & 1960 \\
\hline A2 & 1887 \\
\hline A3 & 1871 \\
\hline A4 & 1850 \\
\hline A5 & 1835 \\
\hline A6 & 1817 \\
\hline
\end{tabular}

These results highly suggest that, unlike the TBIPV/T system, the OBIPV/T's optimal configuration is not a combination of different collectors with different internal emissivities (i.e., the optimal configuration is when all the collectors have high internal emissivities). 


\subsubsection{Heating season results}

The heating season results for seven row configurations where each row has a different number of collectors with 0.9 and 0.1 internal emissivities are presented; these configurations are presented in Table 4-12. The first row configuration consisted of all six collectors of the row equipped with 0.1 emissivities; in the second row configuration the internal emissivities of A1 were 0.9 , A2-A6 was 0.1 ; in the third row configuration, the internal emissivities of A1 and A2 were 0.9 and A3-A6 was 0.1 etc. the thermal and electrical energy generated for the heating season for these configurations are presented in Figure 4-35 and Figure 4-36, respectively. Unlike the TBIPV/T system, there is an overwhelming frequency of hours where $T_{u}>T_{l}$, hence over the heating season, each collector generates when equipped with internal emissivities of 0.9 .

Table 4-12 Row configuration with different collectors with different emissivity values

\begin{tabular}{|c|c|}
\hline Collectors with $\epsilon_{u}=\epsilon_{l}=0.9$ & Collectors with $\epsilon_{u}=\epsilon_{l}=0.1$ \\
\hline N/A & A1-A6 \\
\hline A1 & A2-A6 \\
\hline A1-A2 & A3-A6 \\
\hline A1-A3 & A4-A6 \\
\hline A1-A4 & A5-A6 \\
\hline A1-A5 & A6 \\
\hline A1-A6 & N/A \\
\hline
\end{tabular}

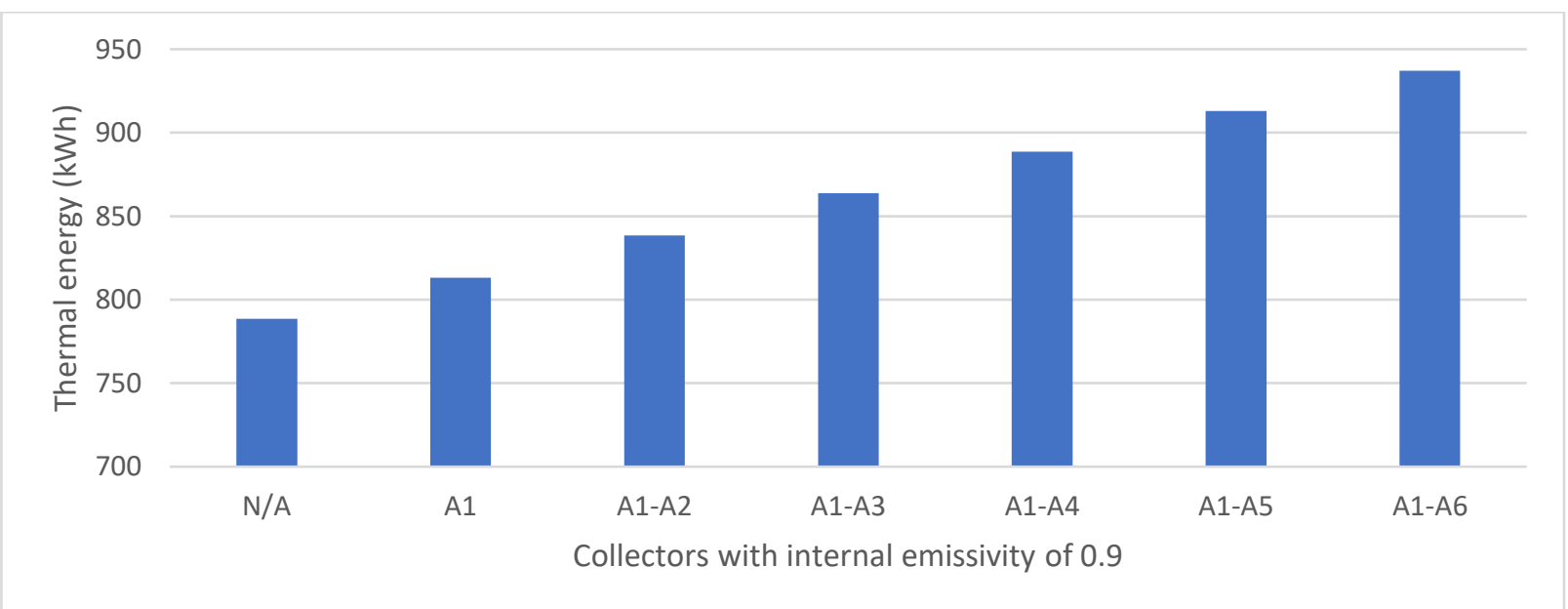

Figure 4-35 Heating season thermal energy generated for different row configuration 


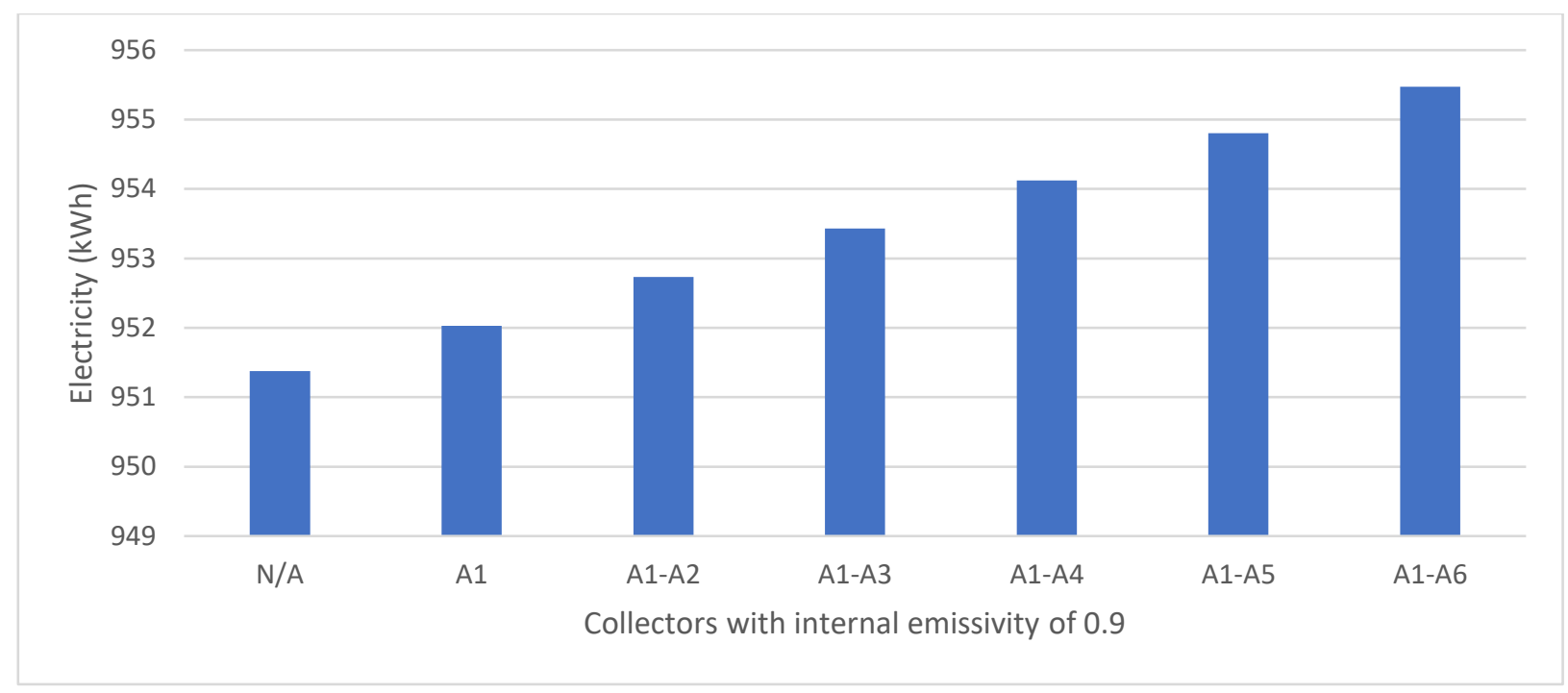

Figure 4-36 Heating season electrical energy generated for different row configuration

Since an optimal configuration does not exist by combining collectors with different internal emissivities to form a row, the optimal configuration consists collectors all equipped with the same internal emissivity. Based on the thermal and electrical energy generation during the heating season, the optimal configuration is obtained when the OBIPV/T collector uses a high emissivity, as shown in Figure 4-37 and Figure 4-38.

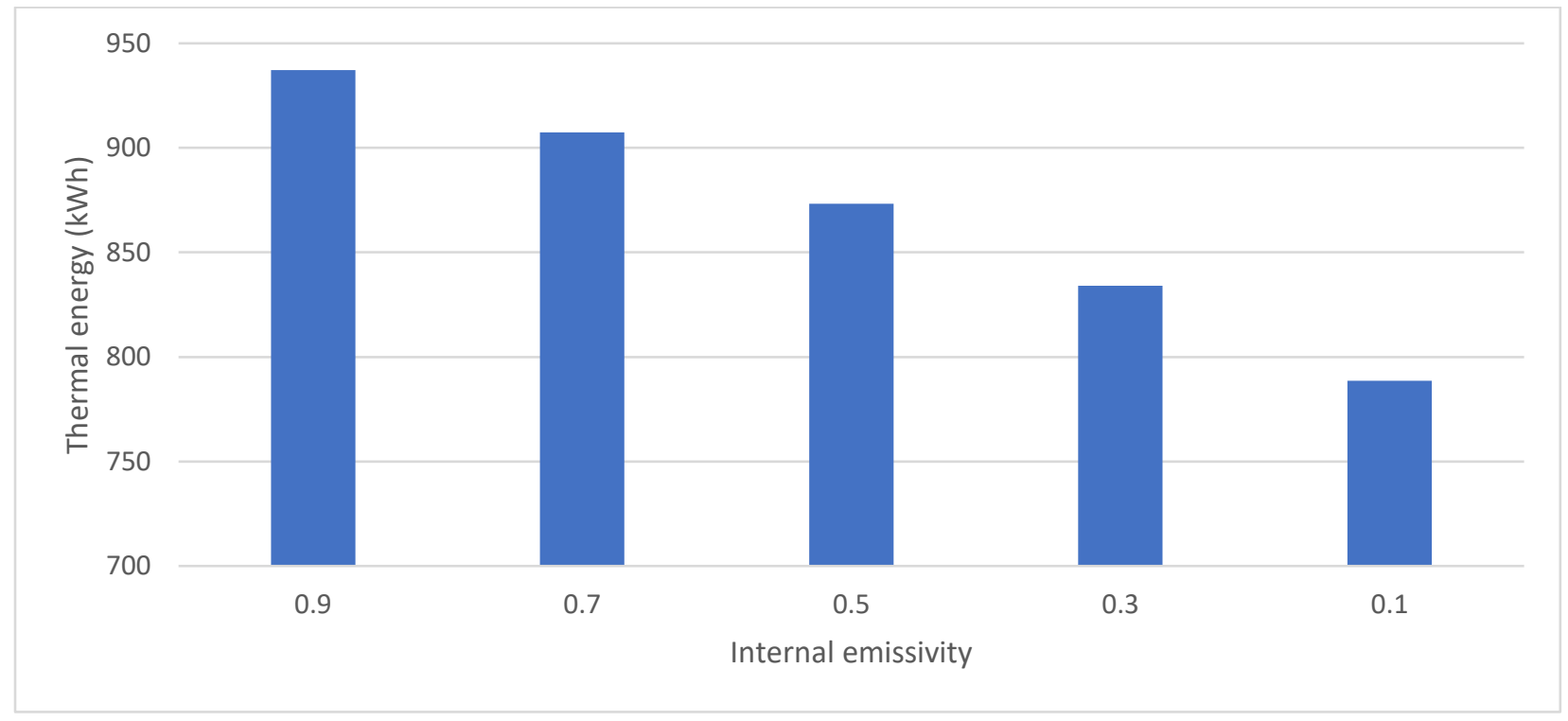

Figure 4-37 Heating season thermal energy generated for one row for various internal emissivities 


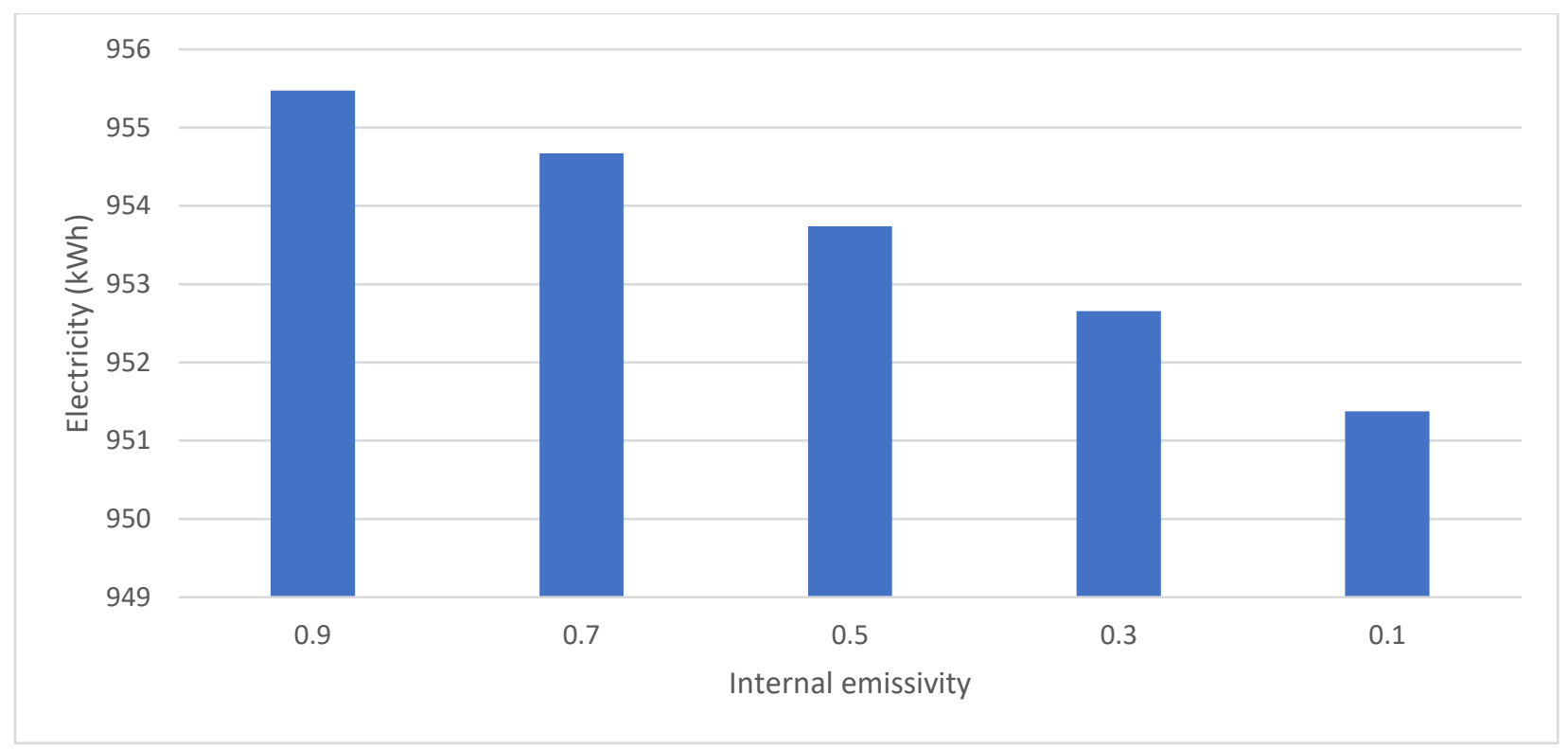

Figure 4-38 Heating season electrical energy generated for one row for various internal emissivities

\subsubsection{OBIPV/T-Cover emissivity}

For this study, the parameters of the OBIPV/T system used for simulations are shown in Table 4-13.

Table 4-13 OBIPV/T collector parameters for cover emissivity analysis

\begin{tabular}{|c|c|}
\hline$K$ & $4 \mathrm{~m}^{-1}$ \\
\hline$l_{g}$ & $0.0032 \mathrm{~m}$ \\
\hline$n$ & 1.526 \\
\hline$k_{g}$ & $3.78 \mathrm{~kJ} / \mathrm{hr} \cdot \mathrm{m} \cdot \mathrm{K}$ \\
\hline$R_{p v-u}$ & $0.01 \mathrm{~kJ} / \mathrm{hr} \cdot \mathrm{m}^{2} \cdot \mathrm{K}$ \\
\hline$w$ & $1.6 \mathrm{~m}$ \\
\hline$L$ & $1 \mathrm{~m}$ \\
\hline$d$ & $0.0635 \mathrm{~m}$ \\
\hline$R_{\text {ins }}$ & $1.9562 \mathrm{hr} \cdot \mathrm{m}^{2} \cdot \mathrm{K} / \mathrm{kJ}$ \\
\hline$\epsilon_{u}$ & 0.9 \\
\hline$\epsilon_{l}$ & 0.9 \\
\hline$P F$ & 0.9 \\
\hline
\end{tabular}

\subsubsection{Heating season results for a single collector}

The thermal and electrical energy generated for the heating season of the a single OBIPV/T collector for various cover emissivities are presented in Figure 4-39 and Figure 4-40, respectively. 
Decreasing the cover emissivity increases the thermal generation but decreases electrical generation; a trend that TBIPV/T collectors also depict. Additionally, lowering the cover emissivity allows the collector to generate thermal energy longer. Decreasing the cover emissivity from 0.6 to 0.3 increases the thermal energy generation hours by 208 over the heating seasons, mostly during the early morning and late afternoon hours.

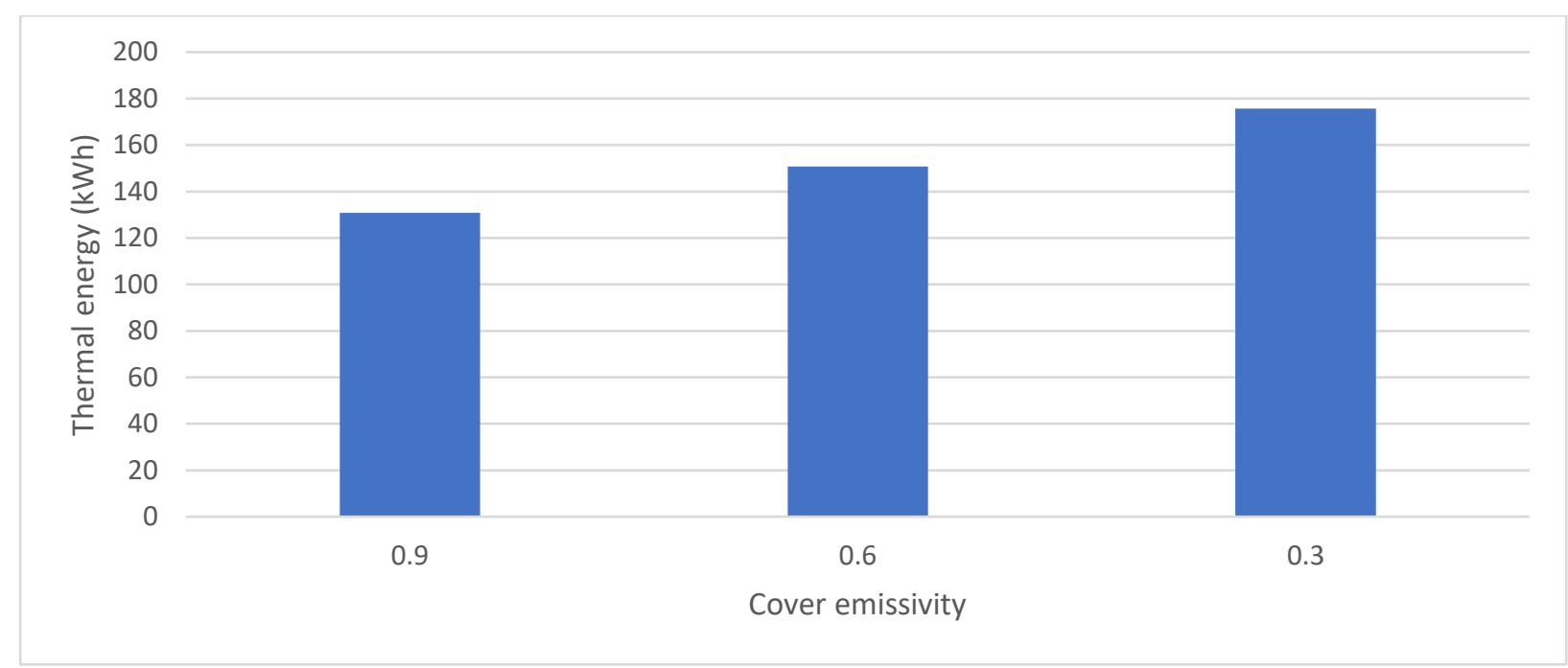

Figure 4-39 Heating season thermal energy generated by a collector for various cover emissivities

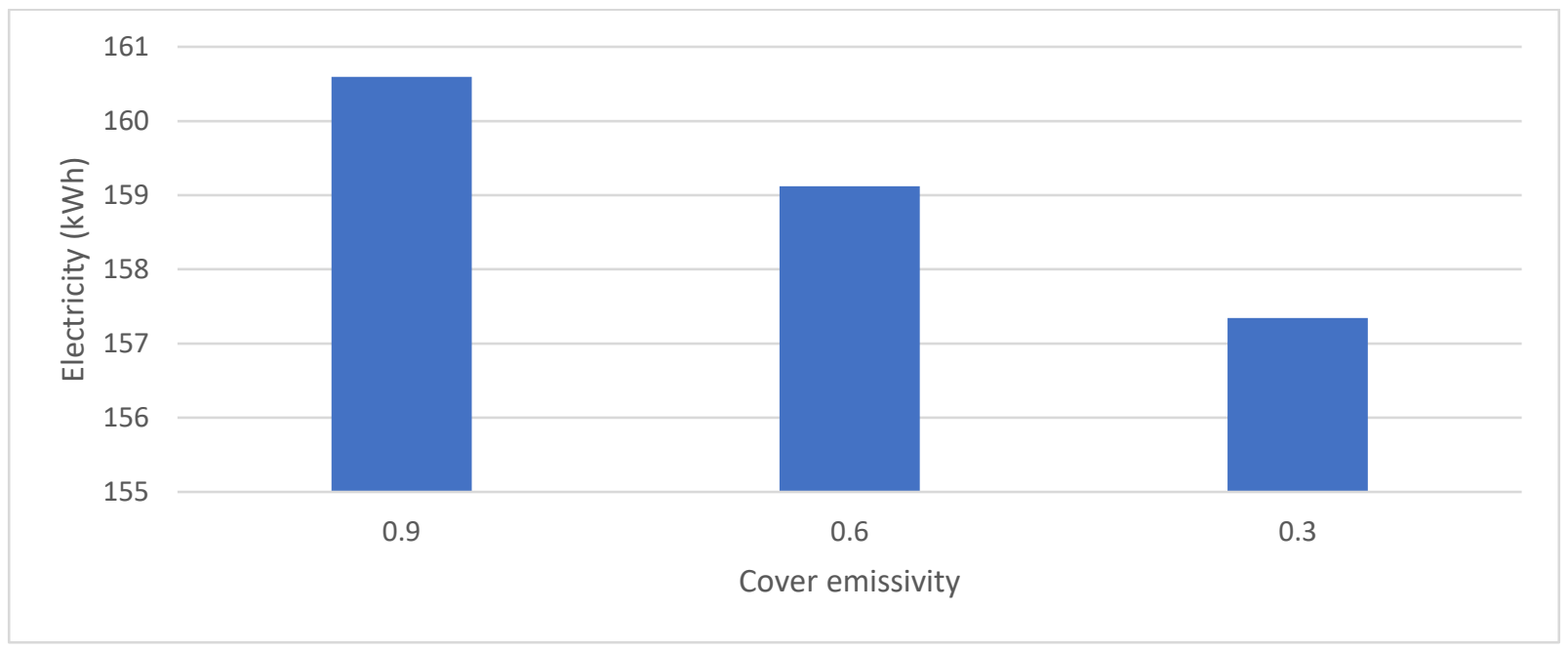

Figure 4-40 Heating season electrical energy generated by a collector for various cover emissivities 


\subsubsection{Detailed heat transfer analysis of a collector on January 1st}

With regards to the cover emissivity parameter, the OBIPV/T system exhibits the same trend as the TBIPV/T system. As the cover emissivity is lowered, the sky radiation loss reduces but the convective loss increases due to the higher cover temperature. This relationship is depicted in Figure 4-41.

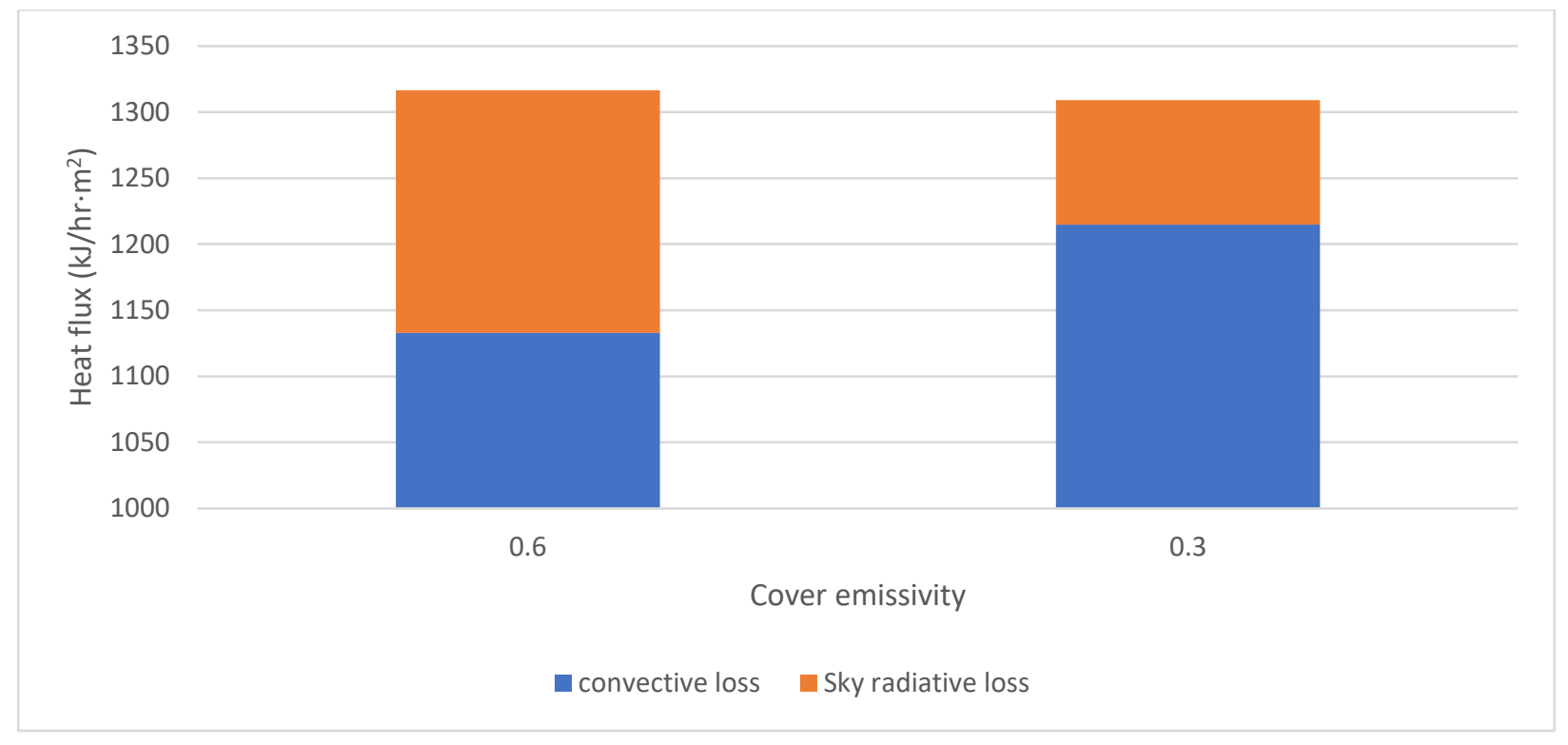

Figure 4-41 Convective and radiative heat loss for the collector on January $1^{\text {st }}$ at $1 \mathrm{pm}$

It is due to a reduced overall heat loss to the environment that more of absorbed solar radiation is retained, the PV temperature increases (electricity generation reduction) and the heat transfer to the air stream increases (increase in thermal generation).

\subsubsection{Heating season results}

Just as in previous sections, where a single row combined different collectors with different emissivity values, the same analysis was done to examine the cover emissivity of OBIPV/T systems; the configurations studied are presented in Table 4-14. In the first configuration, all the collectors were equipped with cover emissivities of 0.9 ; in the second configuration, the cover emissivity of A1 changed to 0.1 while collector A2-A6 had cover emissivities of 0.9 ; in the third configuration, the cover emissivities of A1-A2 were 0.1 while A3-A6 had cove emissivities of 0.9, etc. 
Table 4-14 Row configuration with different collectors with different emissivity values

\begin{tabular}{|c|c|}
\hline Collectors with $\epsilon_{u}=\epsilon_{l}=0.1$ & Collectors with $\epsilon_{u}=\epsilon_{l}=0.9$ \\
\hline N/A & A1-A6 \\
\hline A1 & A2-A6 \\
\hline A1-A2 & A3-A6 \\
\hline A1-A3 & A4-A6 \\
\hline A1-A4 & A5-A6 \\
\hline A1-A5 & A6 \\
\hline A1-A6 & N/A \\
\hline
\end{tabular}

The results of these configurations are presented in Figure 4-42 and 4-43 for the thermal and electrical energy generated over the heating season, respectively. An optimal configuration is not found in these results as it was determined in Section 4.1.1.4 for the TBIPV/T system. These results however can offer additional options between increasing thermal generation at the expense of reducing electricity generation, in addition to the results that follows where all the collectors' cover emissivity was changed in unison.

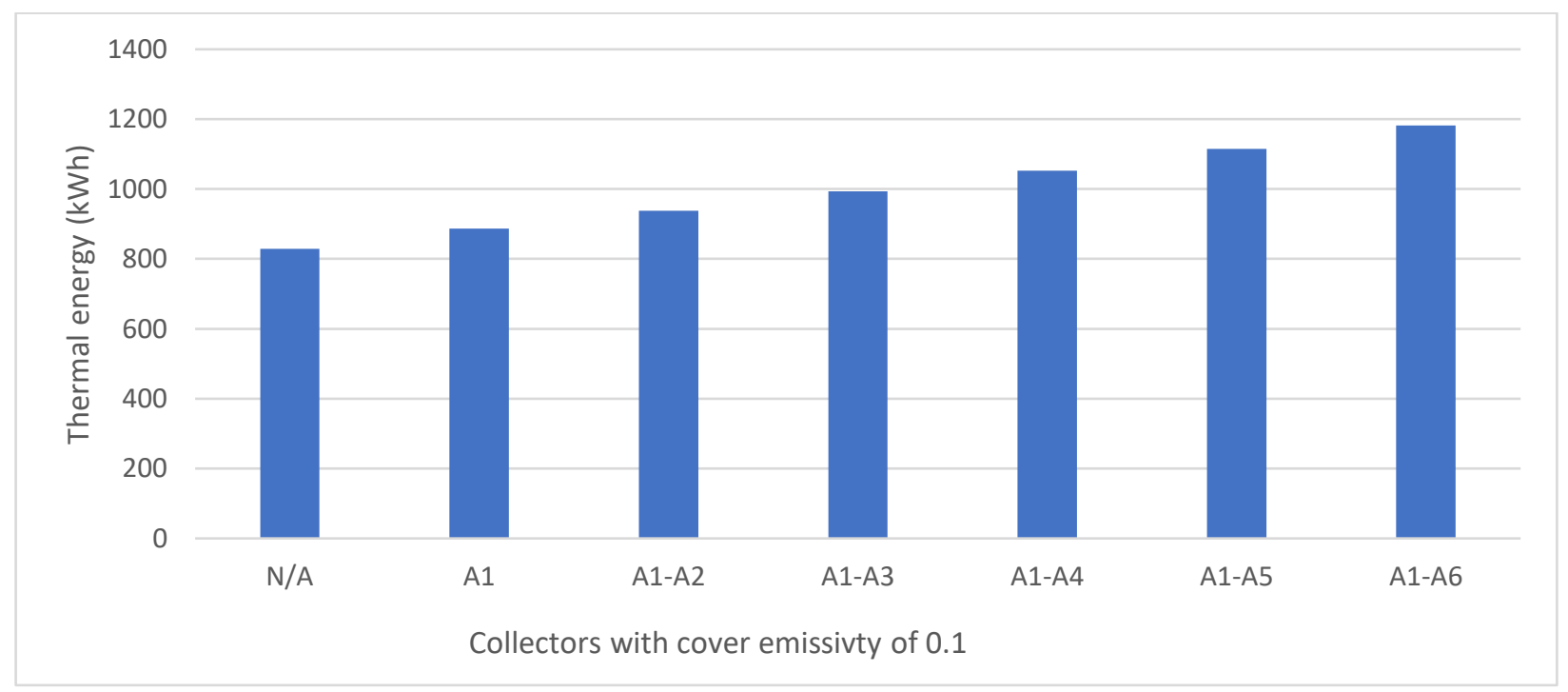

Figure 4-42 Heating season thermal energy generated by different row configurations 


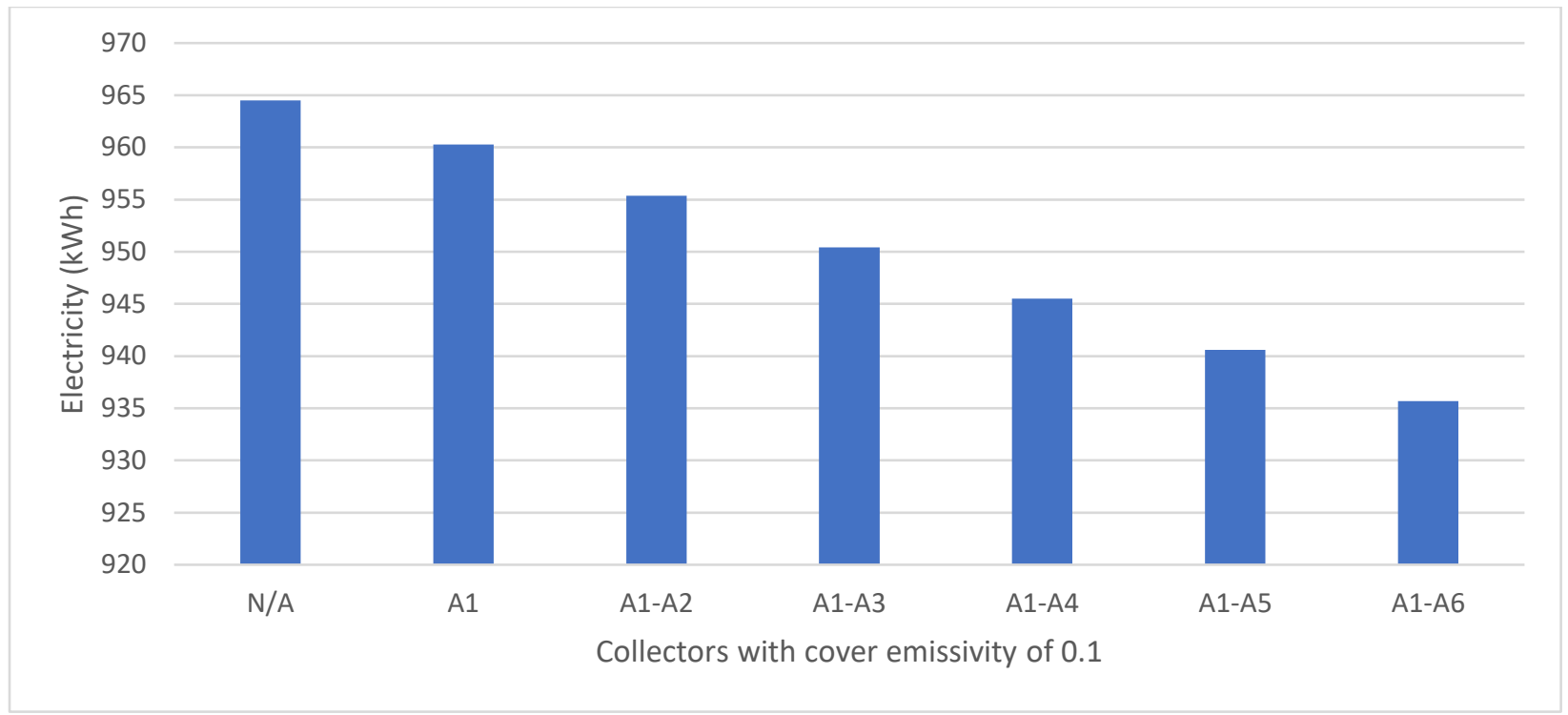

Figure 4-43 Heating season electrical energy generated by different row configurations

In Figure 4-44 and 4-45, the thermal energy and electrical energy generated, respectively, for one row for the entire heating season, where the all the collectors have the same cover emissivity, are presented. The results show that decreasing the cover emissivity from 0.9 to 0.1 increases the thermal generation by $352 \mathrm{kWh}$, while the electrical energy generated decreases by $29 \mathrm{kWh}$, approximately a 12 to 1 ratio, in contrast to the $14: 1$ ratio that the TBIPV/T exhibited.

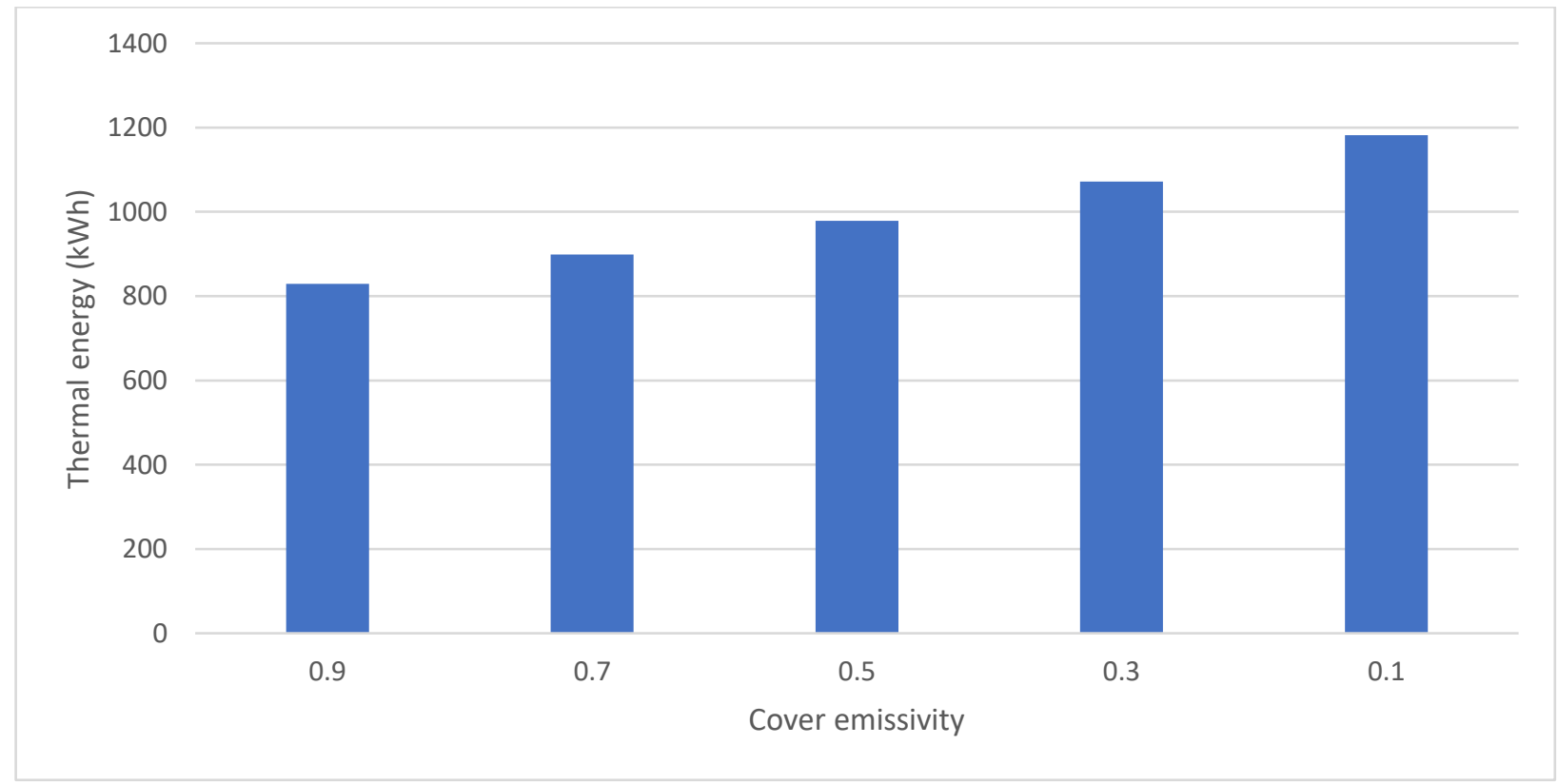

Figure 4-44 Heating season thermal energy generated by rows with different cover emissivity 


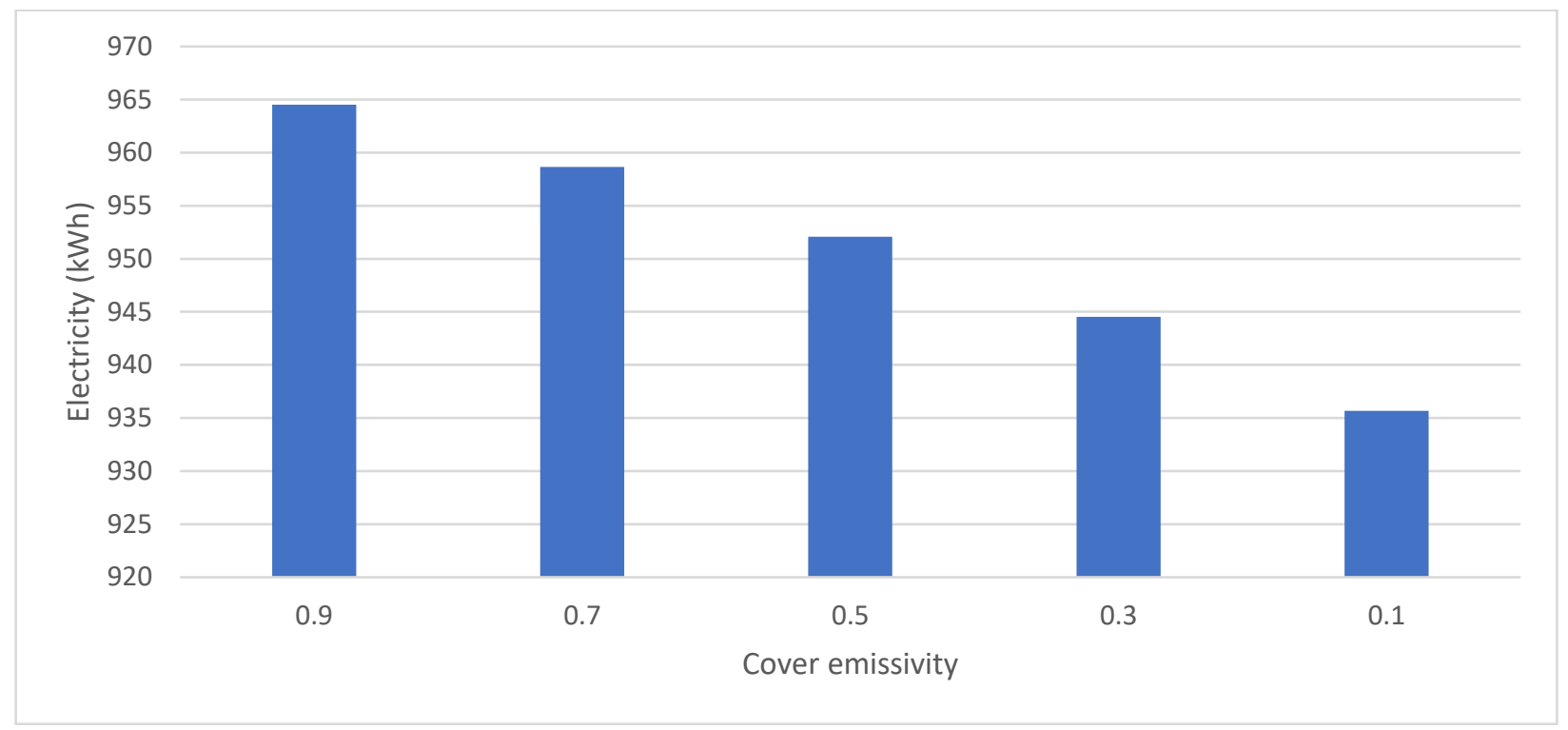

Figure 4-45 Heating season electrical energy generated by rows with different cover emissivity

\subsection{Collector arrangement analysis}

An enhancement of BIPV/T systems can be achieved with the inclusion of solar thermal collectors and/or TBIPV/T collectors. Pantic, Candanedo, and Athienitis (2010) examined the addition of a vertical SAH at the end of a BIPV/T system. However, vertical collectors are difficult to install at the end of a BIPV/T system if the air is to flow upward along a façade, the transition in the angle of the flow will increase the fan power consumption. Secondly, their study was limited to a single collector in one configuration. As the sensitivity work completed for individual collectors have shown, identical collectors perform differently when located at different positions along the row because the air flowing through the channel changes in temperature. Therefore, an analysis on the collector arrangement provides better understanding for optimizing BIPV/T systems.

The collector arrangement analyses undertaken examined the benefit of the inclusion of different collectors to for a whole BIPV/T-BISAH system, with enhanced collectors based on the results of the parameter analysis of the individual collectors. A total of three collector arrangement analyses were completed using an annual simulation of the system in Toronto, Canada, a common collector tilt of $35^{\circ}$, and a constant flowrate of $0.2 \mathrm{~kg} / \mathrm{s}$ for each row. Results below are reported 
on a per row basis (unless specified otherwise) and configurations for an array can be obtained by simple addition of each row's energy generation.

\subsubsection{Enhancing OBIPV/T and TBIPV/T systems with BISAH collectors}

\subsubsection{5 OBIPV/T and 1 BISAH}

An OBIPV/T system consisting of 5x5 system can be improved by including an air heater at the end of the row to boost the temperature of the air as it exits the array. In Figure 4-46, a single row of 5 OBIPV/T collectors is shown. The parameters of the individual OBIPV/T collectors are found in Table 4-15. A heating season simulation shows that this row generates $1118 \mathrm{kWh}$ of thermal energy and $758 \mathrm{kWh}$ of electricity. The addition of a single BISAH collector is shown in Figure 4-47; the parameters of the BISAH collector are found in Table 4-16. A similar heating analysis shows that the entire row generates $1965 \mathrm{kWh}$ of thermal energy and $758 \mathrm{kWh}$ of electricity. The lone BISAH collector increases the total thermal energy by $846 \mathrm{kWh}$ or approximately $76 \%$ increase in thermal generation. The advantage of this system is that the system's electrical generation is unaffected, there is no trade off between thermal and electrical generation. 


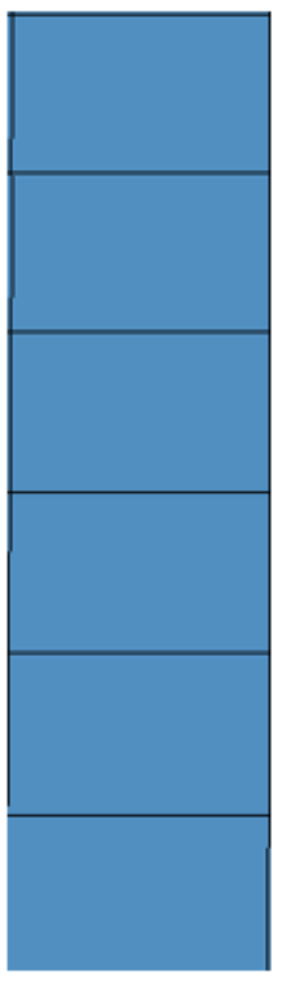

仓ิ

Figure 4-46 One row of 5 OBIPV/T collectors

Table 4-15 OBIPV/T collector parameters

\begin{tabular}{|c|c|}
\hline$K$ & $4 \mathrm{~m}^{-1}$ \\
\hline$l_{g}$ & $0.0032 \mathrm{~m}$ \\
\hline$n$ & 1.526 \\
\hline$k_{g}$ & $3.78 \mathrm{~kJ} / \mathrm{hr} \cdot \mathrm{m} \cdot \mathrm{K}$ \\
\hline$R_{p v-u}$ & $0.01 \mathrm{~kJ} / \mathrm{hr} \cdot \mathrm{m}^{2} \cdot \mathrm{K}$ \\
\hline$w$ & $1.6 \mathrm{~m}$ \\
\hline$L$ & $1 \mathrm{~m}$ \\
\hline$d$ & $0.0635 \mathrm{~m}$ \\
\hline$R_{\text {ins }}$ & $1.9562 \mathrm{hr} \cdot \mathrm{m}^{2} \cdot \mathrm{K} / \mathrm{kJ}$ \\
\hline$\epsilon_{c}$ & 0.6 \\
\hline$\epsilon_{u}$ & 0.9 \\
\hline$\epsilon_{l}$ & 0.9 \\
\hline$P F$ & 0.85 \\
\hline
\end{tabular}




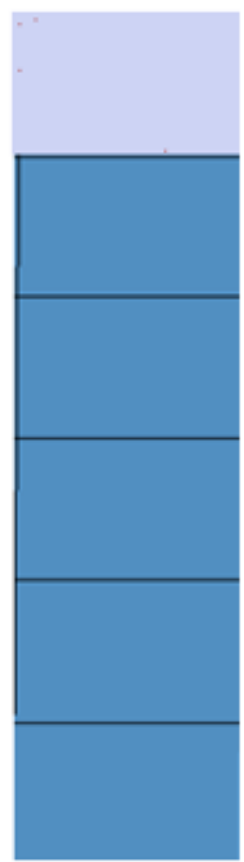

$\widehat{\mathrm{v}}$

Figure 4-47 5 OBIPV/T collectors with 1 BISAH collector

Table 4-16 BISAH collector parameters

\begin{tabular}{|c|c|}
\hline$K$ & $4 \mathrm{~m}^{-1}$ \\
\hline$l_{g}$ & $0.0032 \mathrm{~m}$ \\
\hline$n$ & 1.526 \\
\hline$k_{g}$ & $3.78 \mathrm{~kJ} / \mathrm{hr} \cdot \mathrm{m} \cdot \mathrm{K}$ \\
\hline$w$ & $1.6 \mathrm{~m}$ \\
\hline$L$ & $1 \mathrm{~m}$ \\
\hline$d$ & $0.0635 \mathrm{~m}$ \\
\hline$R_{\text {ins }}$ & $1.9562 \mathrm{hr} \cdot \mathrm{m}^{2} \cdot \mathrm{K} / \mathrm{kJ}$ \\
\hline$\epsilon_{c}$ & 0.1 \\
\hline$\epsilon_{\mathrm{u}}$ & 0.1 \\
\hline$\epsilon_{\mathrm{l}}$ & 0.1 \\
\hline$P F$ & 0.9 \\
\hline$\alpha_{l}$ & 0.9 \\
\hline
\end{tabular}




\subsubsection{4 OBIPV/T and 2 BISAH}

In the interest of coupling the BIPV/T system with an ASHP where electrical savings can be achieved with increased air temperature from the BIPV/T system, an analysis of a row consisting of OBIPV/T collectors and 2 BISAH collectors in series (see Figure 4-48) was conducted. This analysis considered the possibility of replacing one PV panel with an SAH and determined if the ratio of thermal energy gain to electricity loss could make this a viable design option. A heating season simulation shows that this row generates $2597 \mathrm{kWh}$ of thermal energy and $607 \mathrm{kWh}$ of electrical energy; a ratio of thermal gain to loss of electrical of approximately 4:1. These results are summarized in Table 4-17. In a 5x6 array system (5 rows, 6 collectors in series in each row), comparing an array with the $4 \mathrm{OBIPV} / \mathrm{T}+2 \mathrm{BISAH}$ row to another array with 5 OBIPV/T + 1 BISAH row, shows in a gain of $3161 \mathrm{kWh}$ of thermal energy and a decrease in electricity of $756 \mathrm{kWh}$. Considering that overall electricity generation of the $5 \mathrm{OBIPV} / \mathrm{T}+1$ BISAH row is only $3792 \mathrm{kWh}$ of electricity, the $4: 1$ ratio of thermal gain to loss in electricity does not make this a viable option because the loss in electricity is too great proportion-wise.

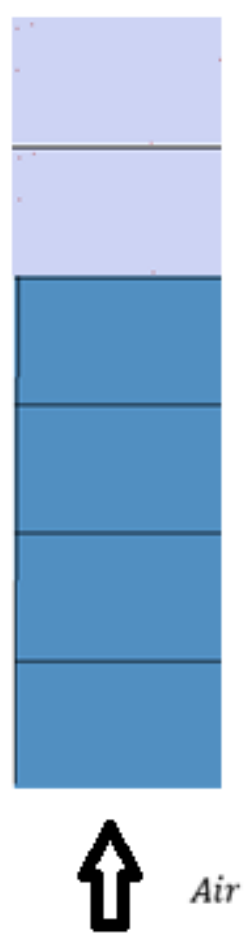

Figure 4-48 5 OBIPV/T collectors with 2 BISAH collectors 
Table 4-17 Summary of the 5 OBIPV/T +1 BISAH and 4 OBIPV/T + 2 BISAH thermal and electrical energy generated during the heating season

\begin{tabular}{|c|c|c|}
\hline Row configuration & $\begin{array}{c}\text { Thermal energy generated } \\
(\mathrm{kWh})\end{array}$ & $\begin{array}{c}\text { Electrical energy generated } \\
(\mathrm{kWh})\end{array}$ \\
\hline 5 OBIPV/T +1 BISAH & 1965 & 758 \\
\hline 4 OBIPV/T +2 BISAH & 2597 & 607 \\
\hline
\end{tabular}

\subsubsection{5 TBIPV/T and 1 BISAH}

The BIPV/T system presented in Section 4.2.1.1 used 5 OBIPV/T collectors, an enhancement on that system could be to replace the OBIPV/T collectors with TBIPV/T collectors. The parameters of the TBIPV/T collectors are shown in Table 4-18. A heating season analysis shows that a single row of 5 TBIPV/T + 1 BISAH generates $2304 \mathrm{kWh}$ of thermal energy and 770 $\mathrm{kWh}$ of electricity; which is $340 \mathrm{kWh}$ and $12 \mathrm{kWh}$ more thermal energy and electrical energy than the $5 \mathrm{OBIPV} / \mathrm{T}+1$ BISAH row. This is summarized in Table 4-19.

Table 4-18 TBIPV/T collector parameters

\begin{tabular}{|c|c|}
\hline$K$ & $4 \mathrm{~m}^{-1}$ \\
\hline$l_{g}$ & $0.0032 \mathrm{~m}$ \\
\hline$n$ & 1.526 \\
\hline$k_{g}$ & $3.78 \mathrm{~kJ} / \mathrm{hr} \cdot \mathrm{m} \cdot \mathrm{K}$ \\
\hline$R_{p v-u}$ & $0.000847 \mathrm{~kJ} / \mathrm{hr} \cdot \mathrm{m}^{2} \cdot \mathrm{K}$ \\
\hline$w$ & $1.6 \mathrm{~m}$ \\
\hline$L$ & $1 \mathrm{~m}$ \\
\hline$d$ & $0.0635 \mathrm{~m}$ \\
\hline$R_{\text {ins }}$ & $1.9562 \mathrm{hr} \cdot \mathrm{m}^{2} \cdot \mathrm{K} / \mathrm{kJ}$ \\
\hline$\epsilon_{c}$ & 0.6 \\
\hline$\epsilon_{\mathrm{u}}$ & 0.9 \\
\hline$\epsilon_{\mathrm{l}}$ & 0.9 \\
\hline$P F$ & 0.9 \\
\hline$\alpha_{l}$ & 0.9 \\
\hline
\end{tabular}


Table 4-19 Summary of the 5 OBIPV/T +1 BISAH and 5 TBIPV/T + 1 BISAH thermal and electrical energy generated during the heating season

\begin{tabular}{|c|c|c|}
\hline Row configuration & $\begin{array}{c}\text { Thermal energy generated } \\
(\mathrm{kWh})\end{array}$ & $\begin{array}{c}\text { Electrical energy generated } \\
(\mathrm{kWh})\end{array}$ \\
\hline $5 \mathrm{OBIPV} / \mathrm{T}+1 \mathrm{BISAH}$ & 1965 & 758 \\
\hline $5 \mathrm{TBIPV} / \mathrm{T}+1 \mathrm{BISAH}$ & 2304 & 770 \\
\hline
\end{tabular}

The increase in thermal energy is because the TBIPV/T collector allows shortwave solar radiation to transmit through its glazing layers via gaps between the PV cells (pockets of glass) and to be absorbed by the lower layer. In effect, this prevents the thermal energy from escaping the system. In OBIPV/T collectors, all the solar radiation is absorbed by the PV-absorber layer, which is in intimate contact with the glazing layer; the cold ambient conditions on the top glass surface and the low resistance of the glass allows the heat to easily escape to the ambient. In contrast, at the lower surface, the thermal energy is gained by the air and a small portion is transferred into the zone (due to the high resistance of the roof, only a small portion of heat is transferred).

The increase in electricity is due to the low level of insulation behind the PV layer and the reduced absorbing area at the PV cell layer in the TBIPV/T compared to the OBIPV/T system. The reduced insulation allows better conduction from the PV layer to the upper surface. Additionally, in OBIPV/T collectors, all the solar radiation that the collector receives after the glazing layer is absorbed by the PV-absorber layer, thus, more of the thermal energy is concentrated at the layer, compared to the TBIPV/T collector that transmit a portion to the lower surface. Hence, lowering the insulation level and reducing the concentration of solar thermal energy at the PV layer, will allow the cell temperature to decrease and thus increase electrical generation.

\subsubsection{4 TBIPV/T and 2 BISAH}

Following the analysis of Section 4.2.1.2, a single row consisting of 4 TBIPV/T and 2 BISAH collectors were simulated. The heating season simulation shows that the 4 TBIPV/T +2 BISAH row generates $2871 \mathrm{kWh}$ and $617 \mathrm{kWh}$ of thermal and electrical energy, respectively. Compared to the $5 \mathrm{OBIPV} / \mathrm{T}+1 \mathrm{BISAH}$ row (Section 4.2.1.1), the $4 \mathrm{TBIPV} / \mathrm{T}+2 \mathrm{BISAH}$ row generates $907 \mathrm{kWh}$ more thermal energy and $141 \mathrm{kWh}$ less electrical energy, a thermal gain to electrical loss of approximately 6:1. These results are summarized in Table 4-20. Although the 4 
$\mathrm{TBIPV} / \mathrm{T}+2 \mathrm{BISAH}$ row performs better than the $4 \mathrm{OBIPV} / \mathrm{T}+2 \mathrm{BISAH}$ row $(4: 1$ thermal gain to electricity loss ratio), the loss of electrical energy is too high for this to be a viable design option compared to the $5 \mathrm{OBIPV} / \mathrm{T}+\mathrm{BISAH}$.

Table 4-20 Summary of the 5 OBIPV/T +1 BISAH and 4 TBIPV/T +2 BISAH thermal and electrical energy generated during the heating season

\begin{tabular}{|c|c|c|}
\hline Row configuration & $\begin{array}{c}\text { Thermal energy generated } \\
(\mathrm{kWh})\end{array}$ & $\begin{array}{c}\text { Electrical energy generated } \\
(\mathrm{kWh})\end{array}$ \\
\hline $5 \mathrm{OBIPV} / \mathrm{T}+1 \mathrm{BISAH}$ & 1965 & 758 \\
\hline $4 \mathrm{TBIPV} / \mathrm{T}+2 \mathrm{BISAH}$ & 2871 & 617 \\
\hline
\end{tabular}

\subsubsection{Summary of the different row configurations}

A summary of the heating season's thermal and electrical energy generated is summarized in Table 4-21. The results show that the replacing a PV panel (OBIPV/T or TBIPV/T) for an additional BISAH does not result in a more efficiency integrated BIPV/T coupled ASHP because the ratio of thermal gain to loss in electricity is too small. Additionally, the results also show that the TBIPV/T +1 BISAH row is the most efficient. It does not diminish electrical generation in order to gain thermal energy and it is more efficient than the OBIPV/T + BISAH row.

Table 4-21 Summary of the 4 different row configurations thermal and electrical energy generated during the heating season

\begin{tabular}{|c|c|c|}
\hline Row configuration & $\begin{array}{c}\text { Thermal energy generated } \\
(\mathrm{kWh})\end{array}$ & $\begin{array}{c}\text { Electrical energy generated } \\
(\mathrm{kWh})\end{array}$ \\
\hline $5 \mathrm{OBIPV} / \mathrm{T}+1 \mathrm{BISAH}$ & 1965 & 758 \\
\hline $4 \mathrm{OBIPV} / \mathrm{T}+2 \mathrm{BISAH}$ & 2597 & 607 \\
\hline $5 \mathrm{TBIPV} / \mathrm{T}+1 \mathrm{BISAH}$ & 2304 & 770 \\
\hline $4 \mathrm{TBIPV} / \mathrm{T}+2 \mathrm{BISAH}$ & 2871 & 617 \\
\hline
\end{tabular}

\subsubsection{Comparative analysis of replacing OBIPV/T-BISAH systems with TBIPV/T systems}

Section 4.2.1 showed that TBIPV/T or OBIPV/T systems could be improved by adding BISAH collectors to the system. However, the addition of an extra collector may not be possible due to limited roof area in buildings. Therefore, there is an interest to determine if TBIPV/T systems alone can be as efficient as OBIPV/T + BISAH systems. In this study, three base case 
OBIPV/T + BISAH rows were considered, each row consisted of 5 OBIPV/T collectors and 1 BISAH collector, the difference among the three rows was the size of the BISAH collector. These three OBIPV/T + BISAH rows were compared to three TBIPV/T rows. Each of these rows consisted of $5 \mathrm{TBIPV} / \mathrm{T}$ collectors. The difference among the TIBPV/T rows was the different cell packing factors used-they were adjusted so the total area of the pockets of glass (gap between PV cells) in the TBIPV/T row matched the BISAH collector's area they were compared to. For example, the first OBIPV/T + BISAH row consisted of five $1.6 \mathrm{~m}^{2} \mathrm{OBIPV} / \mathrm{T}$ and a single $0.8 \mathrm{~m}^{2}$ BISAH collector, this row was compared to a TBIPV/T row that consisted of five $1.6 \mathrm{~m}^{2} \mathrm{TBIPV} / \mathrm{T}$ collectors with a PF of 0.9 (a total of $0.8 \mathrm{~m}^{2}$ glass area-area without PV cells). Furthermore, the $\mathrm{PF}$ of the OBIPV/T collectors were also changed in unison with the TBIPV/T they were compared to, in order to facilitate an unbiased comparison of the overall system performance. A summary description of these configuration is presented in Table 4-22.

Table 4-22 Summary description of the row configuration for a comparative analysis of TBIPV/T systems and OBIPV/T + BISAH systems

\begin{tabular}{|c|c|c|c|}
\hline Row ID & PF & Total collector area & Description \\
\hline Row A & 0.9 & $8.8 \mathrm{~m}^{2}$ & $5 \times 1.6 \mathrm{~m}^{2} \mathrm{OBIPV} / \mathrm{T}+1 \times 0.8 \mathrm{~m}^{2} \mathrm{BISAH}$ \\
\hline Row B & 0.8 & $9.6 \mathrm{~m}^{2}$ & $5 \times 1.6 \mathrm{~m}^{2} \mathrm{OBIPV} / \mathrm{T}+1 \times 1.6 \mathrm{~m}^{2} \mathrm{BISAH}$ \\
\hline Row C & 0.7 & $10.4 \mathrm{~m}^{2}$ & $5 \times 1.6 \mathrm{~m}^{2} \mathrm{OBIPV} / \mathrm{T}+1 \times 2.4 \mathrm{~m}^{2} \mathrm{BISAH}$ \\
\hline Row D1 & 0.9 & $8 \mathrm{~m}^{2}$ & $5 \times 1.6 \mathrm{~m}^{2} \mathrm{TBIPV} / \mathrm{T}\left(0.8 \mathrm{~m}^{2}\right.$ glazing area total $)$ \\
\hline Row D2 & 0.8 & $8 \mathrm{~m}^{2}$ & $5 \times 1.6 \mathrm{~m}^{2} \mathrm{TBIPV} / \mathrm{T}\left(1.6 \mathrm{~m}^{2}\right.$ glazing area total $)$ \\
\hline Row D3 & 0.7 & $8 \mathrm{~m}^{2}$ & $5 \times 1.6 \mathrm{~m}^{2} \mathrm{TBIPV} / \mathrm{T}\left(2.4 \mathrm{~m}^{2}\right.$ glazing area total $)$ \\
\hline
\end{tabular}

The thermal and electrical energy generated during the heating season by each row is presented in Table 4-23. The results shows that the OBIPV/T + BISAH rows (Row A-C) performed better thermally in all cases; the TBIPV/T rows (Row D1-D3) generated a bit more electricity. The OBIPV/T + BISAH rows generated more thermal energy, even though the TBIPV/T had the same glass area because the overall collector area of the OBIPV/T+BISAH was greater; there were five OBIPV/T collectors plus an additional area for a single BISAH collector; in contrast, the TBIPV/T rows had only five TBIPV/T collectors. In this respect, TBIPV/T systems cannot perform better thermally on a row and array basis. 
Table 4-23 Summary of the thermal and electrical energy generated for Row A to Row D3

\begin{tabular}{|c|c|c|c|}
\hline Row ID & PF & $\begin{array}{c}\text { Thermal energy } \\
\text { generated } \\
(\mathrm{kWh})\end{array}$ & $\begin{array}{c}\text { Electricity } \\
\text { generated } \\
(\mathrm{kWh})\end{array}$ \\
\hline Row A & 0.9 & 1535 & 804 \\
\hline Row B & 0.8 & 1975 & 713 \\
\hline Row C & 0.7 & 2407 & 623 \\
\hline Row D1 & 0.9 & 1407 & 814 \\
\hline Row D2 & 0.8 & 1535 & 727 \\
\hline Row D3 & 0.7 & 1662 & 639 \\
\hline
\end{tabular}

In comparing Row A to Row D3 it should be noted that the TBIPV/T row could be further enhanced by reducing each collector's cover emissivity from 0.6 to 0.1 . Cover emissivity optimized TBIPV/T collectors could improve thermal energy generation, compared to the OBIPV/T+BISAH case. The degradation of electrical generation, due to the reduce cover emissivity, could be compensated by the additional electricity that TBIPV/T generate over OBIPV/T collectors. Thus, for a comparative analysis, Row D4-Row D6 were developed and simulated (a description of these rows is presented in Table 4-24; Row D1 is now Row D3 etc.). They were simulated over a heating season and the thermal and electrical energy generated by them were compared to the generation of Row A-C; these results are presented in Table 4-25.

Table 4-24 Summary description of the enhanced TBIPV/T row configuration for a comparative analysis of TBIPV/T systems and OBIPV/T + BISAH systems

\begin{tabular}{|c|c|c|c|}
\hline Row ID & $\mathrm{PF}$ & Total collector area & Description \\
\hline Row D4 & 0.9 & $8 \mathrm{~m}^{2}$ & $\begin{array}{c}5 \times 1.6 \mathrm{~m}^{2} \mathrm{TBIPV} / \mathrm{T}\left(\text { with } \epsilon_{c}=0.1\right) \\
\left(0.8 \mathrm{~m}^{2} \text { glazing area total }\right)\end{array}$ \\
\hline Row D5 & 0.8 & $8 \mathrm{~m}^{2}$ & $\begin{array}{c}5 \times 1.6 \mathrm{~m}^{2} \mathrm{TBIPV} / \mathrm{T}\left(\text { with } \epsilon_{c}=0.1\right) \\
\left(1.6 \mathrm{~m}^{2} \text { glazing area total }\right)\end{array}$ \\
\hline Row D6 & 0.7 & $8 \mathrm{~m}^{2}$ & $\begin{array}{c}5 \times 1.6 \mathrm{~m}^{2} \mathrm{TBIPV} / \mathrm{T}\left(\text { with } \epsilon_{c}=0.1\right) \\
\left(2.4 \mathrm{~m}^{2} \text { glazing area total }\right)\end{array}$ \\
\hline
\end{tabular}


Table 4-25 Summary of the thermal and electrical energy generated for Row A to Row B and Row D4 to Row D6

\begin{tabular}{|c|c|c|c|}
\hline Row ID & PF & $\begin{array}{c}\text { Thermal energy } \\
\text { generated } \\
(\mathrm{kWh})\end{array}$ & $\begin{array}{c}\text { Electricity } \\
\text { generated } \\
(\mathrm{kWh})\end{array}$ \\
\hline Row A & 0.9 & 1535 & 804 \\
\hline Row B & 0.8 & 1975 & 713 \\
\hline Row C & 0.7 & 2407 & 623 \\
\hline Row D4 & 0.9 & 1679 & 803 \\
\hline Row D5 & 0.8 & 1797 & 718 \\
\hline Row D6 & 0.7 & 1913 & 631 \\
\hline
\end{tabular}

Comparing the base case Row A, with the enhanced TBIPV/T Row D1 (now Row D4), it can be seen that Row D4 generates $144 \mathrm{kWh}$ more thermal energy and $1 \mathrm{kWh}$ less electrical energy than Row A. Row D4 generates less electricity because the lowered cover emissivity results in the collectors retaining more thermal energy and increasing its PV cell temperature. However, since TBIPV/T collectors inherently operate with lower PV temperature, this effect is diminished, and in a comparison with the OBIPV/T collectors in Row A, the TBIPV/T row only generated $1 \mathrm{kWh}$ less electricity over the heating season. This means, that a 5x6 OBIPV/T + BISAH system (5 rows of Row 1) can be replaced with a 5x5 array (5 rows of Row D4). In this context, the array with Row D4 configuration would generate $720 \mathrm{kWh}$ more thermal energy than the array with Row A configuration, while only generating $5 \mathrm{kWh}$ less electrical energy over the heating season.

An examination of the other configuration show that the enhanced TBIPV/T systems (Row D4 and D5) does not perform better than their counter parts (Row B and C, respectively). Although Row D4 is not as efficient as Row B, the performance of Row D3 is an acceptable trade off if the area of the roof is limited. In the end, these results suggest that TBIPV/T can perform more efficiently than, or as well as, an OBIPV/T system equipped with a BISAH collector, if the area of BISAH collector is small. As the BISAH collector increases, the total area for solar radiation absorption in the OBIPV/T + BISAH increases such that TBIPV/T systems, with the same number of TBIPV/T collectors as OBIPV/T collectors in the OBIPV/T + BISAH system, cannot outperform.

\subsubsection{Concentrating and dispersing solar radiation collection}

In a row of TBIPV/T collectors the pockets of glass in the collectors allow additional heating of the air throughout the length of the air path while a BISAH collector, in BIPV/T systems, 
concentrates the solar energy at the end of the row. It is of interest to determine if TBIPV/T systems perform better when dispersing the collection of solar radiation along the air flow or concentrating the solar energy at the end.

In this study, the row configurations were designed to allow a comparison between dispersing and concentrating solar radiation by simulating some TBIPV/T systems with multiple small BISAH collectors scattered along the row and other configurations where the BISAH were placed at the end of the row. In this study, three sets of three (total nine) row configuration were simulated, a description of the configuration is presented in Table 4-26. In Table 4-26, "T" refers to TBIPV/T collector and "A" refers to BISAH; the "Collector order" describes the type of collectors used in order from the first collector (where ambient air enters) to the last; "BISAH area" defines the area of the individual BISAH used in the row. As shown in Table 4-26, Rows $\mathrm{E} 1, \mathrm{~F} 1$, and $\mathrm{G} 1$ are the rows where the solar radiation is concentrated at the end; all other rows have dispersed the solar radiation collection by using the same total BISAH collector area along the air path. The parameters used for the TBIPV/T collectors and BISAH are found in Table 4-27 and Table 4-28, respectively.

Table 4-26 Description of the row configuration for concentration vs dispersion analysis

\begin{tabular}{|c|c|c|c|c|}
\hline Set ID & $\begin{array}{l}\text { Row } \\
\text { ID }\end{array}$ & Configuration & Collector order & $\begin{array}{c}\text { BISAH (“A”) } \\
\text { area } \\
\end{array}$ \\
\hline \multirow{3}{*}{$\begin{array}{c}\text { Set E } \\
\text { (Total BISAH area: } \\
\left.0.8 \mathrm{~m}^{2}\right)\end{array}$} & E1 & concentrating & $\mathrm{T}, \mathrm{T}, \mathrm{T}, \mathrm{T}, \mathrm{T}, \mathrm{A}$ & $0.8 \mathrm{~m}^{2}$ \\
\hline & E2 & dispersing & $\mathrm{T}, \mathrm{A}, \mathrm{T}, \mathrm{A}, \mathrm{T}, \mathrm{T}, \mathrm{T}$ & $0.4 \mathrm{~m}^{2}$ \\
\hline & E3 & dispersing & $\begin{array}{c}\mathrm{T}, \mathrm{A}, \mathrm{T}, \mathrm{A}, \mathrm{T}, \mathrm{A}, \mathrm{T}, \\
\mathrm{A}, \mathrm{T}\end{array}$ & $0.2 \mathrm{~m}^{2}$ \\
\hline \multirow{3}{*}{$\begin{array}{c}\text { Set F } \\
\text { (Total BISAH area: } \\
\left.1.6 \mathrm{~m}^{2}\right)\end{array}$} & F1 & concentrating & $\mathrm{T}, \mathrm{T}, \mathrm{T}, \mathrm{T}, \mathrm{T}, \mathrm{A}$ & $1.6 \mathrm{~m}^{2}$ \\
\hline & $\mathrm{F} 2$ & dispersing & $\mathrm{T}, \mathrm{A}, \mathrm{T}, \mathrm{A}, \mathrm{T}, \mathrm{T}, \mathrm{T}$ & $0.8 \mathrm{~m}^{2}$ \\
\hline & F3 & dispersing & $\begin{array}{c}\mathrm{T}, \mathrm{A}, \mathrm{T}, \mathrm{A}, \mathrm{T}, \mathrm{A}, \mathrm{T}, \\
\mathrm{A}, \mathrm{T}\end{array}$ & $0.4 \mathrm{~m}^{2}$ \\
\hline \multirow[b]{3}{*}{$2.4 \mathrm{~m}^{2}$ ) } & G1 & concentrating & $\mathrm{T}, \mathrm{T}, \mathrm{T}, \mathrm{T}, \mathrm{T}, \mathrm{A}$ & $2.4 \mathrm{~m}^{2}$ \\
\hline & $\mathrm{G} 2$ & dispersing & $\mathrm{T}, \mathrm{A}, \mathrm{T}, \mathrm{A}, \mathrm{T}, \mathrm{T}, \mathrm{T}$ & $1.2 \mathrm{~m}^{2}$ \\
\hline & G3 & dispersing & $\begin{array}{c}\mathrm{T}, \mathrm{A}, \mathrm{T}, \mathrm{A}, \mathrm{T}, \mathrm{A}, \mathrm{T}, \\
\mathrm{A}, \mathrm{T}\end{array}$ & $0.6 \mathrm{~m}^{2}$ \\
\hline
\end{tabular}


Table 4-27 TBIPV/T collector parameters for the solar concentration vs dispersion analysis

\begin{tabular}{|c|c|}
\hline$K$ & $4 \mathrm{~m}^{-1}$ \\
\hline$l_{g}$ & $0.0032 \mathrm{~m}$ \\
\hline$n$ & 1.526 \\
\hline$k_{g}$ & $3.78 \mathrm{~kJ} / \mathrm{hr} \cdot \mathrm{m} \cdot \mathrm{K}$ \\
\hline$R_{p v-u}$ & $0.000847 \mathrm{~kJ} / \mathrm{hr} \cdot \mathrm{m}^{2} \cdot \mathrm{K}$ \\
\hline$w$ & $1.6 \mathrm{~m}$ \\
\hline$L$ & $1 \mathrm{~m}$ \\
\hline$d$ & $0.0635 \mathrm{~m}$ \\
\hline$R_{i n s}$ & $1.9562 \mathrm{hr} \cdot \mathrm{m}^{2} \cdot \mathrm{K} / \mathrm{kJ}$ \\
\hline$\epsilon_{c}$ & 0.6 \\
\hline$\epsilon_{u}$ & 0.9 \\
\hline$\epsilon_{l}$ & 0.9 \\
\hline$P F$ & 0.85 \\
\hline$\alpha_{l}$ & 0.9 \\
\hline
\end{tabular}

Table 4-28 BISAH collector parameters for the solar concentration vs dispersion analysis

\begin{tabular}{|c|c|}
\hline$K$ & $4 \mathrm{~m}^{-1}$ \\
\hline$l_{g}$ & $0.0032 \mathrm{~m}$ \\
\hline$n$ & 1.526 \\
\hline$k_{g}$ & $3.78 \mathrm{~kJ} / \mathrm{hr} \cdot \mathrm{m} \cdot \mathrm{K}$ \\
\hline$R_{p v-u}$ & $0.000847 \mathrm{~kJ} / \mathrm{hr} \cdot \mathrm{m}^{2} \cdot \mathrm{K}$ \\
\hline$d$ & $0.0635 \mathrm{~m}$ \\
\hline$R_{i n s}$ & $1.9562 \mathrm{hr} \cdot \mathrm{m}^{2} \cdot \mathrm{K} / \mathrm{kJ}$ \\
\hline$\epsilon_{c}$ & 0.6 \\
\hline$\epsilon_{u}$ & 0.1 \\
\hline$\epsilon_{l}$ & 0.1 \\
\hline$\alpha_{l}$ & 0.9 \\
\hline
\end{tabular}

The heating season thermal energy and electrical energy generated is shown in Table 4-29. For TBIPV/T systems, it is more efficient to concentrate the BISAH collector(s) at the end of the row, regardless of the area of BISAH collector $\left(0.8 \mathrm{~m}^{2}\right.$ to $\left.2.4 \mathrm{~m}^{2}\right)$. This can be explained by examining the thermal and electrical energy per collector for the heating season in Table 4-30 and Table 4-31, respectively. 
Table 4-29 Heating season generated thermal and electrical energy for Set $E, F$, and G rows

\begin{tabular}{|c|c|c|c|}
\hline \multirow{2}{*}{ Set ID } & Row ID & $\begin{array}{c}\text { Thermal energy generated } \\
(\mathrm{kWh})\end{array}$ & $\begin{array}{c}\text { Electrical energy } \\
\text { generated }(\mathrm{kWh})\end{array}$ \\
\hline \multirow{2}{*}{$\begin{array}{c}\text { Set E } \\
(\text { Total BISAH area: } \\
\left.0.8 \mathrm{~m}^{2}\right)\end{array}$} & $\mathrm{E} 1$ & 1892 & 770 \\
\cline { 2 - 4 } & $\mathrm{E} 2$ & 1842 & 769 \\
\cline { 2 - 4 } $\begin{array}{c}\text { Set F } \\
(\text { Total BISAH area: } \\
\left.1.6 \mathrm{~m}^{2}\right)\end{array}$ & $\mathrm{E} 3$ & 1856 & 769 \\
\cline { 2 - 4 } & $\mathrm{F} 1$ & 2304 & 770 \\
\hline \multirow{2}{*}{$\begin{array}{c}\text { Set G } \\
\text { Total BISAH area: }\end{array}$} & $\mathrm{F} 3$ & 2204 & 768 \\
\cline { 2 - 4 } $\left.2.4 \mathrm{~m}^{2}\right)$ & $\mathrm{G} 1$ & 2232 & 770 \\
\cline { 2 - 4 } & $\mathrm{G} 2$ & 2709 & 767 \\
\hline
\end{tabular}

In Table 4-30, the $2^{\text {nd }}$ and $4^{\text {th }}$ collectors of E2 and the $6^{\text {th }}$ (last) collector of E1 are BISAH collectors; it can be seen that the scattered collectors generate more thermal energy overall (439 $\mathrm{kWh}$ ) than the larger concentrated collector $(421 \mathrm{kWh})$. This is because the air flowing through the scattered collectors is cooler than the air at the end of row E1. However, in Row E2, because the BISAH were placed at positions closer to the start of the row, where the air is cooler, the BISAH collectors greatly heats the air for the TBIPV/T collectors following the first collector. Comparing the $2^{\text {nd }}$ collector from row E1 and $3^{\text {rd }}$ collector from Row E2 (both are the $2^{\text {nd }} \mathrm{TBIPV} / \mathrm{T}$ collectors of their respective rows) it can be seen that the Row E2 collector generates less thermal energy (280 kWh), compare to the Row E1 collector (291 kWh). This is because the preceding BISAH in Row E2 made the air warmer and thus, the thermal efficiency of the 2nd TBIPV/T collector in Row E2 is lower. This can also be seen in a comparison of the $3^{\text {rd }}, 4^{\text {th }}$, and $5^{\text {th }}$ TBIPV/T collectors of the two rows.

The overall electricity generated also decreases as shown in Table 4-31, this is due to the same phenomenon that leads to diminished thermal energy gains; the air flowing through each TBIPV/T collector in Row E1 is warmer than their counterpart collector in Row E1, thus the PV temperature increases and the electricity generated decreases. 
Table 4-30 Heating season thermal energy generated by Row E1 and E2

\begin{tabular}{|c|c|c|c|c|c|c|c|c|}
\hline & \multicolumn{7}{|c|}{ Collector order } & Total \\
& & & & & & & & \\
thermal \\
energy \\
Row ID & 1 & 2 & 3 & 4 & 5 & 6 & 7 & $(\mathrm{kWh})$ \\
\hline E1 & 388 & 291 & 277 & 264 & 252 & 421 & - & 1892 \\
\hline E2 & 388 & 222 & 280 & 217 & 257 & 245 & 234 & 1842 \\
\hline
\end{tabular}

Table 4-31 Heating season electrical energy generated by Row E1 and E2

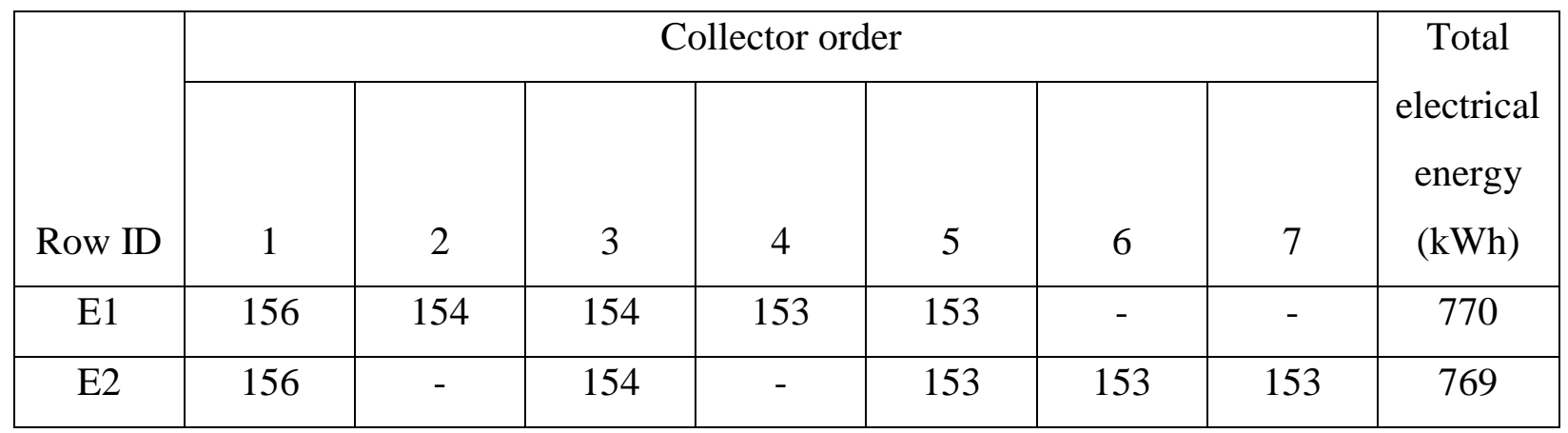

\subsection{BIPV/T coupled ASHP system}

In this study, two integrated BIPV/T coupled ASHP system are presented. Two different houses were equipped with the same BIPV/T array and similar ASHP; one house is a house intended to be net-zero energy and the other is an energy efficient house. A heating season study of the two houses in Toronto was conducted. Over the study period, the flowrate of the BIPV/T system was modulated by the ASHP, according to its needs in satisfying the heating load of the house and the fan power consumed by operating the BIPV/T. In the hours when the BIPV/T could not provide energy savings in terms of electricity overall, the flow through BIPV/T was set to 0 $\mathrm{kg} / \mathrm{s}$ and outdoor air was used by the ASHP as the heat source. These results were compared to the base case of the same hours with the same ASHP but without a BIPV/T system.

\subsubsection{Net-zero energy house}

\subsubsection{Description of the NZE house}

The house was based on a house design that a student organized group, EcoStudio developed for real world residential energy system research and monitoring facility that is slated 
for construction at the TRCA BRE Innovation Park. A description of the house's construction is presented in Table 4-32 and a Sketchup model of the house is presented in Figure 4-49.

Table 4-32 Net-zero energy house construction

\begin{tabular}{|c|c|}
\hline Parameter & Parameter value \\
\hline Wall & $7.40 \mathrm{RSI}$ \\
\hline Roof & $8.85 \mathrm{RSI}$ \\
\hline Window & $0.383 \mathrm{RSI}$ \\
\hline Floor & $4.50 \mathrm{RSI}$ \\
\hline BIPV/T Roof slope & $35^{\circ}$ \\
\hline BIPV/T Roof cardinal direction & South \\
\hline Volume & $460 \mathrm{~m}^{3}$ \\
\hline Gross area & $182 \mathrm{~m}^{2}$ \\
\hline
\end{tabular}

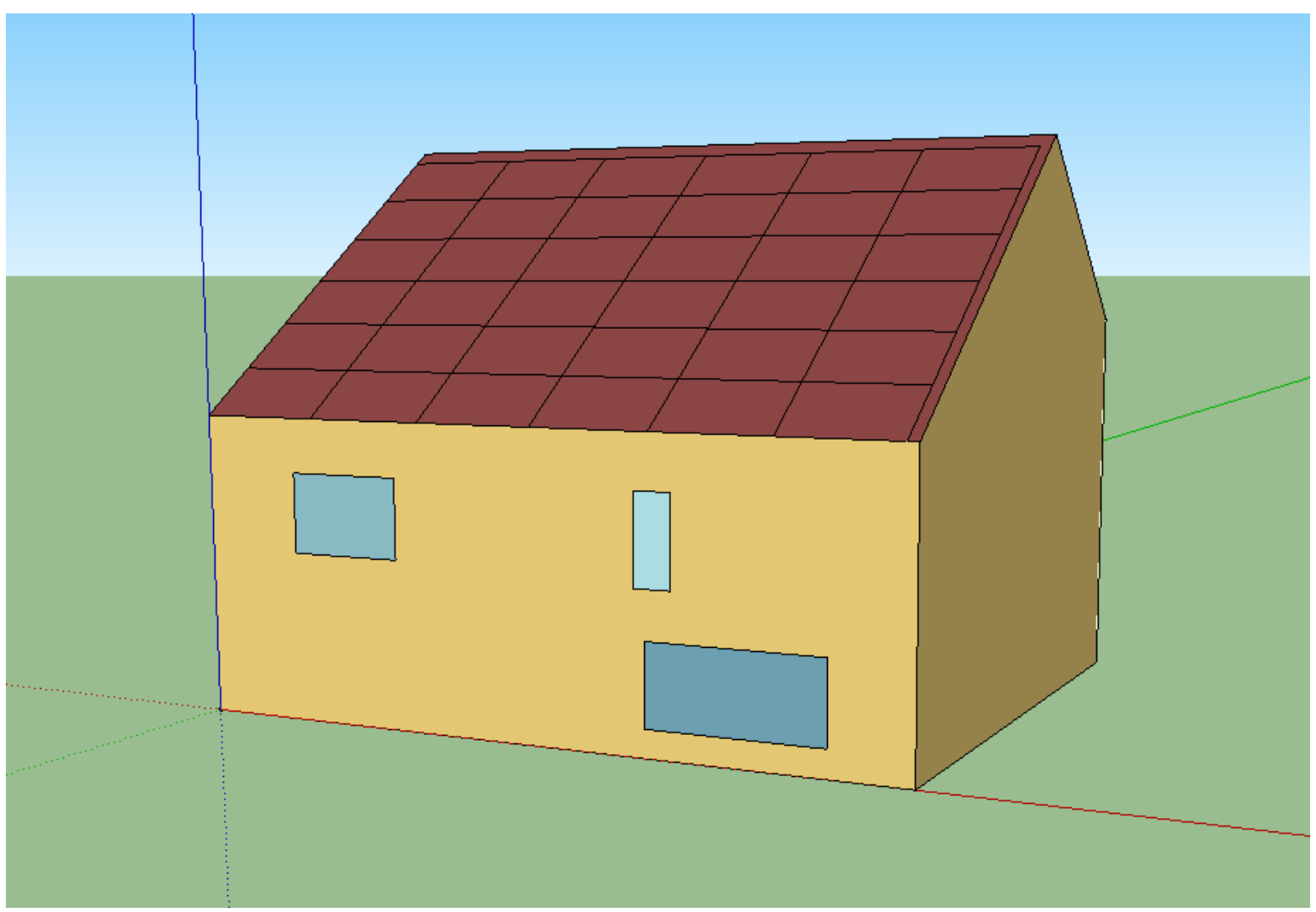

Figure 4-49 Sketchup model of the NZE house 


\subsubsection{Mechanical HVAC system}

The main components simulated contain a constant air volume (CAV) system, an energy recovery ventilator (ERV) and a MSHP. The CAV system was chosen because the performance for the HP listed a single indoor flowrate; the system operates a cycling on and off fan-compressor system where the fan and compressor cycle on and off in unison to handle the heating load. The performance parameters used for the ERV simulation came from a base dataset provided in an EnergyPlus example file; the flowrates were changed to satisfy the NZE house's fresh air requirements. The fresh air requirements were based on $0.3 \mathrm{ACH}$ - it was assumed that infiltration supplied $0.0032 \mathrm{~m}^{3} / \mathrm{s}$ (for $0.025 \mathrm{ACH}$ at $1 \mathrm{~atm}$ or $0.5 \mathrm{ACH}$ at $50 \mathrm{~Pa}$ ) and the ERV supplied 0.0352 $\mathrm{m}^{3} / \mathrm{s}$. The MSHP used in the simulation was a scaled version of the one used for the energy efficient house simulation (Section 4.3.2); the rated capacity and flowrate (indoor and outdoor) were scaled down by 50\%; the parameters of the MSHP used in the simulation is summarized in Table 4-33. The original performance data can be found in Appendix B.

Table 4-33 MSHP simulation parameters for the NZE house

\begin{tabular}{|c|c|}
\hline Parameter & Parameter value \\
\hline $\begin{array}{r}\text { Rated capacity }\left(8.3^{\circ} \mathrm{C} \text { outdoor door, } 21\right. \\
\left.\text { indoor }{ }^{\circ} \mathrm{C}\right) \text { at max. speed }\end{array}$ & $3459.5 \mathrm{~W}$ \\
\hline $\begin{array}{r}\text { Rated indoor flowrate at max. speed } \\
\text { Rated COP }\left(8.3^{\circ} \mathrm{C} \text { outdoor door, } 21 \text { indoor }\right. \\
\left.{ }^{\circ} \mathrm{C}\right) \text { at max. speed }\end{array}$ & $0.2125 \mathrm{~m}^{3} / \mathrm{s}$ \\
\hline $\begin{array}{r}\text { Rated capacity }\left(8.3^{\circ} \mathrm{C} \text { outdoor door, } 21\right. \\
\left.\text { indoor }{ }^{\circ} \mathrm{C}\right) \text { at min. speed }\end{array}$ & 4.705 \\
\hline Rated indoor flowrate at min. speed & $2126 \mathrm{~W}$ \\
\hline $\begin{array}{r}\text { Rated COP }\left(8.3^{\circ} \mathrm{C} \text { outdoor door, } 21 \text { indoor }\right. \\
\left.{ }^{\circ} \mathrm{C}\right) \text { at min. speed }\end{array}$ & $0.118 \mathrm{~m}^{3} / \mathrm{s}$ \\
\hline Outdoor (source) air flowrate & 5 \\
\hline
\end{tabular}

\subsubsection{Description of the BIPV/T-BISAH array system for the NZE house}

A BIPV/T-BISAH system was used and it consisted of 6 rows, where each row contained $5 \mathrm{TBIPV} / \mathrm{T}$ collectors and a single BISAH collector at the end for a total of $36 \mathrm{BIPV} / \mathrm{T}$ collectors 
in this system. The parameters of the TBIPV/T and BISAH collectors are presented in Table 4-34 and Table 4-35, respectively.

Table 4-34 TBIPV/T collector parameters of the 6x6 BIVP/T-BISAH system

\begin{tabular}{|c|c|}
\hline$K$ & $4 \mathrm{~m}^{-1}$ \\
\hline$l_{g}$ & $0.0032 \mathrm{~m}$ \\
\hline$n$ & 1.526 \\
\hline$k_{g}$ & $3.78 \mathrm{~kJ} / \mathrm{hr} \cdot \mathrm{m} \cdot \mathrm{K}$ \\
\hline$R_{p v-u}$ & $0.000847 \mathrm{~kJ} / \mathrm{hr} \cdot \mathrm{m}^{2} \cdot \mathrm{K}$ \\
\hline$w$ & $1.6 \mathrm{~m}$ \\
\hline$L$ & $1 \mathrm{~m}$ \\
\hline$d$ & $0.0635 \mathrm{~m}$ \\
\hline$R_{\text {ins }}$ & $1.9562 \mathrm{hr} \cdot \mathrm{m}^{2} \cdot \mathrm{K} / \mathrm{kJ}$ \\
\hline$\epsilon_{c}$ & 0.6 \\
\hline$\epsilon_{u}$ & 0.9 \\
\hline$\epsilon_{l}$ & 0.9 \\
\hline$P F$ & 0.9 \\
\hline$\alpha_{l}$ & 0.9 \\
\hline
\end{tabular}

Table 4-35 BISAH collector parameters of the 6x6 BIVP/T-BISAH system

\begin{tabular}{|c|c|}
\hline$K$ & $4 \mathrm{~m}^{-1}$ \\
\hline$l_{g}$ & $0.0032 \mathrm{~m}$ \\
\hline$n$ & 1.526 \\
\hline$k_{g}$ & $3.78 \mathrm{~kJ} / \mathrm{hr} \cdot \mathrm{m} \cdot \mathrm{K}$ \\
\hline$w$ & $1.6 \mathrm{~m}$ \\
\hline$L$ & $1 \mathrm{~m}$ \\
\hline$d$ & $0.0635 \mathrm{~m}$ \\
\hline$R_{i n s}$ & $1.9562 \mathrm{hr} \cdot \mathrm{m}^{2} \cdot \mathrm{K} / \mathrm{kJ}$ \\
\hline$\epsilon_{c}$ & 0.6 \\
\hline$\epsilon_{u}$ & 0.1 \\
\hline$\epsilon_{l}$ & 0.1 \\
\hline$P F$ & 0.9 \\
\hline$\alpha_{l}$ & 0.9 \\
\hline
\end{tabular}

The fan model used in the simulation to draw the air through the BIPV/T-BISAH and draw outdoor air for mixing was detailed in Section 3.8.3.1. When mixing, it was assumed that there were two fans drawing in air and directing it to the MSHP; one for BIPV/T-BISAH array and another for the outdoor air stream. The parameters of the BIPV/T-BISAH fan and the outdoor air fan are 
presented in Table 4-36 and Table 4-37, respectively. The performance coefficients were taken from an EnergyPlus example of a variable fan object. In normal standalone operation, additional fan power was not estimated.

Table 4-36 BIPV/T-BISAH air supply variable speed fan parameters

\begin{tabular}{|c|c|}
\hline Fan parameter & Parameter value \\
\hline$\Delta P_{\text {design,PVT }}$ & $42 \mathrm{~Pa}$ \\
\hline$\dot{m}_{\text {design }}\left(\dot{m}_{H P}\right)$ & $0.75 \mathrm{~kg} / \mathrm{s}$ \\
\hline$\eta_{\text {fan }}$ & 0.9 \\
\hline$c_{1}$ & 0.35071223 \\
\hline$c_{2}$ & 0.30850535 \\
\hline$c_{3}$ & -0.54137364 \\
\hline$c_{4}$ & 0.8718823 \\
\hline$c_{5}$ & 0 \\
\hline
\end{tabular}

Table 4-37 Outdoor air supply variable speed fan parameters

\begin{tabular}{|c|c|}
\hline Fan parameter & Parameter value \\
\hline$\Delta P_{\text {design,outdoor Air }}$ & $2 \mathrm{~Pa}$ \\
\hline$\dot{m}_{\text {design }}\left(\dot{m}_{H P}\right)$ & $0.75 \mathrm{~kg} / \mathrm{s}$ \\
\hline$\eta_{f a n}$ & 0.9 \\
\hline$c_{1}$ & 0.35071223 \\
\hline$c_{2}$ & 0.30850535 \\
\hline$c_{3}$ & -0.54137364 \\
\hline$c_{4}$ & 0.8718823 \\
\hline$c_{5}$ & 0 \\
\hline
\end{tabular}

\subsubsection{Simulation results - NZE house}

A heating simulation of the house with the same MSHP was completed with and without a BIPV/T system. The base case, without a BIPV/T system the MSHP outputted $4300 \mathrm{kWh}$ of thermal energy (i.e., the actual energy supplied by the MSHP to the zone) over the heating season 
in Toronto, Canada and the MSHP consumed $1258 \mathrm{kWh}$ of electricity, thus an seasonal COP of 3.41. The same house and ASHP equipped with the BIPV/T-BISAH array, over the same heating season, the MSHP outputted $4067 \mathrm{kWh}$ of thermal energy, the BIPV/T-BISAH coupled MSHP consumed $1169 \mathrm{kWh}$ of electricity, and the additional fans consumed $7 \mathrm{kWh}$ of electricity (seasonal COP of 3.46). Overall, the integrated BIPV/T-BISAH coupled MSHP system reduced space heating electricity consumption by $6.5 \%$ over the heating season. This is largely due to passive features of the houses and such that it requires limited heating during the day when the BIPV/T-BISAH is the most efficient; thus, there is a mismatch between solar availability and heating demand.

The BIPV/T-BISAH was used for 430.67 hours (20 min timesteps were used) out of the 2524 hours when the sun was shining; hence it was used approximately $17 \%$ of the time hours with sunlight. Tardif et al. (2017) controlled their BIPV/T coupled ASHP by operating the BIPV/T only if the irradiance was greater than $50 \mathrm{~W} / \mathrm{m}^{2}$. Therefore, considering the hours where the irradiance was greater than $50 \mathrm{~W} / \mathrm{m}^{2}$, the BIPV/T-BISAH was used approximately $23 \%$ of the time.

On December $29^{\text {th }}$, from 10 am to $4 \mathrm{pm}$, the BIPV/T-BISAH is in continuous operation. In Figure 4-50, the modulated BIPV/T-BISAH system air flowrate and the outdoor air flowrate are presented, together they sum to $0.75 \mathrm{~kg} / \mathrm{s}$ (the MSHP required source flowrate scaled by $50 \%$ ). For the air leaving the array system, this range of mass flowrate translate to 2.5 to $4.5 \mathrm{~m} / \mathrm{s}$. As can be seen, most of the flowrate is delivered by the BIPV/T-BISAH system; on average, for this day, the BIPV/T-BISAH supplies $71 \%$ of the required air flowrate of the MSHP. 


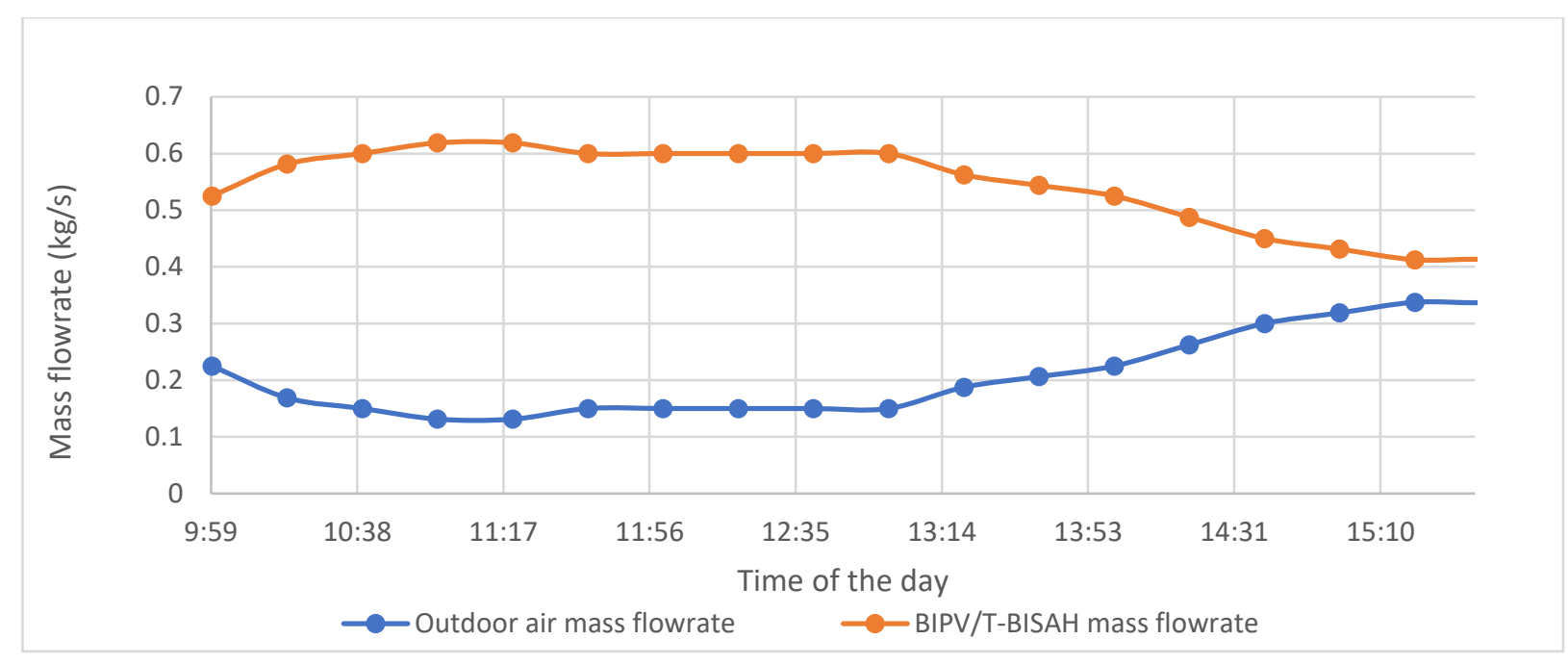

Figure 4-50 BIPV/T-BISAH and outdoor air flowrate for December $29^{\text {th }}$

The BIPV/T-BISAH system preheats the air, and mixes it with outdoor air to form mixed air that is supplied to the MSHP. The temperature of these air streams is shown in Figure 4-51. As it can be seen, the mixing lowered the air temperature.

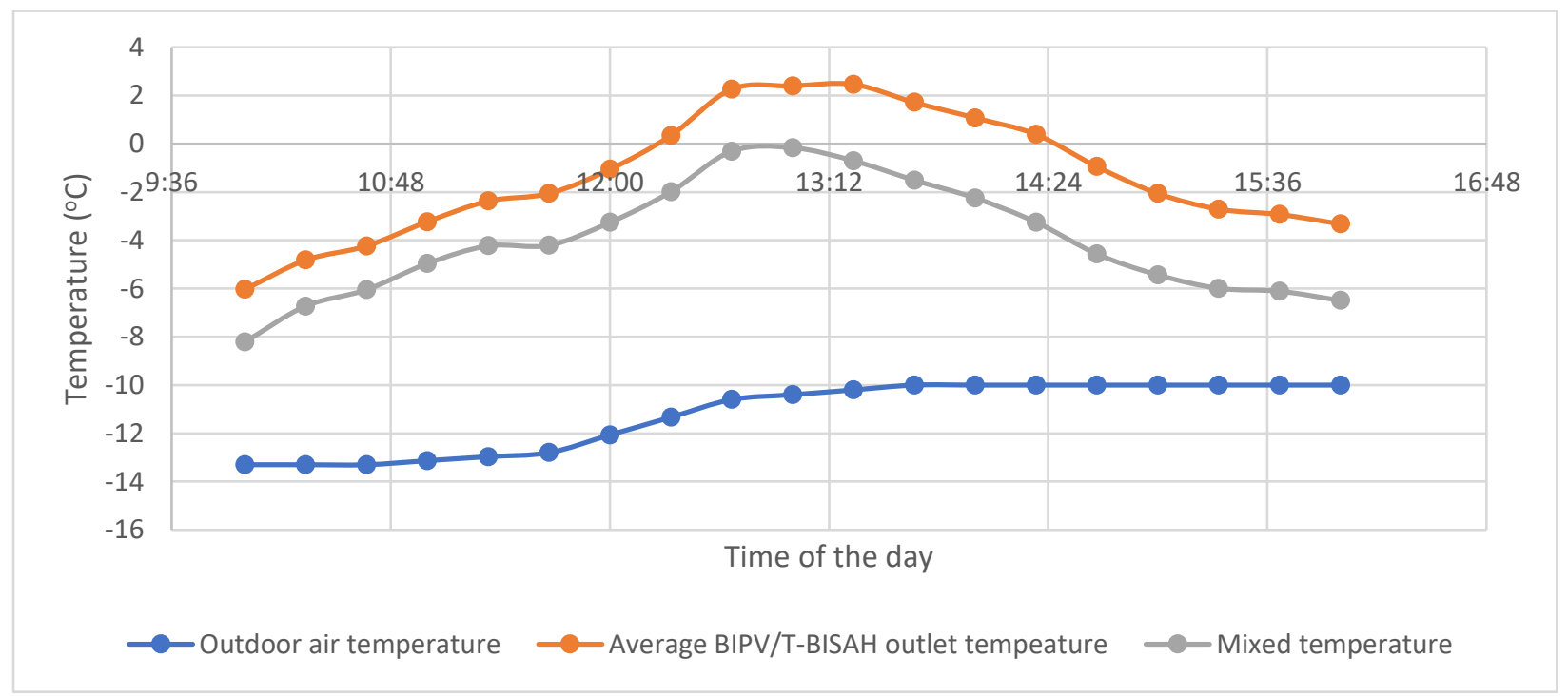

Figure 4-51 BIPV/T-BISAH average outlet temperature, outdoor temperature, and mixed air temperature for December $29^{\text {th }}$

During these hours, the electricity consumption of the integrated BIPV/T-BISAH coupled MSHP system and the MSHP in the base case are shown in Figure 4-52. 


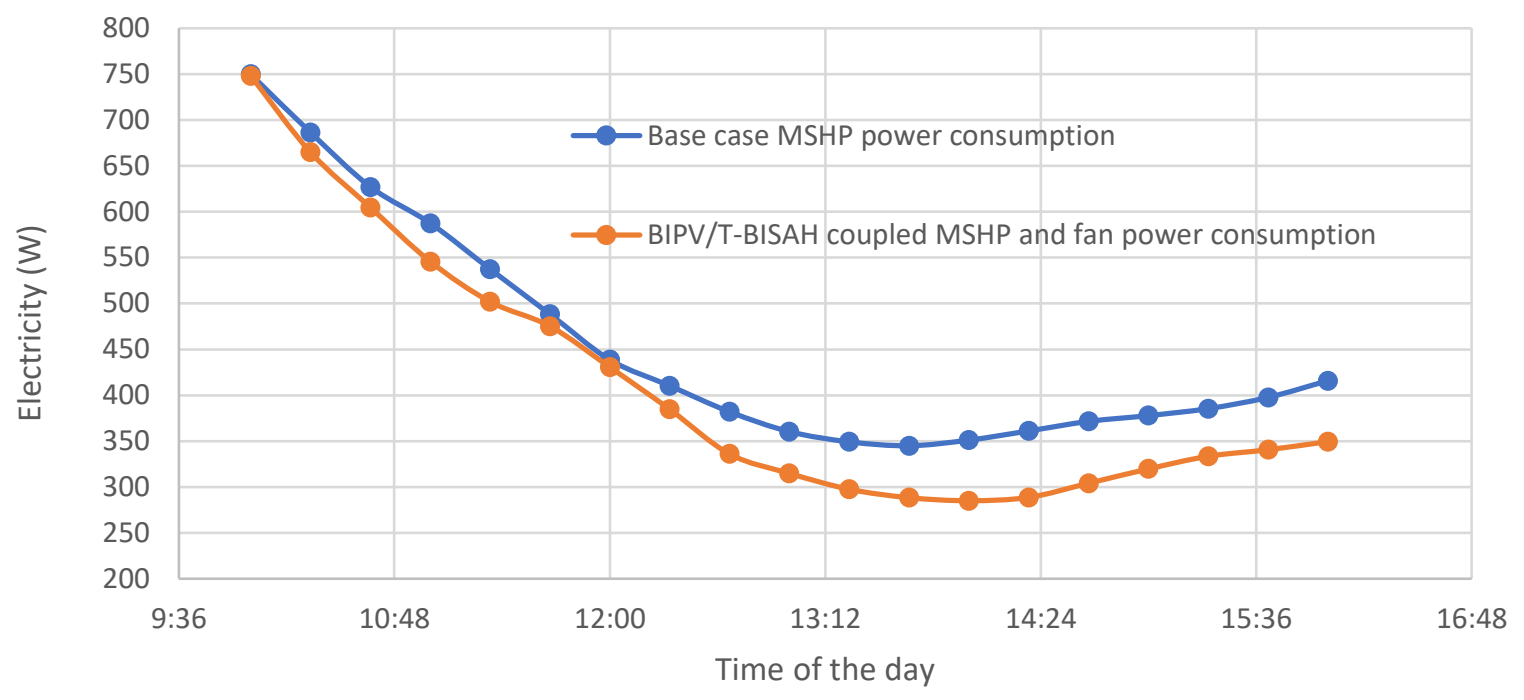

Figure 4-52 BIPV/T-BISAH coupled MSHP and base case MSHP electricity consumption

\subsubsection{Energy efficient house}

\subsubsection{Description of the energy efficient house}

The energy efficient house was based on the TRCA Archetype House A located in Vaughan, Canada (Kamel and Fung, 2014). The design of the house is architecturally different but the construction material is based on House A. The house's construction details are presented in Table 4-38 and a Sketchup model of the house is presented in Figure 4-53.

Table 4-38 Energy efficient house construction

\begin{tabular}{|c|c|}
\hline Parameter & Parameter value \\
\hline Wall & 5.62 RSI \\
\hline Roof & 7.04 RSI \\
\hline Window & 0.383 RSI \\
\hline Floor & 1.85 RSI \\
\hline BIPV/T Roof slope & $35^{\circ}$ \\
\hline BIPV/T Roof cardinal direction & South \\
\hline Volume & $933 \mathrm{~m}^{3}$ \\
\hline Gross area & $182 \mathrm{~m}^{2}$ \\
\hline
\end{tabular}




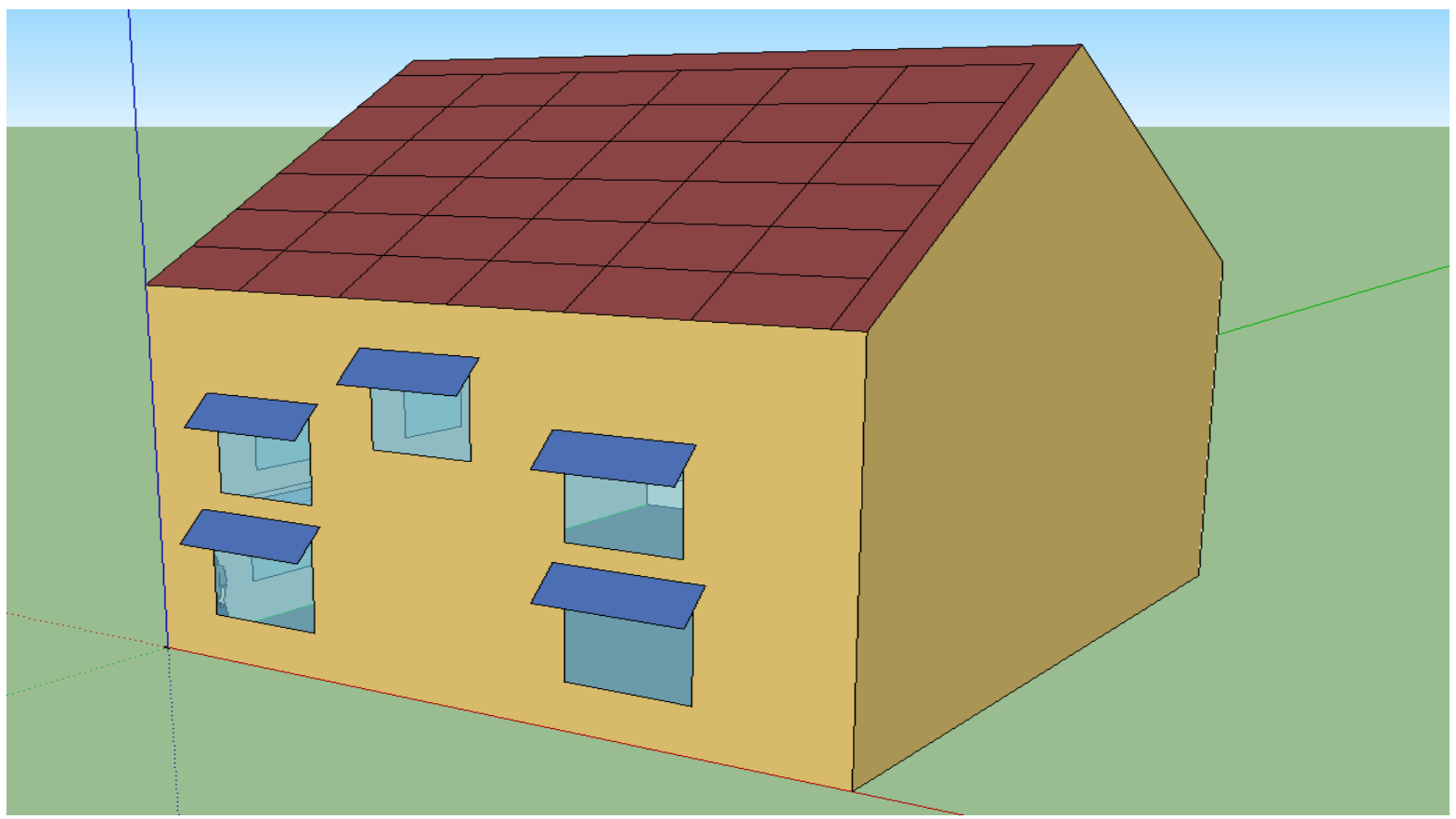

Figure 4-53 Sketchup model of the energy efficient house

\subsubsection{Mechanical HVAC system}

The same mechanical HVAC system that was used in simulating the NZE house was used in the simulation of the energy efficient house with a few parameters adjusted. The fresh air required was based on $0.3 \mathrm{ACH}$ and it was assumed that the infiltration supplied $0.0156 \mathrm{~m}^{3} / \mathrm{s}$ (for $0.0602 \mathrm{ACH}$ at $1 \mathrm{~atm}$, or $1.2 \mathrm{ACH}$ at $50 \mathrm{~Pa}$ ) and the ERV supplied $0.062 \mathrm{~m}^{3} / \mathrm{s}$. The MSHP used was unscaled; the data was directly from the performance table presented in Appendix B. the parameters of the MSHP used in this simulation is presented in Table 4-39. 
Table 4-39 MSHP simulation parameters for the energy efficient house

\begin{tabular}{|c|c|}
\hline Parameter & Parameter value \\
\hline $\begin{array}{r}\text { Rated capacity }\left(8.3^{\circ} \mathrm{C} \text { outdoor door, } 21\right. \\
\left.\text { indoor }{ }^{\circ} \mathrm{C}\right) \text { at max. speed }\end{array}$ & $6919 \mathrm{~W}$ \\
\hline $\begin{array}{r}\text { Rated indoor flowrate at max. speed } \\
\text { Rated COP }\left(8.3^{\circ} \mathrm{C} \text { outdoor door, 21 indoor }\right. \\
\left.{ }^{\circ} \mathrm{C}\right) \text { at max. speed }\end{array}$ & $0.425 \mathrm{~m}^{3} / \mathrm{s}$ \\
\hline $\begin{array}{r}\text { Rated capacity }\left(8.3{ }^{\circ} \mathrm{C} \text { outdoor door, } 21\right. \\
\left.\text { indoor }{ }^{\circ} \mathrm{C}\right) \text { at min. speed }\end{array}$ & 4.705 \\
\hline Rated indoor flowrate at min. speed & $4252 \mathrm{~W}$ \\
\hline $\begin{array}{r}\text { Rated COP }\left(8.3^{\circ} \mathrm{C} \text { outdoor door, } 21 \text { indoor }\right. \\
\left.{ }^{\circ} \mathrm{C}\right) \text { at min. speed }\end{array}$ & $0.236 \mathrm{~m}^{3} / \mathrm{s}$ \\
\hline Outdoor (source) air flowrate & $1.274 \mathrm{~m}^{3} / \mathrm{s}$ \\
\hline
\end{tabular}

\subsubsection{Description of the BIPV/T-BISAH array system for the energy efficient house}

The same BIPV/T array system used in the simulation of the NZE house was used for the energy efficient house.

\subsubsection{Simulation results-energy efficient house}

A heating simulation of the energy efficient house with the MSHP in Toronto, Canada with and without a coupled BIPV/T-BISAH system was conducted. For the base case (house with ASHP) the MSHP outputted $10849 \mathrm{kWh}$ of thermal energy (i.e., heating energy supplied to the zone by the MSHP) and the MSHP consumed $3102 \mathrm{kWh}$ of electricity (seasonal COP of 3.5). The energy efficient house with the BIPV/T-BISAH coupled MSHP outputted $10582 \mathrm{kWh}$ of thermal energy, the MSHP consumed $2979 \mathrm{kWh}$ of electricity (with seasonal COP of 3.55), and the fan power consumed $16 \mathrm{kWh}$ of electricity. Overall the BIPV/T-BISAH coupled MSHP system reduced the heating electricity consumption by $107 \mathrm{kWh}$ or $3.4 \%$.

In this simulation with the energy efficient house, the BIPV/T-BISAH system was used for 495.67 hours out of 2524 sunny hours or approximately $20 \%$; similarly, considering only the hours where the irradiance was greater than $50 \mathrm{~W} / \mathrm{m}^{2}$, the BIPV/T was on for $26 \%$ of the time. 


\subsubsection{BIPV/T-BISAH coupled MSHP for different houses}

In this work, the same BIPV/T-BISAH array system was used on two different houses, a comparison of the houses show that the energy efficient house saves more energy over the year because it operates the BIPV/T system for more hours. The NZE house did not use the BIPV/TBISAH system as often as the energy efficient house because the NZE house was designed to require minimal heating during the day for most days. Therefore, there were less opportunities to reduce heating during the day. Additionally, on a relative scale, because the NZE was designed to consume minimal energy, it is harder for additional system to further introduce energy savings. The BIPV/T-BISAH system reduces the heating electricity usage by $6.5 \%$, compared to the $3.4 \%$ reduction of the energy efficient house.

\subsubsection{Limitations on the energy savings of integrated BIPV/T-BISAH coupled MSHP systems}

The low savings of the BIPV/T-BISAH system is attributed to several factors, a few based on the weather and modeling limits. Firstly, the wind data may not be accurate, as wind speed is heavily dependent on the surrounding structure and location throughout the city. With respect to simulation limits, the savings presented are based on a single ASHP, a different ASHP may perform differently when operating with the same outdoor conditions, that is, an increase in source temperature for one flowrate yields a certain change in COP, however, a different ASHP may yield a different change in COP. This is due to different heat exchanger designs. For this work due to limited HP performance data for the outdoor temperature range that is common in Toronto, only one dataset was used for the analysis. As Payne et al., (2009) and Li et al., (2015), the actual flowrate through the outdoor unit of the MSHP can be an additional variable that influences COP. That is, increasing the flowrate increases the COP as more heat transfers to the refrigerant, which increases the superheat at the evaporator exit and reduces compressor power consumption. However, this was not simulated due to a limitation in variable capacity HP performance data. Hence, the low level of savings presented is a combination of several factors. 


\subsection{Conclusion}

In this work, enhancements to BIPV/T systems were presented, analyzed, and evaluated, in simulation, as an integrated BIPV/T-BISAH coupled MSHP system installed as the sole heating system in two different houses located in Toronto, Canada. For the analysis, OBIPV/T, TBIPV/T, BISAH, and flow modulated MSHP coupled with BIPV/T-BISAH array model were incorporated into EnergyPlus V8.0 for simulation. Analyses of the effect of individual collector's air channel surface's and the glass cover's emissivity on its performance were conducted. In addition, an investigation on the arrangement of OBIPV/T, TBIPV/T, and BISAH collectors in a single row system was also completed. A BIPV/T-BISAH array system developed from the results of these analyses were simulated using an energy efficient and NZE home and the results presented.

The collector models used were quasi-steady state models and implemented into EnergyPlus V8.0's source code; the original program did not have detailed BIPV/T-BISAH collector models. As part of this work, the BISAH collector and flow modulated MSHP model were developed. The BISAH collector was developed base on energy balances and the flow modulated MSHP model was based on the Coil:Heating:DX:Multispeed object in EnergyPlus V8.0; the OBIPV/T and TBIPV/T collector models used were slightly modified from their original Type 298 and Type 289.

A parametric sensitivity analysis was conducted to investigate the enhancement in thermal and electrical performance of the collectors of interest as individual systems and in a row configuration. The results showed the performance of OBIPV/T collectors can be improved by using high internal air channel surface emissivities, while the performance of BISAH collectors were enhanced for low emissivities, regardless of collector position along the air path. In contrast, the performance of TBIPV/T collectors were optimized by enhancing the collectors at the start of the row with high internal emissivities and the collectors at the end with low internal emissivities. The use of high or low internal emissivities depend how frequent and at what hours of the day the individual collectors; collectors with an upper internal channel surface that is warmer than the lower surface benefits from high internal emissivities and the collectors with warmer lower surfaces benefit from low internal emissivities. In either case, the high or low emissivities reduce losses to the environment and allows the collectors to retain more of the solar energy it collected. With respect to cover emissivity, its effects on OBIPV/T and TBIPV/T collectors were the same: lowering the cover emissivity increases thermal energy and decreases electricity generation in a 
14:1 ratio for a row of 6 TBIPV/T collectors and 12:1 ratio for a row of 6 OBIPV/T collectors. These ratios depend on the collector parameters.

The collector arrangement analyses of OBIPV/T, TBIPV/T, and BISAH showed that the arrangement of the collectors greatly affect the overall row performance. The addition of a BISAH to the end of a row of OBIPV/T collector increased performance, however it was also shown that for certain configuration, enhanced TBIPV/T collectors could perform just as well while requiring less area and collectors. Lastly, the analysis also determined that placing BISAH at the end of a row to concentrate the solar radiation at one location was better than dispersing the solar collection at various points throughout the air path. This is due to the BISAH heating the air at the beginning of the flow path and lowering the thermal and electrical efficiencies of the collectors that followed.

Finally, a heating season long simulation of a NZE house and an energy efficient house, both located in Toronto, using the same integrated BISAH-BISAH coupled MSHP systems was conducted. For the NZE, the integrated BISAH-BISAH coupled MSHP reduced space heating demand and MSHP energy consumption, overall the system reduced electricity consumption by $82 \mathrm{kWh}(6.5 \%)$. For the energy efficient house, the integrated system reduced electricity consumption by $107 \mathrm{kWh}(3.4 \%)$. This is largely due to passive features of the houses and such that it requires relatively limited heating during the day when the BIPV/T-BISAH is most efficient; thus there was a mismatch between solar availability and heating demand. 


\subsection{Future work and recommendation}

The following research are recommended:

- Develop of collectors with flow arrangements that reduce convective and radiative losses.

- Develop empirical variable capacity air source heat pump performance data to include the outdoor unit's air flowrate. This will allow consideration of increased air flow as additional variable that enhances COP.

- Integration of the BIPV/T-BISAH coupled ASHP to thermal storage systems should be investigated for energy efficient houses. This is due to the mismatch between the availability of solar energy and space heating demand. Integrating the BIPV/T-BISAH coupled ASHP system to thermal storage systems will increase the overall usage of the device which would be provided additional opportunities to provide energy savings.

- Develop the coupling between the BIPV/T-BISAH system and a domestic hot water heat pump to increase overall system energy savings when space heating is not required by energy efficient homes.

- Develop a control strategy that integrates the BIPV/T-BISAH array system with the ASHP, thermal storage, and hot water HP. 


\section{Appendix A-Algebraic grouped terms of the BISAH model}

The algebraic terms, $a$ and $b$, are expressed in the following equations:

$$
\begin{gathered}
a=2 \frac{h_{r a d, u-l} h_{a}{ }^{2}}{j m}+\frac{h_{a}{ }^{2}}{m}-2 h_{a}+\frac{h_{a}{ }^{2}}{j}+\frac{h_{r a d, u-l}{ }^{2} h_{a}{ }^{2}}{j^{2} m} \\
b=\frac{h_{a} h_{r a d, u-l} T_{z}}{R_{\text {ins }} j m}+\frac{h_{a} h_{r a d, u-l} S}{j m}+\frac{h_{a} h_{r s} T_{s k y}+h_{a} h_{c} T_{a m b}}{F m}+\frac{h_{a} T_{z}}{R_{\text {ins }} j}+\frac{h_{a} S}{j} \\
+\frac{h_{a} h_{r a d, u-l}{ }^{2} T_{z}}{R_{\text {ins }} j^{2} m}+\frac{h_{a} h_{r a d, u-l}{ }^{2} S}{j^{2} m} \\
+\frac{h_{a} h_{r a d, u-l} h_{r s} T_{s k y}+h_{a} h_{r a d, u-l} h_{c} T_{a m b}}{F m j}
\end{gathered}
$$


Appendix B-Variable speed air source heat pump performance data

The HP performance data used was for the Carrier 25VNA024A**30 (with indoor section FE4ANB006) model. The HP is a variable speed HP.

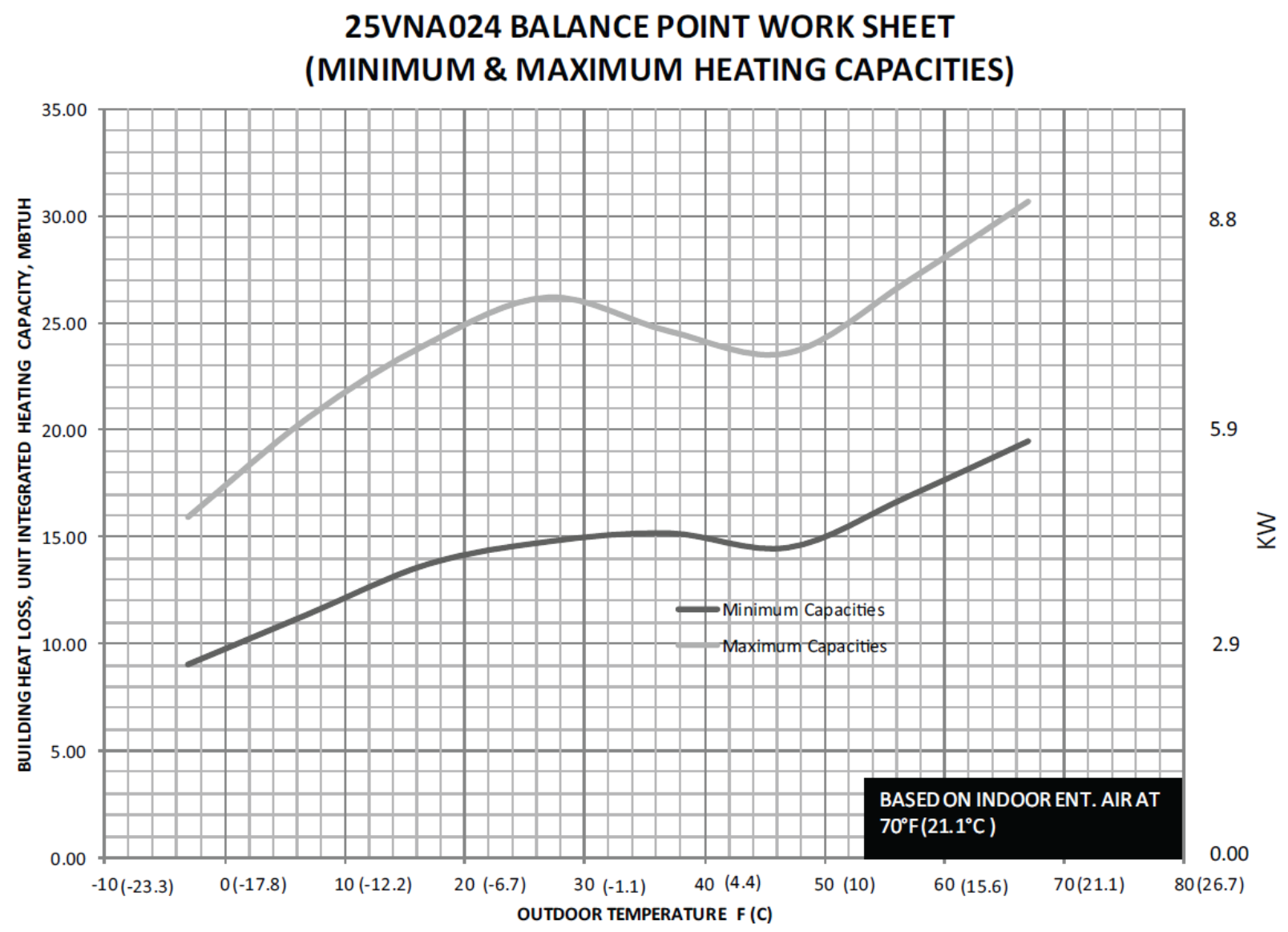

Figure Appendix B-1 25VNA024 Balance point work sheet (Carrier, 2017) 
Table Appendix A -1 25VNA024 performance table

HEAT PUMP HEATING PERFORMANCE

\begin{tabular}{|c|c|c|c|c|c|c|c|c|c|c|c|c|c|c|c|c|}
\hline \multirow{4}{*}{$\begin{array}{c}\text { INDOOR AIR } \\
\text { EDB } \\
{ }^{\circ} \mathrm{F}\left({ }^{\circ} \mathrm{C}\right)\end{array}$} & \multicolumn{16}{|c|}{ OUTDOOR COIL ENTERING AIR TEMPERATURES ${ }^{\circ} \mathrm{F}\left({ }^{\circ} \mathrm{C}\right)$} \\
\hline & \multicolumn{4}{|c|}{$-3(-19.4)$} & \multicolumn{4}{|c|}{$7(-13.9)$} & \multicolumn{4}{|c|}{$17(-8.3)$} & \multicolumn{4}{|c|}{$27(-2.8)$} \\
\hline & \multirow{2}{*}{ ID SCFM } & \multicolumn{2}{|c|}{ Capacity MBtuh } & \multirow{2}{*}{$\begin{array}{l}\text { Total } \\
\text { Sys. } \\
\text { KWH }\end{array}$} & \multirow{2}{*}{ ID SCFM } & \multicolumn{2}{|c|}{ Capacity MBtuh } & \multirow{2}{*}{$\begin{array}{l}\text { Total } \\
\text { Sys. } \\
\text { KW† }\end{array}$} & \multirow{2}{*}{ ID SCFM } & \multicolumn{2}{|c|}{ Capacity MBtuh } & \multirow{2}{*}{$\begin{array}{l}\text { Total } \\
\text { Sys. } \\
\text { KW† }\end{array}$} & \multirow{2}{*}{ ID SCFM } & \multicolumn{2}{|c|}{ Capacity MBtuh } & \multirow{2}{*}{$\begin{array}{l}\text { Total } \\
\text { Sys. } \\
\text { KWH }\end{array}$} \\
\hline & & Total & Integ* & & & Total & Integ* & & & Total & Integ* & & & Total & Integ* & \\
\hline & \multicolumn{16}{|c|}{ 25WA024A*30 Outdoor Section WTh FE4ANB006 Indoor Section - Maximum } \\
\hline $\begin{array}{l}65 \\
(18.3)\end{array}$ & \multirow{3}{*}{900} & 17.60 & 16.19 & 239 & \multirow{3}{*}{900} & 22.65 & 20.82 & 2.68 & \multirow{3}{*}{900} & 26.64 & 24.29 & 2.80 & \multirow{3}{*}{900} & 29.76 & 26.43 & 2.74 \\
\hline $\begin{array}{c}70 \\
(21.1)\end{array}$ & & 1728 & 15.90 & 251 & & 22.37 & 20.56 & 2.83 & & 26.37 & 24.05 & 2.96 & & 29.51 & 26.21 & 2.91 \\
\hline $\begin{array}{c}75 \\
(23.9)\end{array}$ & & 16.92 & 15.57 & 262 & & 22.05 & 20.26 & 2.97 & & 26.09 & 23.79 & 3.12 & & 29.24 & 25.97 & 3.08 \\
\hline \multirow{2}{*}{ INDOOR AIR } & \multicolumn{16}{|c|}{ OUTDOOR COIL ENTERING AIR TEMPERATURES ${ }^{\circ} \mathrm{F}\left({ }^{\circ} \mathrm{C}\right)$} \\
\hline & & & & & & & & & & & & & & & & \\
\hline EDB & ID SCEM & & Bituh & Total & ID SCEM & Caps & Bttuh & Total & ID SCFM & Cape & Bituh & Total & ID SCFU & & MBtuh & Total \\
\hline${ }^{\circ} \mathrm{F}\left({ }^{\circ} \mathrm{C}\right)$ & 10 Scrm & Total & Integ* & KWH & $1050 \mathrm{rm}$ & Total & Integ & KW† & 10 $50 \mathrm{rm}$ & Total & Integ* & $\mathrm{KWH}$ & 10 Schm & Total & Integ* & KWH \\
\hline & & & & & & $24 A^{*+30 C}$ & or Sectio & FEAANE & Indoor Secti & - Maximu & & & & & & \\
\hline $\begin{array}{c}65 \\
(18.3)\end{array}$ & & 27.30 & 24.84 & 202 & & 23.84 & 23.84 & 1.36 & & 27.25 & 27.25 & 1.34 & & 31.00 & 31.00 & 1.33 \\
\hline $\begin{array}{c}70 \\
\text { (21.1) }\end{array}$ & 900 & 27.07 & 24.63 & 2.16 & 900 & 23.60 & 23.60 & 1.47 & 900 & 26.98 & 26.98 & 1.45 & 900 & 30.70 & 30.70 & 1.44 \\
\hline $\begin{array}{c}75 \\
(23.9) \\
\end{array}$ & & 26.83 & 24.41 & 232 & & 23.36 & 23.36 & 1.59 & & 26.71 & 26.71 & 1.57 & & 30.39 & 30.39 & 1.56 \\
\hline INDOOR AR & & & & & & & TDOOR & NTERIN & R TEMPERA & $\overline{E S}{ }^{\circ} F^{\circ} \mathrm{C}$ & & & & & & \\
\hline INUOOH AIR & & & & & & & & & & & & & & & & \\
\hline & IDSCEY & & MBtuh & Total & IDSCEM & Cара & IBtuh & Total & InSCF & Cape & Bituh & Total & IDSCFM & & Mbtuh & Total \\
\hline${ }^{\circ} \mathrm{F}\left({ }^{\circ} \mathrm{C}\right)$ & IOSCrm & Total & Integ* & $\begin{array}{l}\text { Sys. } \\
\text { KW† }\end{array}$ & Ioscrm & Total & Integ* & $\begin{array}{l}\text { Sys. } \\
\text { KW† }\end{array}$ & IUSCFM & Total & Integ* & $\begin{array}{l}\text { Sys. } \\
\text { KW† }\end{array}$ & ID SCFM & Total & Integt & $\begin{array}{l}\text { Sys. } \\
\text { KWH }\end{array}$ \\
\hline & & & & & & $24 A^{* 1+30}$ & or Sectio & FEAAN & Indoor Secti & - Minimu & & & & & & \\
\hline $\begin{array}{c}65 \\
(18.3)\end{array}$ & & 10.11 & 9.30 & 1.34 & & 12.64 & 11.62 & 1.40 & & 15.28 & 13.94 & 1.45 & & 16.85 & 14.97 & 1.37 \\
\hline $\begin{array}{c}70 \\
\text { (21.1) }\end{array}$ & 500 & 9.83 & 9.05 & 1.41 & 500 & 12.41 & 11.40 & 1.48 & 500 & 15.07 & 13.74 & 1.54 & 500 & 16.65 & 14.79 & 1.46 \\
\hline $\begin{array}{c}75 \\
(23.9) \\
\end{array}$ & & 9.53 & 8.76 & 1.47 & & 12.15 & 11.17 & 1.56 & & 14.84 & 13.53 & 1.63 & & 16.44 & 14.60 & 1.56 \\
\hline & & & & & & & TDOORC & NTERIN & R TEMPERA & IES of ('C & & & & & & \\
\hline INDOOR AlR & & & & & & & & & & & & & & & & \\
\hline EDB & ID SCEM & & MBtuh & Total & ID SCEM & Cape & Btituh & Total & ID SCFY & Cape & ABtuh & Total & ID SCEM & & Mbtuh & Total \\
\hline${ }^{\circ} \mathrm{F}\left({ }^{\circ} \mathrm{C}\right)$ & Dovrim & Total & Integ* & $\mathrm{KWH}$ & 10 Jur im & Total & Integ* & KW† & (10) & Total & Integ* & $\mathrm{KW \dagger}$ & 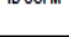 & Total & Integ* & KWH \\
\hline & & & & & & $24 A^{4+30}$ & or Sectio & FEAAN & Indoor Secti & - Minimu & & & & & & \\
\hline $\begin{array}{c}65 \\
(18.3) \\
\end{array}$ & & 16.89 & 15.37 & 1.14 & & 14.71 & 14.71 & 0.79 & & 17.12 & 17.12 & 0.78 & & 19.72 & 19.72 & 0.77 \\
\hline $\begin{array}{c}70 \\
\text { (21.1) }\end{array}$ & 500 & 16.70 & 15.19 & 1.22 & 500 & 14.51 & 14.51 & 0.85 & 500 & 16.90 & 16.90 & 0.84 & 500 & 19.48 & 19.48 & 0.83 \\
\hline $\begin{array}{c}75 \\
(23.9)\end{array}$ & & 16.49 & 15.01 & 1.31 & & 14.31 & 14.31 & 0.92 & & 16.68 & 16.68 & 0.91 & & 19.23 & 19.23 & 0.90 \\
\hline
\end{tabular}




\section{References}

Aboul-Enein, S., El-Sabii, A. A., Ramadan, M. R., \& El-Gohary, H. G. (2000). Parametric study of a solar air heater with and without thermal storage for solar drying applications. Renewable Energy, 21, 505-522.

Agnihotri, O. P., \& Gupta, B. K. (1981). Solar Selective Surfaces. New York: Wiley.

ASHRAE/ANSI Standard 93-2003. (2003). Methods of Testing to Determine the Thermal Performance of Solar Collectors. Atlanta: American Society of Heating, Refrigeration, and Air Conditioning Engineers.

Badescu, V. (2002). Model of a space heating system integrating a heat pump, photothermal collectors and solar cells. Renewable Energy, 27, 489-505.

Bilbao, J. I., \& Sproul, A. B. (2015). Detailed PVT-Water model for transient analysis using RC networks. Solar Energy, 115, 680-693.

Bourdouxhe, J. P., Grodent, M., Lebrun, J., Saavedra, C., \& Silva, K. (1994). A toolkit for primary HVAC system energy calculation- part 2: reciprocating chiller models. ASHRAE Transaction, 100(2), 774-786.

Calmidi, V. V., \& Mahajan, R. L. (2000). Forced convection in high porosity metal foams. J. Heat Transfer, 122, 557-565.

Candanedo, L. M., Athienitis, A. K., Candanedo, J. A., O'Brien, W., \& Chen, Y. (2010). Transient and Steady State Models for Open-Loop Air Based BIPV/T Systems. ASHRAE Transactions, 116, 600-612.

Candanedo, L. M., Athienitis, A., \& Park, K.-W. (2011). Convective Heat Transfer Coefficients in a Building-Integrated Photovoltaic/ Thermal System. Journal of Solar Engineering, $133(2), 21002$.

Carrier. (2017, 6 13). 25VNA-04PD. Retrieved from Carrier Home Comfort- Carrier Residential: http://www.carrier.com/residential/en/ca/products/heat-pumps/25vna0/

Cecchini, C., \& Marchal, D. (1991). A simulation model of refrigerant and air-conditioning equipment based on experimental data. ASHRAE Transaction, 97(2), 388-393.

Chabert, J. L. (1999). A History of Algorithms: From the Pebble to the Microchip. New York: Springer-Verlag. 
Chen, Y., Athienitis, A. K., \& Galal, K. (2010). Modeling, design and thermal performance of a BIPV/T system thermally coupled with a ventilated concrete slab in a low energy solar house: Part 1, BIPV/T system and house energy concept. Solar Energy, 84(11), 1892-1907.

Domanski, P., \& Didion, D. (1984). Mathematical model of an air-to-air heat pump equipped with a capillary tube. International Journal of Refrigeration, 7(4), 249-255.

Duffie, J. A., \& Beckman, W. A. (2006). Solar engineering of thermal processes. Hoboken: John Wiley \& Sons.

Ernest Orlando Lawrence Berkeley National Laboratory. (2013a). EnergyPlus Engineering Reference. US Department of Energy.

Ernest Orlando Lawrence Berkeley National Laboratory. (2013b). EnergyPlus V8.0.

Fath, H. E. (1995). Thermal performance of a simple design solar air heater with built-in thermal energy storage system. Energy Conversion \& Management, 36(10), 989-997.

Fudholi, A., Sopian, K., Ruslan, M. H., \& Mohd, Y. O. (2013). Performance and cost benefits analysis of double-pass solar collector with and without fins. Energy Conversion and Management, 76, 8-19.

Garg, H. P., \& Datta, G. (1989). Performance studies on a finned-air heater. Energy, 14, 87-82.

Garg, H. P., Jha, R., \& Datta, G. C. (1991). Theoretical analysis on. Energy, 16, 1231-1238.

Ghafarian, M., Mobebbi-Kalhori, D., \& Sadegi, J. (2013). Analysis of heat transfer in oscillating flow through a channel filled with metal foam using computational fluid dynamics. International Journal of Thermal Sciences, 66, 42-50.

Ghosh, L. (2009). Heat transfer correlation for high porosity open-cell foam. International Journal of Heat and Mass Transfer, 52, 1488-1494.

Hailu, G., Dash, P., \& Fung, A. S. (2015). Performance Evaluation of an Air Source Heat Pump Coupled with a Building-Integrated Photovoltaic/ Thermal (BIPV/T) System under Cold Climatic Conditions. Energy Procedia, 78, 1913-1918.

Heaton, H. S., Reynolds, W. C., \& Kays, W. M. (1964). Heat transfer in annular passages, simultaneous development of velocity and temperature fields in laminar flow. International Journal of Heat Mass Transfer, 7, 763.

Ibrahim, A., Fudholi, A., Sopian, K., Othman, M. Y., \& Ruslan, M. H. (2014). Efficiencies and improvement potential of building integrated photovoltaic thermal (BIPVT) system. Energy Conversion and Management, 77, 527-534. 
Ji, J., Keliang, L., Chow , T. T., Gang, P., Wei, H., \& Hanfeng, H. (2008). Performance analysis of a photovoltaic heat pump. Applied Energy, 85(8), 680-693.

Kamel, R. S., \& Fung, A. S. (2014). Modeling, simulation and feasibilitiy analysis of residential BIPV/T + ASHP system in cold climate-Canada. Energy and Buildings, 82, 758-770.

Kamel, R. S., \& Fung, A. S. (2015). Modelling and Characterization of Transparent Building Integrated PV/T Collector. Energy Procedia, 78, 1871-1876.

Kamel, R. S., Fung, A. S., \& Dash, P. R. (2015). Solar systems and their integration with heat pump: A review. Energy and Buildings, 87, 395-412.

Karim, M. A., \& Hawlader, M. N. (2006). Performance investigation of flat plate, v-corrugated and finned air collectors. Energy, 452-470.

Kim, S. Y., Paek, J. W., \& Kang, B. H. (2000). Flow and heat transfer correlations for porous fin in plate-fin heat exchanger. J. Heat Transfer, 122, 572-578.

Klein, S. (1975). Calculation of flat-plate collector loss coefficients. Solar Energy, 17(1), 79-80.

Koyuncu, T. (2006). Performance of various design of solar air heaters for crop drying applications. Renewable Energ. Renewable Energy, 31, 1073-1088.

Kuang, Y. H., Wang, R. Z., \& Yu, L. Q. (2003). Experimental study on solar assisted heat pump system for heat supply. Energy Conversion and Management, 44, 1089-1098.

Li, H., Cao, C., Feng, G., Zhang, R., \& Huang, K. (2015). A BIPV/T System Designed Based on Simulation and its Application in Integrated Heating System. Procedia Engineering, 121, 1590-1596.

Liu, Y., Wang, Z., Lei, D., \& Wang, C. (2014). A new solar spectral selective absorbing coating of SS-(FE3O4)/Mo/TiZrN/TiZrON/SiON for high temperature application. Solar Energy Materials \& Solar Cells, 127, 143-146.

Malik, M., \& Buelow, F. H. (1973). Heat transfer characteristic of a solar dryer. Sun Serfvice Mankind. Paris: UNESCO Congress.

Mancin, S., Zilio, C., Cavallini, A., \& Rossetto, L. (2010). Heat transfer during air flow in aluminum foams. International Journal of Heat and Mass Transfer, 53, 4976-4984.

McIntosh, K. R., Cotsell, J. N., Cumpston, J. S., Norris, A. W., Powell, N. E., \& Ketola, B. M. (2009). An optical comparison of silione and EVA encapsulants for conventional silicon PV modules: A ray-tracing study. Photovoltaic Specialists Conference (PVSC), 2009 34th IEEE. Philadelphia: IEEE. 
Mittal, M. K., \& Varshney, L. (2006). Optimal thermohydraulic performance of a wire mesh packed solar air heater. Solar Energy, 80, 1112-1120.

Naphon, P. (2005). On the performance and entropy generation of double-pass solar air heater with longitudinal fins. Renewable Energy, 30, 1345-1357.

Niles, P., Caxnegie, E. J., Pohl, J. G., \& Cherne, J. M. (1979). Design and performance of an air collector for industrial crop drying. Solar Energy, 20, 19-28.

Njomo, D., \& Daguenet, M. (2006). Sensitivity analysis of thermal performances of flat plate solar air heaters. Heat Mass Transfer, 42, 1065-1081.

NRCan. (2016). Energy Efficiency Trends in Canada 1999-2013. Ottawa: NRCan.

Ong, K. S. (1995). Thermal performance of solar air heaters: Mathematical model and solution procedure. Solar Energy, 55(2), 93-109.

Othman, M. Y., Yatim, B., Sopian, K., \& Abu Bakar, M. N. (2005). Performance analysis of a double-pass photovoltaic/ thermal (PV/T) solar collector with $\mathrm{CPC}$ and fins. Renewable Journal, 2005-2017.

Pantic, S., Candanedo, L., \& Athienitis, A. K. (2010). Modeling of energy performance of a house with three configurations of building-integrated photovoltaic/thermal systems. Energy and Buildings, 42, 1779-1789.

Payne, W. V., Yoon, S. H., \& Domanski, P. A. (2009). Heating mode performance measurements for a residential heat pump with single-faults imposed. Gaithersburg: National Institute of Standards and Technology.

Peng, D., Zhang, X., Dong, H., \& Lv, K. (2010). Performance study of a novel solar air collector. Applied Thermal Engineering, 30(16), 2594-2601.

Rajarajeswari, K., \& Sreekumar, A. (2016). Matrix solar air heaters- A review. Renewable and Sustainble Energy Reviews, 57, 704-712.

Rice, C. K. (1991). The ORNL modulating heat pump design tool-mark IV user's guide. Oak Ridge: Oak Ridge National Laboratory .

Ronnelid, M. (1998). Optical design of stationary solar concentrators for high latitudes. Uppsala: Faculty of Science and Technology, Doctoral Dissertation, Uppsala University.

Saini, R. P., \& Verma, J. (2008). Heat transfer and friction factor correlations for a duct having simple dimple-shape artificial roughness for solar air heaters. Energy, 33, 1277-1287. 
Scarpa, M., Emmi, G., \& De Carli, M. (2012). Validation of a numerical model aimed at the estimation of performance of vapor compression based heat pumps. Energy and Buildings, 47, 410-420.

Sherwin, K. (1985). The heat transfer of plate fin and circular tube geometry. Third Australian Conference on Heat and Mass Transfer (pp. 441-447). Melbourne: Third Australian Conference on Heat and Mass Transfer.

Stefanuk, N., Aplevich, J., \& Renksizbulut, M. (1992). Modeling and simulations of a superheatcontrolled water-to-water heat pump. ASHRAE Transaction, 98(2), 172-184.

Tahat, M., Kodah, Z. H., Jarrah, B. A., \& Probert, S. D. (2000). Heat transfers from pin-fin arrays experiencing forced convection. Applied Energy, 416-442.

Tan, H. M., \& Charters, W. S. (1970). An experimental investigation of forced-convective heat transfer for fully developed turbulent flow in a rectangular duct with asymmetric heating. Solar Energy, 13, 121-125.

Tang, C. C. (2003). Modeling packaged heat pumps in a quais-steady state energy simulation program. Stillwater, Oklahoma: Oklahoma State University.

Tardif, J. M., Tamasauskas, J., Delisle, V., \& Kegel, M. (2017). Performance of Air Based BIPV/T Heat Management Strategies in a Canadian Home. Procedia Environmental Sciences, 38, $140-147$.

Tesfamichael, T., \& Wackelgard, E. (2000). Angular solar absorptance and incident angle modifier of selective absorbers for solar thermal collectors. Solar Energy, 68(4), 335-341.

Tripanagnostopoulos, Y. (2007). Aspects and improvements of hybrid photovoltaic/thermal solar energy systems. Solar Energy, 81(9), 1117-1131.

TRNSYS17. (2012). Reference Manual. Madison: Solar Energy Laboratory, Univ of WisconsinMadison.

Varma , H., Ahmad, A., \& Saini, J. (1996). Thermohydraulic performance of packed-bed solar air heaters. Energy Conversion Management, 37, 205-214.

Vaziri, R., Ilkan, M., \& Egelioglu, F. (2015). Experimental performance of perforated glazed solar air heaters and unglazed transpired solar air heater. Solar Energy, 119, 251-260.

Wang, F. Q., Shuai, Y., Tan, H. P., \& Yu, C. L. (2013). Thermal performance analysis of porous media receiver with concentrated solar irradiation. International Journal of Heat and Mass Transfer, 62, 247-254. 
Wang, X., Wu, X., Yuan, L., Zhou, C., Wang, Y., Huang, K., \& Feng, S. (2016). Solar selective absorbers with foamed nanostructure prepared by hydrothermal method on stainless steel. Solar Energy Materials \& Solar Cells, 146, 99-106.

Xu, H., Gong, L., Huang, S., \& Xu, M. (2014). Non-equilibrium heat transfer in metal-foam solar collector with no-slip boundary condition. International Journal of Heat and Mass Transfer, 76, 357-365.

Yeh, H.-M., Ho, C.-D., \& Lin, C.-Y. (2000). Effect of collector aspect ratio on the collector efficiency of upward type baffled solar air heaters. Energy Conversion \& Management, 41, 971-981.

Zongdag, H. A., De Vries, D. W., Van Helden, W. G., Van Zolingen, R. J., \& Van Steenhoven, A. A. (2002). The thermal and electrical yield of a PV-thermal collector. Solar Energy, 72(2), 113-128. 